INSTITUTO DE PESQUISAS ENERGÉTICAS E NUCLEARES

Autarquia associada à Universidade de São Paulo

\title{
ESTUDO DE RADIOMARCAÇÃO COM GÁLIO-68 DO INIBIDOR DE PSMA BASEADO EM UREIA - AVALIAÇÃO COMPARATIVA DE MÉTODO AUTOMATIZADO E NÃO AUTOMATIZADO
}

LAIS FERNANDA ALCARDE

\begin{abstract}
Tese apresentada como parte dos requisitos para obtenção do Grau de Mestre em Ciências na Área de Tecnologia Nuclear - Aplicações
\end{abstract}

Orientadora:

Profa. Dra. Elaine Bortoleti de Araújo

SÃO PAULO 
"A mente que se abre a uma nova idéia jamais voltará ao tamanho original" Albert Einstein 


\section{AGRADECIMENTOS}

À Deus por me amparar nos momentos difíceis, me dar força e paz interior para superar as dificuldades, mostrar o caminho nas horas incertas e me suprir em todas as necessidades.

À minha orientadora Dra. Elaine Bortoleti de Araújo, o meu sincero agradecimento por acreditar em mim, pelos ensinamentos transmitidos, pela amizade construída no decorrer dos últimos 4 anos e, sobretudo por ter me ajudado a realizar um sonho.

Aos meus pais, Ines e Antonio, pelo exemplo de dignidade e perseverança, pela confiança na minha capacidade, pelo incentivo, quando as dúvidas surgiam, mesmo não compreendendo meus motivos de escolher esta área, por todo o amor e compreenção em esperar a concretização deste sonho. Vocês são o que possuo de mais precioso, a base que dá coragem para cada novo passo.

Ao meu noivo, por compartilhar cada pequeno momento, da ansiedade na espera de um resultado à frustação de um experimento sem sucesso. Obrigada por fazer dos meus sonhos seus e por compreender minha ausência para a realização deste trabalho.

Especialmente agradeço:

À Dra. Adriana Vidal, por permitir que "o bichinho da pesquisa" me picasse e por me ensinar quase tudo que sei sobre radiofármacia. Há quatro anos me apaixonei por este mundo por suas mãos. Obrigada por toda a amizade e ensinamentos, não só no âmbito profissional, mas principalmente no da vida. Acredito que Deus coloca anjinhos no nosso caminho para auxiliar nossa jornada, e você, sem dúvida, é um deles!

Ao Dr. Luis Alberto Dias, por todo o auxilio nas marcações em módulo de síntese automatizado, sem sua ajuda este trabalho não seria possível.

À Dra. Maria Tereza Colturato por acompanhar este trabalho desde o início e contribuir ativamente para seu desenvolvimento. 
À Dra. Miriam Fussae Suzuki e ao Dr Johny pela disposição, sempre repleta de símpatia, em ajudar. Raras vezes encontrei pessoas com tamanha facilidade e boa vontade em transmitir seus conhecimentos.

A todos os funcionários do Centro de Radiofármacia, pricipalmente aos funcionários do controle de qualidade e em especial:

À Dra. Neuza Takeo O. Fukumori e a Dra. Margareth Mie N. Matsuda por sempre compreenderem a correria envolvida no desenvolvimento deste trabalho com o radionuclídeo gálio-68 e se mobilizarem para tornar possível a utilização conjunta dos equipamentos.

Aos amigos, aos quais sempre lembrarei saudosamente, Priscila Pujatti, Camila Zanette, Renata Martinussi, Adriana Vidal, Ricardo Oliveira, Daniele Seo, Beatriz Correia, Luis Alberto, Thaís Castro, Raquel Benedetto, Jefferson Silva, Cristian Villas Boas e Juliana Marques, vocês tornaram esta jornada muito mais leve, obrigada por cada momento vivido, pelas risadas, que foram muitas, pelas ajudas, ensinamentos e todo o apoio. Cada um de vocês representou um papel importante em minha vida e no desenvolvimento deste trabalho.

Aos membros da banca examinadora por aceitar o convite.

Ao Instituto de Pesquisas Energéticas e Nucleares pelo auxilio financeiro.

A CNEN pela bolsa concedida. 


\title{
ESTUDO DE RADIOMARCAÇÃO COM GÁLIO-68 DO INIBIDOR DE PSMA BASEADO EM UREIA - AVALIAÇÃO COMPARATIVA DE MÉTODO AUTOMATIZADO E NÃO AUTOMATIZADO
}

\author{
Lais Fernanda Alcarde
}

\section{RESUMO}

Os métodos para o diagnóstico clínico de câncer de próstata incluem o toque retal e a dosagem do antígeno prostático específico (PSA). Entretanto, o nível de PSA encontra-se elevado em cerca de 20 a $30 \%$ dos casos relacionados a patologias benignas, o que resulta em falsos positivos e leva os pacientes a realização de biópsias desnecessárias. 0 antígeno de membrana prostático específico (PSMA), ao contrário, é sobre expresso no câncer de próstata e encontrado em baixos níveis em órgãos saudáveis. Em razão disso, estimulou-se o desenvolvimento de pequenas moléculas inibidoras do receptor de PSMA, que carreguem agentes de imagem ao tumor e que não sejam prejudicadas pela microvasculatura deste. Estudos recentes sugerem que o quelante HBED-CC contribui intrinsicamente para a ligação do peptídeo inibidor de PSMA baseado em ureia (Glu-ureia-Lys) ao grupo farmacofórico. Este trabalho descreve os estudos de otimização das condições de radiomarcação do PSMA-HBED-CC com ${ }^{68} \mathrm{Ga}$, utilizando sistema automatizado (módulo de síntese) e método não automatizado, buscando estabelecer uma condição adequada de preparação deste novo radiofármaco, com ênfase no rendimento da marcação e na pureza radioquímica do produto. Também objetivou avaliar a estabilidade do peptídeo radiomarcado em condições de transporte e estudar a distribuição biológica do radiofármaco em camundongos sadios. O estudo dos parâmetros de radiomarcação possibilitou definir um método não automatizado que resultou em alta pureza radioquímica (> 95\%), sem a necessidade de purificação do radiomarcado. Já o método de marcação automatizado foi adaptado para utilizar módulo de síntese e software já disponíveis no IPEN, e também resultou em rendimento de síntese elevado $(\geq 90 \%)$ e superior aos descritos em literatura, com a vantagem associada de maior controle do processo produtivo em atendimento aos requisitos de Boas Práticas de Fabricação. O estudo dos parâmetros de radiomarcação permitiu a obtenção do PSMA-HBED-CC- ${ }^{68} \mathrm{Ga}$ com atividade específica superior à utilizada em estudos clínicos publicados ( $\geq 140,0 \mathrm{GBq} / \mu \mathrm{mol})$, com estabilidade suficientemente longa, que permitirá o transporte às clínicas para aplicação na obtenção de imagens diagnósticas. Os perfis de biodistribuição e farmacocinético do peptídeo radiomarcado foram compatíveis com os encontrados na literatura. Conclui-se que o PSMA-HBED-CC- ${ }^{68} \mathrm{Ga}$, é uma importante ferramenta de diagnóstico do câncer de próstata por imagem PET, pode ser produzido tanto por método automatizado ou não automatizado, com alta pureza radioquímica, alto rendimento de síntese e estabilidade do radiofármaco. 


\title{
STUDY RADIOLABELING OF UREA-BASED PSMA INIBITOR WITH 68-GALLIUM - COMPARATIVE EVALUATION OF AUTHOMATED AND NOT AUTHOMATED METHODS
}

\author{
Lais Fernanda Alcarde
}

\begin{abstract}
The methods for clinical diagnosis of prostate cancer include rectal examination and the dosage of the prostatic specific antigen (PSA). However, the PSA level is elevated in about 20 to $30 \%$ of cases related to benign pathologies, resulting in false positives and leading patients to unnecessary biopsies. The prostate specific membrane antigen (PSMA), in contrast, is over expressed in prostate cancer and founded at low levels in healthy organs. As a result, it stimulated the development of small molecule inhibitors of PSMA, which carry imaging agents to the tumor and are not affected by their microvasculature. Recent studies suggest that the HBED-CC chelator intrinsically contributes to the binding of the PSMA inhibitor peptide based on urea (Glu-urea-Lys) to the pharmacophore group. This work describes the optimization of radiolabeling conditions of PSMA-HBED-CC with ${ }^{68} \mathrm{Ga}$, using automated system (synthesis module) and no automated method, seeking to establish an appropriate condition to prepare this new radiopharmaceutical, with emphasis on the labeling yield and radiochemical purity of the product. It also aimed to evaluate the stability of the radiolabeled peptide in transport conditions and study the biological distribution of the radiopharmaceutical in healthy mice. The study of radiolabeling parameters enabled to define a non-automated method which resulted in high radiochemical purity ( $>95 \%$ ) without the need for purification of the labeled peptide. The automated method has been adapted, using a module of synthesis and software already available at IPEN, and also resulted in high synthetic yield ( $\geq 90 \%$ ) specially when compared with those described in the literature, with the associated benefit of greater control of the production process in compliance with Good Manufacturing Practices. The study of radiolabeling parameters afforded the PSMA-HBED-CC- ${ }^{68} \mathrm{Ga}$ with higher specific activity than observed in published clinical studies $\quad(\geq 140,0 \mathrm{GBq} / \mu \mathrm{mol})$, with a sufficiently long stability, which will enable transport to clinics for use in diagnostic imaging. Biodistribution and pharmacokinetic profiles of the radiolabeled peptide were consistent with those founded in the literature. We concluded that PSMA-HBED-CC- ${ }^{68} \mathrm{Ga}$, important diagnostic tool for prostate cancer imaging with PET, can be produced by either automated or not automated method with high radiochemical purity, high synthetic yield and stability of the radiopharmaceutical.
\end{abstract}




\section{SUMÁRIO}

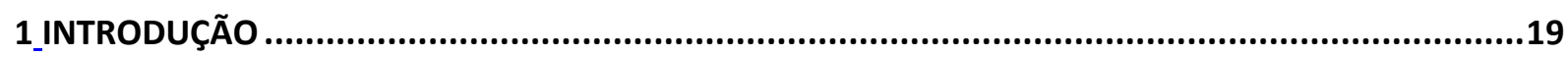

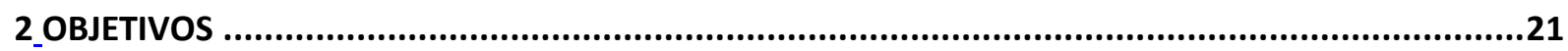

2.1 OBJETIVO GERAL .............................................................................................................21

2.2 OBJETIVOS ESPECÍFICOS..................................................................................................21

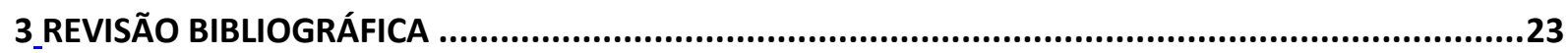

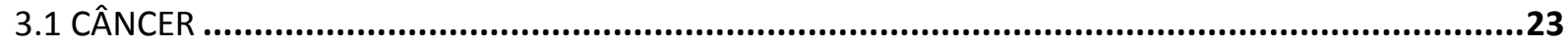

3.1.1 Câncer de próstata .............................................................................................................24

3.2 ANTÍGENO DE MEMBRANA PROSTÁTICO ESPECÍFICO ………….................................................26

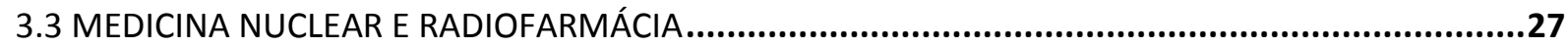

3.3.1 Tomografia por emissão de pósitrons .....................................................................................

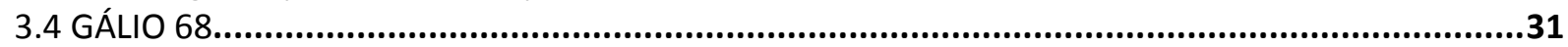

3.5 QUELANTES BIFUNCIONAIS MACROCÍCLICOS ......................................................................34

3.5.1 Incorporação do gálio-68 ao marcador molecular ..................................................................36

3.6 INIBIDORES DO PSMA .......................................................................................................

3.6.1 Aplicação clínica do PSMA-HBED-CC- ${ }^{68}$ Ga................................................................................41

3.6.2 Outros radiofármacos utilizados no diagnóstico do câncer de próstata ......................................45

3.7 RADIOMARCAÇÃO EM MÓDULO DE SÍNTESE AUTOMATIZADA...............................................45

3.8 CONTROLE DE QUALIDADE DE RADIOFÁRMACOS .........................................................47

3.8.1 Pureza radioquímica ................................................................................................................47

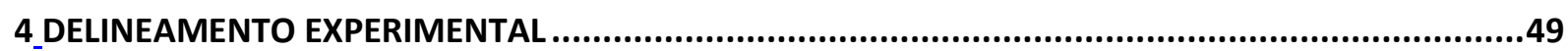

4.1 RESUMO DO DELINEAMENTO EXPERIMENTAL...................................................................49

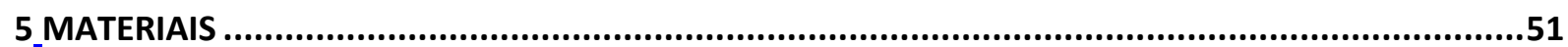

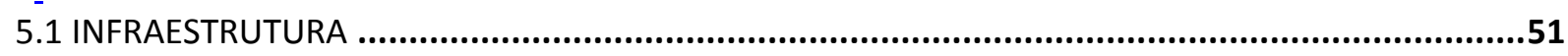

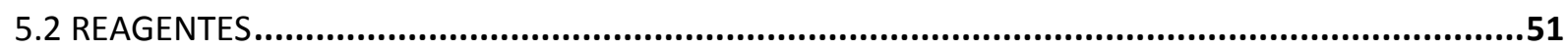

5.3 EQUIPAMENTOS......................................................................................................52

5.4 ANIMAIS ...............................................................................................................

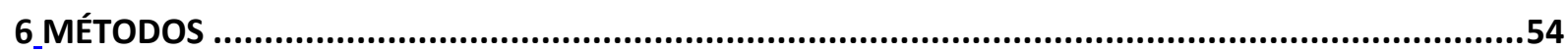

6.1 METODOLOGIAS ANALÍTICAS ............................................................................................54

6.1.1 Cromatografia líquida de alta eficiência (CLAE) ...................................................................55

6.1.2 Cromatografia em camada delgada (CCD) e papel................................................................55

6.1.3 Determinação da identidade radionuclídica .............................................................................56

6.1.4 Determinação do coeficiente de partição (log P) experimental................................................56

6.2 OTIMIZAÇÃ̃O DA RADIOMARCAÇÃO DO PSMA-HBED-CC COM ${ }^{68}$ Ga EM MÉTODO NÃO AUTOMATIZADO.............................................................................................................

6.2.1 Marcação não automatizada baseada na literatura..................................................................57

6.2.2 Marcação não automatizada baseada nas condições de marcação em módulo automatizado para o peptídeo DOTATATO...........................................................................................................58

6.3 ESTUDOS DE ESTABILIDADE......................................................................................61

6.3.1 Análise da integridade do peptídeo após a marcação e estabilidade frente a condições de transporte ..............................................................................................................................61

6.3.2 Análise da estabilidade em soro humano e ligação às proteínas plasmáticas "in vitro"..............61 
6.4 OTIMIZAÇÃO DA RADIOMARCAÇÃO DO PSMA-HBED-CC COM ${ }^{68} \mathrm{Ga}$ EM MÓDULO DE SÍNTESE

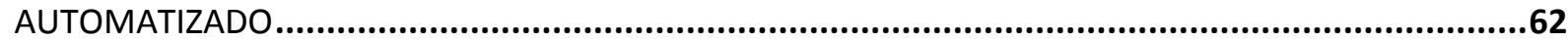

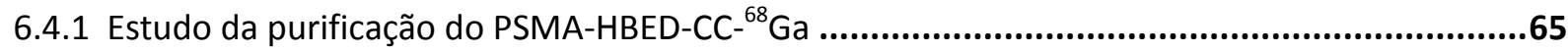

6.4.2 Estudo dos parâmetros de marcação em módulo de síntese automatizado .............................66

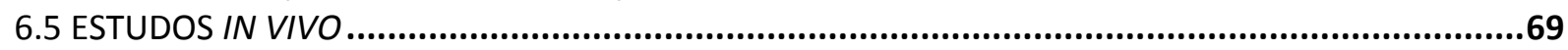

6.5.1 Estudos de biodistribuição em camundongos Balb/c sadios.....................................................69

6.5.2 Estudos de farmacocinética em camundongos Balb/c sadios ..................................................71

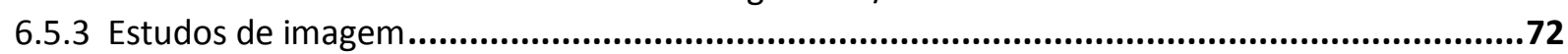

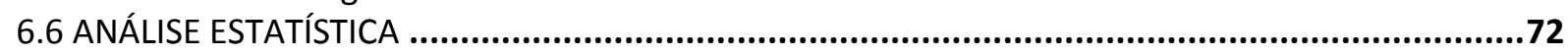

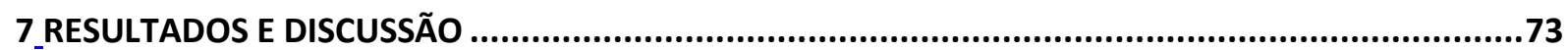

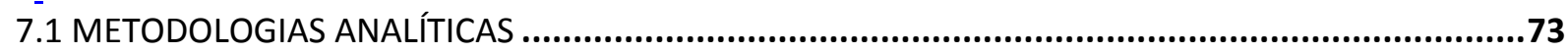

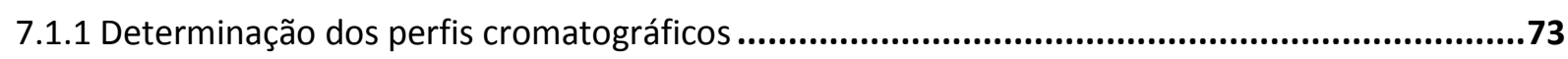

7.1.2 Determinação da identidade radionuclídica ............................................................................79

7.1.3 Determinação do coeficiente de partição (log P) experimental ................................................81

7.2 OTIMIZAÇÃO DA RADIOMARCAÇÃO DO PSMA-HBED-CC COM ${ }^{68}$ Ga EM MÉTODO NÃO

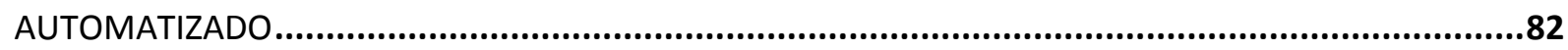

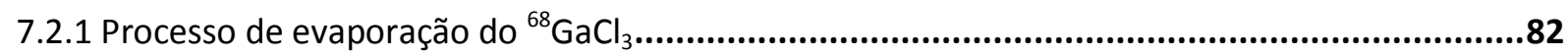

7.2.2 Determinação do tampão de marcação.......................................................................................82

7.2.3 Análise da variação da massa do peptídeo ...............................................................................84

7.2.4 Determinação da temperatura e tempo de marcação .............................................................84

7.2.5 Determinação do volume do tampão de radiomarcação ........................................................91

7.2.6 Avaliação dos tampões de radiomarcação (acetato de sódio e HEPES) em reações com

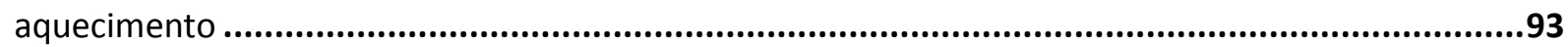

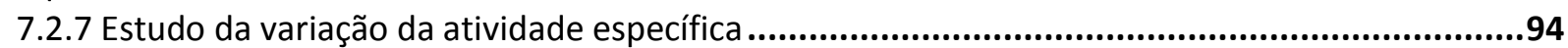

7.2.8 Influência do pH na radiomarcação............................................................................................99

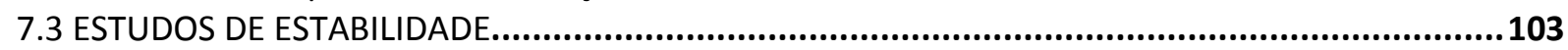

7.3.1 Análise da integridade do peptídeo após a marcação e estabilidade frente a condições de

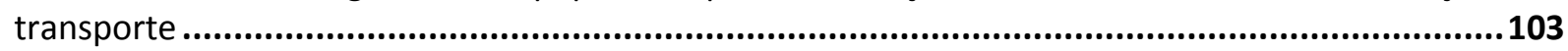

7.3.2 Análise da estabilidade em soro humano e ligação às proteínas plasmáticas "IN VITRO"........107

7.4 OTIMIZAÇÃO DA RADIOMARCAÇÃO DO PSMA-HBED-CC COM ${ }^{68} \mathrm{Ga}$ EM MÓDULO DE SÍNTESE

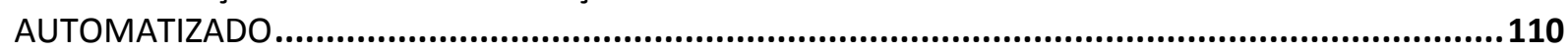

7.4.1 Estudo da purificação do PSMA-HBED-CC ${ }^{68}{ }^{\text {Ga }}$...........................................................110

7.4.2 Estudo dos parâmetros de marcação em módulo de síntese automatizado.............................114

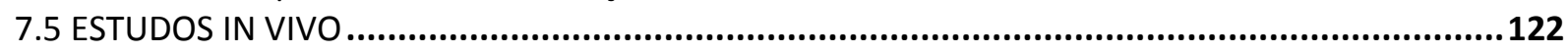

7.5.1 Estudos de farmacocinética em camundongos Balb/c sadios ............................................122

7.5.2 Estudos de biodistribuição em camundongos Balb/c sadios...................................................125

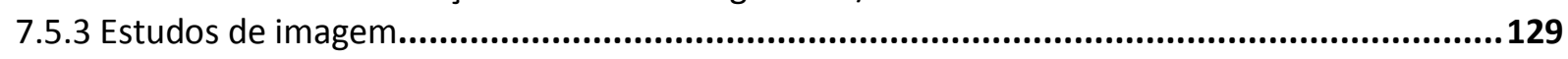

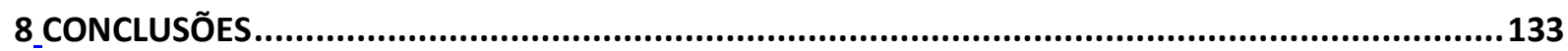

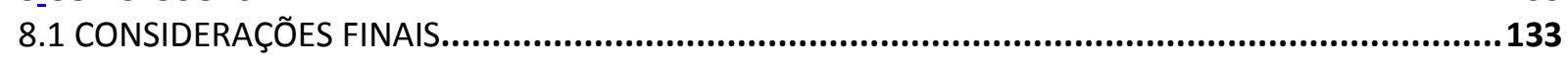

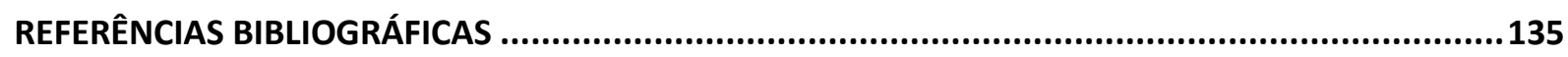




\section{LISTA DE FIGURAS}

FIGURA 1: Localicação anatômica e morfologia da próstata (Próstata, 2015).

FIGURA 2: Evento de aniquilação entre pósitron e elétron resultando em fótons de $511 \mathrm{keV}$ que percorrem trajetórias opostas (Powsner e Powsner, 2006)

FIGURA 3: Equipamento de tomografia por emissão de pósitrons (PET). Adaptado de Powsner e Powsner, 2006.

FIGURA 4: Geradores ${ }^{68} \mathrm{Ge} /{ }^{68} \mathrm{Ga}$ comercialmente disponíveis (Cyclotron Co, 2016; Eckert Ziegler, 2016; ITG, 2016; IThemba, 2016).

FIGURA 5: PSMA conjugado ao quelante bifuncional HBED-CC conjugado ao peptídeo Glu-NH-CO-NH-Lys (Eder et al, 2012).

FIGURA 6: Esquema de sub-classificações químicas (Juaristi e Stefani, 2012). .37

FIGURA 7: Configuração estérica dos diasteroisômeros do PSMA-HBED-CC ligado ao ${ }^{68} \mathrm{Ga}$ (Schuhmacher et al, 1995).

FIGURA 8: Esquema do delineamento experimental do trabalho. .50

FIGURA 9: Módulo automático Modular-Lab PharmTracer (Eckert and Ziegler) utilizado para a marcação do PSMA-HBED-CC com ${ }^{68} \mathrm{Ga}$.

FIGURA 10: Cassete utilizado no módulo para marcação do PSMA-HBED-CC com ${ }^{68} \mathrm{Ga}$ : coluna de troca iônica (1); coluna Sep Pack C18 (2); frasco de reação (3); membrana esterilizante (4)...63

FIGURA 11: Cassete para marcação do peptídeo DOTATATO acoplado ao módulo de síntese automatizado (Modular-Lab PharmTracer), juntamente aos seus demais componentes: gerador ${ }^{68} \mathrm{Ge} /{ }^{68} \mathrm{Ga}$ (1), frascos de solução salina e etanol:água (50\%) (2), frasco de reação (3), frasco de rejeito do processo de purificação do produto radiomarcado em coluna do tipo Sep Pack C18 (4) e frasco de coleta do produto final (5). .64

FIGURA 12: Fluxograma das etapas envolvidas no processo de radiomacação de peptídeos em módulo de síntese automatizado.

FIGURA 13: Radiocromatograma do ${ }^{68} \mathrm{GaCl}_{3}$ diluído em $800 \mu \mathrm{L}$ de $\mathrm{HCl} 0,02 \mathrm{M}$ em acetona ultrapura (A) e do PSMA-HBED-CC- ${ }^{68} \mathrm{Ga}$ na seguinte condição de marcação: $5 \mu \mathrm{g}$ do peptídeo 
PSMA-HBED-CC, $740 \mathrm{MBq}(20 \mathrm{mCi})$ de ${ }^{68} \mathrm{GaCl}_{3}$, por 7 minutos a $95^{\circ} \mathrm{C}$ sem agitação em tampão acetato de sódio $0,2 \mathrm{M} \mathrm{pH} 4$ (B)

FIGURA 14: Perfil cromatográfico do ${ }^{68} \mathrm{GaCl}_{3}$ diluído em $800 \mu \mathrm{L}$ de $\mathrm{HCl} 0,02 \mathrm{M}$ em acetona ultrapura, em fase móvel metanol:acetato de amônio $1 \mathrm{M} \mathrm{pH} \mathrm{8,5} \mathrm{(1:1,v/v),} \mathrm{utilizando} \mathrm{TLC-SG} \mathrm{(A),}$ ITLC-SG (B) e papel Whatman no3 (C), e em fase móvel tampão citrato:ácido cítrico 0,1M pH 5, utilizando TLC-SG (D), ITLC-SG (E) e papel Whatman no3 (F).

FIGURA 15: Perfil cromatográfico do radiofármaco PSMA-HBED-CC- ${ }^{68} \mathrm{Ga}$, em fase móvel metanol:acetato de amônio $1 \mathrm{M} \mathrm{pH} \mathrm{8,5} \mathrm{(1:1,} \mathrm{v/v),} \mathrm{utilizando} \mathrm{TLC-SG} \mathrm{(A),} \mathrm{ITLC-SG} \mathrm{(B)} \mathrm{e}$

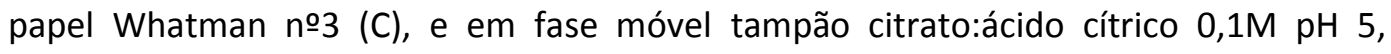
utilizando TLC-SG (D), ITLC-SG (E) e papel Whatman no3 (F). Condições de

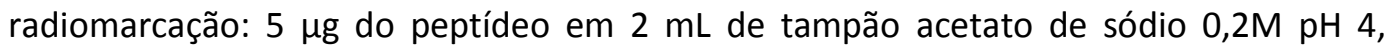
$740 \mathrm{MBq}(20 \mathrm{mCi})$ de ${ }^{68} \mathrm{GaCl}_{3}$ diluído em $800 \mu \mathrm{L}$ de $\mathrm{HCl}$ 0,02M em acetona ultrapura, por 7 minutos, à $95^{\circ} \mathrm{C}$ sem agitação.

FIGURA 16: Gráfico linear das medidas de atividade do radiofármaco PSMA-HBED-CC ${ }^{68}$ Ga a cada 10 minutos, referente a três procedimentos de marcações diferentes. 80

FIGURA 17: Pureza radioquímica obtida na radiomarcação do PSMA-HBED-CC com ${ }^{68} \mathrm{Ga}$ em diferentes tempos de reação. Condições de radiomarcação: Tp. Acetato de sódio - $20 \mu \mathrm{g}$ do peptídeo em $1 \mathrm{~mL}$ de tampão acetato de sódio $0,2 \mathrm{M} \mathrm{pH} \mathrm{4,} 185 \mathrm{MBq}(5 \mathrm{mCi}$ ) de ${ }^{68} \mathrm{GaCl}_{3}$ diluído em $10 \mu \mathrm{L}$ de $\mathrm{HCl} 0,02 \mathrm{M}$ em acetona ultrapura, à $25^{\circ} \mathrm{C}$, sem agitação; Tp. HEPES - $20 \mu \mathrm{g}$ do peptídeo em $100 \mu \mathrm{L}$ de tampão HEPES 0,1M pH 7,5 e $10 \mu \mathrm{L}$ de tampão HEPES 2,1M pH 7,5, $185 \mathrm{MBq}(5 \mathrm{mCi})$ de ${ }^{68} \mathrm{GaCl}_{3}$ diluído em $10 \mu \mathrm{L}$ de $\mathrm{HCl} 0,02 \mathrm{M}$ em acetona ultrapura, à $25^{\circ} \mathrm{C}$, sem agitação, o pH foi ajustado para 4,2 com NaOH. Sistema cromatográfico: metanol:acetato de amônio $1 \mathrm{M}(1: 1 \mathrm{v} / \mathrm{v})$ em TLC-SG ( $n \geq 3) \ldots . .83$

FIGURA 18: Análise da variação de massa do peptídeo PSMA-HBED-CC sobre a pureza radioquímica da marcação com ${ }^{68} \mathrm{Ga}$. Condições de radiomarcação: 20, 15 e $5 \mu \mathrm{g}$ do peptídeo diluído em $1 \mathrm{~mL}$ de tampão acetato de sódio $0,2 \mathrm{M} \mathrm{pH} 4,185 \mathrm{MBq}(5 \mathrm{mCi})$ de ${ }^{68} \mathrm{GaCl}_{3}$ diluído em $800 \mu \mathrm{L}$ de $\mathrm{HCl} 0,02 \mathrm{M}$ em acetona ultrapura, à $25^{\circ} \mathrm{C}$, por 10 minutos, sem agitação. Sistema cromatográfico: metanol:acetato de amônio $1 M(1: 1 \mathrm{v} / \mathrm{v})$ em TLC-SG $(n=3) \ldots .84$

FIGURA 19: Determinação da pureza radioquímica da marcação do PSMA-HBED-CC com ${ }^{68}$ Ga, em diferentes temperaturas e tempos de reação. Condições de radiomarcação: utilizando a condição de marcação padrão, as radiomarcações foram incubadas por 2, 5, 7 e 10 minutos, a diferentes temperaturas $\left(25,85\right.$ e $\left.95^{\circ} \mathrm{C}\right)$. Sistema cromatográfico: metanol:acetato de amônio 1M (1:1 v/v) em TLC-SG ( $n \geq 3)$.

FIGURA 20: Estabilidade das marcações do PSMA-HBED-CC com ${ }^{68} \mathrm{Ga}$, realizadas a diferentes temperaturas e tempos de reação. Condições de radiomarcação: utilizando a condição de marcação padrão, as radiomarcações foram incubadas em diferentes temperaturas $\left(25,85\right.$ e $\left.95^{\circ} \mathrm{C}\right)$. Sistema cromatográfico: metanol:acetato de amônio $1 \mathrm{M}(1: 1 \mathrm{v} / \mathrm{v}) \mathrm{em}$ TLC-SG $(n \geq 3)$. 
FIGURA 21: Perfil cromatográfico em CLAE da formação dos diasteroisômeros do PSMA-HBED-CC radiomarcado com ${ }^{68} \mathrm{Ga}$ à $25^{\circ} \mathrm{C}$ e demais parâmetros conforme condição de marcação padrão. A preparação foi avaliada até 240 minutos após a marcação.

FIGURA 22: Perfil cromatográfico em CLAE da formação dos diasteroisômeros do PSMA-HBED-CC radiomarcado com ${ }^{68} \mathrm{Ga}$ à $85^{\circ} \mathrm{C}$ e demais parâmetros conforme condição de marcação padrão. A preparação foi avaliada até 240 minutos após a marcação. .88

FIGURA 23: Perfil cromatográfico em CLAE da formação dos diasteroisômeros do PSMA-HBED-CC radiomarcado com ${ }^{68} \mathrm{Ga}$ à $95^{\circ} \mathrm{C}$ e demais parâmetros conforme condição de marcação padrão. A preparação foi avaliada até 240 minutos após a marcação.

FIGURA 24: Determinação da pureza radioquímica da marcação do PSMA-HBED-CC com gálio-68 em diferentes volumes de marcação. Condições de radiomarcação: radiomarcou-se o peptídeo PSMA-HBED-CC com volume final de $1 \mathrm{~mL}$ ou $2 \mathrm{~mL}$, utilizando a condição de marcação padrão. Sistema cromatográfico: metanol:acetato de amônio $1 \mathrm{M}(1: 1 \mathrm{v} / \mathrm{v})$ em TLC-SG $(n \geq 3)$.

FIGURA 25: Análise da estabilidade do PSMA-HBED-CC- ${ }^{68}$ Ga radiomarcado em diferentes tampões. Condições de radiomarcação: Tp. Acetato de sódio - utilizou-se a condição de marcação padrão; Tp. HEPES - $5 \mu \mathrm{g}$ do peptídeo em $100 \mu \mathrm{L}$ de tampão HEPES 0,1M pH 7,5 e $10 \mu \mathrm{L}$ de tampão HEPES 2,1M pH 7,5, $740 \mathrm{MBq}(20 \mathrm{mCi})$ de ${ }^{68} \mathrm{GaCl}_{3}$ diluído em $10 \mu \mathrm{L}$ de

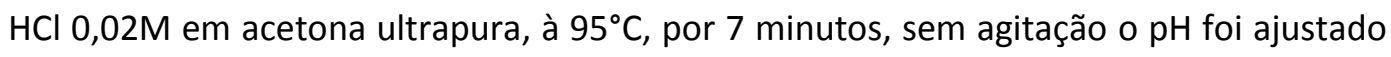
para 4,2 com $\mathrm{NaOH}$. Sistema cromatográfico: metanol:acetato de amônio $1 \mathrm{M}(1: 1 \mathrm{v} / \mathrm{v})$ em TLC-SG $(n \geq 3)$.

FIGURA 26: Perfis cromatográficos em CLAE do PSMA-HBED-CC- ${ }^{68} \mathrm{Ga}$ em diferentes atividades específicas. Condições de radiomarcação: utilizando a condição padrão de marcação, adicionou-se diferentes atividades de ${ }^{68} \mathrm{GaCl}_{3}$ ao frasco de reação $(0,37-1,11 \mathrm{GBq}-$ $10-30 \mathrm{mCi})$ .96

FIGURA 27: Análise da influência da atividade específica na pureza radioquímica e estabilidade do PSMA-HBED-CC ${ }^{68} \mathrm{Ga}$. Condições de marcação: Condições de radiomarcação: utilizando a condição padrão de marcação, adicionou-se diferentes atividades de ${ }^{68} \mathrm{GaCl}_{3}$ ao frasco de reação (0,37-1,11 GBq - 10-30 $\mathrm{mCi})$. Sistema cromatográfico: metanol:acetato de amônio 1M (1:1 v/v) e TLC-SG.

FIGURA 28: Perfil cromatográfico em CLAE mostrando a formação dos produtos de degradação do PSMA-HBED-CC- ${ }^{68} \mathrm{Ga}$ com atividade específica de $210,0 \mathrm{GBq} / \mu \mathrm{mol}$, após decorrido 60 minutos da radiomarcação. Condições de marcação: Condições de radiomarcação: utilizando a condição padrão de marcação, adicionou-se $1,11 \mathrm{GBq}(30 \mathrm{mCi})$ de ${ }^{68} \mathrm{GaCl}_{3} .98$

FIGURA 29: Avaliação da variação de pH na pureza radioquímica e estabilidade da marcação. Condições de radiomarcação: utilizando a condição padrão de marcação com variação 
nos $\mathrm{pH}\left(3,5,4,4,5\right.$ e 5) e com $550 \mathrm{MBq}(15 \mathrm{mCi})$ de ${ }^{68} \mathrm{GaCl}_{3}$. Sistema cromatográfico: metanol:acetato de amônio 1 M (1:1 v/v) e TLC-SG.

FIGURA 30: Perfil comatográfico de CLAE da formação dos diasteroisômeros do PSMA-HBED-CC- ${ }^{68}$ Ga para a marcação com pH 3,5. Condições de radiomarcação: utilizando a condição padrão de marcação com pH 3,5 e com $550 \mathrm{MBq}(15 \mathrm{mCi})$ de ${ }^{68} \mathrm{GaCl}_{3}$ 101

FIGURA 31: Perfil comatográfico de CLAE da formação dos diasteroisômeros do PSMA-HBED-CC- ${ }^{68}$ Ga para a marcação com pH 5. Condições de radiomarcação: utilizando a condição padrão de marcação com pH 5 e com $550 \mathrm{MBq}(15 \mathrm{mCi})$ de ${ }^{68} \mathrm{GaCl}_{3}$ .102

FIGURA 32: Estabilidade do produto radiomarcado armazenado sob refrigeração $\left(2-8^{\circ} \mathrm{C}\right)$, em temperatura ambiente $\left(15-35^{\circ} \mathrm{C}\right)$ e na temperatura de $40^{\circ} \mathrm{C}$. Condições de radiomarcação: a condição padrão de radiomarcação teve o pH do tampão acetato de sódio $0,2 \mathrm{M}$ alterado para $\mathrm{pH} 4,5$. Sistema cromatográfico: metanol:acetato de amônio $1 \mathrm{M}(1: 1 \mathrm{v} / \mathrm{v})$ e TLC-SG. 104

FIGURA 33: Perfis cromatográficos da influência da temperatura ambiente (A) e a $40^{\circ} \mathrm{C}$ (B) na estabilidade. Condições de radiomarcação: condição padrão de radiomarcação teve o pH do tampão acetato de sódio $0,2 \mathrm{M}$ alterado para pH 4,5. 106

FIGURA 34: Estabilidade do PSMA-HBED- ${ }^{68} \mathrm{Ga}$ em soro humano "in vitro" a $37^{\circ} \mathrm{C}$, analisado por CCD. Condições de radiomarcação: condição padrão de marcação teve o pH do tampão acetato de sódio $0,2 \mathrm{M}$ alterado para $\mathrm{pH} \mathrm{4,5}$. Sistema cromatográfico: metanol:acetato de amônio $1 \mathrm{M}(1: 1 \mathrm{v} / \mathrm{v})$ e TLC-SG.

FIGURA 35: Análise em CLAE da estabilidade do radiofármaco PSMA-HBED-CC- ${ }^{68}$ Ga em soro humano. Condições de radiomarcação: condição padrão de marcação teve $\mathrm{opH}$ do tampão acetato de sódio $0,2 \mathrm{M}$ alterado para $\mathrm{pH} 4,5$. 108

FIGURA 36: Estudo de ligação do PSMA-HBED-CC- ${ }^{68}$ Ga às proteínas plasmáticas "in vitro". Condições de radiomarcação: condição padrão de marcação teve o pH do tampão acetato de sódio $0,2 \mathrm{M}$ alterado para $\mathrm{pH} 4,5$. 109

FIGURA 37: Perfil cromatográfico em CLAE do resíduo resultante da eluição do Sep Pack C18 com a solução contendo o produto radiomarcado. Condições de marcação: $5 \mu \mathrm{g}$ do peptídeo diluído em $2 \mathrm{~mL}$ de tampão acetato de sódio $0,2 \mathrm{M} \mathrm{pH} \mathrm{4,5,} \mathrm{com} 740 \mathrm{MBq}(20 \mathrm{mCi})$, à $95^{\circ} \mathrm{C}$ por 7 minutos, sem agitação.

FIGURA 38: Análise da estabilidade do PSMA-HBED-CC $-{ }^{68}$ Ga (\% PR em função do tempo) produzido em módulo de síntese automatizado (método 3 e 4). Condições de marcação: método 3 - $10 \mu \mathrm{g}$ do peptídeo diluído em $2 \mathrm{~mL}$ de tampão acetato de sódio $0,2 \mathrm{M} \mathrm{pH} \mathrm{4,5}$, à $95^{\circ} \mathrm{C}$ por 10 minutos, sem agitação, utilizando $\mathrm{HCl}$ 0,02M em acetona ultrapura como eluente para o ${ }^{68} \mathrm{GaCl}_{3}$ e purificação do peptídeo radiomarcado em Sep Pack C18 Plus; método 4 - $10 \mu \mathrm{g}$ do peptídeo diluído em $0,4 \mathrm{~mL}$ de tampão acetato de sódio $0,2 \mathrm{M} \mathrm{pH} \mathrm{4}$, à $95^{\circ} \mathrm{C}$ 
por 7 minutos, sem agitação, utilizando $\mathrm{HCl}$ 0,02M em acetona ultrapura como eluente para ${ }^{68} \mathrm{GaCl}_{3}$ e purificação do peptídeo radiomarcado em Sep Pack C18.

FIGURA 39: Perfis cromatográficos obtidos em CLAE para a radiomarcação de acordo com o método 2. Condições de marcação: $10 \mu \mathrm{g}$ do peptídeo diluído em $2 \mathrm{~mL}$ de tampão acetato de sódio $0,2 \mathrm{M} \mathrm{pH} \mathrm{4}$, à $95^{\circ} \mathrm{C}$ por 7 minutos, sem agitação, utilizando $\mathrm{HCl} 0,02 \mathrm{M}$ em acetona ultrapura como eluente para $0^{68} \mathrm{GaCl}_{3}$ e purificação do peptídeo radiomarcado em Sep Pack C18.

FIGURA 40: Perfis cromatográficos obtidos em CLAE para a radiomarcação de acordo com o método 3. Condições de marcação: $10 \mu \mathrm{g}$ do peptídeo diluído em $2 \mathrm{~mL}$ de tampão acetato de sódio $0,2 \mathrm{M} \quad \mathrm{pH} 4,5$, à $95^{\circ} \mathrm{C}$ por 10 minutos, sem agitação, utilizando $\mathrm{HCl} 0,02 \mathrm{M}$ em acetona ultrapura como eluente para $0^{68} \mathrm{GaCl}_{3}$ e purificação do peptídeo radiomarcado em Sep Pack C18 Plus.

FIGURA 41: Perfis cromatográficos obtidos em CLAE para a radiomarcação de acordo com o método 4. Condições de marcação: $10 \mu \mathrm{g}$ do peptídeo diluído em $0,4 \mathrm{~mL}$ de tampão acetato de sódio $0,2 \mathrm{M} \mathrm{pH} 4$, à $95^{\circ} \mathrm{C}$ por 7 minutos, sem agitação, utilizando $\mathrm{HCl} 0,02 \mathrm{M}$ em acetona ultrapura como eluente para $0{ }^{68} \mathrm{GaCl}_{3}$ e purificação do peptídeo radiomarcado em Sep Pack C18.

FIGURA 42: Curva de clareamento sanguíneo do PSMA-HBED-CC $-{ }^{68} \mathrm{Ga}$ em camundongos Balb/c machos sadios $(n=4)$.

FIGURA 43: Biodistribuição do PSMA-HBED-CC ${ }^{68}$ Ga nos órgãos e tecidos (\% Al/g) de camundongos Balb/c machos sadios $(n=4)$

FIGURA 44: Biodistribuição do PSMA-HBED-CC $-{ }^{68} \mathrm{Ga}$ nos órgãos e tecidos (\% Al/órgão) de camundongos Balb/c machos sadios $(n=4)$.

FIGURA 45: Imagens em micro PET/CT de camundongos Balb/c machos sadios, injetados com o radiofármaco PSMA-HBED-CC $-{ }^{68} \mathrm{Ga}$. 


\section{LISTA DE TABELAS}

TABELA 1: Energia, alcance e metodologia de produção de diferentes radioisótopos emissores de pósitrons (Thrall e Ziessman, 2006)

TABELA 2: Características dos geradores ${ }^{68} \mathrm{Ge} /{ }^{68} \mathrm{Ga}$ comercialmente disponíveis (Cyclotron Co, 2016; Eckert Ziegler, 2016; ITG, 2016; IThemba, 2016; Roesch et al, 2012; Velikyan et al, 2014).

TABELA 3: Paramêtros utilizados nos principais estudos clínicos com o PSMA-HBED-CC- ${ }^{68}$ Ga. Adaptado de Lutje et al (2015).

TABELA 4: Sistemas cromatográficos analisados para a determinação dos perfis cromatográficos do ${ }^{68} \mathrm{GaCl}_{3}$ e PSMA-HBED-CC- ${ }^{68} \mathrm{Ga}$.

TABELA 5: Metodologia descrita pela empresa Eckert and Ziegler para radiomarcação do PSMA-HBED-CC e do DOTATATO em módulo de síntese automatizado, utilizando os softwares desenvolvidos específicamente para cada um dos peptídeos.

TABELA 6: Resumo das condições de estudos para otimização da marcação do PSMA-HBED-CC- ${ }^{68}$ Ga em módulo de síntese automatizado. Os pontos em negrito representam as variações em relação ao método sugerido para a marcação do peptídeo DOTATATO.

TABELA 7: $\mathrm{R}_{\mathrm{f}}$ apresentado pelas espécies gálio-68 livre e PSMA-HBED-CC- ${ }^{68}$ Ga em CCD e CP nas fases móveis solução metanol:acetato de amônio $1 \mathrm{M} \mathrm{pH} \mathrm{8,5} \mathrm{(1:1,} \mathrm{v/v)} \mathrm{e} \mathrm{tampão} \mathrm{citrato:ácido}$ cítrico $0,1 \mathrm{M} \mathrm{pH} 5$.

TABELA 8: Porcentagem de pureza radioquímica obtida para a solução de PSMA-HBED-CC- ${ }^{68}$ Ga nos métodos cromatográficos com fase móvel: solução metanol:acetato de amônio $1 \mathrm{M}$ pH 8,5 (1:1 v/v)e fase estacionária: TLC-SG, ITLC-SG e papel Whatman no3. .79

TABELA 9: Dados encontrados através da equação da reta e cálculos de meia vida física do ${ }^{68} \mathrm{Ga}$, a partir de medidas da radioatividade das amostras do PSMA-HBED-CC- ${ }^{68} \mathrm{Ga}$ em três diferentes tempos em calibrador de dose.

TABELA 10: Teste de evaporação do ${ }^{68} \mathrm{GaCl}_{3}$ diluído em $\mathrm{HCl}$ 0,02M em acetona ultrapura, exposto à $95^{\circ} \mathrm{C}$ por 7 minutos. Sistema cromatográfico: solução metanol:acetato de amônio $1 \mathrm{M}$ $\mathrm{pH} 8,5(1: 1 \mathrm{v} / \mathrm{v})$ em TLC-SG.

TABELA 11: Taxa de variação entre as diferentes espécies de diasterorisomeros observados nos perfis em CLAE, durante período de estabilidade de 240 minutos. Valores obtidos pelo 
cálculo da área do pico encontrado nos perfis cromatográficos realizados por CLAE. Condições de radiomarcação: as marcações foram incubadas em diferentes temperaturas $\left(25,85\right.$ e $\left.95^{\circ} \mathrm{C}\right)$ utilizando a condição de marcação padrão.

TABELA 12: Análise da pureza radioquímica em tampões e tempos de reação diferentes. Condições de radiomarcação: Tp. Acetato de sódio - utilizou-se a condição de marcação padrão; Tp. HEPES - $\quad 5 \mu \mathrm{g}$ do peptídeo em $100 \mu \mathrm{L}$ de tampão HEPES 0,1M pH 7,5 e $10 \mu \mathrm{L}$ de tampão HEPES 2,1M pH 7,5, $740 \mathrm{MBq}(20 \mathrm{mCi})$ de ${ }^{68} \mathrm{GaCl}_{3}$ diluído em $10 \mu \mathrm{L}$ de $\mathrm{HCl} 0,02 \mathrm{M}$ em acetona ultrapura, à $95^{\circ} \mathrm{C}$, sem agitação, o pH foi ajustado para 4,2 com NaOH . Sistema cromatográfico: metanol:acetato de amônio 1M (1:1 v/v) em TLC-SG ( $n \geq 3) \ldots 93$

TABELA 13: Análise da influência da atividade específica sobre a pureza radioquímica do PSMA-HBED-CC- ${ }^{68} \mathrm{Ga}$. Condições de radiomarcação: utilizando a condição padrão de marcação, adicionou-se diferentes atividades de ${ }^{68} \mathrm{GaCl}_{3}$ ao frasco de reação (0,37-1,11 GBq - 10-30 mCi). Sistema cromatográfico: metanol:acetato de amônio $1 \mathrm{M}(1: 1 \mathrm{v} / \mathrm{v})$ e TLC-SG.

TABELA 14: Análise da influência do pH na pureza radioquímica do PSMA-HBED-CC- ${ }^{68}$ Ga. Condições de radiomarcação: utilizando a condição padrão de marcação com variação nos $\mathrm{pH} \quad\left(3,5,4,4,5\right.$ e 5) e com $550 \mathrm{MBq}(15 \mathrm{mCi})$ de ${ }^{68} \mathrm{GaCl}_{3}$. Sistema cromatográfico: metanol:acetato de amônio $1 \mathrm{M}(1: 1 \mathrm{v} / \mathrm{v})$ e TLC-SG. .99

TABELA 15: Análise da porcentagem de pureza radioquímica (\% PR) das marcações do PSMA-HEBD-CC com ${ }^{68} \mathrm{Ga}$, realizadas em diferentes $\mathrm{pH}$, antes e após purificação com coluna do tipo Sep Pack C18 e a presença do peptídeo radiomarcado no rejeito proveniente da eluição do Sep Pack C18.

TABELA 16: Análise do rendimento de síntese do PSMA-HEBD-CC radiomarcado com ${ }^{68} \mathrm{Ga}$ em diferentes $\quad \mathrm{pH}$ após purificação em Sep Pack C18.

TABELA 17: Análise da presença de peptídeo radiomarcado no rejeito obtido da eluição do Sep Pack C18 Plus com o radiofármaco radiomarcado em $\mathrm{pH} 4,5$. .113

TABELA 18: Variação do rendimento de síntese e pureza radioquímica obtida após purificação do PSMA-HBED-CC- ${ }^{68}$ Ga produzido em módulo de síntese automatizado em diferentes condições. .116

TABELA 19: Parâmetros farmacocinéticos para o PSMA-HBED-CC- ${ }^{68} \mathrm{Ga}$ em camundongos Balb/c machos sadios $(n=4)$. .124

TABELA 20: Biodistribuição do PSMA-HBED- ${ }^{68}$ Ga nos órgãos e tecidos de camundongos Balb/c machos sadios $(n=4)$ 


\section{LISTA DE ABREVIATURAS}

\begin{tabular}{|c|c|}
\hline$\%$ Al & Porcentagem de dose injetada \\
\hline$\% \mathrm{Al} / \mathrm{g}$ & Porcentagem de dose injetada por grama de tecido \\
\hline $\boldsymbol{\mu C \mathbf { i }}$ & Micro currie \\
\hline$\mu \mathrm{g}$ & Micrograma \\
\hline$\mu \mathrm{L}$ & Microlitro \\
\hline$\mu \mathrm{m}$ & Micrometro \\
\hline$\mu \mathrm{mol}$ & Micromol \\
\hline ADT & Terapia de privação de andrógeno \\
\hline ANVISA & Agência Nacional de Vigilância Sanitária \\
\hline AUC & Área sob a curva \\
\hline BFC & Quelante bifuncional \\
\hline BPF & Boas práticas de fabricação \\
\hline CCD & Cromatografia de camada delgada \\
\hline CL & Depuração \\
\hline CLAE & Cromatografia líquida de alta eficiência \\
\hline $\mathrm{cm}$ & Centimetro \\
\hline CP & Cromatografia em papel \\
\hline cpm & Contagens por minuto \\
\hline CR & Centro de Radiofarmácia \\
\hline CT & Tomografia computadorizada \\
\hline DNA & Ácido desoxirribonucléico \\
\hline DOTA & Ácido 1,4,7,10-tetraazaciclododecano-1,4,7,10-tetracético \\
\hline DOTATATO & Ácido 1,4,7,10-tetraazaciclododecano-1,4,7,10-tetracético-D-Phe1-Tyr3 -octreotato \\
\hline DOTATOC & Ácido 1,4,7,10-tetraazaciclododecano-1,4,7,10-tetracético-D-Phe1-Tyr3 -octreotideo \\
\hline DTPA & Ácido dietileno-triamino-pentacético \\
\hline EDTA & Ácido etilenodiamino tetra-acético \\
\hline EQ & Equação \\
\hline FCH & Fluorometilcolina \\
\hline FDG & Fluordesoxiglicose \\
\hline FIG. & Figura \\
\hline$g$ & Força centrífuga \\
\hline g & Grama \\
\hline GBq & Gigabequerel \\
\hline GMP & Good Manufacturing Practices \\
\hline Glu & Glutamato \\
\hline $\mathrm{H}_{2} \mathrm{O}$ & Água \\
\hline
\end{tabular}


HBED-CC

$\mathrm{HCl}$

HEPES

INCA

IPEN

ITLC-SG

Kel

$\mathrm{KeV}$

$\mathrm{Kg}$

L

Lys

LNCaP

LP

LOR

Log

Log P

M

$\mathrm{MBq}$

$\mathrm{mCi}$

mg

$\min$.

$\mathrm{mL}$

MeV

$\mathrm{mm}$

N

$\mathrm{NaCl} / \mathrm{HCl}$

$\mathrm{NaOH}$

NODAGA

NH-CO-NH

NHS

ng

NOTA

PBS

PCTA

PET

PG

pH

PMPA

PR ácido $\mathrm{N}, \mathrm{N}^{\prime}$-Bis[2-hidroxi-5-carboxiletil-benzil]etilenediamine-N, $\mathrm{N}^{\prime}$-diacético

Ácido clorídrico

Ácido hidroxietil-piperazinaetanosulfônico

Instituto Nacional do Câncer

Instituto de Pesquisas Energéticas e Nucleares

Suporte cormatografico de fibra de vidro impregnada com sílica gel 60

Constante de eliminação

Kilo eletrovolt

Kilograma

Litro

Lisina

Células de carcinoma prostático humano

Proteínas plasmáticas

Linha de resposta

Logarítimo

Coeficiente de partição

Molar

Mega becquerel

Milicurie

Miligrama

Minuto (s)

Mililitro

Mega eletrovolt

Milimetro

Normal

Número

Cloreto de sódio

Hidróxido de sódio

1,4,7-triazaciclononano, -1-ácido glutárico, 4,7-ácido acético

Molécula de ureia

N-hidroxilsuccinamida

Nanograma

Ácido 1,1,7-triazaciclononano-1,4-diacético

Tampão fosfato salina

3,6,9,15-Tetraazabicyclo[9.3.1] pentadeca-1(15),11,13-triene-4-S-3,6,9-triacetic acid Tomografia computadorizada por emissão de pósitorns

Pontuação de Gleason

Potencial hidrogeniônico

2-(fosfonometil)-ácido pentanodióico

Pureza radioquímica 
PSA

PSA-DT

PSMA

RDC

$\mathbf{R}_{\text {f }}$

RM

rpm

SBCAL

SBMN

SPECT

t $1 / 2$

$t 1 / 2 E$

TAB

TFA

TLC-SG

UV

Vd

v/v
Antígeno prostático específico

Nível e tempo de duplicação do antígeno prostático específico

Antígeno de membrana prostático específico

Resolução da Diretoria Colegiada

Fator de retenção

Ressonância magnética

Rotações por minuto

Sociedade Brasileira de Ciência em Animais de Laboratório

Sociedade Brasileira de Medicina Nuclear

Tomografia computadorizada por emissão de fóton único

Meia vida

Meia vida efetiva

Tabela

Ácido trifluoracético

Suporte cromatográfico para cromatografia em camada delgada

Ultra violeta

Volume de distribuição

Volume por volume 


\section{1 \\ INTRODUÇÃO}

A incidência do câncer de próstata tem aumentado, atingindo a colocação de tumor mais frequente entre homens no mundo. Um problema clínico relevante observado nesta neoplasia é o desenvolvimento de recorrência tumoral após prostectomia, radioterapia e/ou outras modalidades de tratamentos locais.

O diagnóstico é feito principalmente por meio da identificação de valores elevados de antígeno prostático específico (PSA) ( $\geq 0,2 \mu \mathrm{g} / \mathrm{L}$ ) (Afshar et al, 2015), o qual não apresenta precisão adequada, com apenas um terço dos diagnósticos corretos (INCAb, 2015).

Embora neoplasias prostáticas detectadas em fase inicial sejam frequentemente curáveis, há um grande número de pacientes com doença metastática, residual e recorrente (Afshar et al, 2015). Desta forma, é eminente a necessidade de modalidades diagnósticas mais precisas, com elevada sensibilidade e especificidade, capazes de identificar lesões, realizar acompanhamento terapêutico e reestadiamento (Szabo et al, 2015). Até o momento, este é um desafio importante para todos os métodos convencionais de imagem (Afshar et al, 2015).

Uma vez que o antígeno de membrana específico da próstata (PSMA) é conhecido por ser sobre-expresso no câncer de próstata e encontrado em baixos níveis em órgãos saudáveis como o cérebro, rins, glândula salivar e intestino delgado, foram feitos esforços para desenvolver marcadores moleculares para esse alvo (Afshar et al, 2014). 
Levando em consideração a microvasculatura dos tumores, foram desenvolvidos peptídeos de baixo peso molecular, baseados em ureia, com ação inibidora do receptor de PSMA, e que servissem de carreadores para radioisótopos (Tang et al, 2003).

Dentre os radionuclídeos metálicos utilizados na marcação de peptídeos, o gálio-68 tem merecido destaque, com inúmeros trabalhos descrevendo a aplicação clínica de novos peptídeos radiomarcados no diagnóstico de diferentes patologias. O gálio-68 é um dos mais antigos radionuclídeos emissores de pósitrons utilizado na medicina nuclear, recebendo destaque na utilização clínica de rotina devido a sua fácil disponibilidade através do gerador de germânio-68 (271 dias de meia-vida), o que permitiu a obtenção do ${ }^{68} \mathrm{Ga}$ sem a necessidade de um cíclotron. $\mathrm{O}$ gerador de ${ }^{68} \mathrm{Ge} /{ }^{68} \mathrm{Ga}$ pode ser utilizado por 1 ano e permite mais de uma eluição diária (Crespo et al, 2013; Maecke et al, 2005).

Há exemplos de estudos pré-clínicos e clínicos de moléculas radiomarcadas com ${ }^{68} \mathrm{Ga}$, algumas das quais atualmente utilizadas marcadas com ${ }^{99 \mathrm{~m}} \mathrm{Tc}$, como o macroagregado de albumina humana e o peptídio octreotídeo para tumores que expressam receptor da somatostatina, além de outros peptídeos tumor-específicos como bombesina e receptores de melacortina 1 (Banerjee e Pomper, 2013; Crespo et al, 2013).

Outro fator a se considerar no desenvolvimento de radiofármacos para diagnóstico é que a radiomarcação de biomoléculas com radioisótopos de origem metálica demanda a utilização de agentes quelantes bifuncionais (BFC) (Liu et al, 2008).

Estudos recentes com o peptídeo inibidor do receptor de PSMA, quelado ao quelante HBED-CC lácido N,N'-Bis[2-hidroxi-5-carboxiletil-benzil]etilenediamine-N, $\mathrm{N}^{\prime}$ diacético) e radiomarcado com ${ }^{68} \mathrm{Ga}$, tem mostrado grande potencial para detectar recidivas e metástases de câncer de próstata com contraste superior quando comparado ao colina- ${ }^{18} \mathrm{~F}$, radifármaco marcado $c o m{ }^{18} \mathrm{~F}$ e utilizado para esta finalidade, em tomografia de emissão de pósitrons (PET) (Afshar et al, 2013; Dietlein et al, 2015; Eder et al, 2014).

Tendo em vista o crescente interesse da classe médica nuclear brasileira pelo desenvolvimento de um radiofármaco receptor-específico para diagnóstico e estadiamento do câncer de próstata, bem como as propriedades físicas favoráveis do elemento gálio-68 para aplicação em estudos PET, além dos resultados promissores apresentados em estudos utilizando peptídeos receptor-específicos radiomarcados, fica evidente o interesse pelo estudo de compostos radiomarcados que representem uma nova alternativa diagnóstica a ser utilizado no Brasil. 


\section{2 \\ OBJETIVOS}

\subsection{OBJETIVO GERAL}

Estudar a marcação com gálio-68 do inibidor do receptor de PSMA baseado em ureia, conjugado ao quelante bifuncional acíclico HBED-CC e avaliar sua estabilidade e propriedades biológicas, de modo a obter um marcador específico para diagnóstico e estadiamento do câncer de próstata.

\subsection{OBJETIVOS ESPECÍFICOS}

Os objetivos específicos deste trabalho foram:

- Estudar as condições de radiomarcação do PSMA-HBED-CC com o radioisótopo gálio-68 visando obter alta pureza radioquímica da preparação (superior a 95\%);

- Avaliar métodos cromatográficos de controle de qualidade da pureza radioquímica das marcações de modo a estabelecer um método adequado para controle rotineiro de lotes de produção;

- Estudar a estabilidade do peptídeo radiomarcado para determinar o prazo de validade do produto;

- Estudar o método de marcação do peptídeo utilizando módulo de síntese automatizado e software disponível no Ipen e avaliar sua viabilidade;

- Avaliar, comparativamente, os métodos de marcação automatizado (em módulo) e não automatizado, por meio de parâmetros de qualidade e custo-efetividade. 
- Analisar a biodistribuição e farmacocinética do peptídeo radiomarcado;

- Avaliar a especificidade do peptídeo radiomarcado in vivo por meio de técnicas invasivas e de imagem (micro PET). 


\section{REVISÃO BIBLIOGRÁFICA}

\subsection{CÂNCER}

Neoplasias são originadas pelo crescimento de massas anormais de tecidos na ausência de qualquer estímulo externo contínuo. As neoplasias, também chamadas de tumores, são classificadas com base na sua morfologia e potencial de agressividade, podendo ser classificados como tumores malignos ou benignos (Robbins e Cotran, 2010).

Tumores malignos são denominados cânceres e apresentam contornos fracamente definidos, alta taxa de crescimento celular e potencial metástatico (Robbins e Cotran, 2010; Stevens e Lowe, 2002).

O câncer é hoje considerado uma doença genética multifatorial originada da relação entre diversas alterações genéticas e fatores ambientais que geram um acúmulo de mutações em genes essenciais no reparo e replicação do DNA (Katz et al, 2013; Souza, 2011). Atualmente, o câncer é reconhecido como um problema de saúde pública mundial e estima-se que 8,2\% das mortes em 2012 foram decorrentes de cânceres (OMS, 2015). O problema do câncer no Brasil recebe destaque por representar 13,39\% dos casos de morte no país e há estimativa de aproximadamente 576 mil de novos casos para 2016 (INCAa, 2015). 


\subsubsection{Câncer de próstata}

A próstata é uma glândula presente apenas no sistema genital masculino que circunda o canal da uretra e está localizada abaixo da bexiga (FIG. 1). Esta glândula é responsável pela produção de parte do sêmen, líquido espesso que contém os espermatozóides e é liberado durante o ato sexual (Robbins e Cotran, 2010).

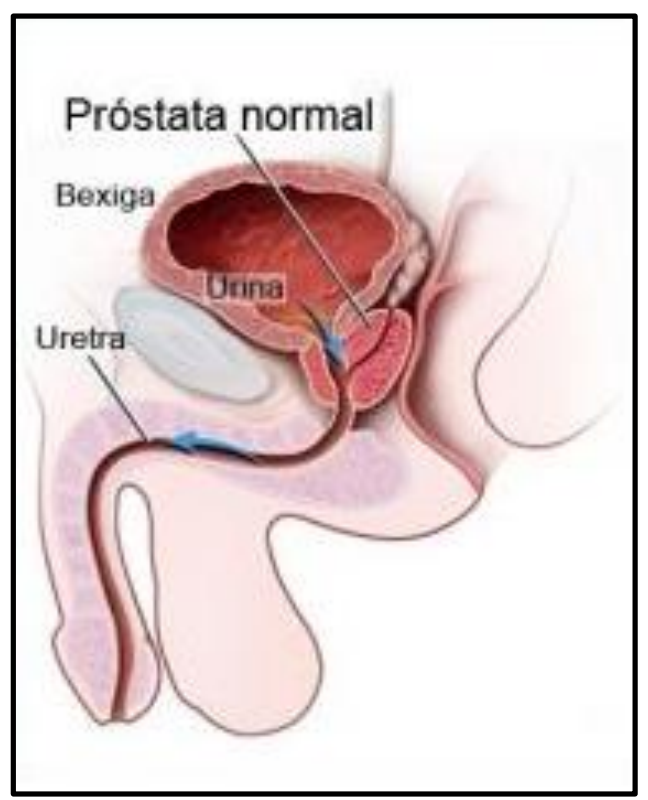

FIGURA 1: Localicação anatômica e morfologia da próstata (Próstata, 2015).

Apenas três processos patológicos relacionados à próstata apresentam frequência suficiente para serem estudados: inflamações, hiperplasia nodosa benigna e câncer. Destes processos, a hiperplasia nodosa benigna é a mais comum e ocorre com tanta frequência que chega a ser considerada uma forma "normal" de envelhecimento. Os cânceres também são bastante comuns e merecem uma importante consideração devido à sua agressividade. Os processos inflamatórios são classificados com pouca importância clínica, pois ocorrem com menor frequência e são tratados facilmente (INCAb, 2015; Robbins e Cotran, 2010).

A neoplasia prostática é caracterizada pelo crescimento anormal da próstata, podendo ser lento ou acelerado (INCAb, 2015). O principal sintoma que alerta o paciente é a diminuição ou interrupção da miç̧ão, em consequência do aumento de volume do órgão que comprime a uretra e impede a passagem da urina. Em fases mais avançadas há o aparecimento de sintomas urinários mais graves, como infecções urinárias e insuficiência 
renal, e desenvolvimento de metástases ósseas e em tecidos próximos (INCAb, 2015; $\mathrm{NCl}$, 2015; Robbins e Cotran, 2010).

O câncer de próstata é comumente classificado pelo sistema de Gleason, onde os valores de 2 - 4 representam cânceres bem diferenciados, 5 - 6 grau intermediário, 7 moderado e 8 - 10 tumores de alto grau. São considerados potencialmente tratáveis tumores com classificação de Gleason entre 5 e 7 e quando $\geq 8$ dificilmente são curáveis. Outra classificação importante é em relação ao estadiamento, onde T1 refere-se ao câncer quando detectado no início, T2 câncer localizado no órgão em questão, T3 o câncer exibe invasão da vesícula seminal e T4 quando ocorre metástase. Estas classificações são responsáveis pelo prognóstico do paciente (Robbins e Cotran, 2010).

O principal fator de risco relacionado ao câncer de próstata é a idade avançada, uma vez que $62 \%$ dos diagnósticos no mundo correspondem a homens com 65 anos ou mais (INCAb, 2015) e raramente acometem homens com idade inferior a 40 anos. A etnia também é um fator importante para esta neoplasia, sendo que africanos e seus descendentes possuem as maiores taxas de incidência, cerca de $60 \%$ mais risco de desenvolver esta neoplasia do que caucasianos ( $\mathrm{NCl}, 2015)$.

O câncer de próstata é o tumor mais frequente em homens em todo o mundo e um aumento da incidência foi observado nos últimos anos (Afshar et al, 2015). A estimativa para o Brasil em 2016 é de 61.200 novos casos da doença e 13.772 mortes, enquanto no ano de 2003 esta estimativa foi de 35 mil novos casos. Em média, 75\% dos casos diagnosticados mundialmente ocorrem em países desenvolvidos, o que pode ser relacionado com melhores condições de rastreamento da doença, aumento da expectativa de vida e melhoria dos métodos diagnósticos (INCAa, 2015). Quando diagnosticado inicialmente é considerado de bom prognóstico. Aproximadamente $100 \%$ dos homens com diagnóstico inicial são considerados livres de doença em cinco anos após o tratamento. Porém, quando não tratada é uma doença potencialmente fatal (Eder et al, 2012; NCl, 2015).

Os métodos de diagnóstico iniciais mais frequentes são a dosagem do PSA e o toque retal, e posteriormente são realizados exames de imagem e biopsia prostática transretal para confirmação (INCAb, 2015).

Entretanto, os exames iniciais não são específicos para detectar o câncer, especialmente os testes de PSA. Entre 20 a 30\% dos exames, os níveis desse marcador estão elevados devido a outras situações benignas, o que resulta em falsos positivos e levam os 
pacientes a realização de biópsias desnecessárias (HILLIER et al, 2009). Em razão disso novos métodos de diagnósticos mais precisos são necessários para uma melhor avaliação inicial desses pacientes.

\subsection{Antígeno de Membrana Prostático Específico}

Diferentemente do PSA que é uma proteína livre no sangue, o antígeno de membrana prostático específico (PSMA) é uma glicoproteína tipo II, transmembrânica composta por 750 aminoácidos, os quais a maior parte representa seu domínio extracelular (Ghosh et al, 2004; Hillier et al, 2009; Malik et al, 2015).

O PSMA é expresso em células do epitélio normal da próstata, glândulas salivares, túbulos renais, mucosa duodenal, glândula salivar e em menor proporção em células neuronais, fígado e baço (Ghosh et al, 2004; Schafer et al, 2012; Silver et al, 1997). No entanto, há uma acentuada superexpressão no câncer de próstata, suas metástases e em neovascularizações relacionadas aos tumores sólidos sendo esta super expressão diretamente relacionada a malignidade deste tumor (Chang et al, 1999; Hillier et al, 2009; Malik et al, 2015).

A função exata deste receptor nas células prostáticas ainda é desconhecida. Nas células neuronais, o PSMA tem atividade NAALADase, onde é responsável por metabolizar o neurotransmissor $\mathrm{N}$-acetil-aspartil-glutamato, e no intestino age como carboxipeptidase e folato hidrolase, possibilitando a absorção de folato livre (Ghosh et al, 2004).

O PSMA pode ser encontrado na forma de monômeros e dímeros, sendo esta a conformação necessária para suas atividades enzimáticas na superfície celular, e possui a característica de ser internalizado, porém ainda não se sabe o que desencadeia esta movimentação. Especula-se que o PSMA tenha a função de transportador transmembrânico para um ligante ainda não identificado, justamente por sua internalização ser muito semelhante à endocitose mediada por receptores (Ghosh et al, 2004).

Na carcinogênese e progressão do câncer de próstata o PSMA possui várias possíveis funções. Sua atividade enzimática de folato hidrolase na superfície das células pode ser responsável pela receptação celular do folato poli-ү-glutamato liberado no meio intersticial pelas células mortas dentro do tumor. Esta ação possibilita que a forma livre do folato participe da síntese e metilação de DNA e síntese de poliaminas, extremamente 
importantes para a proliferação celular. Ao liberar o glutamato o PSMA também pode ativar receptores de glutamato e alterar o potencial de membrana da célula ao modular a função dos canais de potássio/cálcio. Essa alteração faz com que haja um influxo de cálcio nas células neoplásicas, o que está relacionado com a malignidade (Ghosh et al, 2004).

Em razão do PSMA ser superexpresso em praticamente todas as neoplasias prostáticas, de seu possível papel na malignidade destas, assim como na angiogênese de tumores sólidos e sua expressão em tecidos extra prostáticos ser altamente restrita, ele representa um ótimo alvo para novos métodos de diagnóstico por imagem e terapia antineoplásica (Ghosh et al, 2004; Hillier et al, 2009; Malik et al, 2015).

\subsection{MEDiCinA NuClEAR E RADIOFARMÁCIA}

De acordo com Sociedade Brasileira de Medicina Nuclear (SBMN), a medicina nuclear é uma especialidade médica que faz uso de fontes abertas de radionuclídeos, para fins diagnósticos e terapêuticos, utilizados através de métodos não invasivos e seguros (SBMN, 2015).

As fontes abertas de radionuclídeos são, na verdade, medicamentos radiofármacos, cujos perfis farmacocinéticos e farmacodinâmicos são ditados por características do próprio radionuclídeo ou, em sua maioria, por outros grupos funcionais como, compostos orgânicos, peptídeos, anticorpos, partículas e células (Decristoforo et al, 2012; SBMN, 2015).

Os radioisótopos usados em medicina nuclear são produzidos artificialmente em reatores nucleares ou cíclotron (acelerador de partículas) (Oliveira et al, 2006; Zalutsky, 2003). Devido ao tempo de meia vida física curto de alguns radioisótopos, a técnica de utilização de geradores também é bastante empregada. Nela, um radionuclídeo de tempo de meia vida curto (radionuclídeo "filho") é obtido a partir do decaimento de um radionuclídeo "pai" de tempo de meia vida longa (Oliveira et al, 2006).

Segundo a ANVISA (Agência Nacional de Vigilância Sanitária), radiofármacos são preparações farmacêuticas compostas por um ou mais radionuclídeos destinados a utilização em diagnósticos e terapia (BRASIL, 2009).

Radiofármacos utilizados no diagnóstico auxiliam a identificação de tumores e disfunções do organismo (CNEN, 2016). Preferencialmente, são utilizados radionuclídeos 
emissores de radiação gama $(\gamma)$ ou emissores de pósitrons $\left(\beta^{+}\right)$, pois seu decaimento origina radiação eletromagnética penetrante, que apresenta grande capacidade de penetração em tecidos e baixo poder de ionização quando comparada às radiações particuladas ( $\alpha$ e $\beta$ ) (Katz et al, 2013; Liu et al, 2008; Oliveira et al, 2006).

Radiofármacos emissores de radiação $\gamma$ são utilizados em procedimentos diagnósticos, produzindo imagens cintilográficas com equipamentos como gama-câmaras ou SPECT (Single Photon Emission Computed Tomography). Já os radiofármacos que empregam emissores de pósitrons $\left(\beta^{+}\right)$são empregados na técnica diagnóstica de PET (Positron Emission Tomography). Radiofármacos utilizados para finalidade terapêutica utilizam radionuclídeos emissores de radiação particulada ( $\alpha, \beta^{-}$e elétrons Auger), pois possuem pequeno poder de penetração e são altamente energéticos, ionizando o meio e levando à morte celular. Este tipo de terapia é comumente utilizado no tratamento de tumores, sendo considerada uma modalidade bastante efetiva (Liu et al, 2008; Oliveira et al, 2006).

Assim como outros medicamentos, os radiofármacos devem estar isentos de contaminantes. Entretanto, durante sua produção, é necessário garantir que o operador não contamine o produto e que o produto não contamine o operador e o ambiente, por meio da utilização dos principios básicos de Boas Práticas de Fabriação (BPF) de radiofármacos e radioproteção (BRASIL, 2009; Decristoforo et al, 2012).

\subsubsection{Tomografia por emissão de pósitrons}

A utilização de procedimentos diagnósticos por imagem representa um grande avanço no cuidado com pacientes oncológicos, uma vez que são considerados minimamente invasivos e com afinidade por órgãos específicos. Dados disponíveis em literatura evidenciam este importante papel da tecnologia PET no diagnóstico e prognóstico, complementando ou mesmo substituindo métodos diagnósticos já estabelecidos (Katz et al, 2013).

As imagens PET não são um conceito novo, uma vez que os primeiros dispositivos de imagem foram desenvolvidos por Brownell e Anger em 1950 (Sharp e Welch, 2001).

O ponto primordial nesta tecnologia que gerou tanto interesse, se deve ao fato da decomposição de pósitrons permitir a avaliação de diversos parâmetros metabólicos e 
fisiopatológicos in vivo, diferentemente dos demais diagnósticos por imagem que são direcionados para avaliações morfológicas (Katz et al, 2013; Kowalsky e Falen, 2004).

Pósitrons são eletróns expulsos do núcleo carregados positivamente, que viajam uma curta distância até colidir com elétrons presentes na matéria circundante, sofrendo um processo de aniquilação no qual são emitidos dois fótons de 511 keV em trajetórias opostas (FIG. 2) (Katz et al, 2011; Kowalsky e Falen, 2004; Powsner e Powsner, 2006).

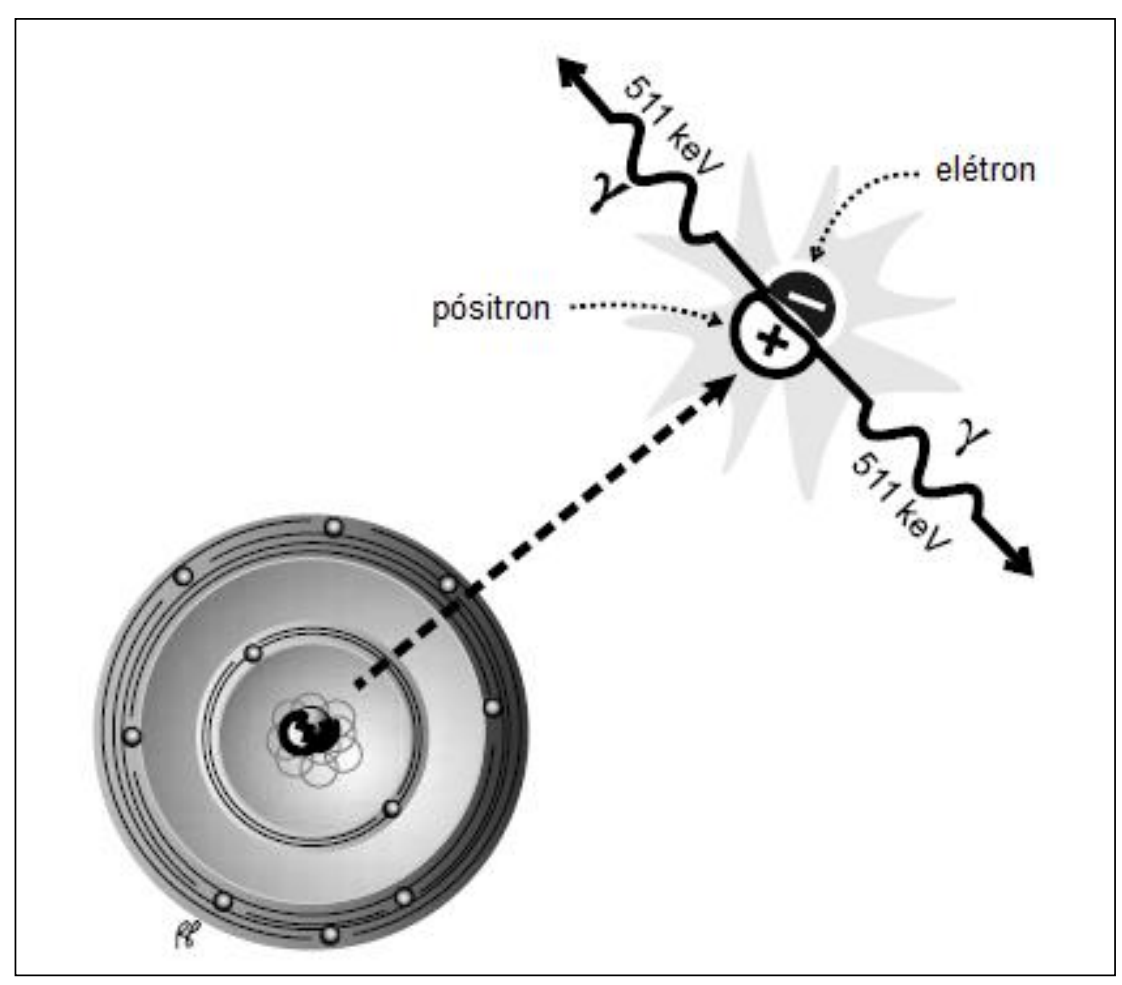

FIGURA 2: Evento de aniquilação entre pósitron e elétron resultando em fótons de 511 keV que percorrem trajetórias opostas (Powsner e Powsner, 2006).

Os equipamentos de tomografia por emissão de pósitrons são câmaras projetadas para detectar a chegada simultânea de fótons provenientes de aniquilação (FIG. 3). Então, assumindo que se encontram ao longo de uma linha, a denominada linha de resposta (LOR), ao unir os dois pontos em que os raios gama atingem o detector, pode-se calcular a integral da atividade ao longo dos conjuntos de LOR e reconstituir a origem da emissão, produzindo uma imagem da distribuição da emissão dos pósitrons (Powsner e Powsner, 2006; Sharp e Welch, 2001). 


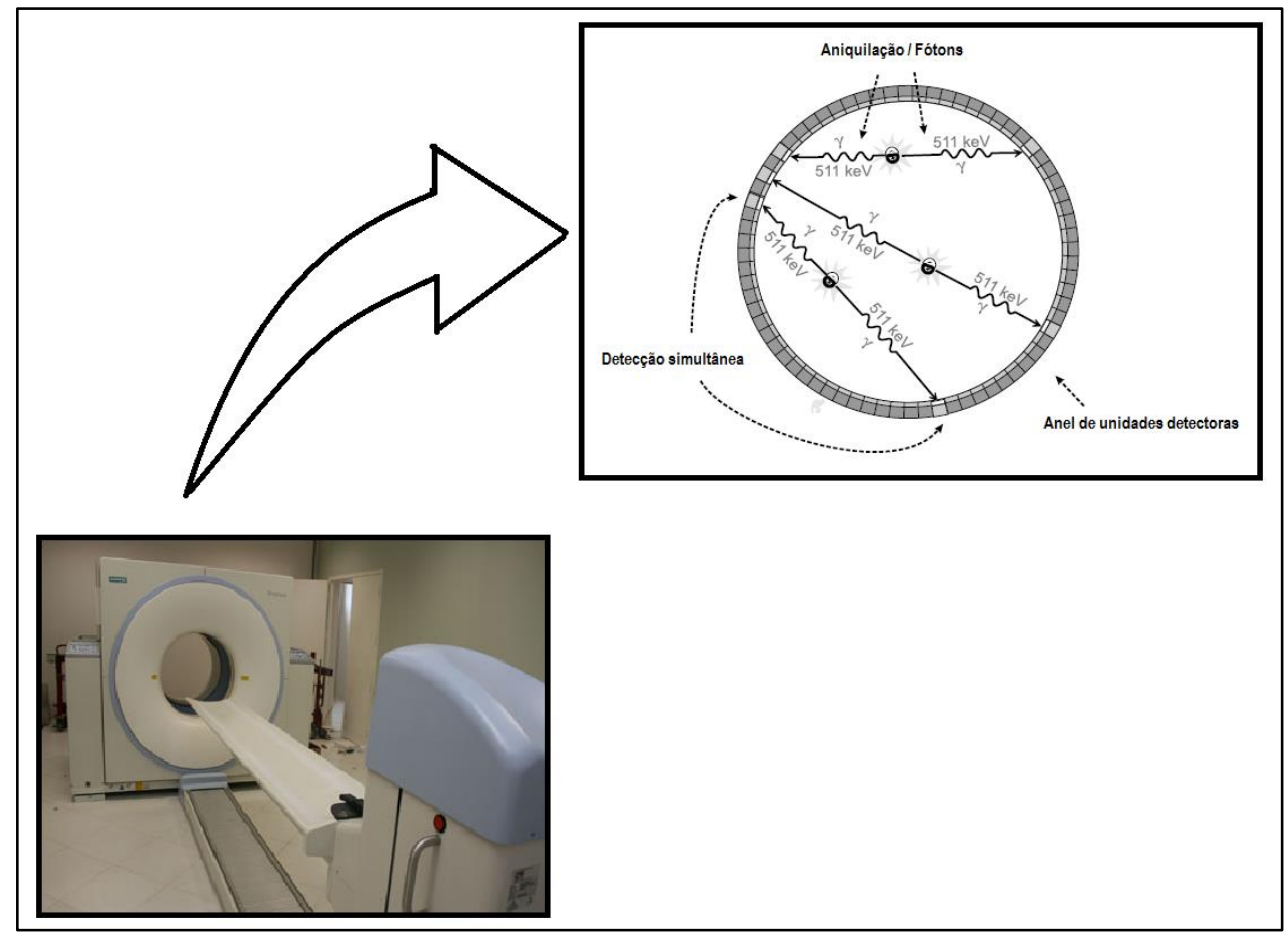

FIGURA 3: Equipamento de tomografia por emissão de pósitrons (PET). Adaptado de Powsner e Powsner, 2006.

Radiofármacos emissores de pósitrons com baixa energia possibilitam imagens mais nítidas. A resolução espacial da PET está associada à distância percorrida pelas partícula $\beta^{+}$até o momento de sua aniquilação, que por sua vez está associada à energia que esta partícula $\beta^{+}(\mathrm{MeV})$ carrega ao ser liberada por cada radioisótopo. Na TAB. 1, encontram-se radioisótopos comumente utilizados, juntamente a suas energias e alcance no tecido (Thrall e Ziessman, 2006). 
TABELA 1: Energia, alcance e metodologia de produção de diferentes radioisótopos emissores de pósitrons (Thrall e Ziessman, 2006).

\begin{tabular}{cccccc}
\hline Radioisótopo & $\begin{array}{c}\text { Meia vida } \\
\text { física (min) }\end{array}$ & $\begin{array}{c}\text { Energia do } \\
\text { pósitron } \\
(\text { MeV })\end{array}$ & $\begin{array}{c}\text { Alcance } \\
\text { máximo linear } \\
(\mathbf{m m})\end{array}$ & $\begin{array}{c}\text { Alcance } \\
\text { médio linear } \\
(\mathbf{m m})\end{array}$ & $\begin{array}{c}\text { Método de } \\
\text { produção }\end{array}$ \\
\hline${ }^{11} \mathrm{C}$ & 20 & 0,96 & 5 & 0,3 & Cíclotron \\
${ }^{13} \mathrm{~N}$ & 10 & 1,19 & 5,4 & 1,4 & Cíclotron \\
${ }^{15} \mathrm{O}$ & 2 & 1,72 & 8,2 & 1,5 & Cíclotron \\
${ }^{18} \mathrm{~F}$ & 110 & 0,64 & 2,4 & 0,2 & Cíclotron \\
${ }^{68} \mathrm{Ga}$ & 68 & 1,89 & 9,1 & 1,9 & Gerador ${ }^{88} \mathrm{Ge}$ \\
${ }^{82} \mathrm{Rb}$ & 1,3 & 3,35 & 15,6 & 2,6 & Gerador ${ }^{82} \mathrm{Sr}$ \\
\hline
\end{tabular}

Atualmente, a maioria dos equipamentos PET são acoplados a equipamentos de tomografia computadorizada (CT), com o objetivo de permitir o registro sincrônico anatômico e metabólico, quando necessário. Esses equipamentos híbridos são denominados PET-CT (Saha, 2003).

\subsection{GÁLIO 68}

$\mathrm{O}{ }^{68} \mathrm{Ga}$ começou a ser utilizado na medicina há mais de 50 anos, porém somente recentemente ganhou destaque entre os centros de pesquisa mundiais (Decristoforo et al, 2007). Algumas razões são a produção de geradores apropriados para o uso diário em centros produtores, elaboração de técnicas de purificação do eluato e a descoberta de pequenos peptídeos com propriedades farmacocinéticas de interesse e que podem ser radiomarcados com grande eficiência (Crespo et al, 2013; Maecke et al, 2005).

No final de 1970 , o ${ }^{18} \mathrm{~F}$ passou a subsituir o ${ }^{68} \mathrm{Ga}$ para imagens $\mathrm{PET}$, devido aos primeiros geradores fornecerem o radionuclídeo ${ }^{68} \mathrm{Ga}$ complexado com EDTA (ácido etilenodiamino tetra-acético), tornando necessário a destruição deste complexo para a realização de preparações radiofarmacêuticas. O desenvolvimento de novos geradores possibilitou a eluição do ${ }^{68} \mathrm{Ga}$ com ácido diluído $(\mathrm{HCl})$ e purificação eficaz do eluato, tornando adequada novamente a utilização deste radionuclídeo, que foi aplicado para produção do DOTATOC- ${ }^{68}$ Ga (ácido 1,4,7,10-tetra-azaciclododecane-1,4,7,10- tetraacetico-D-Phe1-Tyr3 octreotido- ${ }^{68} \mathrm{Ga}$ ), o radiofármaco para PET baseado em ${ }^{68} \mathrm{Ga}$ mais utilizado na clínica (Banerjee et al, 2013; Maecke et al, 2005). 
O radionuclídeo ${ }^{68} \mathrm{Ga}$ é de grande utilidade para exames de imagem empregando a tecnologia PET. Possui meia vida física de 68 minutos e decai principalmente por emissão de pósitrons de 1,92 MeV de energia e com 89\% de abundância. É obtido por gerador de ${ }^{68} \mathrm{Ge} /{ }^{68} \mathrm{Ga}$, que consiste em uma coluna de alumina, dióxido de estanho ou titânio na qual o ${ }^{68} \mathrm{Ge}$ está imobilizado e, à medida que este decai para o ${ }^{68} \mathrm{Ga}$ seu "isótopo filho", pode ser eluído com $\mathrm{HCl} 0,1 \mathrm{M}$ ou $\mathrm{HCl} 0,6 \mathrm{M}$ de acordo com a matriz utilizada. Independente da matriz empregada, o eluato apresentará impurezas metálicas que devem ser separadas, pois podem competir com $0{ }^{68} \mathrm{Ga}$ dificultando sua complexação. A purificação do eluato do gerador é feita por meio de coluna de troca iônica capaz de fornecer solução com níveis adequados de impurezas para utilização em pacientes (Banerjee et al, 2013; Maecke et al, 2005; Petrik et al, 2010; Rosch et al, 2013; Zhernosekov et al, 2007).

Estudos recentes têm proposto a utilização de nano partículas (ceriapoliacrilonitrilo e nano zircônia) na imobilização do ${ }^{68} \mathrm{Ge}$ nos geradores de ${ }^{68} \mathrm{Ge} /{ }^{68} \mathrm{Ga}$, no intuito de fornecer $0{ }^{68} \mathrm{Ga}$ livre de impurezas sem a necessidade de purificação e adequado para uso clínico (Chakravarty et al, 2011).

Devido à longa meia-vida do ${ }^{68} \mathrm{Ge}, 271$ dias, o gerador de ${ }^{68} \mathrm{Ge} /{ }^{68} \mathrm{Ga}$ pode ser utilizado por até um ano, viabilizando uma boa alternativa para unidades de medicina nuclear que utilizam o equipamento PET para realização de imagens e que dependem de radionuclídeos produzidos por cíclotron, um grande limitador dessa técnica (Decristoforo et al, 2007). Já a meia-vida do ${ }^{68} \mathrm{Ga}$ é longa o suficiente para possibilitar a síntese automatizada de radiomarcadores e a aquisição de imagem durante período apropriado (Liu et al, 2008).

Atualmente, vários sistemas geradores ${ }^{68} \mathrm{Ge} /{ }^{68} \mathrm{Ga}$ estão comercialmente disponíveis a partir de distribuidores na Rússia (Obninsk, Cyclotron Co, Eckert \& Ziegler), Alemanha (ITG Isotope Technologies), Estados Unidos (IGG100, Eckert \& Ziegler) e África do Sul (iThemba Labs), além de outros distribuidores em desenvolvimento na Europa, América do Norte e Ásia (Velikyan et al, 2014).

Estes geradores têm características gerais semelhantes, mas diferem na composição da matriz imobilizante para o germânio-68 (Roesch et al, 2012; Velikyan et al, 2014). Na FIG. 4 e TAB. 2 estão representados os geradores de ${ }^{68} \mathrm{Ge} /{ }^{68} \mathrm{Ga}$ disponíveis comercialmente e suas características. 


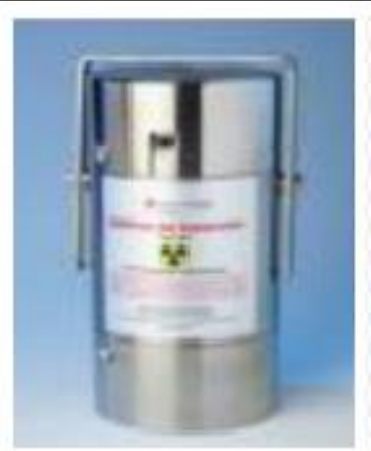

Cyclotron Co

(Rússia)

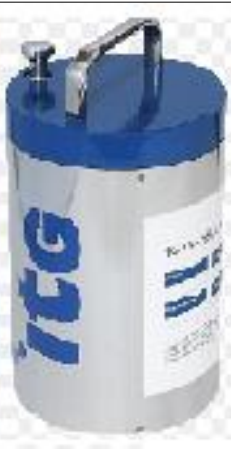

ITG

(Alemanha)

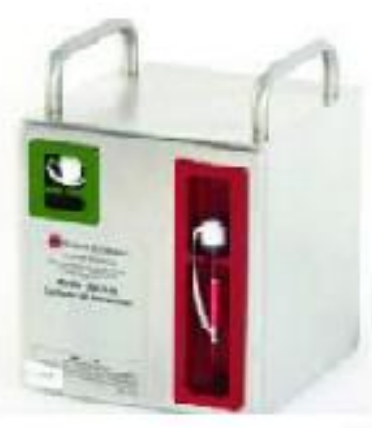

Eckert and Ziegler (USA)

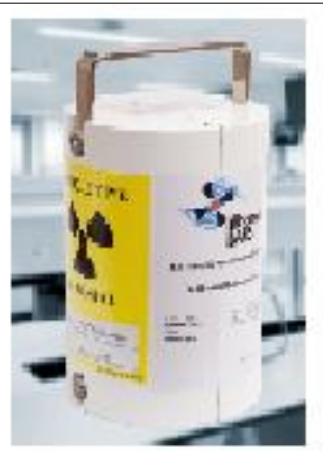

IThemba (África do Sul)

FIGURA 4: Geradores ${ }^{68} \mathrm{Ge} /{ }^{68} \mathrm{Ga}$ comercialmente disponíveis (Cyclotron Co, 2016; Eckert Ziegler, 2016; ITG, 2016; IThemba, 2016).

TABELA 2: Características dos geradores ${ }^{68} \mathrm{Ge} /{ }^{68} \mathrm{Ga}$ comercialmente disponíveis (Cyclotron Co, 2016; Eckert Ziegler, 2016; ITG, 2016; IThemba, 2016; Roesch et al, 2012; Velikyan et al, 2014).

\begin{tabular}{|c|c|c|c|c|}
\hline Fabricante & $\begin{array}{l}\text { Matriz da } \\
\text { coluna }\end{array}$ & Eluente & $\begin{array}{c}\% \text { de } \\
\text { contaminação } \\
\text { com }^{68} \mathrm{Ge}\end{array}$ & Vida útil \\
\hline $\begin{array}{l}\text { Eckert and } \\
\text { Ziegler }\end{array}$ & $\begin{array}{c}\text { Óxido de titânio } \\
\left(\mathrm{TiO}_{2}\right)\end{array}$ & $\mathrm{HCl} 0,1 \mathrm{~N}$ & $<0,001$ & $\begin{array}{l}1 \text { ano/300 } \\
\text { eluições }\end{array}$ \\
\hline Cyclotron Co & $\begin{array}{l}\text { Óxido de titânio } \\
\qquad\left(\mathrm{TiO}_{2}\right)\end{array}$ & $\mathrm{HCl} 0,1 \mathrm{~N}$ & 0,005 & $\begin{array}{l}1 \text { ano/300 } \\
\text { eluições }\end{array}$ \\
\hline IThemba & $\begin{array}{l}\text { Óxido de estanho } \\
\qquad\left(\mathrm{SnO}_{2}\right)\end{array}$ & $\begin{array}{l}\mathrm{HCl} 0,6 \mathrm{~N} \\
\mathrm{HCl} 1,0 \mathrm{~N}\end{array}$ & $\sim 0,002$ & $\begin{array}{l}1 \text { ano/200 } \\
\text { eluições }\end{array}$ \\
\hline ITG & Sílica/Orgânica & $\begin{array}{l}\mathrm{HCl} 5,5 \mathrm{~N} \\
\mathrm{HCl} 0,05 \mathrm{~N}\end{array}$ & $<0,005$ & 400 eluições \\
\hline
\end{tabular}

A disponibilidade e confiabilidade dos sistemas de geradores torna o ${ }^{68} \mathrm{Ga}$ um potencial radioisótopo para ser utilizado em imagens $\mathrm{PET}$, assim como ${ }^{99 \mathrm{~m}} \mathrm{Tc}$ provou ser para SPECT (Banerjee et al, 2013).

Atualmente, somente o gerador ${ }^{68} \mathrm{Ge} /{ }^{68} \mathrm{Ga}$ da fabricante ITG permite a eluição do ${ }^{68} \mathrm{GaCl}_{3}$ classificado como GMP (Good Manufacturing Practice), ou seja, eluente estéril que respeita os mais altos padrões de segurança, sendo adequado para uso imediato em pacientes sem a necessidade de purificação pós eluição (ITG, 2016). A aprovação para os 
geradores produzidos pela Eckert and Ziegler e IThemba também são esperadas para um futuro próximo, uma vez que detêm licença para Boas Práticas de Fabricação (Velikyan et al, 2014; Mukherjee et al, 2014).

Em consequência destas recentes melhorias na obtenção do radionuclídeo ${ }^{68} \mathrm{Ga}$, procedimentos de marcação direta utilizando-se reagentes para pronta marcação (kit) vêm sendo altamente desejados (Chakravart et al, 2010; Ebenhan et al, 2015; Mukherjee et al, 2014).

Recentemente, foram propostas formulações de reagentes liofilizados (Kits) para radiomarcação direta de peptídeos com ${ }^{68} \mathrm{Ga}$ em sistema não automatizado, conforme descrito para DOTA-peptídeo, NODAGA (Mukherjee et al, 2014; Shukla et al, 2013) e mais recentemente para o PSMA-HBED-CC (Ebenhan et al, 2015). A utilização de kits tem demonstrado vantagens por minimizar a manipulação do radiofármaco diminuindo o risco de contaminações e o tempo de produção, com boa relação custo-efetividade, além de permitir o aumento do escopo de radiofármacos baseados em ${ }^{68} \mathrm{Ga}$ para atender às crescentes demandas de imaginologia (Ebenhan et al, 2015; Mukherjee et al, 2014; Shukla et al, 2013).

Outra tecnologia, atualmente bastante utilizada para otimizar o processo de radiomarcação com ${ }^{68} \mathrm{Ga}$ é a utilização de módulos de síntese automatizado, pois reduzem riscos de contaminação, são altamente reprodutíveis, além de também respeitarem as normas BPF (Velikyan et al, 2014).

A produção de geradores de ${ }^{68} \mathrm{Ga}$ não somente permite exames PET em hospitais remotos, distantes dos distribuidores de radionuclídeos produzidos em cíclotron (por exemplo, de ${ }^{18} \mathrm{~F}$ ) como também o enriquecimento do arsenal medicamentoso em centros médicos (Velikyan et al, 2014).

\subsection{QUElantes Bifuncionais Macrocíclicos}

Para a radiomarcação de biomoléculas com um radionuclídeo de origem metálica é necessário a utilização prévia de um agente quelante bifuncional (BFC "Bifunctional chelator"). O BFC é ligado covalentemente à molécula alvo, diretamente ou através de um ligante modificador de farmacocinética, e se coordena fortemente com o radiometal. A 
escolha do BFC a ser utilizado depende principalmente da natureza e estado de oxidação do radiometal empregado (Liu et al, 2008).

Para que o BFC seja considerado ideal, deve possuir algumas características específicas: ser capaz de realizar uma quelação estável do radiometal, pois, em sistemas biológicos, competem frequentemente com quelantes naturais, como a transferrina; possuir uma alta estabilidade termodinâmica para evitar a sua perda durante as técnicas de marcação; e ser cineticamente inerte, por este fator refletir na razão de dissociação do íon metálico do quelante bifuncional, proporcionando uma melhor estabilidade in vivo (Liu et al, 2008; Maecke e Good, 2003).

Uma vez que o quelante tem um impacto significante nas propriedades biológicas do radiometal, a biodistribuição do radiofármaco pode ser alterada por meio da modificação do ambiente no qual o radiometal está inserido, alterando o BFC usado na conjugação do radiometal com a biomolécula (Liu et al, 2008). Escolhendo o BFC ideal pode-se obter grandes melhorias na cinética de radiomarcação, aumentar a estabilidade do composto e influenciar na farmacocinética do mesmo (Ferreira et al, 2010).

Em seus estudos, Banerjee e colaboradores (2010) conjugaram um inibidor do PSMA baseado em ureia (Glu-NH-CO-NH-Lys) com o BFC DOTA-NHS-éster e obtiveram bons resultados. Eder e colaboradores (2012) conjugaram o mesmo inibidor do PSMA com o quelante metálico acíclico HBED-CC, demonstrando maior eficiência quando comparado aos demais quelantes, uma vez que esta combinação introduz na molécula um grupo aromático que favorece a interação com o receptor, devido a uma bolsa hidrofóbica presente no sítio de ligação S1 do PSMA. Essa conjugação também tem demonstrado maior lipofilicidade que - DOTA, apresentando melhorias, como a redução de ligação inespecífica e maior internalização em células LNCaP, o que resultou em melhores imagens em PET. Quando comparado aos demais métodos diagnósticos, também tem mostrado vantagens, apresentando imagens com maior contraste e melhor detecção de recidivas e metástases. (Barinka et al, 2008; Zang et al, 2010).

Em detrimento, o quelante acíclico HBED-CC (ácido N,N'-Bis[2-hidroxi-5carboxiletil-benzil]etilenediamino- $\mathrm{N}, \mathrm{N}^{\prime}$-diacético), quando acoplado ao gálio-68, sofre alterações estruturais podendo formar até três diasteroisômeros (RR, RS e SS), cuja formação está diretamente ligada à variação de temperatura e pH (Eder et al, 2014; Schafer et al, 2012; Schuhmacher et al, 1995). 
Neste trabalho será utilizado o peptídeo Glu-NH-CO-NH-Lys (PSMA) conjugado ao quelante aciclíco HBED-CC obtido da empresa ABX (Alemanha) (ABX, 2015) (FIG. 5).

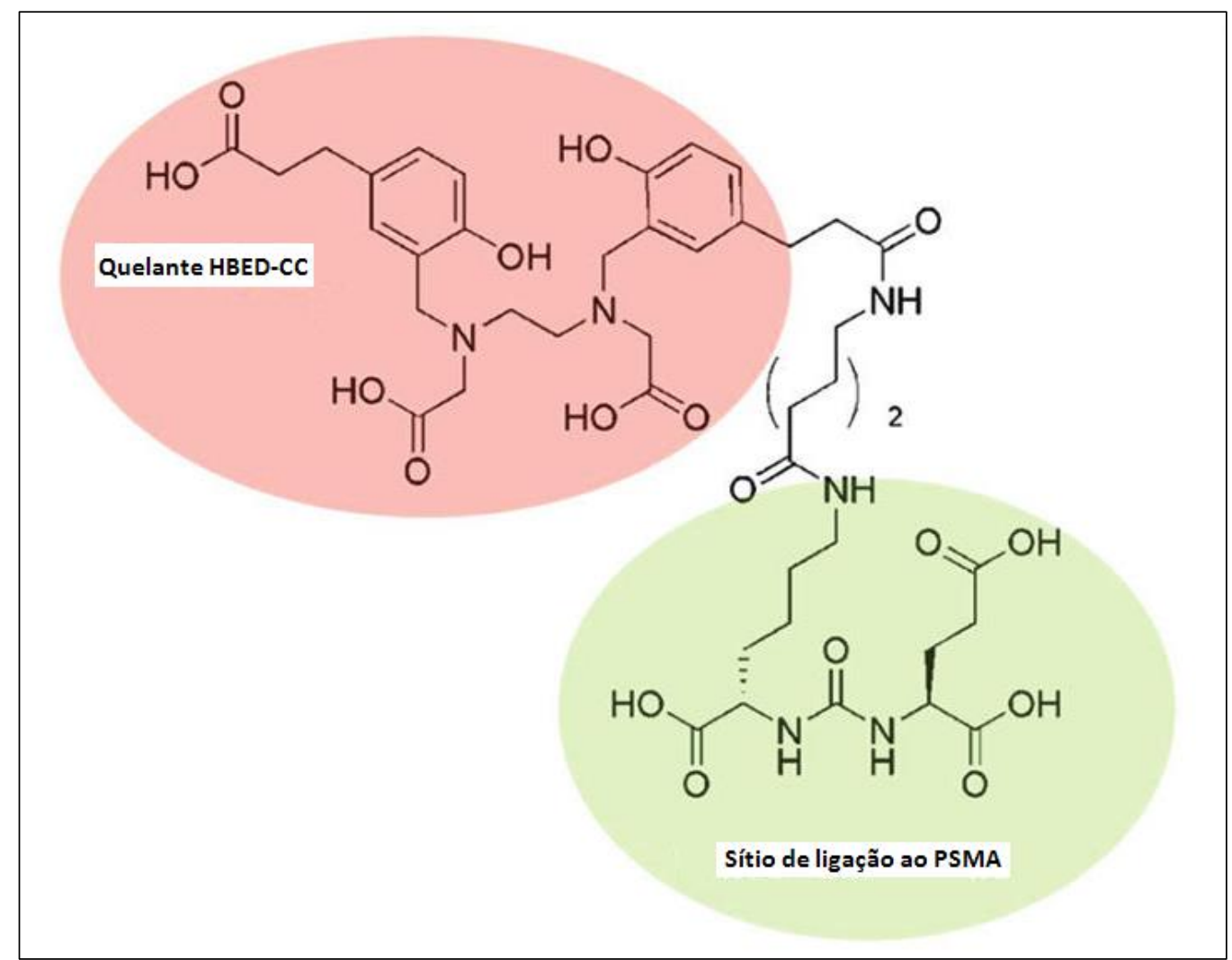

FIGURA 5: PSMA conjugado ao quelante bifuncional HBED-CC conjugado ao peptídeo Glu-NH-CO-NH-Lys (Eder et al, 2012).

\subsubsection{Incorporação do gálio-68 ao marcador molecular}

Tipicamente, quelantes bifuncionais são utilizados para quelar radionuclídeos metálicos aos marcadores moleculares. Este é um fator que pode influenciar propriedades como farmacocinética, estabilidade e condições de radiomarcação (Ferreira et al, 2010). O HBED-CC é considerado um dos quelantes mais eficazes para metais trivalentes, e assim apropriado para o uso com gálio-68 (Schuhmacher et al, 1995).

Estudos demonstraram uma elevada estabilidade cinética do complexo ${ }^{68} \mathrm{Ga}-\mathrm{HBED}-\mathrm{CC}$ em pH fisiológico, resultando em um complexo estável in vivo, além de permitir radiomarcação à temperatura ambiente (Eder et al, 2014; Schuhmacher et al, 1995). 
Em contraste aos demais quelantes, foi demonstrado que o $\mathrm{Ga}^{3+}$ ocupa um prisma triangular que permite a formação de diferentes formas estéricas do PSMA-HBED-CC- ${ }^{68} \mathrm{Ga}$ (diasteroisômeros) (Schuhmacher et al, 1995). A formação destes diasteroisômeros é influenciada pelo processo de radiomarcação (Eder et al, 2014; Schafer et al, 2012; Schuhmacher et al, 1995). Entretanto, estudos recentes sugerem que estes diasteroisômeros não tem influência sobre a ligação in vivo da molécula com o receptor tumoral específico (Eder et al, 2014).

\subsubsection{Diasteroisômeros}

A esterioquímica é uma sub-área da química que estuda a disposição dos átomos em uma molécula. Quando compostos diferentes apresentam mesma fórmula molecular são classificados como esterioisômeros e posteriormente sub-divididos novamente conforme suas propriedades em enantiômeros e diasteroisômeros (FIG. 6) (Juaristi e Stefani, 2012).

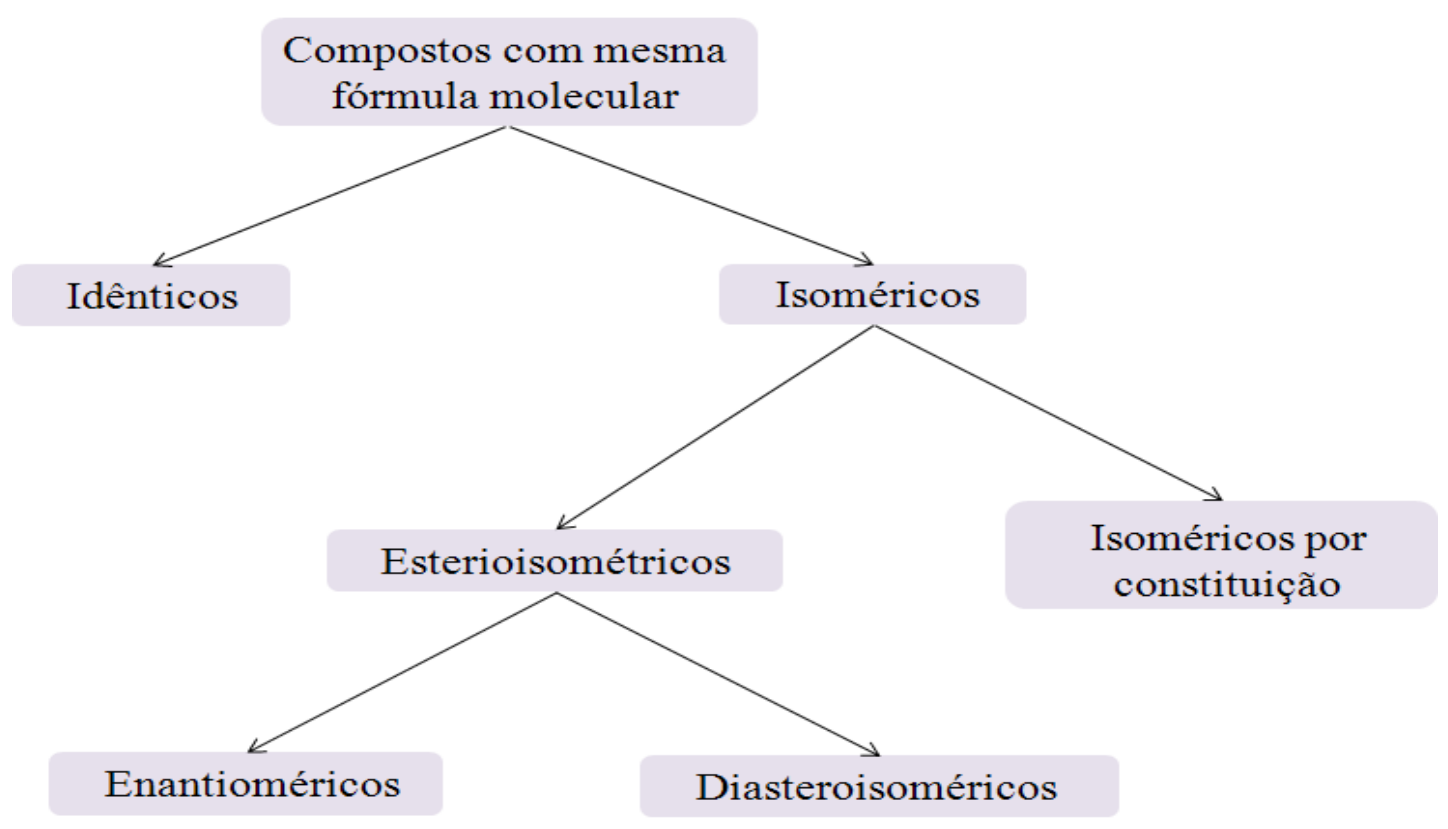

FIGURA 6: Esquema de sub-classificações químicas (Juaristi e Stefani, 2012).

Diferentemente dos enantiômeros, os diasteroisômeros não são a imagem especular um do outro, são compostos com propriedades e comportamento químico distinto (Juaristi e Stefani, 2012). 
Schuhmacher e colaboradores (1995) desenvolveram um estudo de modelagem molecular que indicou a formação de três diasteroisômeros na conjugação do peptídeo HBED-CC com o radionuclídeo ${ }^{68} \mathrm{Ga}$, dando origem aos isômeros RR, RS e SS (configurações dos átomos de nitrogênio da amina). Cada um dos diasteroisômeros está presente como uma mistura racêmica de dois enantiômeros ( $D$ e $L$ ) (FIG. 7).

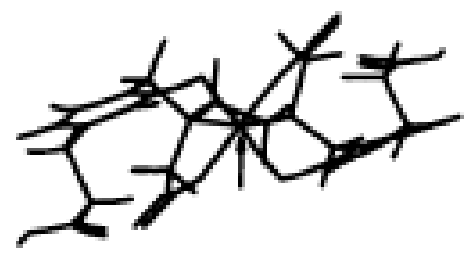

SS
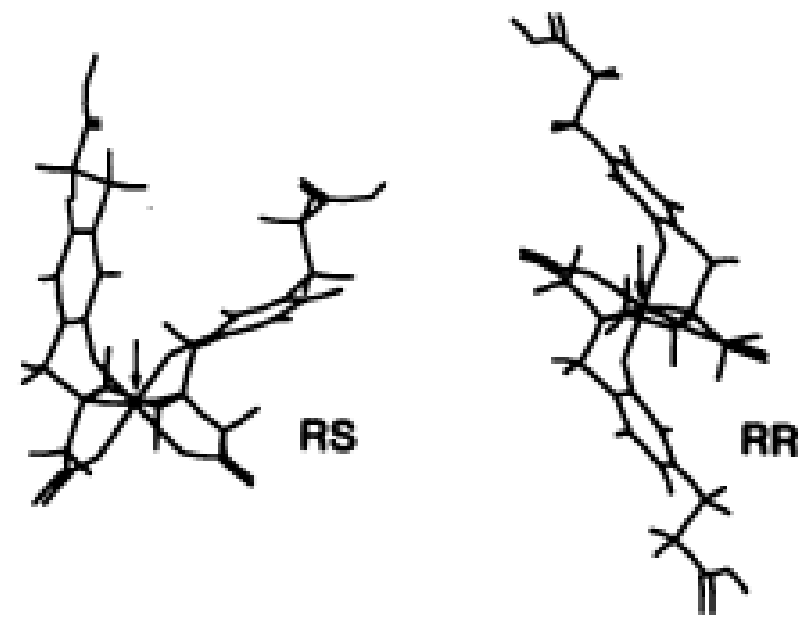

FIGURA 7: Configuração estérica dos diasteroisômeros do PSMA-HBED-CC ligado ao ${ }^{68} \mathrm{Ga}$ (Schuhmacher et al, 1995).

Há relatos que descrevem a sensibilidade dos diasteroisômeros do PSMA-HBED-CC $-{ }^{68} \mathrm{Ga}$ quanto a variações de $\mathrm{pH}$ e temperatura, sempre demonstrando uma tendência das conformações menos estáveis se converterem na mais estável termodinamicamente (RR) (Eder et al, 2012; Eder et al, 2014; Schafer et al, 2012; Schuhmacher et al, 1995).

Pensando na importância da esterioquímica para o efeito biológico através de ligação peptídeo-receptor, Eder e col. (2012) e Schafer e col. (2012) desenvolveram estudos onde as formas enantioméricas D-PSMA-HBED-CC e L-PSMA-HBED-CC foram analisadas quanto sua capacidade de ligação específica e ligação in vivo. Os estudos concluiram que a forma D-PSMA-HBED-CC é rapidamente clareada dos rins e apresenta menor ligação específica devido sua afinidade 1000 vezes inferior pelo receptor quando comparado a forma L-PSMA-HBED-CC que fica retida nos rins e apresenta alta ligação específica. No entanto, estes estudos foram realizados separando apenas os enantiômeros $D$ e $L$, sem referência a qual dos diasteroisômeros. 
Outro estudo variou os métodos de marcação obtendo diferentes concentrações dos diasteroisômeros, que foram submetidos a análises de ligação específica e imagem por PET, demonstrando não haver qualquer influência negativa entre as conformações menos estáveis de diasteroisômeros sobre a ligação às células tumorais e na qualidade das imagens (Eder et al, 2014).

No entando, os estudos realizados não permitem confirmar a ausência desta influência, uma vez que as três conformações não foram separadas e avaliadas individualmente (Eder et al, 2014).

\subsection{INIBIDORES DO PSMA}

Com base em descobertas anteriormente descritas na literatura e a necessidade de metodologias mais precisas para o tratamento e diagnóstico do câncer de próstata, foram desenvolvidos anticorpos monoclonais que reconhecem epítopos intra e extracelulares dos receptores de PSMA (Milowsky et al, 2007; Troyer et al, 1997). No entanto, houve desvantagens consideráveis na utilização de anticorpos, uma vez que direcionados a epítopos intracelulares, reconhecem apenas células em apoptose ou já mortas (Troyer et al, 1997). Além disto, anticorpos têm dificuldade em penetrar adequadamente na microvasculatura do tumor e sofrem rápida degradação através de proteólise (Tang et al, 2003).

Desta forma, o desenvolvimento de pequenas moléculas inibidoras de PSMA, que carreguem agentes de imagem ao tumor e que não sejam prejudicadas pela microvasculatura deste, mostrou-se um ramo promissor para a evolução das tecnologias de diagnóstico de neoplasias.

Levando em consideração a atividade enzimática NAALADase do receptor de PSMA, Tang e colaboradores (2003) produziram moléculas baseadas em ureia com propriedades inibitórias deste receptor e testaram suas atividades em células da linhagem LNCaP (células de carcinoma prostático humano) que expressam o PSMA na superfície celular, confirmando a utilidade dessas moléculas (Tang et al, 2003).

Os inibidores do PSMA baseados em ureia são peptídeos de baixo peso molecular, compostos basicamente por dois aminoácidos ligados através dos grupamentos R-amino por uma uréia (Maresca et al, 2009). São excluídos da circulação rapidamente, 
possibilitando imagens com a relação tumor/órgãos não alvo mais elevada (Eder et al, 2013; Schafer et al, 2012).

Inicialmente, os inibidores do PSMA baseados em ureia foram complexados com ${ }^{99 \mathrm{~m}} \mathrm{Tc}$ e ${ }^{123} \mathrm{I}$ para análises em tomografia computadorizada por emissão de fóton único (SPECT) (Banerjee et al, 2008; Hillier et al, 2009). Com o advento do PET iniciaram-se estudos com estes inibidores de PSMA radiomarcados com ${ }^{18} \mathrm{~F}$ (Mease et al, 2008). Em razão da evolução das técnicas de produção do gálio-68, Banerjee e col. (2010) analisaram dois compostos com diferenças estruturais na região ligante do inibidor do PSMA baseado em ureia (estrutura básica - Glu-NH-CO-NH-Lys), quelados ao BFC DOTA e marcados com ${ }^{68} \mathrm{Ga}$, que se mostraram bastante promissores para técnicas de diagnóstico do câncer de próstata por PET (Banerjee et al, 2010).

Estudos de radiomarcação do PSMA com ${ }^{68} \mathrm{Ga}$ utilizando diferentes quelantes bifuncionais (DTPA, DOTA, NOTA e PCTA) também foram avaliados. O quelante NOTA apresentou melhores resultados, obteve maior pureza radioquímica (PR) com menor massa do peptídeo e melhor clareamento sanguíneo (Chakravarty et al, 2012), porém este rápido claremente sanguíneo pode limitar seu acúmulo no tecido alvo (Ferreira et al, 2010), assim a estabilidade cinética e propriedades observadas in vivo tornaram o BFC PCTA um alvo promissor (Ferreira et al, 2012). Contudo, estudos de marcação com anticorpos demonstraram alta eficiência do quelante HBED na radiomarcação com ${ }^{68} \mathrm{Ga}$, além de alta estabilidade in vitro e in vivo (Eder et al, 2008; Eder et al, 2010). Liu e colaboradores (2008) demonstraram que a natureza lipofílica do HBED-CC favorece sua ligação ao receptor PSMA, o que estimulou o desenvolvimento dos diversos estudos com este quelante.

Nos últimos anos, o número de radiotraçadores para PET tem crescido, evidenciando a eficácia de peptídeos de baixo peso molecular para reconhecimento do antígeno de membrana PSMA. Além do PSMA-HBED-CC- ${ }^{68} \mathrm{Ga}$ outros peptídeos de baixo peso molecular direcionados ao receptor PSMA vêm sendo estudados.

Um derivado radiomarcado com flúor-18, o DCFPyL- ${ }^{18} \mathrm{~F}$, foi comparado com PSMA-HBED-CC- ${ }^{68}$ Ga no diagnóstico do câncer de próstata apresentando bons resultados (Dieltlein et al, 2015; Szabo et al, 2015). No entanto, deve-se levar em consideração o número reduzido de estudos para o DCFPyL- ${ }^{18} \mathrm{~F}$ e a dificuldade logística na distribuição de um radiofármaco à base de isótopo produzido por cíclotron e de meia vida curta. 
Também encontra-se estudo de antagonista do PSMA radiomarcado com ${ }^{18} \mathrm{~F}$ (Glu-Urea-Lys- ${ }^{18} \mathrm{~F}$ ), que apresenta alta captação na recorrência de tumores e diagnóstico inicial da doença, incovenienimente apresentando uma captação elevada não somente nos rins como o PSMA-HBED-CC- ${ }^{68} \mathrm{Ga}$ mas também no fígado (Fan et al, 2015).

Outros estudos utilizam o peptídeo inibidor do PSMA radiomarcado com ${ }^{177} \mathrm{Lu}$ (PSMA-I\&T) para terapia e ${ }^{111}$ In (PSMA-I\&T) para dignóstico com SPECT/CT. Todavia, em uma comparação direta com o PSMA-HBED-CC- ${ }^{68} \mathrm{Ga} P E T / C T$, fica claro a superioridade deste último devido às características do próprio radiofármaco, mas principalmente pelas diferenças intrumentais inerentes (Schottelius et al, 2015).

\subsubsection{Aplicação clínica do PSMA-HBED-CC-68Ga}

A utilização clínica do PSMA-HBED-CC- ${ }^{68}$ Ga tem sido descrita por estudos clínicos recentes.

Um estudo comparativo utilizando $\mathrm{PSMA}^{68} \mathrm{Ga}$ avaliou o volume do tumor através do equipamento PET/CT e Ressonância Magnética (RM) em tumores primários de câncer de próstata. As médias do volume para RM e PET/CT foram $3,83 \mathrm{~cm}^{3}$ e $11,41 \mathrm{~cm}^{3}$, respectivamente. $O$ índice de detecção obtido por PSMA- ${ }^{68} \mathrm{Ga} P E T / C T$ foi significativamente maior, representando um importante papel no planejamento de tratamentos (Zamboglou et al, 2015).

Os radiofármacos colina $-{ }^{11} \mathrm{C}$ e fluorometilcolina- ${ }^{18} \mathrm{~F}$ são comumente utilizados na clínica, embora demonstrem baixa sensibilidade em baixos níveis de PSA. Um estudo realizado por Morigi e colaboradores analisou a eficiência dos radiofármacos fluorometilcolina- ${ }^{18} \mathrm{~F}$ e PSMA-HBED-CC $-{ }^{68} \mathrm{Ga}$ em $\mathrm{PET} / \mathrm{CT}$ com pacientes que realizaram prostatectomia radical, radioterapia, ou ambos, e estavam sendo considerados para terapia-alvo por apresentarem um nível elevado de PSA após o tratamento. 0 PSMA-HBED-CC $-{ }^{68} \mathrm{Ga}$ apresentou uma taxa significativamente mais elevada de detecção que a fluorometilcolina- ${ }^{18} \mathrm{~F}$ em todos os níveis de PSA avaliados $(0,5-2,54 \mathrm{ng} / \mathrm{mL})$. Na taxa mais elevada de PSA avaliada $(1,74 \pm 2,54 \mathrm{ng} / \mathrm{mL})$, apenas um caso foi detectado exclusivamente pela fluorometilcolina- ${ }^{18} \mathrm{~F}$, contra 14 casos detectados exclusivamente pelo PSMA-HBED-CC $-{ }^{68} \mathrm{Ga}$. O PSMA-HBED-CC ${ }^{68} \mathrm{Ga}$ também atingiu melhores resultados na 
identificação de lesões, localizando 59 contra apenas 29 do fluorometilcolina- ${ }^{18} \mathrm{~F}$ (Morigi et al, 2015).

Um estudo piloto, realizado em trinta pacientes com câncer de próstata de alto risco previamente à prostatectomia radical, mensurou a acurácia diagnóstica de metástases em linfonodos do PSMA-HBED-CC $-{ }^{68} \mathrm{Ga}$ em PET/CT. A sensibilidade e especificidade do método e o valor preditivo positivo e negativo obtido foram $33,3 \%, 100 \%, 100 \%$, e $69,2 \%$, respectivamente. Em $92,9 \%$ dos pacientes, os focos tumorais intraprostáticos foram corretamente detectados. Desta forma, o tamanho do linfonodo revelou influência substâncial no diagnóstico. A avaliação diagnóstica do PSMA-HBED-CC- ${ }^{68}$ Ga em equipamento PET/CT foi considerada uma ferramenta promissora para imaginologia (Budäus et al, 2015). Outro estudo, realizado por Herlemann e colaboradores, para identificação de metástases em linfonodos, também concluiu que o PSMA-HBED-CC- ${ }^{68} \mathrm{Ga}$ pode vir a se tornar uma importante ferramenta diagnóstica no futuro (Herlemann et al, 2016).

No intuito de ponderar análises diagnósticas com PSMA-HBED-CC- ${ }^{68} \mathrm{Ga}$ em $\mathrm{PET} / \mathrm{CT}$ sob um número maior de variáveis possivelmente interagindo, Afshar e colaboradores desenvolveram um grande estudo com 319 pacientes. Foram avaliados fatores como antígeno prostático específico (PSA), nível e tempo de duplicação (PSA-DT), pontuação de Gleason (PG), terapia de privação de andrógeno (ADT), idade e quantidade de traçador injetado. O radiofármaco demonstrou ter sua eficácia associada ao nível de PSA e ADT, e independente do PG e PSA-DT. Ao menos uma lesão foi detectada em $82,8 \%$ dos pacientes, demonstrando mais uma vez seu importante papel na avaliação diagnóstica do câncer de próstata (Afshar et al, 2015).

Os estudos analisados permitem concluir que o PSMA-HBED-CC- ${ }^{68} \mathrm{Ga}$ tem 0 potencial de alterar significativamente a tomada de decisão quanto ao tratamento do paciente, e pode tornar-se uma ferramenta valiosa de imagem no futuro, mesmo em casos de decréscimo na expressão de PSA (Afshar et al, 2015; Budäus et al, 2015; Eiber et al, 2015; Eiber et al, 2016; Morigi et al, 2015; Shakespeare et al, 2015; Zamboglou et al, 2015). Segundo Sterzing e colaboradores (2016), 50,8\% da gestão do tratamento do câncer de próstata é alterado quando utilizado o radiofármaco PSMA-HBED-CC- ${ }^{68}$ Ga para diagnóstico.

Um estudo recente desenvolvido por Verburg e colaboradores (2016) visou examinar, retrospectivamente, em 155 pacientes, qual a relação entre a capacidade de identificação da doença determinada pelo PSMA-HBED-CC- ${ }^{68}$ Ga em relação às atuais 
medidas clínicas da doença (PSA, PSA-DT e PG), uma vez que há especulações sobre em quais situações este radiofármaco deve ser empregado. O estudo concluiu que o PSMA-HBED-CC $-{ }^{68} \mathrm{Ga}$ é efetivamente capaz de identificar a recorrência de câncer de próstata mesmo quando os níveis de PSA e PSA-DT encontram-se reduzidos. Deste modo, não relacionando-se diretamente a PG, atual medida clínica mais utilizada para câncer de próstata (Verburg et al, 2016).

$\mathrm{Na}$ TAB. 3 estão sucintamente descritos os principais estudos clínicos encontrados para o PSMA-HBED-CC- ${ }^{68} \mathrm{Ga}$. 
TABELA 3: Paramêtros utilizados nos principais estudos clínicos com o PSMA-HBED-CC ${ }^{68}$ Ga. Adaptado de Lutje et al (2015).

\begin{tabular}{|c|c|c|c|c|c|c|c|}
\hline PSMA - ligante & Estudo & Ano & Radionuclídeo & $\begin{array}{l}\text { Número de } \\
\text { pacientes }\end{array}$ & $\begin{array}{c}\text { Média do nível } \\
\text { de PSA } \\
\text { (ng/mL) }\end{array}$ & $\begin{array}{l}\text { Média de dose } \\
\text { administrada } \\
\text { (MBq) }\end{array}$ & $\begin{array}{c}\text { Parâmetros para aquisição } \\
\text { de imagem }\end{array}$ \\
\hline PSMA-HBED-CC & Afshar-Oromieh et al. & 2013 & Ga-68 & 37 & 3,3 & 121 & 1 e 3 h após injeção (PET/CT) \\
\hline PSMA-HBED-CC & Afshar-Oromieh et al. & 2014 & Ga-68 & 20 & 2,62 & 149 & $\begin{array}{c}1 \mathrm{~h} \text { após injeção } \\
\text { (PET/CT) } \\
3 \mathrm{~h} \text { após injeção } \\
\text { (PET/MRI) }\end{array}$ \\
\hline PSMA-HBED-CC & Afshar-Oromieh et al. & 2014 & Ga-68 & 37 & 11,1 & 132 & $\begin{array}{c}1 \mathrm{~h} \text { após injeção } \\
\text { (PET/CT) }\end{array}$ \\
\hline PSMA-HBED-CC & Afshar-Oromieh et al. & 2015 & Ga-68 & 319 & 161 & 154 & $\begin{array}{l}\text { 45-75 min. após injeção } \\
\text { (PET/CT) }\end{array}$ \\
\hline PSMA-HBED-CC & Eiber et al. & 2015 & Ga-68 & 248 & 1,99 & 155,5 & $\begin{array}{l}\text { 47-61 min. após injeção } \\
\text { (PET/CT) }\end{array}$ \\
\hline PSMA-HBED-CC & Eiber et al. & 2016 & Ga-68 & 53 & 12 & 141 & $\begin{array}{l}1 \mathrm{~h} \text { após injeção } \\
\text { (PET/MRI) }\end{array}$ \\
\hline PSMA-HBED-CC & Sahmann et al. & 2015 & Ga-68 & 35 & -------------- & 300 & $\begin{array}{c}1 \mathrm{~h} \text { após injeção } \\
\text { (PET/CT) } \\
3 \mathrm{~h} \text { após injeção } \\
\text { (PET/MRI) }\end{array}$ \\
\hline PSMA-HBED-CC & Verburg et al. & 2016 & Ga-68 & 155 & 4 & $190 \pm 58,2$ & $\begin{array}{c}1 \mathrm{~h} \text { após injeção } \\
\text { (PET/CT) }\end{array}$ \\
\hline PSMA-HBED-CC & Sterzing et al. & 2016 & Ga-68 & 57 & 3 & 175 & $\begin{array}{c}60 \pm 10 \text { min. após injeção } \\
\text { (PET/CT) }\end{array}$ \\
\hline
\end{tabular}




\subsubsection{Outros radiofármacos utilizados no diagnóstico do câncer de próstata}

O radiofármaco metionina- ${ }^{11} \mathrm{C}$ tem sido utilizado na identificação de uma ampla gama de tumores devido ao seu acúmulo em células tumorais, possivelmente pelo aumento do transporte de aminoácidos e metabolismo. A captação em ossos, lesões de tecidos moles e metástases de câncer de próstata é significativante mais eficaz que com FDG $-{ }^{18} \mathrm{~F}$ (Nuñes et al, 2002).

O FDG $-{ }^{18} \mathrm{~F}$ (fludeoxiglicose $(18 \mathrm{~F})$ ), um análogo da glicose, é o radiofármaco mais utilizado em oncologia. Uma grande variedade de tumores apresenta boa resposta ao FDG $-{ }^{18} \mathrm{~F}$, porém os resultados com câncer de próstata não são promissores, com relativa baixa captação nas células cancerosas, além da proximidade com a bexiga e a alta excreção renal (Minamimoto et al, 2011; Morris et al, 2002; Sanz et al, 1999; Vali et al, 2015).

A colina é o precursor da biossíntese de fosfolípidos na membrana celular. Há descrições que justificam o uso do $\mathrm{FCH}-{ }^{18} \mathrm{~F}$ (fluorometilcolina- ${ }^{18} \mathrm{~F}$ ) em pacientes com câncer de próstata primário, devido sua sensibilidade e alta especificidade na identificação de nódulos linfáticos e metástases (Vali et al, 2015). No entanto, esta capacidade de detecção ocorre apenas em pacienes com níveis aumentados de PSA (>2 ng/mL) (Colombié et al, 2015; Evangelista et al, 2015; Sterzing et al, 2016; Vali et al, 2015). Outra utilização da colina é na forma de colina- ${ }^{11} \mathrm{C}$, que tem demonstrado melhor captação tumoral em níveis mais baixos de PSA e maior eficácia comparado ao FDG ${ }^{18}$ F (Hara, 1998; Picchio e Castellucci, 2012). Estudos comparativos tem demonstrado detecção de recidivas e metástases com maior contraste na utilização do PSMA-HBED-CC- ${ }^{68} \mathrm{Ga}$ em comparação a colina- ${ }^{11} \mathrm{C}$ (Afshar et al, 2014).

\subsection{RadiomarcaÇão EM Módulo de SínTeSe Automatizada}

A radiomarcação de marcadores moleculares para utilização intravenosa tem apresentado maiores exigências regulátorias nos últimos anos devido a uma maior regularização dos radiofármacos frente as agencias regulatórias, prevendo ausência de contaminação com metais e microorganismos, utilização de pequenos volumes e curto período de tempo de produção. Tais exigências regulatórias dificultam a implementação da 
utilização clínica em larga escala de peptídeos radiomarcados em bancada (Decristoforo et al, 2007).

As normas de BPF (Boas Práticas de Fabricação) ou GMP (Good Manufacturing Practices), são um conjunto de normas definidas para padronizar e definir procedimentos envolvidos no processo de produção de medicamentos, como: métodos de controle de qualidade, fabricação, condições da instalação, equipamentos e manutenção, embalagens, armazenamento e distribuição de produtos, sendo esta a ferramenta mais segura da garantia da qualidade para assegurar a segurança dos medicamentos comercializados (BRASIL, 2003; BRASIL, 2011).

A síntese automatizada reduz a exposição à radiação para o operador, aumenta a robustez da produção, evita contaminações cruzadas, bem como fornece uma documentação on-line do processo de fabricação, melhorando assim o cumprimento das normas BPF (Decristoforo et al, 2007).

Atualmente, existe um número considerável de dispositivos semi-automatizados e automatizados disponíveis no mercado para marcações de moléculas com gálio-68. Comumente, três métodos são disponibilizados por estes dispositivos: eluição do gerador, pré-concentração/pré-purificação do eluato do gerador utilizando resina de troca catiônica ou aniônica e sintetizadores baseados em cassetes esterilizados descartáveis (Velikyan et al, 2014).

A automação dos métodos de radiomarcação com ${ }^{68} \mathrm{Ga}$ amplia as possibilidades de estudos clínicos multicêntricos harmonizados e padronizados que, por sua vez pode acelerar a introdução de novos radiofármacos, bem como a sua aprovação regulatória (Velikyan et al, 2014).

Outro ponto importante a se ressaltar na produção de radiofármacos baseados em radionuclídeos com curto tempo de meia vida física é a necessidade de liberação e até mesmo administração destes radiofármacos sem a conclusão de alguns ensaios. Desta forma o ensaio de esterilidade normalmente tem seu resultado revelado apenas após a utilização do radiofármaco, reforçando a necessidade de métodos de produção que certifiquem a segurança e eficácia do medicamento (WHO, 2004). 


\subsection{ConTrole DE QUALIDADE DE RADIOFÁRMACoS}

A garantia da qualidade de um produto envolve diversos processos que se destinam a garantir a adequação do produto para uma finalidade previamente estabelecida (Sharp et al, 2005). Dentre esses processos, um conjunto de medidas, denominado controle de qualidade, é empregado com intuito de analisar a qualidade de cada lote, de acordo com normas establecidas de atividade, pureza, eficácia e inocuidade do medicamento (ANVISA, 2015).

Todos os procedimentos de controle de qualidade aplicavéis a produtos farmacêuticos não radioativos também são aplicavéis a radiofármacos, além de ser imperativo que neste caso seja analisada a pureza radioquímica (PR) e radionuclídica. Em geral estes procedimentos de controle de qualidade se dividem em duas categorias: testes físico-químicos e testes biológicos (Saha, 2003).

Até o presente momento não há monografia estabelecida para o radiofármaco PSMA-HBED-CC $-{ }^{68} \mathrm{Ga}$, porém com base na Farmacopeia Americana, radiofármacos para PET com tempo de meia-vida maior ou igual 20 minutos devem ser analisados quanto ao $\mathrm{pH}$, determinação de identidade radionuclídica, pureza radioquímica, atividade específica, inspeção visual e testes biológicos (USP 35).

\subsubsection{Pureza radioquímica}

A análise da pureza radioquímica (PR) é o método analítico mais utilizado em radiofarmácia, uma vez que assegura a qualidade, efetividade e seletividade do radiofámaco (Sharp et al, 2005). A PR é determinada pela porcentagem de radioatividade do radiofármaco em relação à atividade total da amostra (BRASIL, 2009). A presença de impurezas pode aumentar potencialmente a dose de radiação para o paciente, além de afetar diretamente a qualidade de procedimentos diagnósticos por imagem devido a alta radioatividade de fundo em tecidos circundantes e do sangue (Sharp et al, 2005; Saha, 2003).

Atualmente, existem diversos métodos de análise, no entanto a cromatográfia ainda se destaca devido à simplicidade com que realiza separações, identificações e quantificações de espécies químicas (Collins et al, 2007). 
A cromatografia faz uso de duas fases (fase estacionária e fase móvel) intimamente ligadas para separar substâncias químicas com propriedades físico-químicas distintas. No decorrer desta técnica os componentes de uma mistura são retidos em diferentes fragmentos da fase estacionária, permitindo estabelecer o tempo necessário para o retardamento $\left(R_{f}\right)$ de cada componente (Collins et al, 2007).

A cromatografia em papel (CP) é uma técnica de partição líquido-líquido, baseada na diferença de solubilidade. Esta é a técnica mais simples dentre as cromatografias, mas ainda muito utilizada, pois pode apresentar boa resolução e baixo custo (Degani et al, 2011).

A cromatografia em camada delgada (CCD), ocorre pelo princípio de adsorção líquido-sólido, cuja separação ocorre pela diferença de afinidade entre os componentes de uma amostra e a fase estacionária. Existem diversos tipos de fase estacionária, no entanto, a sílica gel é a mais utilizada, seguida pela alumina, terra diatomácea e celulose (Degani et al, 2011).

Em geral, a utilização desta técnica se dá pela facilidade em identificar e quantificar espécies quimicamente diferentes. Alguns microlitros da amostra são aplicados na base da fita cromatográfica, de aproximadamente $10 \mathrm{~cm}$, e posteriormente introduzida em cuba de vidro previamente saturada com a fase móvel. Após a fase móvel percorrer toda a fita, determina-se o fator de retenção $\left(R_{f}\right)$, pela equação 1 :

$$
R_{f}=\frac{d_{r}}{d_{m}}
$$

Onde, $d_{r}$ é a distância percorrida pela substância em questão e $d_{m}$ a distância percorrida pela fase móvel (Degani et al, 2011; Sharp et al, 2005).

A cromatográfia líquida de alta eficiência (CLAE) possui maior capacidade de resolução e quantificação entre as técnicas cromatográficas. Esta técnica pode ser total ou parcialmente automatizada, convenientemente, dependendo menos do tempo do operdor e permitindo resultados em poucos minutos. Na CLAE podem ser empregadas diferentes fases estacionárias e móveis possibilitando separações de especíes radioquímicas diferentes (Collins et al, 2007). 


\section{4 \\ DELINEAMENTO EXPERIMENTAL}

Neste tópico é apresentado o delineamento experimental empregado para investigar o potencial de aplicação do marcador molecular.

\subsection{RESUMO DO DELINEAMENTO EXPERIMENTAL}

Primeiramente, foram avaliados os métodos para análise da pureza radioquímica em cromatografia em papel (CP), cromatografia em camada delgada (CCD) e cromatografia líquida de alta eficiência (CLAE) com diferentes fases móveis, no intuito de avaliar a resolução e precisão dos métodos. Nesta etapa do trabalho também foi realizado um estudo para confirmação da identidade do radionuclídeo.

Após estabelecer os métodos cromatográficos iniciou-se o estudo das condições de radiomarcação do PSMA-HBED-CC com ${ }^{68} \mathrm{Ga}$. As condições analisadas foram escolhidas com base na literatura referente a peptídeos radiomarcados. Os parâmetros de marcação foram avaliados a fim de obter pureza radioquímica $\geq 95 \%$ e a formação, em sua maioria, do diasteroisômero mais estável.

Uma vez concluídos os estudos de radiomarcação do PSMA-HBED-CC- ${ }^{68}$ Ga avaliou-se a estabilidade do radiofármaco em diferentes condições, simulando possíveis condições de transporte e armazenamento, e em soro humano.

Estudos de marcação em módulo de síntese automatizado também foram conduzidos e estabelecidos para otimização de uma possível produção do radiofármaco em rotina industrial, além da avalização comparativa com o método de produção não automatizado por meio de parâmetros de qualidade e custo-efetividade. 
Foram conduzidos estudos in vitro a fim de determinar a porcentagem de ligação do radiofármaco a proteínas plasmáticas.

Estudos in vivo com animais sadios foram realizados com intuito de estabelecer a biodistribuição e farmacocinética para o radiofármaco PSMA-HBED-CC- ${ }^{68}$ Ga.

Por fim, os parâmetros obtidos nos estudos in vitro e in vivo foram confirmados por meio de imagens em micro-PET.

O fluxograma a seguir (FIG. 8) descreve as etapas deste trabalho.

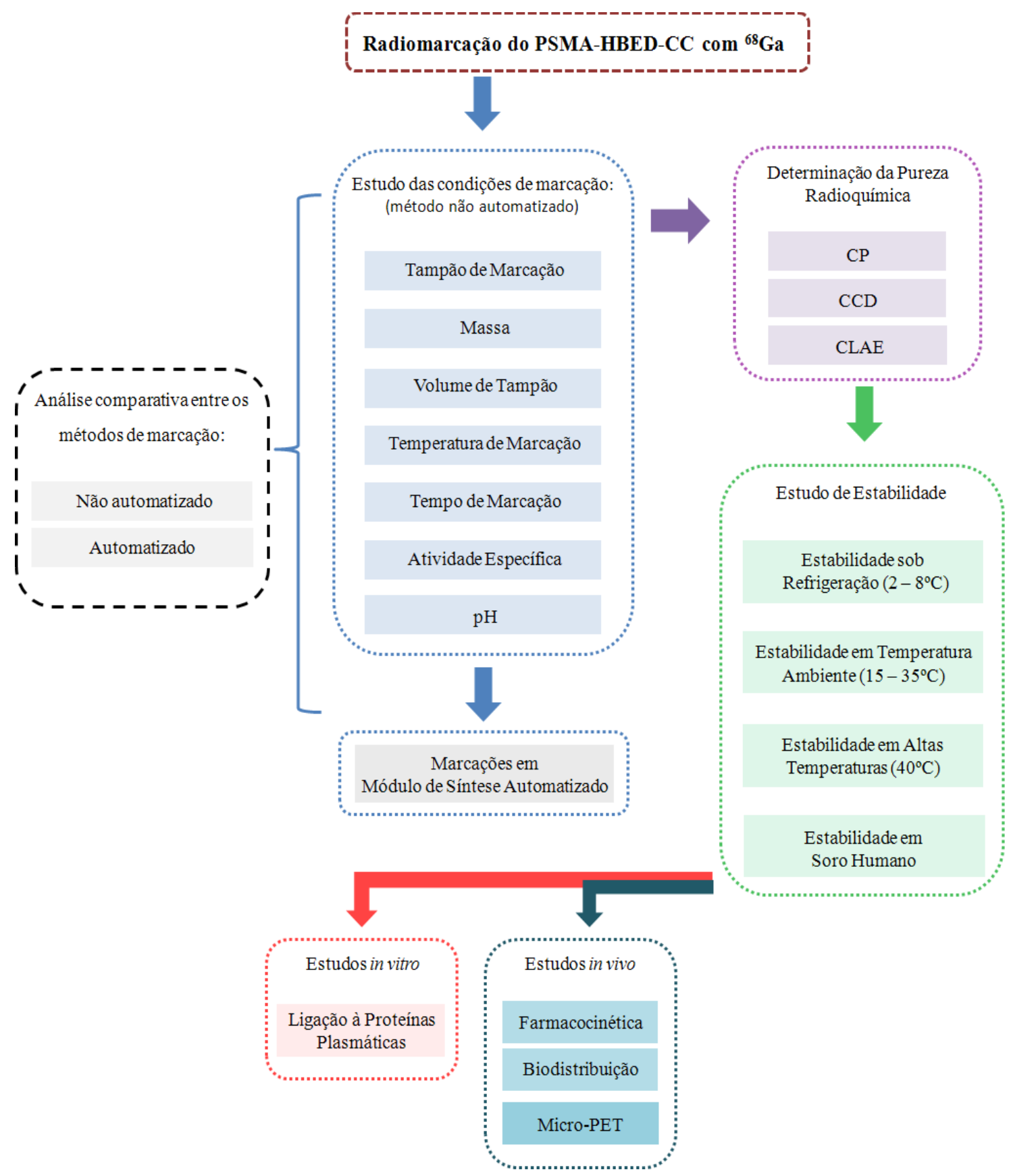

FIGURA 8: Esquema do delineamento experimental do trabalho. 


\section{5 \\ MATERIAIS}

\subsection{INFRAESTRUTURA}

Os ensaios compreendidos neste trabalho foram realizados nos laboratórios de Controle de Qualidade e Pesquisa e Desenvolvimento da Instalação de Radiofarmácia, do Centro de Radiofarmácia (CR), dependências sitiadas na área do IPEN. Esses laboratórios possuem toda a infraestrutura necessária para a manipulação de materiais radioativos e animais de experimentação.

\subsection{REAGENTES}

Os principais reagentes utilizados neste trabalho foram:

$\checkmark$ Acetato de sódio tri-hidratado (Merck, Alemanha);

$\checkmark$ Acetato de amônia (Merck, Alemanha);

$\checkmark$ Acetona ultrapura (Merck, Alemanha);

$\checkmark$ Acetonitrila para CLAE (Merck, Alemanha);

$\checkmark$ Ácido acético glacial 100\% (Merck, Alemanha);

$\checkmark$ Ácido cítrico (Merck, Alemanha);

$\checkmark$ Ácido clorídrico ( $\mathrm{HCl}$ ) 30\% ultrapuro (Merck, Alemanha);

$\checkmark$ Ácido trifluoroacético para CLAE (Sigma Aldrich, EUA);

$\checkmark$ Água purificada - Purificador Milli-RX 45 (Millipore, EUA);

$\checkmark$ Anestésico para uso animal cloridrato de quetamina - Dopalen ${ }^{\circledR}$ (Ceva, Brasil); 


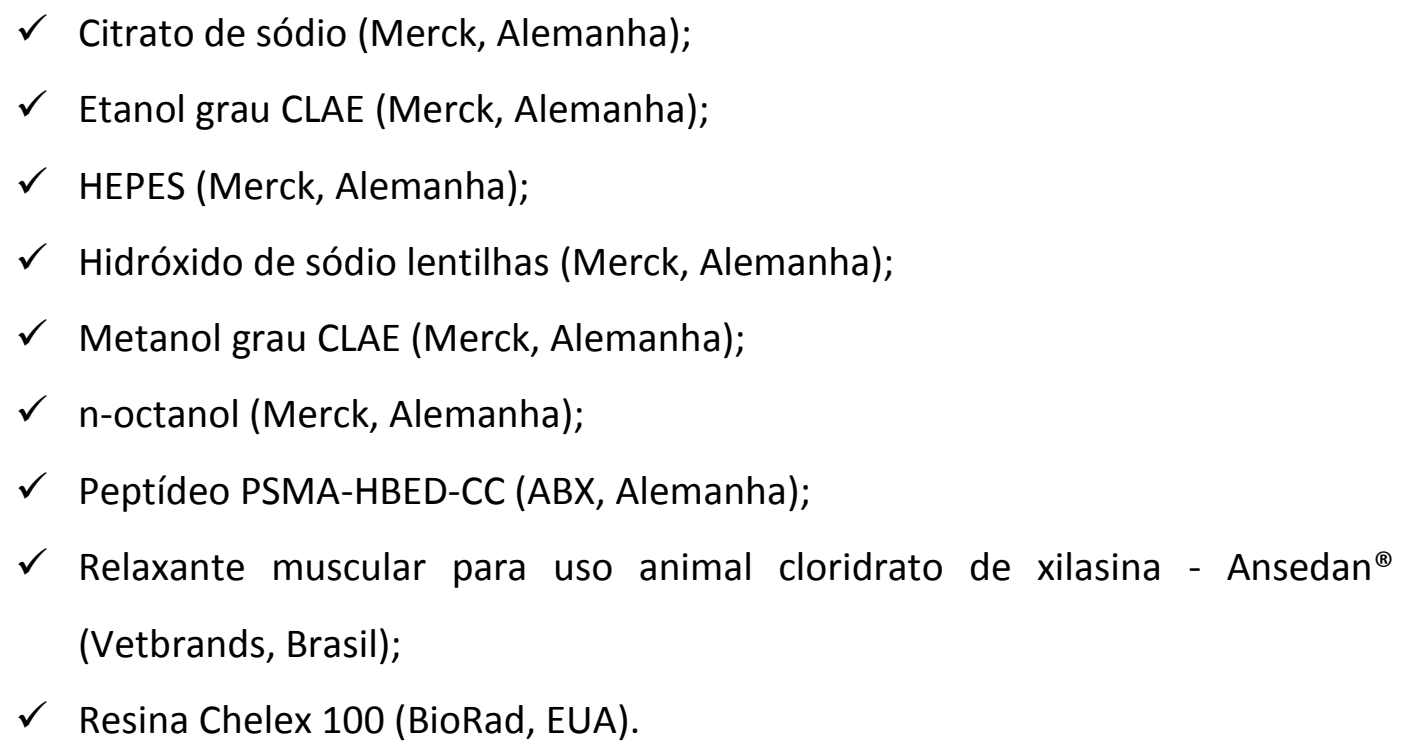

\subsection{EQUIPAMENTOS}

Os principais equipamentos e materiais utilizados neste trabalho foram:

$\checkmark$ Agitador/aquecedor Thermomixer Comfort 1,5 mL (Eppendorf, EUA);

$\checkmark$ Balança analítica (Mettler Toledo, EUA);

$\checkmark$ Calibrador de atividade CRM $^{\mathrm{TM}}$ - 35R (Capintec, EUA);

$\checkmark$ Centrífuga refrigerada Mikro 220 (Hettich, Alemanha);

$\checkmark$ Coluna de fase reversa C18 para cromatografia líquida de alta eficiência (Waters, $150 \mathrm{~mm} \times 4,0 \mathrm{~mm}, 5 \mu \mathrm{m}$ );

$\checkmark$ Contador automático tipo poço com cristal Nal (TI) - D5002 cobra II (PackardCamberra, EUA);

$\checkmark$ Cromatógrafo líquido de alta eficiência, modelo 1260 Infinity, composto por sistema modulado constituído por bomba G1311B (1260 Quant Pump), injetor automático de amostras G1329B (1260 ALS), detector UV G4212B (1260 DAD) e forno G1316A (1260 TCC) (Agilent Technologies, EUA);

$\checkmark$ Detector radioativo (câmara de cintilação - Nal) do sistema CLAE (Agilent), modelo $2 \times 2$ " Pinhole, acoplado à interface de processamento, modelo Gabi Star (Raytest, Alemanha);

$\checkmark$ Equipamento microPET Albira, Bruker BioSpin Corp. Software: Albira Software suite; 
$\checkmark$ Gerador de ${ }^{68} \mathrm{Ge} /{ }^{68} \mathrm{Ga}$ de $50 \mathrm{mCi}(1850 \mathrm{MBq}$ ) (Eckert e Ziegler Eurotope, Alemanha);

$\checkmark$ GraphPad Prism 5.00 ${ }^{\circledR}$ (GraphPad Software, Inc., USA);

$\checkmark$ Medidor de $\mathrm{pH}$ (Mettler Toledo, EUA);

$\checkmark$ Pipetas automáticas (Brand, Alemanha; Socorex, Suíça e Eppendorf, EUA);

$\checkmark$ Suporte cromatográfico de sílica gel 60 em placa de alumina (TLC-SG) (Merck, Alemanha);

$\checkmark$ Suporte cormatografico de fibra de vidro impregnada com sílica gel 60 (ITLC-SG) (Varian, EUA);

$\checkmark$ Tiras indicadoras de $\mathrm{pH}$ (Merck, Alemanha);

$\checkmark$ Vidraria em geral, tais como béqueres, erlemeyers, balões volumétricos e provetas.

\subsection{ANIMAIS}

Os estudos in vivo foram realizados em camundongos machos Balb-c e Nude, de doze a vinte quatro semanas de idade e 20 a 40 gramas de peso (Biotério - IPEN). 


\section{6 \\ MÉTODOS}

Estudos de radiomarcação foram realizados para estabelecer a melhor condição de marcação do inibidor de PSMA. Todos os reagentes utilizados nas reações foram preparados com água purificada por equipamento de osmose reversa e tratada com resina Chellex 100 para remoção de íons metálicos. As replicatas dos experimentos foram realizadas em dias diferentes.

\subsection{Metodologias Analíticas}

$\mathrm{O}{ }^{68} \mathrm{GaCl}_{3}$ foi obtido a partir da eluição do gerador de ${ }^{68} \mathrm{Ge} /{ }^{68} \mathrm{Ga}$ (Eckert and Ziegler), com $10 \mathrm{~mL}$ de $\mathrm{HCl}$ 0,1 N ultrapuro e purificado em coluna de troca catiônica do módulo de síntese automatizado para peptídeos. $0{ }^{68} \mathrm{GaCl}_{3}$ foi recuperado em $800 \mu \mathrm{L}$ de $\mathrm{HCl}$ 0,02M em acetona ultrapura.

A radiomarcação preliminar do peptídeo PSMA-HBED-CC com ${ }^{68} \mathrm{Ga}$ utilizada nos estudos a seguir foi realizada com base na literatura (Banerjee et al, 2010; Eder et al, 2012; Ferreira et al, 2010; Pujatti, 2012; Schafer et al, 2012). As condições utilizadas foram: 5 g do peptídeo diluído em $2 \mathrm{~mL}$ de tampão acetato de sódio $0,2 \mathrm{M} \mathrm{pH} \mathrm{4,740} \mathrm{MBq} \mathrm{(20} \mathrm{mCi)} \mathrm{de}$ ${ }^{68} \mathrm{GaCl}_{3}$ diluído em $800 \mu \mathrm{L}$ de $\mathrm{HCl} 0,02 \mathrm{M}$ em acetona ultrapura, à $25^{\circ} \mathrm{C}$, sem agitação por 7 minutos. 


\subsubsection{Cromatografia líquida de alta eficiência (CLAE)}

A CLAE foi utilizada para determinar a pureza radioquímica do marcador molecular e avaliar a estabilidade das marcações. Procedeu-se à cromatografia em fase reversa em sistema Agilent equipado com detector UV $190-300 \mathrm{~nm}$, coluna de fase reversa C18 (Waters, $150 \mathrm{~mm} \times$ 4,0 mm, $5 \mu \mathrm{m}$ ) e detector de radiação gama (Raytest). Foi utilizado método de gradiente linear com fluxo de $1,0 \mathrm{~mL} /$ minuto, $0-3$ minutos $100 \%$ TFA: $\mathrm{H}_{2} 0$ $(0,1 \% \mathrm{v} / \mathrm{v}) ; 3-20$ minutos $90 \%-70 \%$ TFA: $\mathrm{H}_{2} \mathrm{O}(0,1 \% \mathrm{v} / \mathrm{v})$ e $10 \%-30 \%$ TFA: $\mathrm{CH}_{3} \mathrm{CN}(0,1 \% \mathrm{v} / \mathrm{v})$; 20 - 23 minutos $100 \%$ TFA: $\mathrm{H}_{2} \mathrm{O}(0,1 \% \mathrm{v} / \mathrm{v}) ; 23-27$ minutos $100 \%$ TFA: $\mathrm{H}_{2} \mathrm{O}(0,1 \% \mathrm{v} / \mathrm{v})$, o estado inicial foi mantido por 5 minutos para estabilização do sistema.

\subsubsection{Cromatografia em camada delgada (CCD) e papel}

Os perfis cromatográficos foram previamente determinados para $0{ }^{68} \mathrm{GaCl}_{3} \mathrm{e}$ PSMA-HBED-CC- ${ }^{68}$ Ga em cromatografia em camada delgada de sílica gel 60 (TLC-SG), cromatografia instantânea em camada fina de sílica gel 60 (ITLC-SG) e em papel Whatman $\mathrm{n}$ 으, em diferentes fases móveis, conforme descrito na TAB. 4 a seguir.

TABELA 4: Sistemas cromatográficos analisados para a determinação dos perfis cromatográficos do ${ }^{68} \mathrm{GaCl}_{3}$ e PSMA-HBED-CC- ${ }^{68} \mathrm{Ga}$

\begin{tabular}{ccc}
\hline Fase móvel & Fase estacionária & $\begin{array}{c}\text { Comprimento/ } \\
\text { Largura da fita }\end{array}$ \\
\hline $\begin{array}{c}\text { Solução metanol:acetato de } \\
\text { amônio } 1 \mathrm{M} \mathrm{pH} \mathrm{8,5}\end{array}$ & TLC-SG & $10,5 \mathrm{~cm} / 1 \mathrm{~cm}$ \\
$(1: 1 \mathrm{v} / \mathrm{v})$ & ITLC-SG & $10,5 \mathrm{~cm} / 1 \mathrm{~cm}$ \\
\hline \multirow{2}{*}{ Tampão citrato:ácido cítrico } & Whatman no3 & $10,5 \mathrm{~cm} / 1 \mathrm{~cm}$ \\
0,1M pH 5 & TLC-SG & $10,5 \mathrm{~cm} / 1 \mathrm{~cm}$ \\
& ITLC-SG & $10,5 \mathrm{~cm} / 1 \mathrm{~cm}$ \\
\hline
\end{tabular}

Aplicou-se uma alíquota da solução de ${ }^{68} \mathrm{GaCl}_{3}$ ou da mistura de radiomarcação sobre as fitas cromatográficas e procedeu-se à cromatografia com as diferentes fases móveis. Após a fase móvel percorrer a fase estacionária, a fita cromatografica foi cortada em 
10 fragmentos e a radioatividade foi determinada em contador automático tipo poço devidamente calibrado para o radioisótopo.

\subsubsection{Determinação da identidade radionuclídica}

A identidade radionuclídica foi determinada com base na Farmacopeia Europeia 7.6 (2010) segundo a monografia para o radiofármaco "edotreotide injection", peptídeo derivado de somastostatina radiomarcado com gálio-68. Foram realizadas três medidas da atividade do produto radiomarcado com intervalos de 10 minutos cada. Os valores obtidos foram utilizados na construção de um gráfico linear, para calcular o coeficiente de determinação $\left(r^{2}\right)$ e encontrar a equação da reta. O tempo de meia vida foi calculado (EQ. 3 ) utilizando-se o valor de $\alpha$ (coeficiente angular) encontrado pela EQ. 2. Posteriormente, foi comparado com o tempo de meia vida conhecido do gálio-68 (67,7 minutos). Os experimentos foram realizados em triplicata.

$$
\ln \text { Atividade }=\alpha x+b
$$

$$
T 1 / 2=\frac{\ln 2}{\alpha}
$$

\subsubsection{Determinação do coeficiente de partição $(\log P)$ experimental}

Adicionou-se, em triplicata, $30 \mu \mathrm{L}(12 \mathrm{MBq})$ do radiofármaco PSMA-HBED-CC- ${ }^{68} \mathrm{Ga}$ obtido a partir da condição padrão de marcação a um tubo contendo $3 \mathrm{~mL}$ de n-octanol (fase orgânica) e $3 \mathrm{~mL}$ de solução fosfato-salina pH 7,4 (PBS) (fase aquosa), pré-saturadas por 24 horas. Agitou-se o tubo por uma hora à temperatura ambiente $\left(15-35^{\circ} \mathrm{C}\right)$ (Brasil, 2012) e após a separação das fases aquosa e orgânica, coletou-se $10 \mu \mathrm{L}$ da fase aquosa e $10 \mu \mathrm{L}$ da fase orgânica para contagem em contador automático tipo poço. O coeficiente de partição $(\log P)$ foi determinado pela equação: 


$$
\log P=\log \frac{\text { cpm da fase orgânica }}{\text { cpm da fase aquosa }}
$$

\subsection{OTIMIZAÇÃo dA RADIOMARCAÇÃo DO PSMA-HBED-CC COM ${ }^{68}$ Ga EM MÉTodo NÃo AUTOMATIZADo}

\subsubsection{Marcação não automatizada baseada na literatura}

Baseando-se inicialmente em estudos desenvolvidos por Banerjee e col. (2010), Ferreira e col. (2010), Pujatti (2012), Eder e col. (2012) e Schafer e col. (2012) desenvolveu-se a radiomarcação do PSMA-HBED-CC com ${ }^{68} \mathrm{Ga}$ utilizando-se solução de ${ }^{68} \mathrm{GaCl}_{3}$ com volume reduzido por evaporação do solvente de eluição, e temperatura ambiente.

As metodologias de marcação descritas em literatura não especificam a temperatura de marcação considerada como temperatura ambiente, desta forma foi pressuposto a temperatura de $25^{\circ} \mathrm{C}$ para este trabalho.

\subsubsection{Processo de evaporação do ${ }^{68} \mathrm{GaCl}_{3}$}

Algumas metodologias descritas em literatura para a radiomarcação do PSMA-HBED-CC e outros peptídeos com ${ }^{68} \mathrm{Ga}$ realizam procedimento de evaporação do ${ }^{68} \mathrm{GaCl}_{3}$ para redução do volume final (Eder et al, 2012; Schafer et al, 2012; Pujatti, 2012). Desta forma, foi avaliada a possível perda e oxidação do ${ }^{68} \mathrm{GaCl}_{3}$ quando diluído em solução $\mathrm{HCl}$ 0,02M em acetona ultrapura, após aquecimento e evaporação.

$\mathrm{O}$ estudo foi realizado com o aquecimento da solução de ${ }^{68} \mathrm{GaCl}_{3}$ à $95^{\circ} \mathrm{C}$ durante 7 minutos, reduzindo o volume inicial de $800 \mu \mathrm{L}$ de $\mathrm{HCl}$ 0,02M em acetona ultrapura para cerca de $10 \mu \mathrm{L}$.

Após evaporação, a solução de ${ }^{68} \mathrm{GaCl}_{3}$ resultante foi analisada por $\mathrm{CCD}$, conforme descrito na sessão 6.1 .2 e realizou-se a verificação da perda de atividade. 


\subsubsection{Estudo do tampão de marcação}

A fim de obter melhores resultados de pureza radioquímica e estabilidade, dois tampões foram testados no processo de radiomarcação, tampão HEPES e tampão acetato de sódio.

$\mathrm{O}^{68} \mathrm{GaCl}_{3}$ diluído em $800 \mu \mathrm{L}$ de $\mathrm{HCl}$ 0,02M em acetona ultrapura foi previamente evaporado a $95^{\circ} \mathrm{C}$ por 7 minutos, reduzindo o volume para cerca de $10 \mu \mathrm{L}$.

A marcação com tampão HEPES utilizou os seguintes parâmetros: $185 \mathrm{MBq}$ (5 mCi) de ${ }^{68} \mathrm{GaCl}_{3}, 20 \mu \mathrm{g}$ do peptídeo, diluído em $100 \mu \mathrm{L}$ de tampão HEPES 0,1M pH 7,5 e $10 \mu \mathrm{L}$ de tampão HEPES 2,1M pH 7,5 e o pH final da solução foi ajustado com $\mathrm{NaOH}$ para para 4,2 (Eder et al, 2012; Schafer et al, 2012). Os parâmetros para o tampão acetato de sódio foram: $185 \mathrm{MBq}(5 \mathrm{mCi})$ de ${ }^{68} \mathrm{GaCl}_{3}, 20 \mu \mathrm{g}$ do peptídeo diluído em $1 \mathrm{~mL}$ de tampão acetato de sódio 0,2M pH 4 (Banerjee et al, 2010; Ferreira et al, 2010; Pujatti, 2012).

As radiomarcações foram realizadas à $25^{\circ} \mathrm{C}$ e mantidas em reação pelos seguintes intervalos: $2,5,7,10,15,30$ e 60 minutos. Ao final, a pureza radioquímica foi determinada por CCD (TLC-SG), conforme descrito na seção 6.1.2. Os experimentos foram realizados em triplicata.

\subsubsection{Análise da variação da massa do peptídeo}

Para avaliar a influência da massa na pureza radioquímica da marcação, utilizou-se massas de 20, 15 e $5 \mu \mathrm{g}$ do peptídeo PSMA-HBED-CC diluído em $1 \mathrm{~mL}$ de tampão acetato de sódio $0,2 \mathrm{M} \mathrm{pH} 4$, com $185 \mathrm{MBq}(5 \mathrm{mCi})$ de ${ }^{68} \mathrm{GaCl}_{3}$ diluído em $10 \mu \mathrm{L}$ de $\mathrm{HCl}$ 0,02M em acetona ultrapura, à $25^{\circ} \mathrm{C}$, por 10 minutos, sem agitação. Ao final, a pureza radioquímica foi determinada por CCD (TLC-SG), conforme descrito na seção 6.1.2. Os experimentos foram realizados em triplicata.

\subsubsection{Marcação não automatizada baseada nas condições de marcação em módulo automatizado para o peptídeo DOTATATO}

Após os estudos preliminares e ainda com base na literatura citada acima foram otimizados os parâmetros de marcação do PSMA-HBED-CC com ${ }^{68} \mathrm{Ga}$, assemelhando o método de marcação ao utilizado para o peptídeo DOTATATO em módulo de síntese 
automatizado (Modular-Lab PharmTracer), com intuito de avaliar o potencial para radiomarcação e produção rotineira de PSMA-HBED-CC- ${ }^{68} \mathrm{Ga}$, possivelmente empregando módulo automatizado e programa já existentes no CR.

Os estudos foram iniciados considerando-se as condições utilizadas na marcação do peptídeo DOTATATO, a saber: peptídeo diluído em $2 \mathrm{~mL}$ de tampão acetato de sódio $0,2 \mathrm{M} \mathrm{pH} \mathrm{4}$, radiomarcado com atividades entre $740-1850 \mathrm{MBq}(20-50 \mathrm{mCi})$ de ${ }^{68} \mathrm{GaCl}_{3}$ diluído em $800 \mu \mathrm{L}$ de $\mathrm{HCl} 0,02 \mathrm{M}$ em acetona ultrapura, à $95^{\circ} \mathrm{C}$, por 7 minutos sem agitação (Modular-Lab PharmTracer, 2014).

Desta forma, utilizou-se como condição padrão para as marcações em bancada (não automatizada): $5 \mu \mathrm{g}$ do peptídeo PSMA-HBED-CC diluído em $2 \mathrm{~mL}$ de tampão acetato de sódio $0,2 \mathrm{M} \mathrm{pH} \mathrm{4,} 740 \mathrm{MBq}(20 \mathrm{mCi})$ de ${ }^{68} \mathrm{GaCl}_{3}$, diluído em $800 \mu \mathrm{L}$ de $\mathrm{HCl}$ 0,02M em acetona ultrapura, à $95^{\circ} \mathrm{C}$, por 7 minutos, sem agitação.

\subsubsection{Determinação da temperatura e tempo de marcação}

As misturas de reação foram incubadas por 2, 5, 7 e 10 minutos, a diferentes temperaturas $\left(25,85\right.$ e $\left.95^{\circ} \mathrm{C}\right)$ utilizando a condição de marcação padrão. A estabilidade foi analisada apenas para as marcações com 7 minutos de reação. Ao final, a pureza radioquímica foi determinada por CCD (TLC-SG), conforme descrito na seção 6.1 .2 e confirmada por CLAE, conforme descrito na seção 6.1.1. Os experimentos foram realizados em triplicata.

\subsubsection{Determinação do volume do tampão de radiomarcação}

Para avaliação da influência do volume de tampão na pureza radioquímica da marcação, radiomarcou-se o peptídeo PSMA-HBED-CC com volume final de $1 \mathrm{~mL}$ ou $2 \mathrm{~mL}$, utilizando a condição de marcação padrão. Ao final, a pureza radioquímica foi determinada por CCD (TLC-SG), conforme descrito na seção 6.1 .2 e confirmada por CLAE, conforme descrito na seção 6.1.1. Os experimentos foram realizados em triplicata. 


\subsubsection{Avaliação dos tampões de radiomarcação (acetato de sódio e HEPES) em reações com aquecimento}

No intuito de analisar comparativamente a eficiência de marcação da metodologia descrita em literatura para o tampão HEPES, porém sob alta temperatura e comparar com o tampão acetato de sódio, foram realizados os ensaios a seguir.

No primeiro método adicionou-se $740 \mathrm{MBq}(20 \mathrm{mCi})$ de ${ }^{68} \mathrm{GaCl}_{3}$ diluído em $800 \mu \mathrm{L}$ de $\mathrm{HCl}$ 0,02M em acetona ultrapura a $5 \mu \mathrm{g}$ do peptídeo, diluído em $100 \mu \mathrm{L}$ de tampão HEPES $0,1 \mathrm{M}$ pH 7,5 e $10 \mu \mathrm{L}$ de tampão HEPES 2,1M pH 7,5 e o pH final da solução foi ajustado com $\mathrm{NaOH}$ para 4,2 (Eder et al, 2012; Schafer et al, 2012).

No segundo método, utilizou-se a condição de marcação padrão (Banerjee et al, 2010; Ferreira et al, 2010).

As misturas de reações de ambos os métodos foram incubadas por diferentes tempos (2, 5, 7 e 10 minutos), à $95^{\circ} \mathrm{C}$ sem agitação. Ao final, a pureza radioquímica foi determinada por CCD (TLC-SG), conforme descrito na seção 6.1.2 e confirmada por CLAE, conforme descrito na seção 6.1.1. Os experimentos foram realizados em triplicata.

\subsubsection{Estudo da variação da atividade específica}

Utilizando a condição padrão de marcação, adicionou-se diferentes atividades de ${ }^{68} \mathrm{GaCl}_{3}$ ao frasco de reação $(0,37-1,11 \mathrm{GBq}(10-30 \mathrm{mCi}))$. Ao final, a pureza radioquímica foi determinada por CCD (TLC-SG), conforme descrito na seção 6.1.2 e confirmada por CLAE, conforme descrito na seção 6.1.1. Os experimentos foram realizados em triplicata.

\subsubsection{Influência do pH na radiomarcação}

As marcações foram realizadas na condição padrão de marcação, com variação do $\mathrm{pH}\left(3,5,4,4,5\right.$ e 5) e com $550 \mathrm{MBq}(15 \mathrm{mCi})$ de ${ }^{68} \mathrm{GaCl}_{3}$. O pH do tampão acetato de sódio $0,2 \mathrm{M}$ foi ajustado previamente com ácido acético $0,2 \mathrm{M}$ e verificado antes e após a reação e durante todo o período de estabilidade estudado, utilizando tiras que indicam o pH entre $0-6$. Ao final, a pureza radioquímica foi determinada por CCD (TLC-SG), conforme descrito na seção 6.1.2 e confirmada por CLAE, conforme descrito na seção 6.1.1. Os experimentos foram realizados em triplicata. 


\subsection{ESTUDOS DE ESTABILIDADE}

Foram realizados estudos de estabilidade do peptídeo radiomarcado empregando-se o método não automatizado, semelhante ao utilizado na marcação do peptídeo DOTATATO em módulo de síntese. Os estudos a seguir utilizaram a condição padrão de radiomarcação (sessão 6.2.2) com pH do tampão acetato de sódio alterado para 4,5 .

\subsubsection{Análise da integridade do peptídeo após a marcação e estabilidade frente a condições de transporte}

A estabilidade do peptídeo radiomarcado foi avaliada por cromatografia líquida de alta eficiência conforme descrito na sessão 6.1.2, imediatamente após a marcação, 30, 60, 120, 180 e 240 minutos após o fim da marcação. A integridade do radiofármaco foi avaliada primeiramente com o produto armazenado em temperatura ambiente $\left(15-35^{\circ} \mathrm{C}\right)$. Os experimentos foram realizados em duplicata.

A fim de estabelecer o prazo de validade do peptídeo radiomarcado, a estabilidade do radiofármaco foi avaliada à temperatura ambiente $\left(15-35^{\circ} \mathrm{C}\right)$, sob-refrigeração $\left(2-8^{\circ} \mathrm{C}\right)$ e à temperatura de $40^{\circ} \mathrm{C}$. Devido à meia vida curta do radioisótopo utilizado, a estabilidade foi avaliada por um período de até 4 horas após o processo de marcação em diferentes tempos (0, 30, 60, 120, 180 e 240 minutos após marcação). Ao final de cada tempo, a pureza radioquímica foi determinada por CCD (TLC-SG), conforme descrito na seção 6.1.2 e confirmada por CLAE, conforme descrito na seção 6.1.1. Os experimentos foram realizados em triplicata.

\subsubsection{Análise da estabilidade em soro humano e ligação às proteínas plasmáticas "in vitro"}

Para obtenção do soro humano, coletou-se $10 \mathrm{~mL}$ de sangue de doador sadio sem anticoagulante, centrifugou-se a $1400 \mathrm{~g}$ (1500 rpm) por 10 minutos à temperatura ambiente, separou-se o coágulo de fibrina e centrifugou-se novamente para separação do soro. 
Adicionou-se $37 \mathrm{MBq}(1 \mathrm{mCi})$ do radiofármaco com pureza radioquímica acima de $95 \%$ a $1,5 \mathrm{~mL}$ do soro humano, em duplicata, e incubou-se a $37^{\circ} \mathrm{C}$, sob agitação de $350 \mathrm{rpm}$, por diferentes tempos (5, 15, 30, 60 e 90 minutos). Após decorrido cada tempo de incubação, uma alíquota foi retirada das misturas (200 $\mu \mathrm{L})$, uma pequena parte foi utilizada para determinar a porcentagem do marcador íntegro por análise por CCD e ao restante da alíquota adicionou-se $200 \mu \mathrm{L}$ etanol $(1: 1 \mathrm{v} / \mathrm{v})$ para precipitação das proteínas e centrifugou-se a $9.720 \mathrm{~g}$ (10.000 rpm) por 5 minutos. Uma alíquota foi retirada do sobrenadante e o precipitado foi separado e a radioatividade determinada em contador automático tipo poço. A porcentagem do marcador molecular ligado às proteínas plasmáticas (LP) foi determinada pela equação:

$$
L P \%=\frac{c p m \text { no preciptado }}{\text { cpm no sobrenadante }+ \text { cpm no preciptado }} \times 100
$$

\subsection{OTIMIZAÇÃO DA RADIOMARCAÇÃO DO PSMA-HBED-CC COM ${ }^{68} \mathbf{G a}$ EM Módulo de SínTese Automatizado}

As marcações do PSMA-HBED-CC com ${ }^{68}$ Ga foram realizadas utilizando módulo automático Modular-Lab PharmTracer (Eckert and Ziegler) (FIG. 9), equipado com software para operação do módulo e cassetes para marcação e purificação do peptídeo DOTATATO (FIG. 10). O objetivo principal foi avaliar a utilização do software na marcação do peptídeo PSMA-HBED-CC, uma vez que este possui software específico, comercializado pelo fabricante do módulo.

O software empregado na marcação do DOTATATO apresenta limitações inerentes à alteração dos parâmetros de radiomarcação, tornando impossível reproduzir, de forma idêntica, as condições de marcação do software específico para o PSMA-HBED-CC. Portanto, foi desenvolvida uma metodologia de marcação utilizando o software disponível no CR para radiomarcação do DOTATATO que permitisse a radiomarcação do PSMA-HBED-CC com alto rendimento de síntese. 


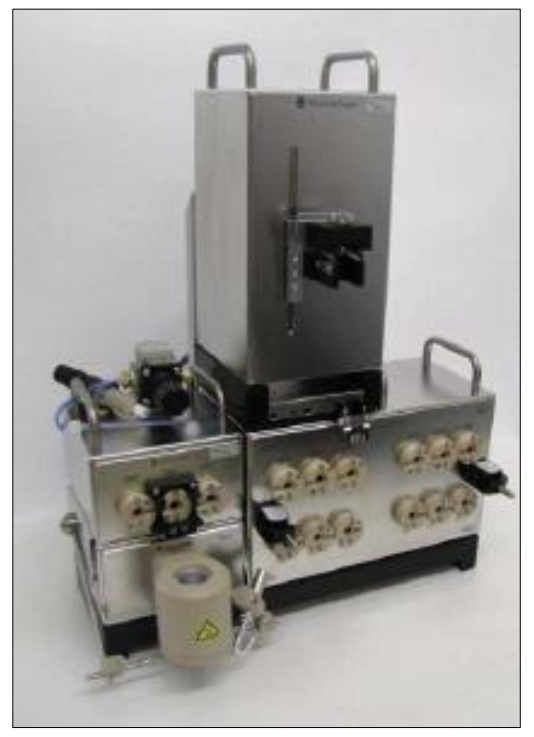

FIGURA 9: Módulo automático Modular-Lab PharmTracer (Eckert and Ziegler) utilizado para a marcação do PSMA-HBED-CC com ${ }^{68} \mathrm{Ga}$.

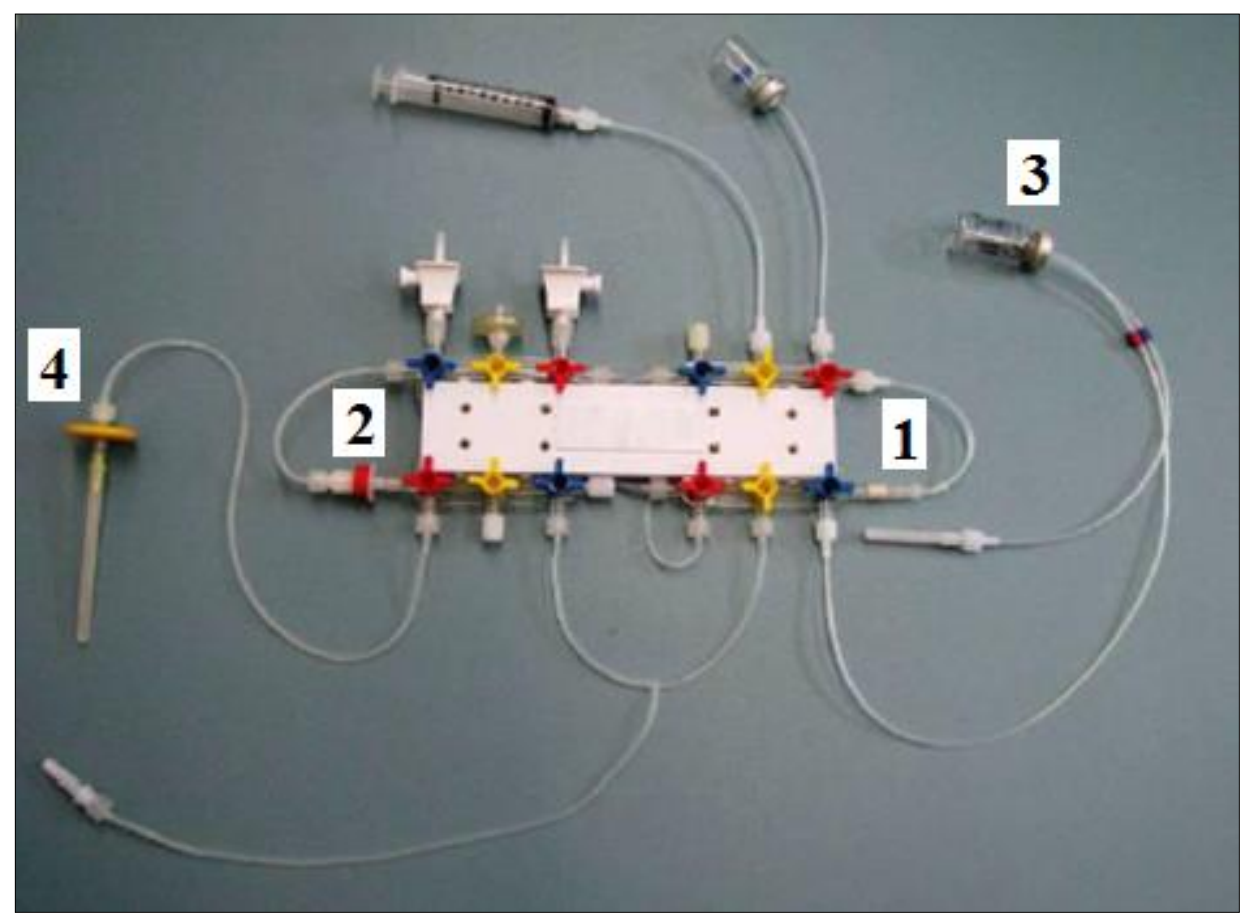

FIGURA 10: Cassete utilizado no módulo para marcação do PSMA-HBED-CC com ${ }^{68}$ Ga: coluna de troca iônica (1); coluna Sep Pack C18 (2); frasco de reação (3); membrana esterilizante (4).

Primeiramente, acoplou-se o cassete no módulo automático (FIG. 11) e realizou-se o teste de pressão para verificação prévia das condições de operação do equipamento. 


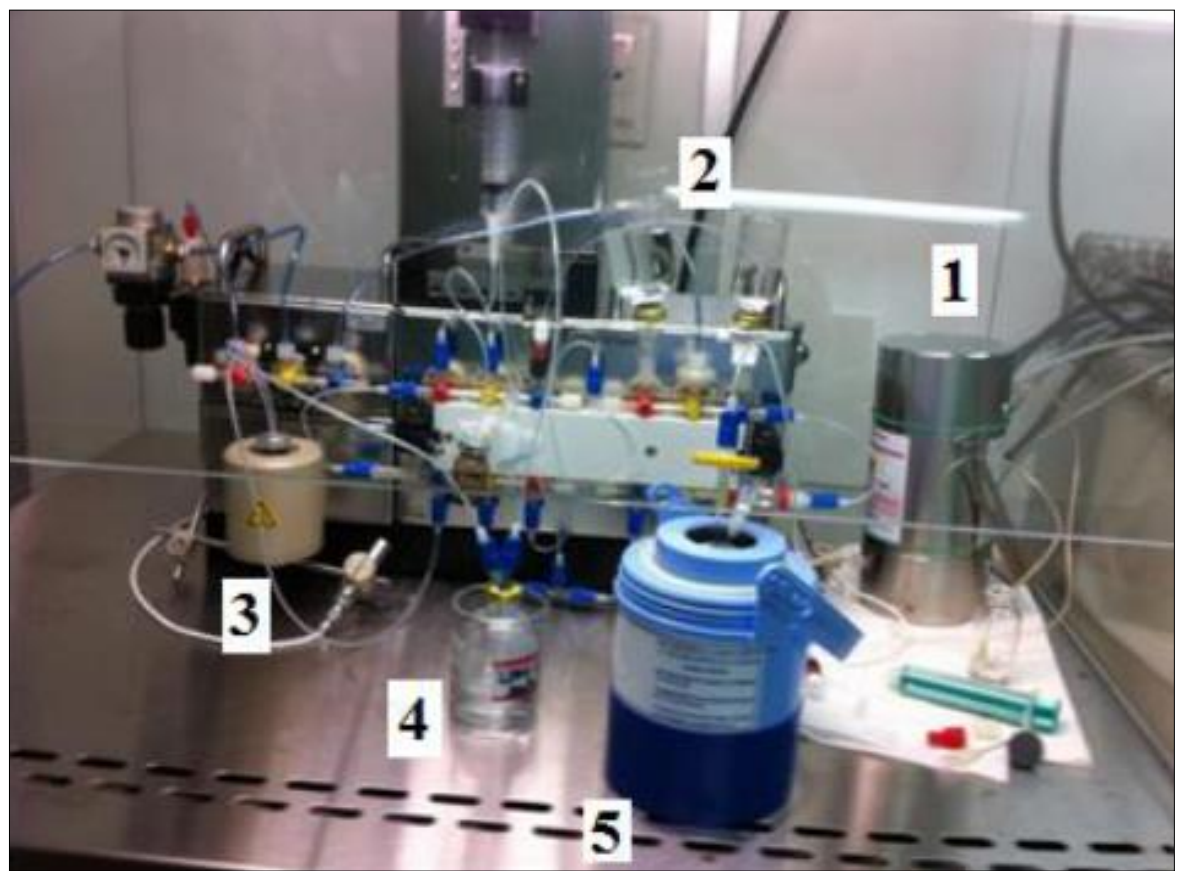

FIGURA 11: Cassete para marcação do peptídeo DOTATATO acoplado ao módulo de síntese automatizado (Modular-Lab PharmTracer), juntamente aos seus demais componentes: gerador ${ }^{68} \mathrm{Ge} /{ }^{68} \mathrm{Ga}$ (1), frascos de solução salina e etanol:água (50\%) (2), frasco de reação (3), frasco de rejeito do processo de purificação do produto radiomarcado em coluna do tipo Sep Pack C18 (4) e frasco de coleta do produto final (5).

Conforme identificados na FIG. 11, o gerador de ${ }^{68} \mathrm{Ge} /{ }^{68} \mathrm{Ga}$ (1) foi conectado a um frasco de $10 \mathrm{~mL}$ de $\mathrm{HCl}$ 0,1M pela mangueira de entrada e a mangueira de saída foi conectada à entrada do cassete de marcação no módulo. O sistema é também composto pelos frascos das soluções utilizadas no processo de marcação (2), frasco de reação, envolto pelo sistema de aquecimento (3), frasco para coleta do rejeito do processo (4) e frasco e blindagem de chumbo para coleta do produto final (5).

Após a eluição do gerador, $0{ }^{68} \mathrm{GaCl}_{3}$ fica retido em uma coluna de resina catiônica, a qual é eluida com a solução de $\mathrm{HCl}$ 0,02M em acetona ultrapura e transferido no volume de $800 \mu \mathrm{L}$ para o frasco de reação contendo a mistura do peptídeo PSMA-HBED-CC.

Após o tempo de reação sob aquecimento, a purificação do produto é realizada em coluna do tipo Sep Pack C18, previamente condicionada com $5 \mathrm{~mL}$ de etanol:água (1:1 v/v) e $5 \mathrm{~mL}$ de salina. O Sep Pack C18 é eluido com a solução de marcação, onde o peptídeo radiomarcado deve ficar retido na coluna e o gálio-68 livre deve ser eluído sem que haja interação. Posteriormente, é realizada a lavagem do frasco de reação com $2 \mathrm{~mL}$ de solução salina que é transferida para o Sep Pack C18. Todo o resíduo da purificação pela 
coluna Sep Pack é depositado em um frasco de rejeito. O produto radiomarcado é retirado do Sep Pack com $1 \mathrm{~mL}$ de solução de etanol:água (1:1 v/v) e, por fim, a coluna é eluida com $8 \mathrm{~mL}$ de solução de cloreto de sódio $0,9 \%$, garantindo a concentração do etanol inferior aos 10\% permitidos (Farmacopeia Europeia, 2010) e pH de produto final de aproximadamente 5,0. O volume final da radiomarcação é de aproximadamente $7 \mathrm{~mL}$, devido a uma pequena perda do volume na linha de produção.

Na FIG. 12 encontra-se uma representação esquemática do processo de radiomarcação em módulo de síntese automatizado.

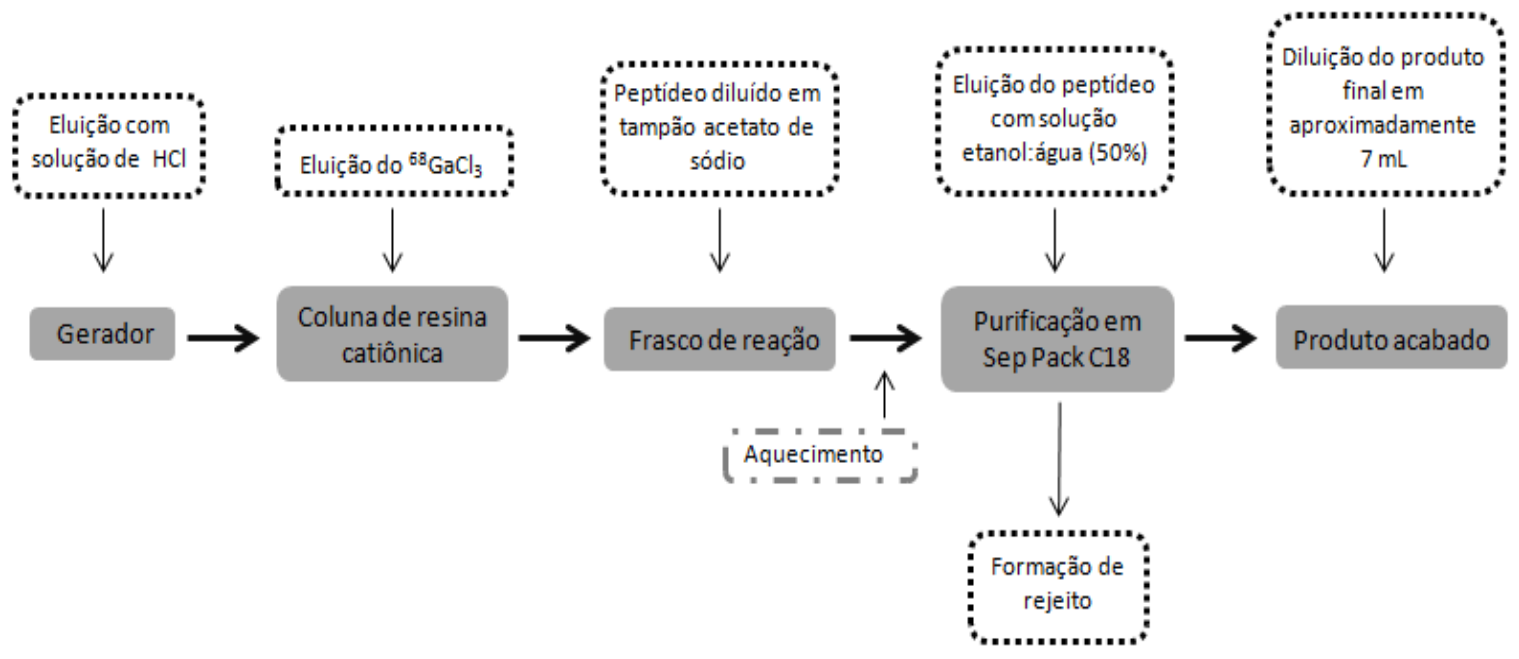

FIGURA 12: Fluxograma das etapas envolvidas no processo de radiomacação de peptídeos em módulo de síntese automatizado.

\subsubsection{Estudo da purificação do PSMA-HBED-CC-68Ga}

Marcações preliminares do PSMA-HBED-CC- ${ }^{68} \mathrm{Ga}$ em módulo de síntese automatizado obtiveram rendimento de marcação baixo, tendo em vista que parte do peptídeo radiomarcado não foi adsorvido pelo Sep Pack C18. Desta forma, foram realizados estudos de purificação do PSMA-HBED-CC- ${ }^{68}$ Ga radiomarcado em bancada (modo não automatizado), com objetivo de solucionar esse problema de falta de retenção do peptídeo radiomarcado.

Os estudos de purificação do peptídeo radiomarcado foram previamente realizados em coluna do tipo Sep Pack C18, após a marcação do PSMA-HEBD-CC com ${ }^{68} \mathrm{Ga}$ 
utilizando a condição padrão de marcação (sessão 2.2.2) em diferentes pH $(3,5,4$ e 4,5), de modo a verificar se o pH exerce influência sobre a retenção do peptídeo no Sep Pack C18. A amostra que demonstrou melhor resultado foi analisada também em coluna Sep Pack C18 Plus, que apresenta o dobro de matriz. A pureza radioquímica foi determinada por CCD, conforme descrito na sessão 6.1.2.

O rendimento da síntese foi calculado utilizando a EQ. 5 a seguir:

$$
\% R d=\frac{\mathrm{A}_{\mathrm{t}}}{\mathrm{A}_{\mathrm{t}}+\mathrm{A}_{\mathrm{rej}}+\mathrm{A}_{\mathrm{ret}}} \times 100
$$

Onde, $A_{t}$ é a atividade de produto final, $A_{\text {rej }}$ é a atividade do rejeito do Sep Pack e

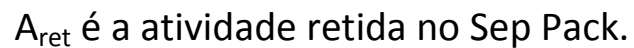

\subsubsection{Estudo dos parâmetros de marcação em módulo de síntese automatizado}

A TAB. 5 a seguir apresenta as condições de marcação previstas pelo software do peptídeo DOTATATO e software do peptídeo PSMA-HBED-CC, sugeridas pelo fabricante do módulo. 
TABELA 5: Metodologia descrita pela empresa Eckert and Ziegler para radiomarcação do PSMA-HBED-CC e do DOTATATO em módulo de síntese automatizado, utilizando os softwares desenvolvidos específicamente para cada um dos peptídeos.

\begin{tabular}{|c|c|c|}
\hline Métodos & DOTATATO* & PSMA-HBED-CC** \\
\hline Tampão de marcação & $\begin{array}{c}\text { Acetato de sódio } \\
0,2 \mathrm{M}\end{array}$ & $\begin{array}{c}\text { Acetato de sódio } \\
0,2 \mathrm{M}\end{array}$ \\
\hline $\begin{array}{l}\text { Volume } \\
\qquad(\mathrm{mL})\end{array}$ & 2 & 0,4 \\
\hline $\mathrm{pH}$ & 4 & 4,5 \\
\hline $\begin{array}{c}\text { Massa do peptídeo } \\
(\mu \mathrm{g})\end{array}$ & 40 & 10 \\
\hline $\begin{array}{l}\text { Tempo de reação } \\
\text { (minutos) }\end{array}$ & $\approx 7$ & $\approx 2$ \\
\hline Temperatura & $95^{\circ} \mathrm{C}$ & $85^{\circ} \mathrm{C}$ \\
\hline $\begin{array}{l}\text { Atividade } \\
\text { (MBq/mCi) }\end{array}$ & $\begin{array}{c}740-1850 / \\
20-50\end{array}$ & $\begin{array}{c}740-1850 / \\
20-50\end{array}$ \\
\hline Sep Pack & $\mathrm{C} 18$ & $\mathrm{C} 18$ \\
\hline $\begin{array}{c}\text { Eluição da coluna de } \\
\text { purificação do } \\
\text { gálio-68 }\end{array}$ & $\begin{array}{c}\mathrm{HCl} \text { 0,02M em } \\
\text { acetona } \\
\text { ultrapura }\end{array}$ & $\mathrm{NaCl} / \mathrm{HCl} 5 \mathrm{M}$ \\
\hline
\end{tabular}

Com base nestas metodologias, procedeu-se à radiomarcação do PSMA-HBED-CC com ${ }^{68} \mathrm{Ga}$, tendo sido avaliados diferentes métodos, variando-se os parâmetros de marcação com o objetivo de obter o maior rendimento de síntese TAB. 6.

O método sugerido pelo fabricante do módulo para a marcação do PSMA-HBED-CC utilizando software específico para este peptídeo prevê a eluição da coluna de purificação do gálio-68 com solução de $\mathrm{NaCl} / \mathrm{HCl} 5 \mathrm{M}(800 \mu \mathrm{L})$. Neste software de síntese, o tempo total do processo, referido pelo fabricante é de 20 minutos, enquanto que o tempo total para o software do DOTATATO é de 33 minutos.

Também foram realizados ensaios de radiomarcação em módulo de síntese automatizado com eluição do gerador ${ }^{68} \mathrm{Ge} /{ }^{68} \mathrm{Ga}$ sem a utilização de acetona, e utilizando-se solução de $\mathrm{NaCl} / \mathrm{HCl} 5 \mathrm{M}$, conforme descrito no manual fornecido pelo fabricante do módulo (Eckert and Ziegler), para a radiomarcação do PSMA-HBED-CC. 
TABELA 6: Resumo das condições de estudos para otimização da marcação do PSMA-HBED-CC- ${ }^{68}$ Ga em módulo de síntese automatizado. Os pontos em negrito representam as variações em relação ao método sugerido para a marcação do peptídeo DOTATATO.

\begin{tabular}{|c|c|c|c|c|c|c|c|}
\hline Métodos & Método 1 & Método 2 & Método 3 & Método 4 & Método 5 & Método 6 & Método 7 \\
\hline $\begin{array}{l}\text { Tampão de } \\
\text { marcação }\end{array}$ & $\begin{array}{l}\text { Acetato de } \\
\text { sódio } 0,2 \mathrm{M}\end{array}$ & $\begin{array}{l}\text { Acetato de } \\
\text { sódio } 0,2 \mathrm{M}\end{array}$ & $\begin{array}{l}\text { Acetato de } \\
\text { sódio } 0,2 \mathrm{M}\end{array}$ & $\begin{array}{l}\text { Acetato de } \\
\text { sódio } 0,2 \mathrm{M}\end{array}$ & $\begin{array}{l}\text { Acetato de } \\
\text { sódio } 0,2 \mathrm{M}\end{array}$ & $\begin{array}{l}\text { Acetato de } \\
\text { sódio } 0,2 \mathrm{M}\end{array}$ & $\begin{array}{l}\text { Acetato de } \\
\text { sódio } 0,2 \mathrm{M}\end{array}$ \\
\hline $\begin{array}{l}\text { Volume } \\
(\mathrm{mL})\end{array}$ & 2 & 2 & 2 & 0,4 & 2 & 0,4 & 0,4 \\
\hline $\mathrm{pH}$ & 4 & 4,5 & 4,5 & 4 & 4,5 & 4 & 4,5 \\
\hline $\begin{array}{c}\text { Massa do peptídeo } \\
(\mu \mathrm{g})\end{array}$ & 10 & 10 & 10 & 10 & 10 & 10 & 10 \\
\hline $\begin{array}{l}\text { Tempo de reação } \\
\text { (minutos) }\end{array}$ & 7 & 7 & 10 & 7 & 7 & 2 & 2 \\
\hline Temperatura & $95^{\circ} \mathrm{C}$ & $95^{\circ} \mathrm{C}$ & $95^{\circ} \mathrm{C}$ & $95^{\circ} \mathrm{C}$ & $95^{\circ} \mathrm{C}$ & $95^{\circ} \mathrm{C}$ & $95^{\circ} \mathrm{C}$ \\
\hline $\begin{array}{l}\text { Atividade } \\
\text { (MBq/mCi) }\end{array}$ & $\begin{array}{c}740-1850 / \\
20-50\end{array}$ & $\begin{array}{c}740-1850 / \\
20-50\end{array}$ & $\begin{array}{c}740-1850 / \\
20-50\end{array}$ & $\begin{array}{c}740-1850 / \\
20-50\end{array}$ & $\begin{array}{c}740-1850 / \\
20-50\end{array}$ & $\begin{array}{c}740-1850 / \\
20-50\end{array}$ & $\begin{array}{c}740-1850 / \\
20-50\end{array}$ \\
\hline Sep Pack & C18 & C18 & C18 Plus & C18 & C18 & $\mathrm{C} 18$ & C18 \\
\hline $\begin{array}{l}\text { Eluição da coluna de } \\
\text { purificação do } \\
\text { gálio-68 }\end{array}$ & $\begin{array}{c}\mathrm{HCl} 0,02 \mathrm{M} \mathrm{em} \\
\text { acetona } \\
\text { ultrapura }\end{array}$ & $\begin{array}{c}\mathrm{HCl} 0,02 \mathrm{M} \mathrm{em} \\
\text { acetona } \\
\text { ultrapura }\end{array}$ & 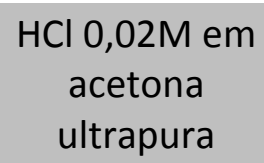 & $\begin{array}{c}\mathrm{HCl} 0,02 \mathrm{M} \mathrm{em} \\
\text { acetona } \\
\text { ultrapura }\end{array}$ & $\mathrm{NaCl} / \mathrm{HCl} 5 \mathrm{M}$ & $\mathrm{NaCl} / \mathrm{HCl} 5 \mathrm{M}$ & $\mathrm{NaCl} / \mathrm{HCl} 5 \mathrm{M}$ \\
\hline
\end{tabular}


O rendimento de marcação foi obtido pelo percentual de atividade presente no produto final após a somatória das atividades encontradas no produto final, no Sep Pack C18 e no rejeito do condicionamento e lavagem do Sep Pack C18, conforme EQ. 5 descrita na sessão 6.5.1.

\subsection{ESTUDOS IN VIVO}

Os estudos de farmacocinética e biodistribuição foram realizados com marcações realizadas de forma não automatizada, pois o volume final das marcações em módulo de síntese automatizado (aproximadamente $7 \mathrm{~mL}$ ) impossibilita a obtenção da atividade necessária para o desenvolvimento do estudo em um volume de $150 \mu \mathrm{L}$ (volume máximo para administração em camundongos).

Conforme conclusões obtidas após estudos de otimização da marcação do PSMA-HBED-CC marcado com ${ }^{68} \mathrm{Ga}$, a condição padrão de radiomarcação não automatizada foi definida como: $5 \mu \mathrm{g}$ do peptídeo PSMA-HBED-CC diluído em $2 \mathrm{~mL}$ de tampão acetato de sódio $0,2 \mathrm{M} \mathrm{pH} 4,5,740 \mathrm{MBq}(20 \mathrm{mCi})$ de ${ }^{68} \mathrm{GaCl}_{3}$ diluído em $800 \mu \mathrm{L}$ de $\mathrm{HCl}$ 0,02M em acetona ultrapura, à $95^{\circ} \mathrm{C}$, por 7 minutos sem agitação.

Os animais foram mantidos no Biotério do IPEN, até o instante da realização dos experimentos, em condições adequadas e controladas de luminosidade (sendo o foto período de $12 \mathrm{~h}$ /claro e $12 \mathrm{~h}$ /escuro), temperatura e umidade. A alimentação foi feita com ração balanceada padrão para roedores e água ad libitum durante todos os experimentos.

Todos os experimentos foram previamente aprovados pelo Comitê de Ética em Pesquisa do IPEN e estão de acordo com as normas estabelecidas pela Sociedade Brasileira de Ciência em Animais de Laboratório (SBCAL).

\subsubsection{Estudos de biodistribuição em camundongos Balb/c sadios}

Utilizaram-se camundongos machos da espécie Balb/c. Os animais foram separados em grupos de quatro animais e pesados. O radiofármaco preparado com atividade específica de 140,0 $\mathrm{GBq} / \mu \mathrm{mol}$, foi dividido em alíquotas contendo uma atividade de 0,185 MBq/150 $\mu \mathrm{L}(300 \mathrm{mCi} / 150 \mu \mathrm{L})$ e injetado por via endovenosa caudal. Após decorrido os tempos previamente determinados $(15,30,45,60$ e 120 minutos) os animais foram 
anestesiados com $100 \mu \mathrm{L}$ a cada 20 gramas de peso corporal, com uma solução de ketamina básica $(20 \mathrm{mg} / \mathrm{mL})$ e xilazina $(4 \mathrm{mg} / \mathrm{mL})$, por via intraperitoneal, eutanasiados por deslocamento cervical e dissecados. Durante a dissecação, foram retirados: sangue, coração, fígado, baço, pulmões, pâncreas, estômago, rins, intestino delgado e grosso, músculo da pata traseira, fêmur e cérebro. Posteriormente à dissecação, os órgãos e tecidos foram lavados, pesados e avaliou-se a radioatividade individual em contador do tipo poço.

A captação nos tecidos e órgãos foi calculada como a porcentagem da atividade injetada (\% Al) e atividade por grama do tecido (\% Al/g), considerando-se, para correção do decaimento radioativo do radionuclídeo, uma solução padrão da atividade administrada, em triplicata, que foi analisada simultaneamente para cada conjunto de órgãos e tecidos de cada animal. A atividade da cauda foi contada, para corrigir possíveis depósitos de PSMA-HBED-CC- ${ }^{68}$ Ga no local de administração.

$$
\% A l=\frac{c p m \text { do órgão }}{(c p m \text { do padrão }-c p m \text { da cauda })} \times 100
$$

$$
\% A l / g=\frac{c p m \text { do órgão }}{\text { peso do órgão }(g) \times(c p m \text { do padrão-cpm da cauda })} \times 100
$$

Para cálculo da porcentagem de atividade injetada por grama presente nos ossos (\% $\mathrm{Al} / \mathrm{osso}$ ) e nos músculos (\% $\mathrm{Al} /$ músculo) dos animais, assumiu-se o peso de esqueleto como $12 \%$ e dos músculos como $40 \%$ do peso corpóreo do camundongo.

$\%$ Al (osso total)

$$
=\frac{c p m \text { da amostra do fêmur } x 12 \times \text { peso do camundongo }(g)}{\text { peso da amostra do fêmur }(g) \times(c p m \text { do padrão }-c p m \text { da cauda })}
$$


$\% A l$ (músculo total)

$$
=\frac{c p m \text { da amosta do músculo } x 40 x \text { peso do camundongo }(g)}{\text { peso da amostra do músculo }(g) x(c p m \text { do padrão - cpm da cauda) }}
$$

\subsubsection{Estudos de farmacocinética em camundongos Balb/c sadios}

Injetou-se, por via endovenosa caudal, 0,185 MBq/150 $\mu \mathrm{L}(300 \mathrm{mCi} / 150 \mu \mathrm{L})$ do radiofármaco estudado preparado com atividade específica de 140,0 GBq/ $\mu$ mol. Após diferentes tempos $(5,15,30,45,60$ e 120 minutos), os camundongos foram anestesiados com $100 \mu \mathrm{L}$ a cada 20 gramas de peso corporal, com uma solução de ketamina básica $(20 \mathrm{mg} / \mathrm{mL})$ e xilazina $(4 \mathrm{mg} / \mathrm{mL})$, por via intraperitoneal e coletou-se amostras de sangue $(60 \mu \mathrm{L})$ pelo plexo orbital dos camundongos, utilizando um tubo capilar heparinizado. A radioatividade do sangue foi analisada em um contador gama tipo poço e os resultados foram utilizados para construir a curva de clareamento sanguíneo em função do tempo utilizando o programa GraphPad Prism 5.00 (GraphPad Software, Inc., San Diego, CA, EUA) para um modelo de distribuição monompartimental. Os parâmetros farmacocinéticos de tempo de meia-vida $\left(\mathrm{t} \frac{1}{2}\right)$, constante de eliminação $\left(\mathrm{K}_{\mathrm{el}}\right)$, bem como a área sob a curva de concentração plasmática versus tempo (AUC), foram calculados utilizando o mesmo programa. A depuração $(\mathrm{CL})$ foi calculada pela equação:

$$
C L=\frac{\text { Atividade total administrada }}{A U C}
$$

O volume de distribuição $(V d)$ foi calculado pela equação:

$$
V d=C L / \mathrm{Kel}
$$

Por fim, a meia vida efetiva foi calculada mediante a seguinte equação: 


$$
t^{1 / 2}=\frac{t^{1 / 2} \text { biológica } \times t^{1 / 2} \text { física }}{t^{1 / 2} \text { biológica }+t^{1 / 2} \text { física }}
$$

\subsubsection{Estudos de imagem}

O tempo empregado para realizar uma imagem varia de acordo com o marcador molecular utilizado, sendo dependente da quantidade de atividade utilizada e da utilização de estudos farmacocinéticos para definir o tempo necessário para o acúmulo do marcador no órgão alvo (Saha, 2003).

Os animais receberam $12,95 \mathrm{GBq}(350 \mathrm{mCi})$ do peptídeo radiomarcado, com atividade específica de 140,0 GBq/ $\mu$ mol, em aproximdamente $150 \mu \mathrm{L}$. Imediatmente após a injeção, os animais foram anestesiados com $2 \%$ de isofurano em oxigênio e as imagens foram captadas por equipamento micro-SPECT/PET/CT-modelo Albira (Bruker BioSpin Corp. Software: Albira Software suite). Foram realizadas imagens dinâmicas com duração de 5 minutos, nos seguintes intervalos: $15,20,25,30,45,60,75$ e 90 minutos, seguidos de imagem CT com captação por 20 minutos.

As imagens foram reconstituídas com auxilido dos software PMOD biomedical Image Quantification Software, versão 3.310.

\subsection{ANÁLISE ESTATÍSTICA}

Os resultados foram expressos como Média \pm Desvio Padrão. A análise estatística foi realizada por intermédio do programa GraphPad Prism 5.00 ${ }^{\circledR}$ (GraphPad Software, Inc., San Diego, CA, EUA), utilizando o teste $t$ de Student com distribuição bicaudal para comparação de pares, análise de variância ANOVA e teste de Bonferroni para comparação de múltiplos grupos. As diferenças foram consideradas significativas quando o valor de $p$ foi menor que 0,05 . Para análise de variáveis condicionais, foi utilizado análise de regressão linear. Nos estudos farmacocinéticos utilizou-se gráfico de ajuste não linear para decaimento de um compartimento. 


\section{7 \\ RESULTADOS E DiSCUSSÃO}

\subsection{Metodologias Analíticas}

\subsubsection{Determinação dos perfis cromatográficos}

Os cromatogramas em CLAE foram obtidos para o produto radiomarcado e ${ }^{68} \mathrm{GaCl}_{3}$ (FIG. 13). Segundo Schuhmacher e colaboradores (1995) a radiomarcação do quelante acíclico HBED-CC com ${ }^{68} \mathrm{Ga}$ forma três diferentes configurações estéricas denominadas diasteroisômeros, os quais podem ser distinguidos por CLAE devido suas características físico-químicas distintas. Entretanto, cada um dos diasteroisômeros estão presentes em uma mistura racêmica de enantiomeros não distinguíveis em CLAE utilizando coluna C18.

As metodologias diponíveis na literatura para CLAE utilizam altos volumes da fase móvel ( $4 \mathrm{~mL} / \mathrm{min}$ ), levando ao aumento de pressão interna na coluna e um curto período de tempo (8 minutos) (Eder et al, 2012; Eder et al, 2014; Schafer et al, 2012), fazendo com que o tempo de retenção para as diferentes formas de diasteroisômeros, possivelmente presentes no produto, sejam muito próximos, podendo ocorrer a co-eluição dos picos.

Eder e colaboradores (2014) apresentam o perfil de CLAE do PSMA-HBED-CC radiomarcado com ${ }^{68} \mathrm{Ga}$, no qual são observados dois picos mal resolvidos, sobrepostos parcialmente, relacionados, segundo os autores, às três formas de diasteroisômeros. 0 
pico com maior tempo de retenção corresponderia a uma forma de diasteroisômero, enquanto as outras duas seriam co-eluídas no pico com tempo de retenção menor.

No perfil de CLAE da FIG. 13B, correspondente à mistura de marcação, observam-se dois picos que podem ser correlacionados às formas diasteroisoméricas, conforme descritas por Eder e col. (2014), porém com melhor resolução entre os picos, devido provavelmente, à alteração no fluxo empregado. O método utilizado em CLAE possibilitou ainda boa separação entre as espécies radiomarcadas e o gálio-68 livre, que apresentou tempo de retenção de aproximadamente 1,77 minutos (FIG. 13A).

Não foi possível diferenciar o perfil cromatográfico no detector de UV devido à pequena massa de peptídeo utilizada e à capacidade de detecção do cromatógrafo.

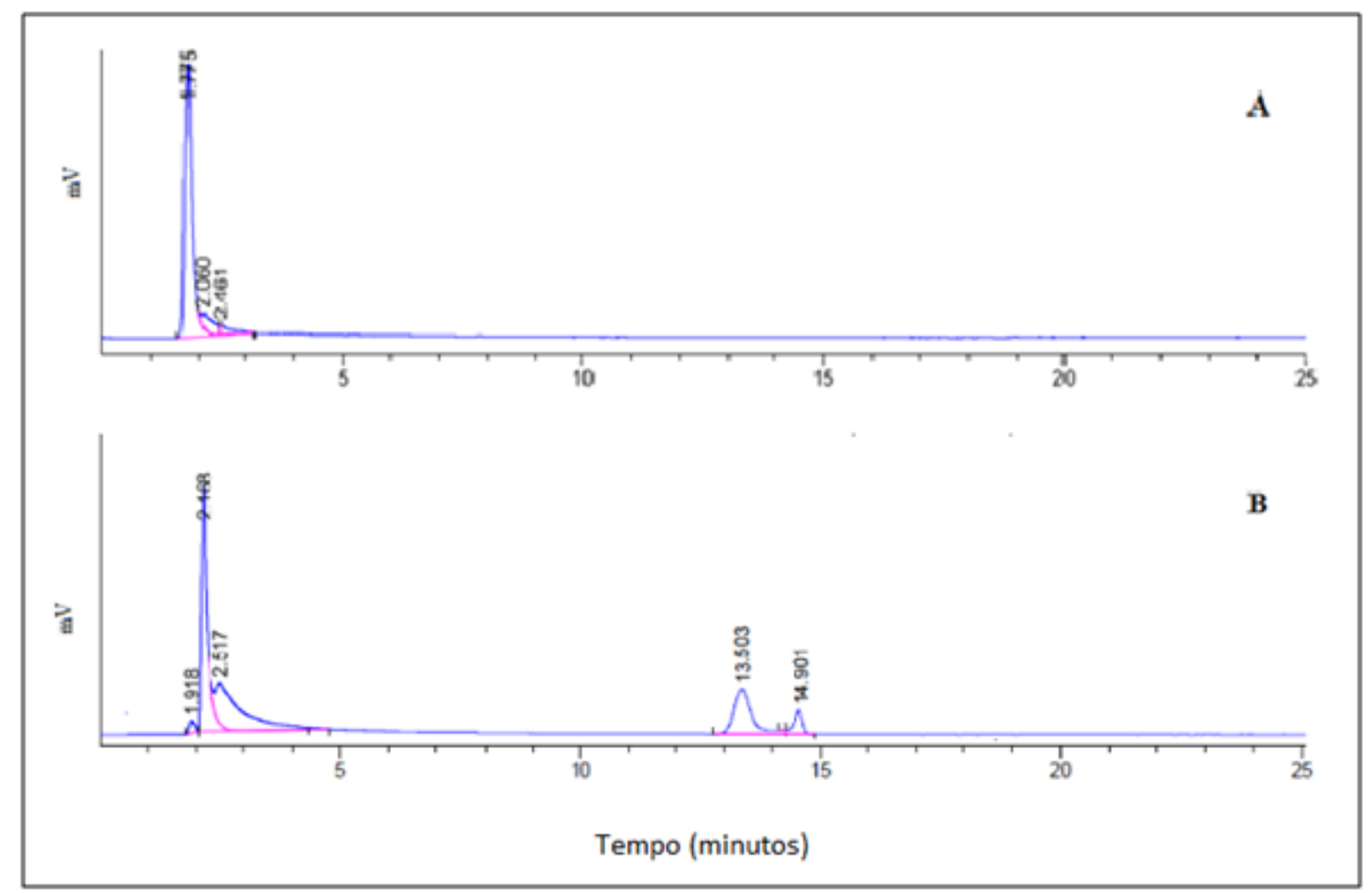

FIGURA 13: Radiocromatograma do ${ }^{68} \mathrm{GaCl}_{3}$ diluído em $800 \mu \mathrm{L}$ de $\mathrm{HCl} 0,02 \mathrm{M}$ em acetona ultrapura (A) e do PSMA-HBED-CC $-{ }^{68} \mathrm{Ga}$ na seguinte condição de marcação: $5 \mu \mathrm{g}$ do peptídeo PSMA-HBED-CC, $740 \mathrm{MBq}(20 \mathrm{mCi})$ de ${ }^{68} \mathrm{GaCl}_{3}$, por 7 minutos a $95^{\circ} \mathrm{C}$ sem agitação em tampão acetato de sódio $0,2 \mathrm{M} \mathrm{pH} 4$ (B).

Os dois picos observados na FIG. 13B, referentes às diferentes formas de diasteroisômeros formados durante a conjugação do PSMA-HBED-CC ao gálio-68, apresentaram $R_{f}$ assumido de aproximadamente 13,5 minutos para o pico 1 e 14,9 minutos para o pico 2. A soma dos picos concedeu uma \% PR de $26,40 \%$ para a marcação analisada. 
Este valor de pureza radioquímica foi considerado como referência para a validação da eficácia dos métodos de CCD e cromatografia em papel analisados.

Os perfis cromatográficos foram previamente determinados para $0{ }^{68} \mathrm{GaCl}_{3}$ (FIG. 14) e PSMA-HBED-CC- ${ }^{68}$ Ga (FIG. 15) em cromatografia em papel Whatman $n \div 03$ e CCD, utilizando-se como suporte tiras de ITLC-SG e TLC-SG.

Como referência para o tempo de retenção das espécies radioquímicas envolvidas, levou-se em consideração o resultado obtido para a análise em CCD em TLC-SG, de outros peptídeos radiomarcados com ${ }^{68} \mathrm{Ga}$ (Pujatti, 2012; Farmacopéia Européia, 2010). Nos resultados publicados, em fase móvel de solução metanol:acetato de amônio $1 \mathrm{M} \mathrm{pH} \mathrm{8,5}$ $(1: 1 \mathrm{v} / \mathrm{v})$, conforme demonstrado para outro peptídeo radiomarcado, o marcador molecular se desloca para o final da fita $\left(R_{f} 0,8-1,0\right)$, enquanto $0{ }^{68} \mathrm{GaCl}_{3}$ permanece na origem da fita $\left(R_{f} 0,0-0,1\right)$. Em fase móvel tampão citrato:ácido cítrico $0,1 \mathrm{M} \mathrm{pH} \mathrm{5,} \mathrm{o} \mathrm{marcador} \mathrm{molecular}$ permanece na origem da fita $\left(R_{f} 0,0-0,1\right)$, enquanto $0{ }^{68} \mathrm{GaCl}_{3}$ se desloca para o final fita $\left(R_{f} 0,7-1,0\right)$

Neste trabalho, em fase móvel de solução metanol:acetato de amônio $1 \mathrm{M} \mathrm{pH} \mathrm{8,5}$ $(1: 1, v / v)$, a forma livre do ${ }^{68} \mathrm{Ga}$ apresentou $R_{f} 0,0-0,3$ em todos os suportes analisados (FIG. 14A, 14B e 14C), enquanto que em fase móvel tampão citrato:ácido cítrico 0,1M pH 5, a espécie radioquímica migrou com a frente do solvente $\left(R_{f}=0,7-1,0\right)$ para os sistemas em ITLC-SG e TLC-SG (FIG. 14C e 14D). Já na cromatografia em papel para este mesmo solvente, uma porcentagem da forma livre do gálio-68 migrou com a frente do solvente $\left(R_{f}=0,9-1,0\right)$, enquanto outra parte ficou retida no ponto de aplicação $\left(R_{f}=0-0,3\right)$ (FIG. 14E).

Com relação à avaliação cromatográfica em CCD e CP da mistura de marcação do peptídeo PSMA-HBED-CC com ${ }^{68} \mathrm{Ga}$, considerando-se como fase móvel o solução metanol:acetato de amônio $1 \mathrm{M} \mathrm{pH} \mathrm{8,5,} \mathrm{o} \mathrm{peptídeo} \mathrm{radiomarcado} \mathrm{migrou} \mathrm{com} \mathrm{a} \mathrm{frente} \mathrm{do}$ solvente $\left(R_{f}=0,7-1,0\right)$ tanto nos sistemas de CCD como na cromatografia em papel (FIG. 15A, 15B e 15C). Ao se utilizar como fase móvel o tampão citrato:ácido cítrico $0,1 \mathrm{M}$ pH5, os resultados obtidos foram variáveis, dependendo do suporte cromatográfico. Desta forma, para TLC-SG, o $R_{f}$ do peptídeo foi de 0,4-0,6 (FIG. 15D); para ITLC-SG o $R_{f}$ foi de 0,8-1,0 (FIG. 15D), enquanto que para a cromatografia em papel foi de 0,0-0,3 (FIG. 15E).

A TAB. 7 a seguir resume o $R_{f}$ das diferentes espécies nos diferentes sistemas cromatográficos utilizados. 
TABELA 7: $R_{f}$ apresentado pelas espécies gálio-68 livre e PSMA-HBED-CC- ${ }^{68} \mathrm{Ga}$ em CCD e CP nas fases móveis solução metanol:acetato de amônio $1 \mathrm{M} \mathrm{pH} \mathrm{8,5} \mathrm{(1:1,} \mathrm{v/v)} \mathrm{e} \mathrm{tampão}$ citrato:ácido cítrico $0,1 \mathrm{M} \mathrm{pH} 5$

\begin{tabular}{cccccccc} 
& \multicolumn{2}{c}{ TLC-SG } & \multicolumn{2}{c}{ ITLC-SG } & \multicolumn{2}{c}{ Whatman n03 } \\
\hline & $\mathrm{S}_{1}$ & $\mathrm{~S}_{2}$ & $\mathrm{~S}_{1}$ & $\mathrm{~S}_{2}$ & $\mathrm{~S}_{1}$ & $\mathrm{~S}_{2}$ \\
\hline Gálio-68 livre & $0-0,3$ & $0,7-1,0$ & $0-0,3$ & $0,8-1,0$ & $0-0,2$ & $0-0,3$ \\
PSMA-HBED-CC- ${ }^{68} \mathrm{Ga}$ & $0,9-1,0$ & $0,4-0,6$ & $0,7-1,0$ & $0,9-1,0$ & $0,9-1,0$ & $0,0-0,3$ \\
\end{tabular}

$\mathrm{S}_{1}=$ fase móvel solução metanol:acetato de amônio $1 \mathrm{M} \mathrm{pH} \mathrm{8,5} \mathrm{(1:1,} \mathrm{v/v)}$

$\mathrm{S}_{2}=$ fase móvel tampão citrato:ácido cítrico $0,1 \mathrm{M} \mathrm{pH} 5$

Com base nos resultados obtidos, descritos na TAB. 7, o sistema cromatográfico que apresentou melhor resolução para a separação das espécies gálio-68 livre e peptídeo radiomarcado foi a CCD em TLC-SG ou ITLC-SG, utilizando como fase móvel solução metanol:acetato de amônio $1 \mathrm{M}$, uma vez que nestes sistemas, a forma livre do gálio-68 permanece próxima ao ponto de aplicação da amostra e o peptídeo radiomarcado migra com a frente do solvente.

A cromatografia em papel, para o mesmo solvente também mostrou boa separação entre as espécies radioquímicas, representando uma alternativa mais econômica para avaliação da pureza radioquímica da preparação. 

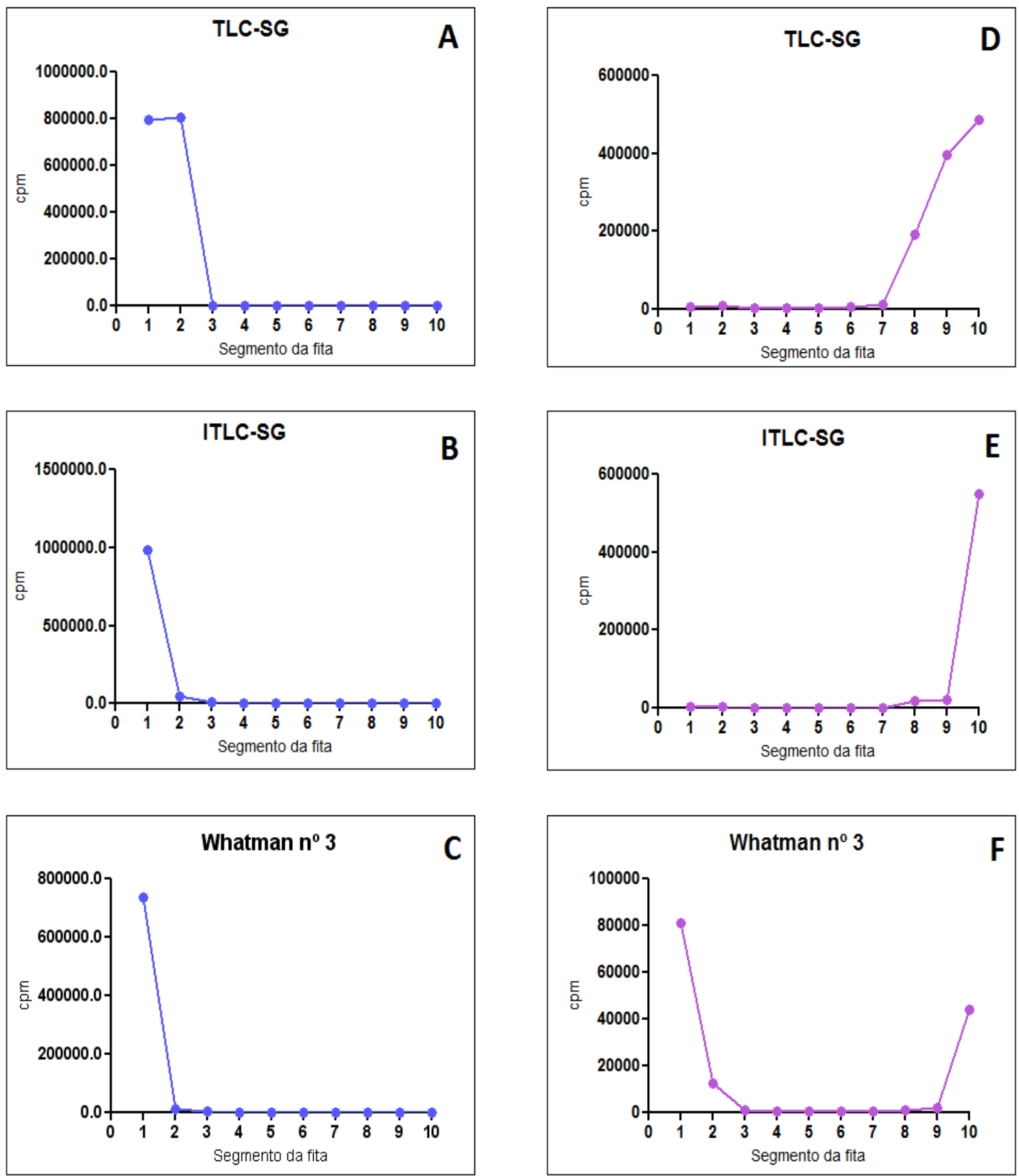

* Metanol:acetato de amônio $1 \mathrm{M}$

- Tampão citrato/ácido cítrico $0,1 \mathrm{M}$

FIGURA 14: Perfil cromatográfico do ${ }^{68} \mathrm{GaCl}_{3}$ diluído em $800 \mu \mathrm{L}$ de $\mathrm{HCl} 0,02 \mathrm{M}$ em acetona ultrapura, em fase móvel metanol:acetato de amônio $1 \mathrm{M} \mathrm{pH} \mathrm{8,5} \mathrm{(1:1,} \mathrm{v/v),} \mathrm{utilizando}$ TLC-SG (A), ITLC-SG (B) e papel Whatman $n=3$ (C), e em fase móvel tampão citrato:ácido cítrico $0,1 \mathrm{M} \mathrm{pH} 5$, utilizando TLC-SG (D), ITLC-SG (E) e papel Whatman $\mathrm{n}$ 으 (F). 

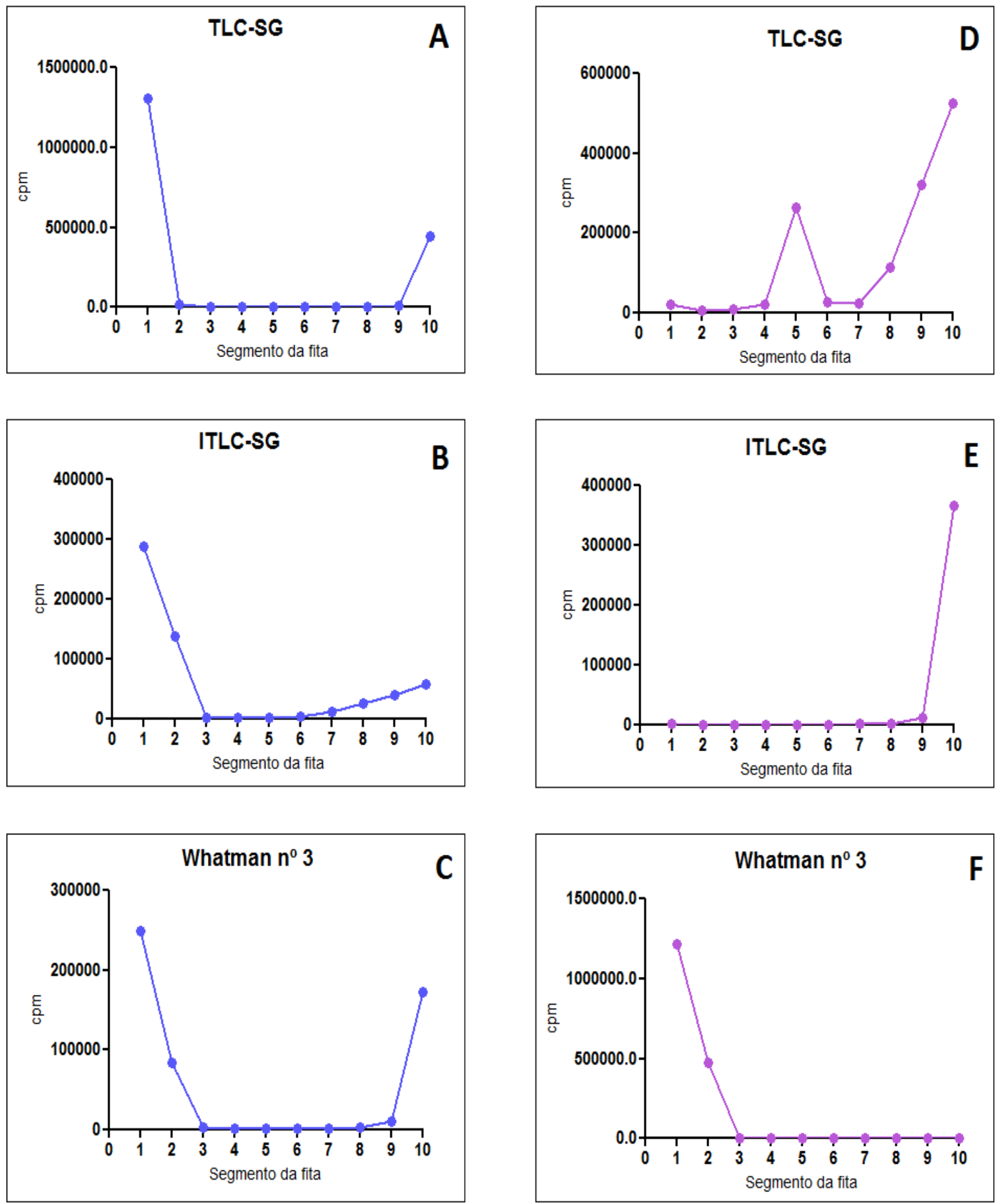

* Metanol:acetato de amônio $1 \mathrm{M}$

* Tampão citrato/ácido cítrico 0,1M

FIGURA 15: Perfil cromatográfico do radiofármaco PSMA-HBED-CC $-{ }^{68} \mathrm{Ga}$, em fase móvel metanol:acetato de amônio $1 \mathrm{M} \mathrm{pH} \mathrm{8,5} \mathrm{(1:1,} \mathrm{v/v),} \mathrm{utilizando} \mathrm{TLC-SG} \mathrm{(A),} \mathrm{ITLC-SG} \mathrm{(B)} \mathrm{e} \mathrm{papel}$ Whatman no3 (C), e em fase móvel tampão citrato:ácido cítrico 0,1M pH 5, utilizando TLC-SG (D), ITLC-SG (E) e papel Whatman no3 (F). Condições de radiomarcação: $5 \mu \mathrm{g}$ do peptídeo em $2 \mathrm{~mL}$ de tampão acetato de sódio $0,2 \mathrm{M} \mathrm{pH} \mathrm{4,740} \mathrm{MBq}(20 \mathrm{mCi})$ de ${ }^{68} \mathrm{GaCl}_{3}$ diluído em $800 \mu \mathrm{L}$ de $\mathrm{HCl} 0,02 \mathrm{M}$ em acetona ultrapura, por 7 minutos, à $95^{\circ} \mathrm{C}$ sem agitação. 
A TAB. 8 apresenta os resultados de \% PR da marcação do peptídeo PSMA-HBED-CC com ${ }^{68} \mathrm{GaCl}_{3}$ obtidos com os diferentes sistemas cromatográticos estudados.

TABELA 8: Porcentagem de pureza radioquímica obtida para a solução de PSMA-HBED-CC- ${ }^{68} \mathrm{Ga}$ nos métodos cromatográficos com fase móvel: solução metanol:acetato de amônio $1 \mathrm{M} \mathrm{pH} \mathrm{8,5} \mathrm{(1:1} \mathrm{v/v)} \mathrm{e} \mathrm{fase} \mathrm{estacionária:} \mathrm{TLC-SG,} \mathrm{ITLC-SG} \mathrm{e} \mathrm{papel}$ Whatman no3.

\begin{tabular}{ccc}
\hline \multicolumn{3}{c}{ PSMA-HBED-CC ${ }^{-68} \mathrm{Ga}$} \\
\hline \multirow{2}{*}{$\begin{array}{c}\text { Solução metanol:acetato de amônio 1M } \\
\text { pH 8,5 (1:1 v/v) }\end{array}$} & TLC-SG & $25,65 \%$ \\
& ITLC-SG & $21,74 \%$ \\
& Whatman no 3 & $28,10 \%$ \\
\hline
\end{tabular}

Devido à capacidade de separação dos diferentes constituintes presentes no processo de marcação, a precisão obtida quando comparado aos resultados obtidos por CLAE, a fácil comercialização e disponibilidade do material no Ipen, optou-se pela cromatografia em camada delgada de sílica gel 60 (TLC-SG) como fase estacionária e solução metanol:acetato de amônio $1 \mathrm{M} \mathrm{pH} \mathrm{8,5} \mathrm{como} \mathrm{fase} \mathrm{móvel.}$

Entretanto, se considerarmos que em média o solvente leva 80 minutos para percorrer a fita cromatográfica de TLC-SG, devido ao curto tempo de meia vida do radionuclídeo, para fins de produção rotineira, a melhor escolha para avaliação da pureza radioquímica seria a cromatografia líquida de alta eficiência, onde o resultado é obtido em 20 minutos, seguido da cromatografia em papel, devido a satisfatoria precisão e baixo custo e fitas de ITLC-SG, ambos os sistemas utilizando solução metanol:acetato de amônio $1 \mathrm{M}$ pH 8,5 como fase móvel.

\subsubsection{Determinação da identidade radionuclídica}

A análise de identificação radionuclídica tem o propósito de confirmar a identidade radionuclídica do isótopo presente em uma amostra. Através de medidas consecutivas da atividade do produto em calibrador de dose, é possível calcular o tempo de 
meia-vida física e correlacioná-lo ao tempo de meia-vida conhecido para cada radioisótopo (Farmacopéia Européia, 2010). O ensaio de identidade radionuclídica possibilitou analisar, apesar de não identificar, a presença de impurezas radionuclídicas na preparação.

Conforme descrito na RDC 64, o tempo de meia-vida física de um radionuclídeo é definido pelo intervalo de tempo necessário para que seus átomos decaiam para outra forma nuclear. A meia-vida física do gálio-68 é de 67,7 minutos.

Na FIG. 16, observa-se o gráfico de regressão linear obtido pelos valores de atividade mensurados em calibrador de doses para três procedimentos de marcações do PSMA-HBED-CC $-{ }^{68} \mathrm{Ga}$ a fim de obter coeficiente de determinação $\left(r^{2}\right)$ e coeficiente angular ( $\alpha$ ) para determinação do tempo de meia vida física.

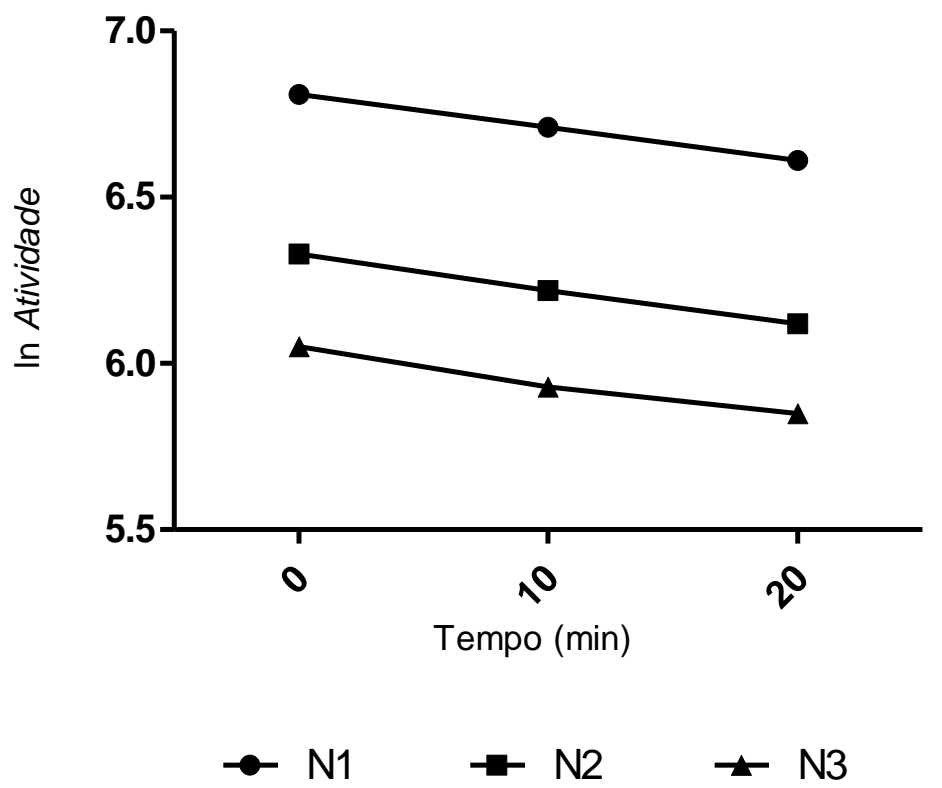

FIGURA 16: Gráfico linear das medidas de atividade do radiofármaco PSMA-HBED-CC- ${ }^{68}$ Ga a cada 10 minutos, referente a três procedimentos de marcações diferentes.

Todas as retas apresentaram $r^{2}$ superior a 0,99 e as meias vidas calculadas obtiveram valores entre 66 e 69 minutos, estando de acordo com o estabelecido pela Farmacopeia Europeia 7.6 (2010) para radionuclídeos com tempo de meia vida curta e corroborando com a meia vida conhecida de 67,7 minutos do gálio-68 (TAB. 9). 
TABELA 9: Dados encontrados através da equação da reta e cálculos de meia vida física do ${ }^{68} \mathrm{Ga}$, a partir de medidas da radioatividade das amostras do PSMA-HBED-CC- ${ }^{68} \mathrm{Ga}$ em três diferentes tempos em calibrador de dose.

\begin{tabular}{ccc}
$\mathbf{r}^{\mathbf{2}}$ & $\boldsymbol{\alpha}$ & $\begin{array}{c}\text { Tempo de meia vida física } \\
\text { T² }\end{array}$ \\
\hline 0,99 & $-0,01011$ & 69 \\
0,99 & $-0,01047$ & 66 \\
0,99 & $-0,01005$ & 69
\end{tabular}

\subsubsection{Determinação do coeficiente de partição $(\log P)$ experimental}

O coeficiente de partição ( $\log P$ ) é determinado pela quantidade de determinada espécie química, quando em equilíbrio, presente na fase orgânica e na fase aquosa (Loyd e Allen, 2016; Rang et al, 2007).

Esta grandeza é considerada um importante parâmetro físico-químico pois o organismo humano se encontra dividido em estruturas apolares e polares. Desta maneira, o valor de log $\mathrm{P}$ auxilia a predição da distribuição e farmacocinética de substancias in vivo, além de ser imprescidível, para a maioria dos fármacos, que atravessem algumas barreiras lipofílicas para atingir o sítio de ação (Loyd e Allen, 2016; Rang et al, 2007).

O log P experimental encontrado para o PSMA-HBED-CC $-{ }^{68} \mathrm{Ga}$ foi 2,60 , indicando características de lipofilicidade importante para interação com o receptor específico, uma vez que os valores de coeficiente de partição estão classificados como: $\quad P=0$, a substância tem a mesma afinidade por ambas as fases; $\mathrm{P}<0$, a substância tem maior afinidade pela fase aquosa; $P>0$, a substância tem maior afinidade pela fase orgânica (Loyd e Allen, 2016).

As vantagens apresentadas na utilização do quelante HBED-CC pode ser explicada, em parte, pelo valor do log P, uma vez que o PSMA acoplado a quelantes como DOTA, DTPA e PCTA apresentam coeficientes de partição -2,89, -3,24 e -1,41, respectivamente (Chakravarty et al, 2012; Eder et al, 2012), indicando menor lipofilicidade quando comparados ao composto radiomarcado com o quelante HBED-CC. 


\subsection{OTIMIZAÇÃO DA RADIOMARCAÇÃO DO PSMA-HBED-CC COM ${ }^{68}$ Ga EM Método Não Automatizado}

\subsubsection{Processo de evaporação do ${ }^{68} \mathrm{GaCl}_{3}$}

A perda de ${ }^{68} \mathrm{GaCl}_{3}$ durante a evaporação do $\mathrm{HCl}$ 0,02M em acetona ultrapura foi de 6,7\%, permitindo utilização do radionuclídeo em radiomarcações com alta temperatura (TAB. 10).

A pureza radioquímica apresentada na TAB. 10 permite concluir que $0{ }^{68} \mathrm{GaCl}_{3}$ não sofreu oxidação, uma vez que, nas diferentes condições, apresentou o mesmo perfil cromatográfico.

TABELA 10: Teste de evaporação do ${ }^{68} \mathrm{GaCl}_{3}$ diluído em $\mathrm{HCl} 0,02 \mathrm{M}$ em acetona ultrapura, exposto à $95^{\circ} \mathrm{C}$ por 7 minutos. Sistema cromatográfico: solução metanol:acetato de amônio $1 \mathrm{M} \mathrm{pH} 8,5(1: 1 \mathrm{v} / \mathrm{v})$ em TLC-SG.

\begin{tabular}{lccc}
\hline & \% Pureza radioquímica & Atividade $(\mathbf{m C i})$ & (n) \\
\hline${ }^{68} \mathrm{GaCl}_{3}$ sem evaporar & $99,92 \% \pm 0,0002$ & $20 \pm 0,00$ & 3 \\
${ }^{68} \mathrm{GaCl}_{3}$ evaporado & $99,97 \% \pm 0,0003$ & $18,66 \pm 0,05$ & 3 \\
\hline
\end{tabular}

\subsubsection{Determinação do tampão de marcação}

A FIG. 17 apresenta o resultado do estudo de marcação do PSMA-HBED-CC com ${ }^{68} \mathrm{Ga}$ à $25^{\circ} \mathrm{C}$ em tampão HEPES, conforme descrito por Eder e col. (2012) e Schafer e col. (2012).

Mesmo tendo realizado as marcações com atividade específica inferior à descrita na literatura $(140 \mathrm{GBq} / \mu \mathrm{mol}$ contra 500 - $1000 \mathrm{GBq} / \mu \mathrm{mol}$ utilizados por Eder e Col. e Schafer e col.), e um tempo maior de marcação ( 7 minutos contra 2 minutos utilizados pelos autores referidos), os resultados de PR obtidos foram inferiores aos obtidos na literatura (99\%). 
Na marcação com tampão HEPES a pureza radioquímica aumentou com o tempo de reação, até 30 minutos, não apresentando incremento na PR para o tempo de 60 minutos. A PR foi inferior a 95\% em todos os tempos experimentados.

A marcação realizada com o tampão acetato de sódio $0,2 \mathrm{M}$ pH 4 apresentou pureza radioquímica siginificativamente maior $(p<0,001)$ quando comparada à marcação utilizando o tampão HEPES 2,1M pH 4,2 nos tempos de reação entre 2 e 30 minutos. Apenas após 60 minutos de reação os resultados não foram significativamente relevantes $(p>0,05)$ (FIG. 17).

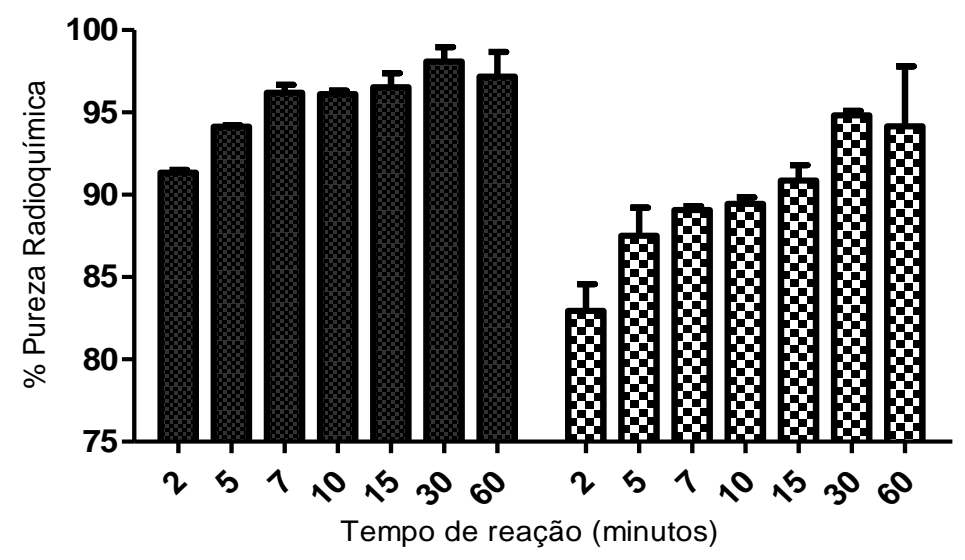

8 Tp. acetato de sódio Ex Tp. HEPES

FIGURA 17: Pureza radioquímica obtida na radiomarcação do PSMA-HBED-CC com ${ }^{68} \mathrm{Ga}$ em diferentes tempos de reação. Condições de radiomarcação: Tp. Acetato de sódio - $20 \mu \mathrm{g}$ do peptídeo em $1 \mathrm{~mL}$ de tampão acetato de sódio $0,2 \mathrm{M} \mathrm{pH} \mathrm{4,} 185 \mathrm{MBq}(5 \mathrm{mCi})$ de ${ }^{68} \mathrm{GaCl}_{3}$ diluído em $10 \mu \mathrm{L}$ de $\mathrm{HCl} 0,02 \mathrm{M}$ em acetona ultrapura, à $25^{\circ} \mathrm{C}$, sem agitação; Tp. HEPES $20 \mu \mathrm{g}$ do peptídeo em $100 \mu \mathrm{L}$ de tampão HEPES 0,1M pH 7,5 e $10 \mu \mathrm{L}$ de tampão HEPES 2,1M $\mathrm{pH} 7,5,185 \mathrm{MBq}(5 \mathrm{mCi})$ de ${ }^{68} \mathrm{GaCl}_{3}$ diluído em $10 \mu \mathrm{L}$ de $\mathrm{HCl}$ 0,02M em acetona ultrapura, à $25^{\circ} \mathrm{C}$, sem agitação, o $\mathrm{pH}$ foi ajustado para $4,2 \mathrm{com} \mathrm{NaOH}$. Sistema cromatográfico: metanol:acetato de amônio $1 \mathrm{M}(1: 1 \mathrm{v} / \mathrm{v})$ em TLC-SG $(n \geq 3)$.

Apesar do tampão acetato de sódio ter apresentado melhor eficiência de radiomarcação, apenas as marcações a partir de 7 minutos apresentaram pureza radioquímica superior a 95\%. O critério de aceitação adotado neste estudo, tendo como base o especificado pela Farmacopeia Europeia 7.6 (2010) para outro peptídeo radiomarcado com ${ }^{68} \mathrm{Ga}$ (edotreotide injection). 


\subsubsection{Análise da variação da massa do peptídeo}

Considerando-se os melhores resultados de PR obtidos com tampão acetato de sódio, os demais estudos de variação dos paramêtros de marcação foram realizados com este tampão.

Ainda considerando marcações realizadas à temperatura de $25^{\circ} \mathrm{C}$, verificou-se que a influência da massa do peptídeo sobre a PR não foi estatisticamente relevante ( $p>0,05$ ) para nenhuma das massas analisadas (FIG. 18), ao se aumentar de $5 \mu \mathrm{g}$ para 15 ou $20 \mu \mathrm{g}$ a massa do peptídeo na reação. No entanto, a pureza radioquímica da radiomarcação com $5 \mu \mathrm{g}$ aproximou-se muito do critério de aceitação pré estabelecido de 95\%.

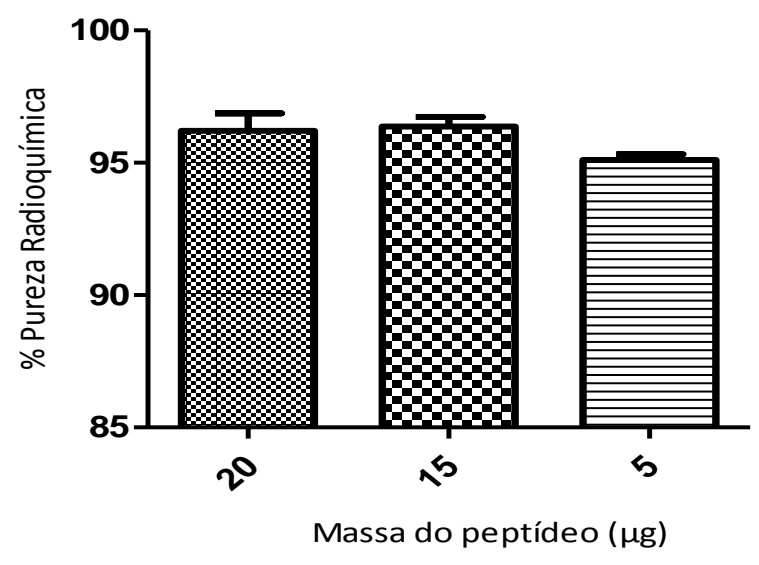

FIGURA 18: Análise da variação de massa do peptídeo PSMA-HBED-CC sobre a pureza radioquímica da marcação com ${ }^{68} \mathrm{Ga}$. Condições de radiomarcação: 20, 15 e $5 \mu \mathrm{g}$ do peptídeo diluído em $1 \mathrm{~mL}$ de tampão acetato de sódio $0,2 \mathrm{M} \mathrm{pH} \mathrm{4,} 185 \mathrm{MBq}(5 \mathrm{mCi}) \mathrm{de}^{68} \mathrm{GaCl}_{3}$ diluído em $800 \mu \mathrm{L}$ de $\mathrm{HCl} 0,02 \mathrm{M}$ em acetona ultrapura, à $25^{\circ} \mathrm{C}$, por 10 minutos, sem agitação. Sistema cromatográfico: metanol:acetato de amônio 1M (1:1 v/v) em TLC-SG ( $n=3)$.

\subsubsection{Determinação da temperatura e tempo de marcação}

Com base em dados publicados e visando posterior radiomarcações em módulo de síntese automatizado, foram alterados os parâmetros de marcação, buscando simular as condições de marcação em módulo automatizado, com o mesmo procedimento empregado para a marcação do peptídeo DOTATATO com ${ }^{68} \mathrm{Ga}$. As alterações foram baseadas nas recomendações descritas pelo fabricante (Modular-Lab PharmTracer, 2014). 
A marcação foi realizada com $5 \mu \mathrm{g}$ do peptídeo diluído em $2 \mathrm{~mL}$ de tampão acetato de sódio $0,2 \mathrm{M} \mathrm{pH} \mathrm{4,} \mathrm{com} 740 \mathrm{MBq}(20 \mathrm{mCi})$ de ${ }^{68} \mathrm{GaCl}_{3}$, sem agitação, variando a temperatura.

Observa-se na FIG. 19 que o procedimento de marcação obteve pureza radioquímica superior sob aquecimento quando comparado a marcações à $25^{\circ} \mathrm{C}$, com melhores resultados para a temperatura de $95^{\circ} \mathrm{C}$. Não foi observado incremento significativo de PR ao se elevar de 7 para 10 minutos o tempo de reação em todas as temperaturas estudadas $(p>0,05)$.

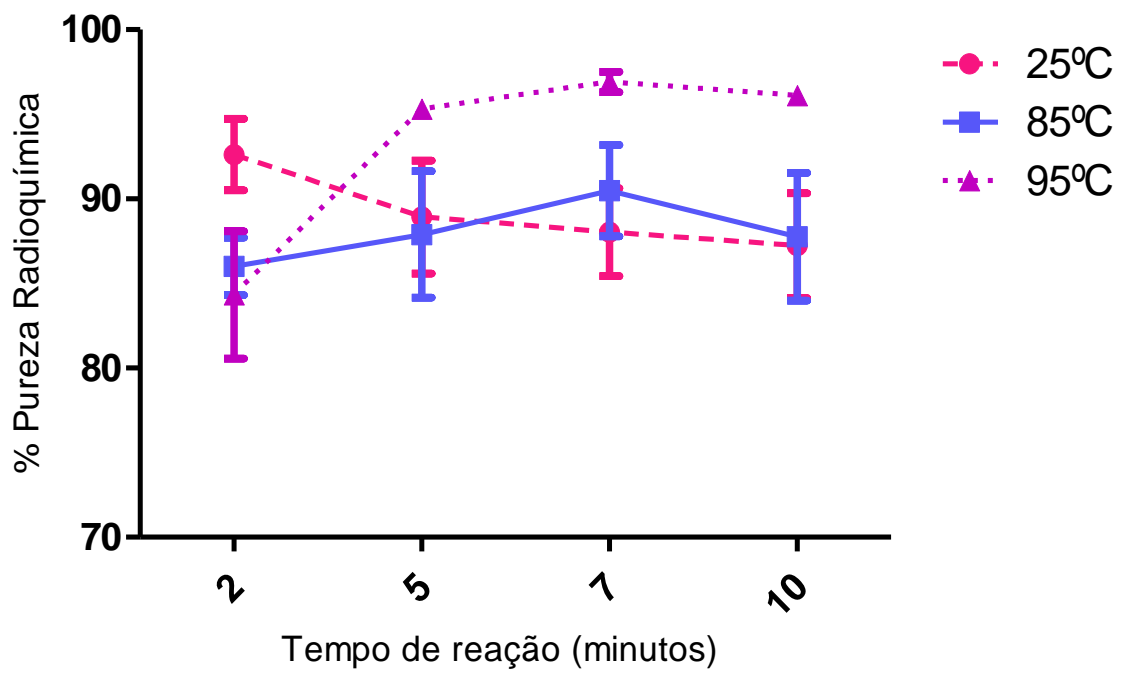

FIGURA 19: Determinação da pureza radioquímica da marcação do PSMA-HBED-CC com ${ }^{68} \mathrm{Ga}$, em diferentes temperaturas e tempos de reação. Condições de radiomarcação: utilizando a condição de marcação padrão, as radiomarcações foram incubadas por 2, 5, 7 e 10 minutos, a diferentes temperaturas $\left(25,85\right.$ e $\left.95^{\circ} \mathrm{C}\right)$. Sistema cromatográfico: metanol:acetato de amônio $1 \mathrm{M}(1: 1 \mathrm{v} / \mathrm{v})$ em TLC-SG $(n \geq 3)$.

Os resultados de $\mathrm{PR}$ obtidos para marcação à $25^{\circ} \mathrm{C}$ e em curto intervalo de reação (2 minutos) conforme empregado por Eder e col. (2012), Eder e col. (2014) e Schafer e col. (2012) foram elevados, porém não alcançaram o critério de aceitação ( $\geq 95 \%$ ). A maior PR obtida para este parâmetro foi de $92,62 \% \pm 3,66$ para o tempo de 2 minutos de reação. No entanto, o aumento da temperatura de marcação e do tempo de reação promoveu aumento de PR do PSMA-HBED-CC- ${ }^{68} \mathrm{Ga}$. Apenas a radiomarcação a $95^{\circ} \mathrm{C}$ resultou em $P R \geq 95 \%$ a partir do intervalo de 5 minutos (FIG. 19). 
Quando analisada a estabilidade das preparações, para o tempo de marcação de 7 minutos, observou-se manutenção da PR acima dos 95\% em um período de 4 horas (240 minutos) para a marcação realizada à $95^{\circ} \mathrm{C}$ (FIG. 20).

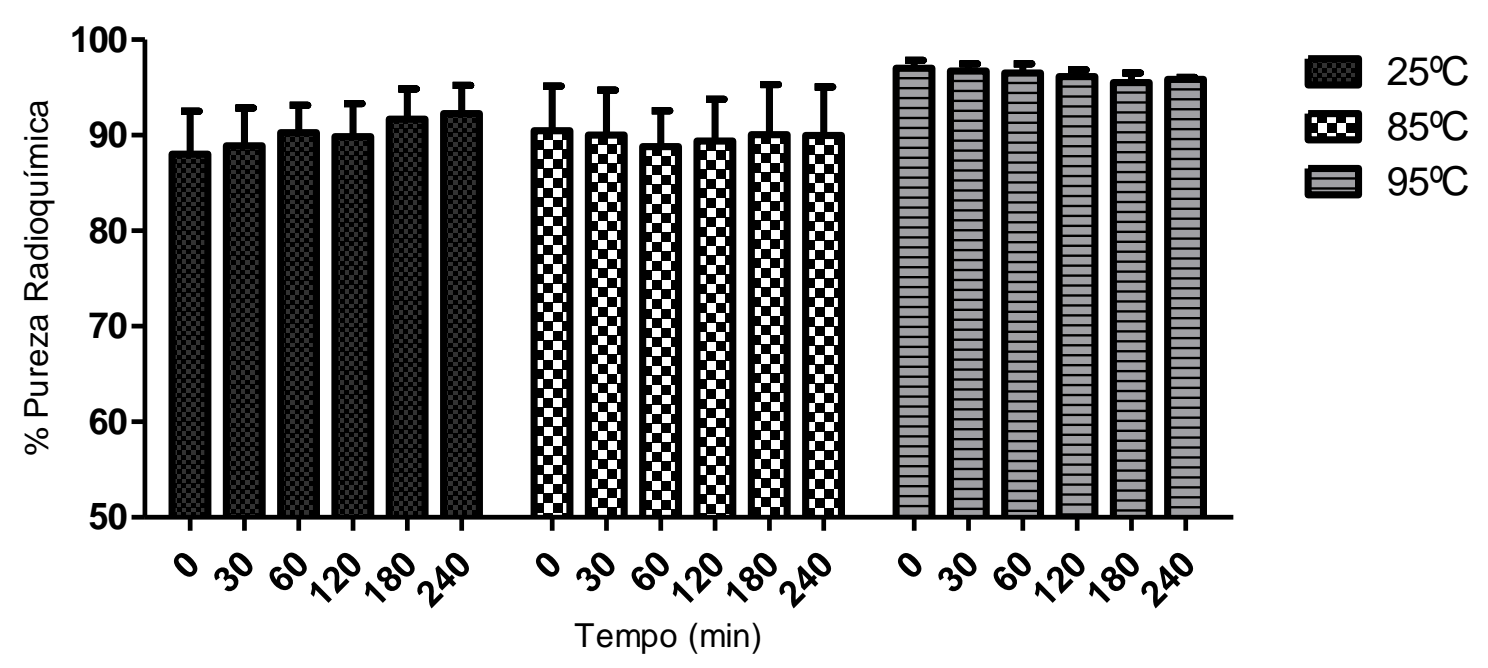

FIGURA 20: Estabilidade das marcações do PSMA-HBED-CC com ${ }^{68} \mathrm{Ga}$, realizadas a diferentes temperaturas e tempos de reação. Condições de radiomarcação: utilizando a condição de marcação padrão, as radiomarcações foram incubadas em diferentes temperaturas $(25,85$ e $\left.95^{\circ} \mathrm{C}\right)$. Sistema cromatográfico: metanol:acetato de amônio $1 \mathrm{M}(1: 1 \mathrm{v} / \mathrm{v})$ em TLC-SG $(n \geq 3)$.

As marcações realizadas à $25^{\circ} \mathrm{C}$ e $85^{\circ} \mathrm{C}$ também apresentaram grande estabilidade, apesar da PR inicial inferior ao critério de aceitação (FIG. 20).

Conforme dito anteriormente, a temperatura de reação pode exercer influência sobre a formação das espécies de diasteroisômeros, sendo a conformação RR termodinamicamente mais estável (Eder et al, 2014; Schuhmacher et al, 1995). Para avaliar esta influência, o produto radiomarcado em diferentes temperaturas foi analisado por CLAE e os perfis obtidos podem ser observados nas FIG. 21, 22 e 23. 


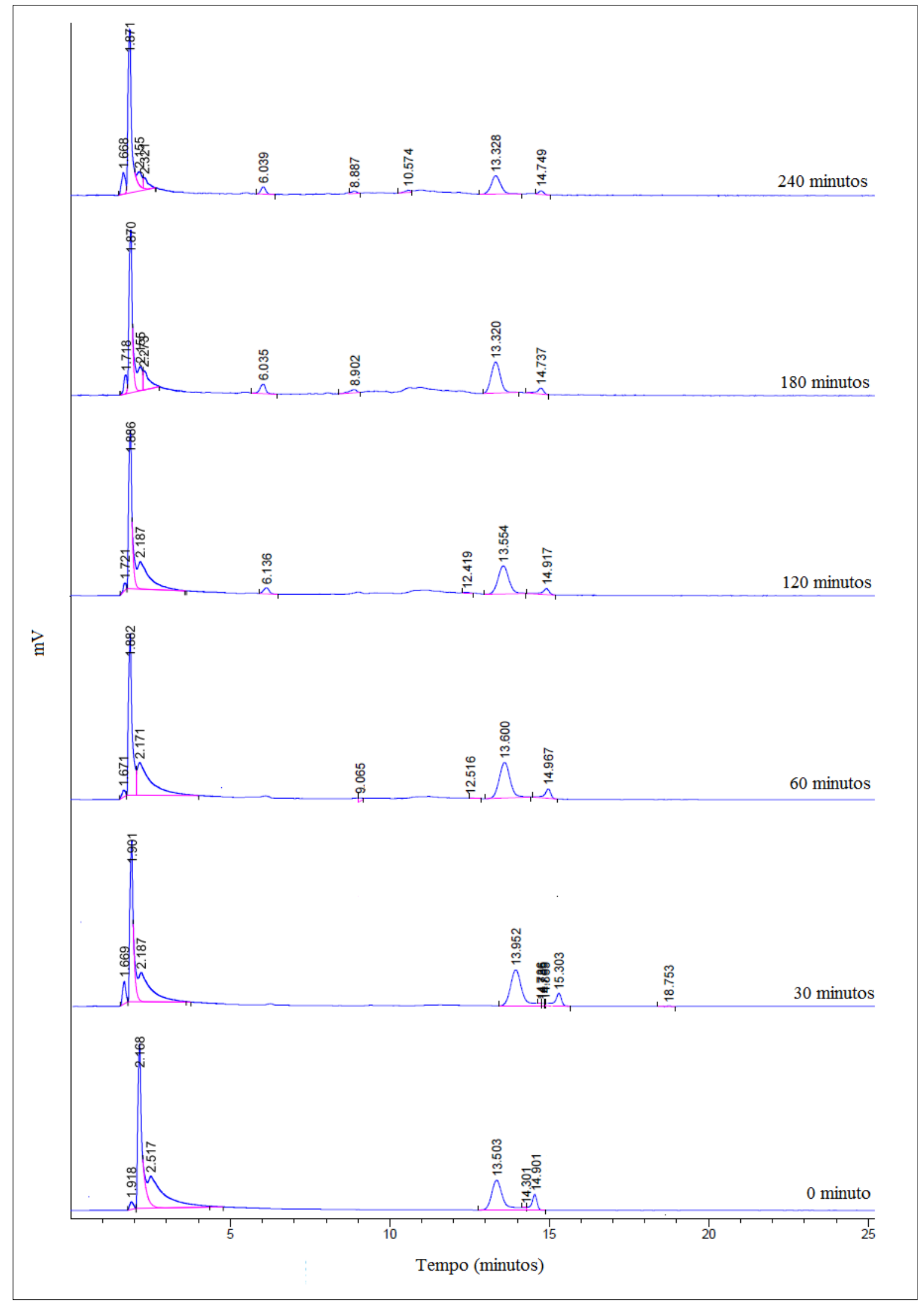

FIGURA 21: Perfil cromatográfico em CLAE da formação dos diasteroisômeros do PSMA-HBED-CC radiomarcado com ${ }^{68} \mathrm{Ga}$ à $25^{\circ} \mathrm{C}$ e demais parâmetros conforme condição de marcação padrão. A preparação foi avaliada até 240 minutos após a marcação. 


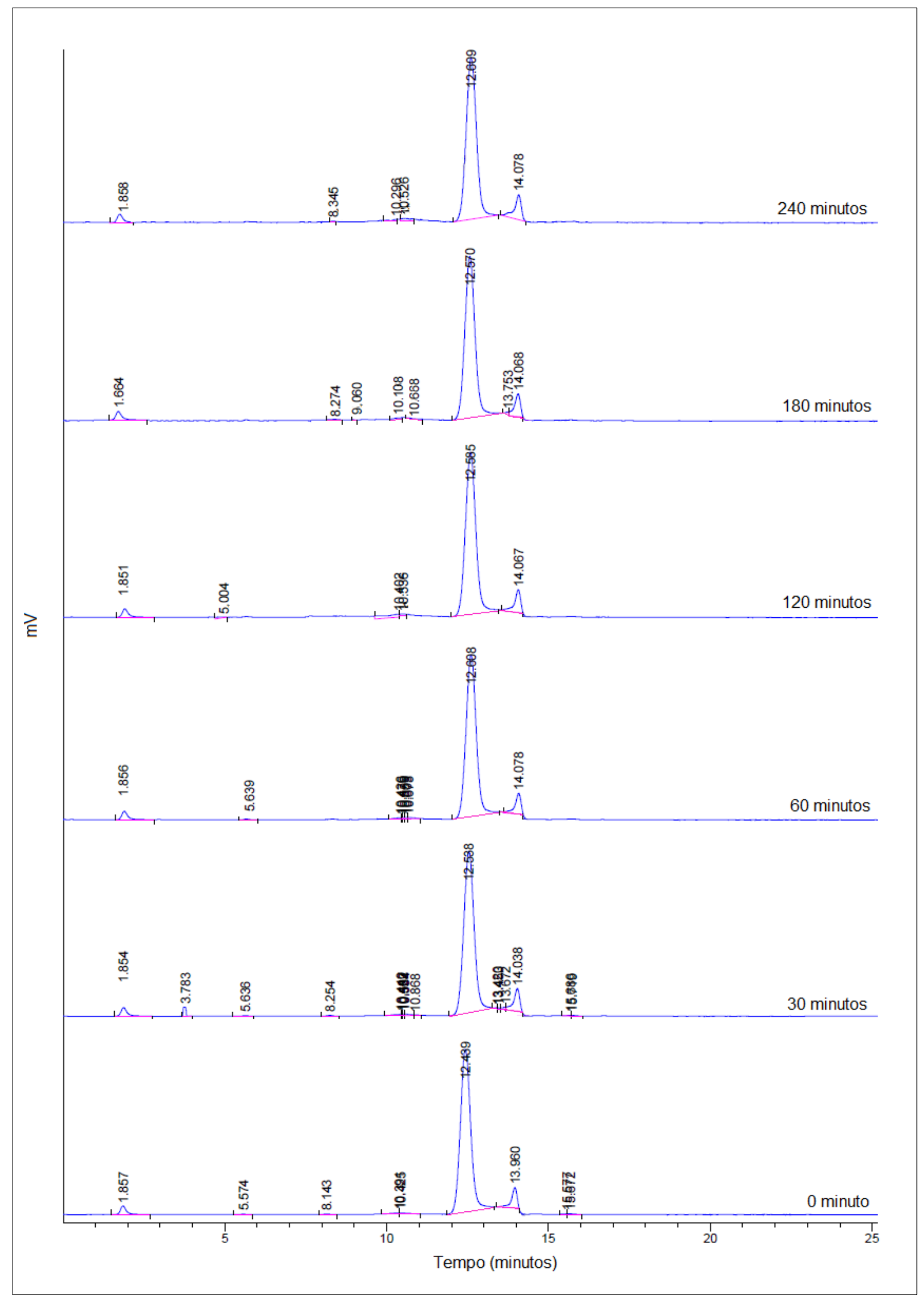

FIGURA 22: Perfil cromatográfico em CLAE da formação dos diasteroisômeros do PSMA-HBED-CC radiomarcado com ${ }^{68} \mathrm{Ga}$ à $85^{\circ} \mathrm{C}$ e demais parâmetros conforme condição de marcação padrão. A preparação foi avaliada até 240 minutos após a marcação. 


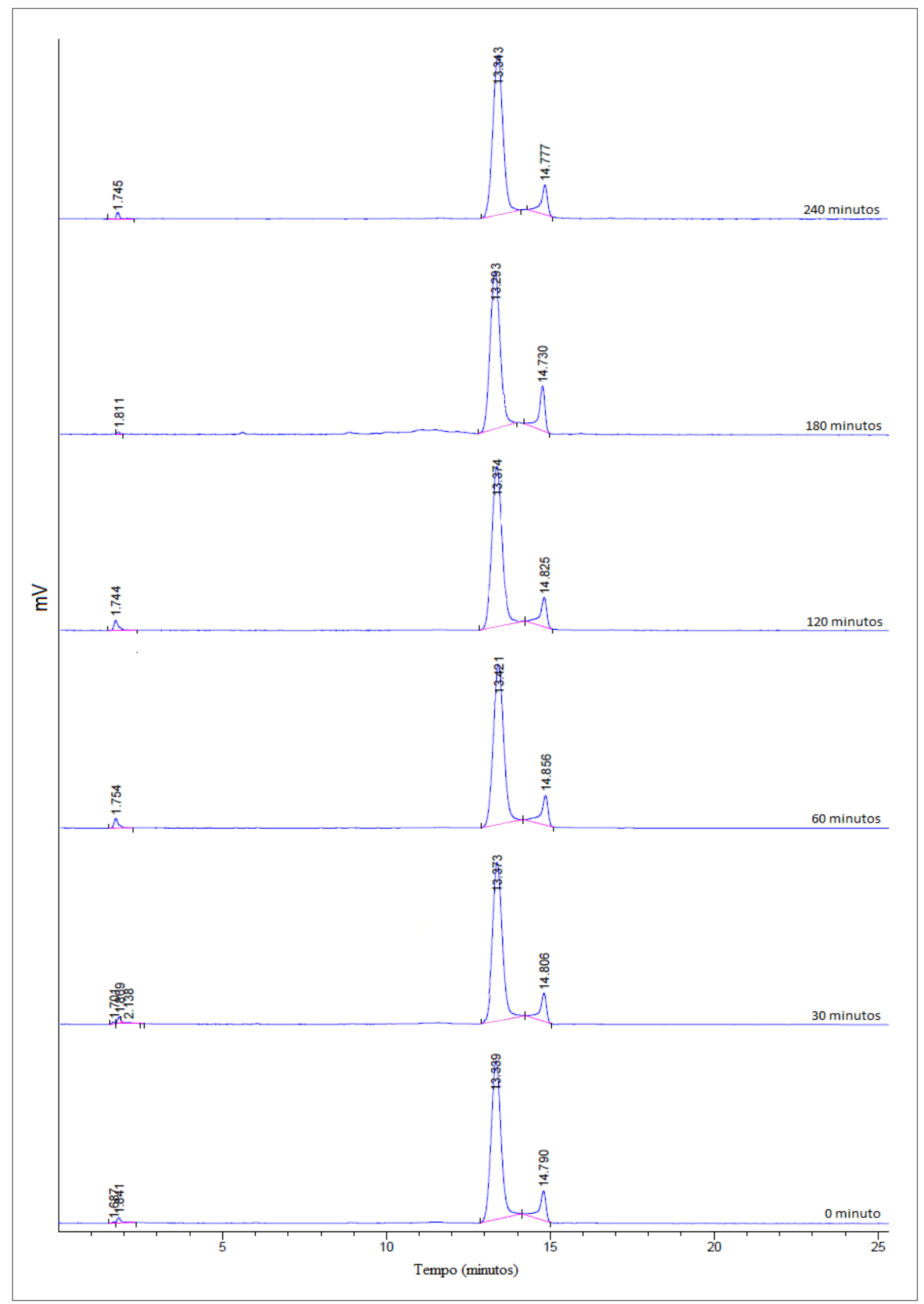

FIGURA 23: Perfil cromatográfico em CLAE da formação dos diasteroisômeros do PSMA-HBED-CC radiomarcado com ${ }^{68} \mathrm{Ga}$ à $95^{\circ} \mathrm{C}$ e demais parâmetros conforme condição de marcação padrão. A preparação foi avaliada até 240 minutos após a marcação. 
No decorrer do período de estabilidade estudado (240 minutos), observou-se na marcação à $25^{\circ} \mathrm{C}$ que a espécie termodinamicamente menos estável (pico 2, maior $R_{f}$ ) teve sua conformação alterada para a termodinamicamente mais estável (pico 1 , menor $\mathrm{R}_{\mathrm{f}}$ ), quando comparada a porcentagem que cada espécie representa no total da pureza radioquímica obtida no tempo 0 e após 240 minutos para os dois principais picos (TAB. 11). A alteração da conformação na radiomarcação à $25^{\circ} \mathrm{C}$, também foi observada nos estudos apresentados por Eder e col. (2014), porém em menor proporção, pois o pico 2 representa cerca de $20 \%$ no primeiro tempo avaliado, enquanto na literatura atinge aproximadamente 50\%. Todavia, esta alteração na formação dos diasteroisômeros ocorre rapidamente somente em $\mathrm{pH} 4$, pois quando em $\mathrm{pH} 7$ esta interconversão pode demorar dias segundo Eder e col. (2014) e Schuhmacher e col. (1995).

A porcentagem do pico $2\left(>R_{f}\right)$ para marcações realizadas à $85^{\circ} \mathrm{C}$ ou $95^{\circ} \mathrm{C}$ não se alterou significativamente no intervalo de tempo observado, além de ser significativamente $(p<0,05)$ menor, para o tempo $t=0$, que a porcentagem obtida na marcação à $25^{\circ} \mathrm{C}$.

Conforme comentado anteriormente, conclusões teóricas sugerem não haver influência na interação do radiofármco e o sítio de ligação do PSMA mesmo na presença das diferentes formas moleculares do PSMA-HBED-CC conjugado ao ${ }^{68} \mathrm{Ga}$, não apresentando redução da qualidade de imagens por PET. No entanto, por se tratar de um medicamento, é imprescindível assegurar uma formulação o mais estável possível.

Desta forma, nenhuma alteração significativa de conversão entre as espécies foi observada na marcação à $95^{\circ} \mathrm{C}$, sendo a relação do decréscimo na formação do diasteroisômero menos estável de 0,72\%. 
TABELA 11: Taxa de variação entre as diferentes espécies de diasterorisomeros observados nos perfis em CLAE, durante período de estabilidade de 240 minutos. Valores obtidos pelo cálculo da área do pico encontrado nos perfis cromatográficos realizados por CLAE. Condições de radiomarcação: as marcações foram incubadas em diferentes temperaturas $\left(25,85\right.$ e $\left.95^{\circ} \mathrm{C}\right)$ utilizando a condição de marcação padrão.

\begin{tabular}{|c|c|c|c|c|c|c|}
\hline & \multicolumn{6}{|c|}{ Temperatura de marcação } \\
\hline & \multicolumn{2}{|c|}{$25^{\circ} \mathrm{C}$} & \multicolumn{2}{|c|}{$85^{\circ} \mathrm{C}$} & \multicolumn{2}{|c|}{$95^{\circ} \mathrm{C}$} \\
\hline & $\begin{array}{c}\text { Pico } 1 \\
\left.\text { (menor } \mathrm{R}_{\mathrm{f}}\right)\end{array}$ & $\begin{array}{c}\text { Pico } 2 \\
\left.\text { (maior } \mathrm{R}_{\mathrm{f}}\right)\end{array}$ & $\begin{array}{c}\text { Pico } 1 \\
\left.\text { (menor } \mathrm{R}_{\mathrm{f}}\right)\end{array}$ & $\begin{array}{c}\text { Pico 2 } \\
\left(\text { maior } R_{f}\right)\end{array}$ & $\begin{array}{c}\text { Pico } 1 \\
\left(\text { menor } \mathrm{R}_{\mathrm{f}}\right)\end{array}$ & $\begin{array}{c}\text { Pico } 2 \\
\left(\text { maior } \mathrm{R}_{\mathrm{f}}\right)\end{array}$ \\
\hline T-0 minuto & $78,15 \%$ & $21,84 \%$ & $94,52 \%$ & $5,47 \%$ & $88,86 \%$ & $11,13 \%$ \\
\hline T-240 minutos & $89,74 \%$ & $10,25 \%$ & $90,72 \%$ & $9,27 \%$ & $89,58 \%$ & $10,41 \%$ \\
\hline $\begin{array}{l}\text { Taxa de variação } \\
\text { entre as espécies }\end{array}$ & \multicolumn{2}{|c|}{$11,59 \%$} & \multicolumn{2}{|c|}{$3,8 \%$} & \multicolumn{2}{|c|}{$0,72 \%$} \\
\hline
\end{tabular}

A temperatura de marcação ideal foi determinada como $95^{\circ} \mathrm{C}$ por 7 minutos, uma vez que a pureza radioquímica foi superior, com baixo desvio padrão $(97,07 \pm 0,01 ; n=4)$ e maior estabilidade molecular do radiofármaco.

\subsubsection{Determinação do volume do tampão de radiomarcação}

O ${ }^{68} \mathrm{Ga}$ é um radionuclídeo de meia vida curta, o que faz com ele seja frequentemente utilizado em módulos de síntese automatizado, sendo necessário garantir a manutenção do $\mathrm{pH}$ pelo tampão de reação após a introdução de solução ácida de ${ }^{68} \mathrm{GaCl}_{3}$ no frasco de reação.

Baseando-se nos estudos encontrados em literatura e considerando-se o alto rendimento radioquímico obtido para marcações realizadas com $1 \mathrm{~mL}$ do tampão de escolha, decidiu-se analizar a influência do volume final de reação, para posterior utilização em módulo automatizado ou ainda, para avaliar uma possível produção de kit liquído para radiomarcação em bancada.

$\mathrm{Na}$ marcação em bancada utilizou-se equipamento thermomixer para aquecimento da radiomarcação, na qual se faz necessário o uso de tubos cônicos (tipo eppendorfs, $1,5-2 \mathrm{~mL}$ ). Desta forma, para o volume final de $1 \mathrm{~mL}$, foi realizado procedimento para evaporar a solução de ${ }^{68} \mathrm{GaCl}_{3}$ em $\mathrm{HCl} 0,02 \mathrm{M}$ em acetona ultrapura, reduzindo o volume para $10 \mu \mathrm{L}$, a fim de manter o $\mathrm{pH}$ da reação. 
O volume de $1 \mathrm{~mL}$ de tampão acetato de sódio $0,2 \mathrm{M}$ não foi capaz de manter o pH inicial da reação, reduzindo para 3,5. Este problema não foi observado com volume de $2 \mathrm{~mL}$. A pureza radioquímica foi significativamente maior $(p<0,001)$ quando a reação ocorreu com $2 \mathrm{~mL}$ e a estabilidade de ambos os volumes foi considerada satisfatória ( $p>0,05)$ (FIG. 24). Assim, o volume de $2 \mathrm{~mL}$ foi escolhido, pois conferiu resultados condizentes com a necessidade (PR $\geq 95 \%)$.

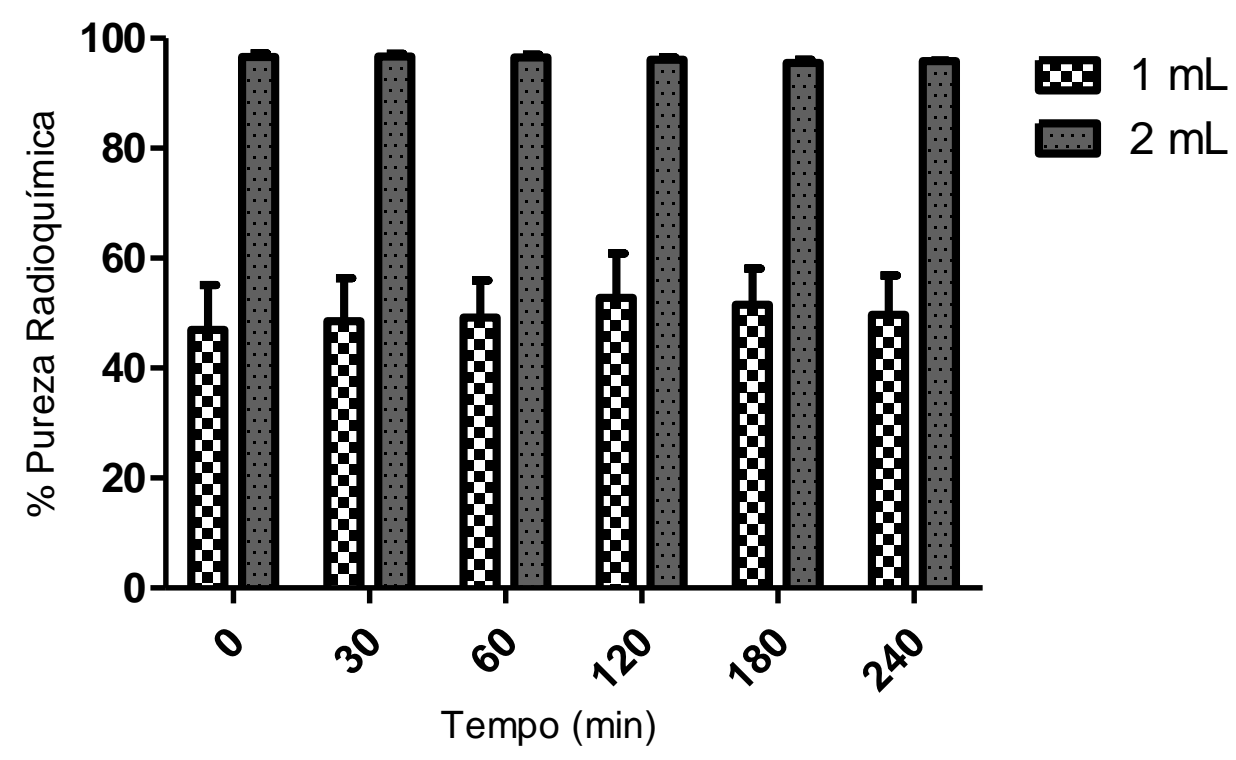

FIGURA 24: Determinação da pureza radioquímica da marcação do PSMA-HBED-CC com gálio-68 em diferentes volumes de marcação. Condições de radiomarcação: radiomarcou-se o peptídeo PSMA-HBED-CC com volume final de $1 \mathrm{~mL}$ ou $2 \mathrm{~mL}$, utilizando a condição de marcação padrão. Sistema cromatográfico: metanol:acetato de amônio $1 \mathrm{M}(1: 1 \mathrm{v} / \mathrm{v}) \mathrm{em}$ TLC-SG ( $n \geq 3)$.

Neste caso, poderia-se supor que a PR elevada observada para o volume final de $2 \mathrm{~mL}$, poderia estar relacionado ao $\mathrm{pH}$ de marcação, uma vez que utilizando-se $10 \mu \mathrm{L}$ em volume final de $1 \mathrm{~mL}$ o $\mathrm{pH}$ da reação foi alterado para 3,5.

Entretanto, conforme estudo de variação do pH de reação irá demonstrar (sessão 7.2.8), a variação de pH 4 para 3,5 não promove alteração significativa na PR da marcação. Desta forma, a diferença verificada na PR nas marcações com volume final de 1,0 e $2,0 \mathrm{~mL}$ pode ser relacionada ao volume de marcação, com melhores resultados observados para $2,0 \mathrm{~mL}$. 


\subsubsection{Avaliação dos tampões de radiomarcação (acetato de sódio e HEPES) em reações com aquecimento}

Com base em trabalhos publicados (Banerjee et al, 2010; Eder et al, 2014; Ferreira et al, 2010; Schafer et al, 2012; Pujatti, 2012), dois tampões foram testados no processo de radiomarcação do PSMA-HBED-CC, com temperatura de $95^{\circ} \mathrm{C}$ a fim de obter melhor pureza radioquímica e estabilidade do radiofármaco. Os resultados obtidos sugerem novamente maior eficiência do tampão acetato de sódio $0,2 \mathrm{M} \mathrm{pH} 4$. Os resultados podem ser observados na TAB. 12.

TABELA 12: Análise da pureza radioquímica em tampões e tempos de reação diferentes. Condições de radiomarcação: Tp. Acetato de sódio - utilizou-se a condição de marcação padrão; Tp. HEPES - $5 \mu \mathrm{g}$ do peptídeo em $100 \mu \mathrm{L}$ de tampão HEPES 0,1M pH 7,5 e $10 \mu \mathrm{L}$ de tampão HEPES 2,1M pH 7,5, $740 \mathrm{MBq}(20 \mathrm{mCi})$ de ${ }^{68} \mathrm{GaCl}_{3}$ diluído em $10 \mu \mathrm{L}$ de $\mathrm{HCl}$ 0,02M em acetona ultrapura, à $95^{\circ} \mathrm{C}$, sem agitação, o $\mathrm{pH}$ foi ajustado para $4,2 \mathrm{com} \mathrm{NaOH}$. Sistema cromatográfico: metanol:acetato de amônio $1 \mathrm{M}(1: 1 \mathrm{v} / \mathrm{v})$ em TLC-SG ( $\mathrm{n} \geq 3)$.

\begin{tabular}{ccc}
\hline & $\begin{array}{c}\text { Tampão Acetato de Sódio } \\
\mathbf{0 , 2} \mathbf{M ~ p H ~ 4} \\
\text { (\% PR) }\end{array}$ & $\begin{array}{c}\text { Tampão HEPES } \\
\mathbf{0 , 1} \mathbf{~ M ~ p H ~ 4 , 2} \\
\text { (\% PR) }\end{array}$ \\
\hline $\begin{array}{c}\text { Tempo de Reação } \\
\text { (minutos) }\end{array}$ & & \\
\hline 2 & $84,33 \pm 0,03$ & $95,31 \pm 0,03$ \\
5 & $95,32 \pm 0,00$ & $95,54 \pm 0,04$ \\
7 & $97,07 \pm 0,01$ & $94,34 \pm 0,04$ \\
10 & $96,12 \pm 0,00$ & $94,22 \pm 0,05$ \\
\hline
\end{tabular}

Os resultados da análise da pureza radioquímica após 2 minutos de marcação apresentaram diferença significativa $(p<0,01)$ entre os dois tampões quando a marcação foi realizada a $95^{\circ} \mathrm{C}$. Conforme esperado (Eder et al, 2012; Eder et al, 2014; Schafer et al, 2012), a radiomarcação com tampão HEPES apresentou pureza radioquímica superior a $95 \%$ a partir do primeiro intervalo de tempo estudado, enquanto para o tampão acetato de sódio um tempo maior ou igual que 5 minutos foi necessário para obter pureza radioquímica semelhante.

As marcações em tampão acetato de sódio e tampão HEPES tiveram sua estabilidade avaliada para o tempo de marcação de 7 minutos, demonstrando leve queda da 
pureza radioquímica após 4 horas (1,05\% e 1\%, respectivamente). A radiomarcação em tampão acetato de sódio manteve-se com PR > 95\% em todo o período estudado (FIG. 25).

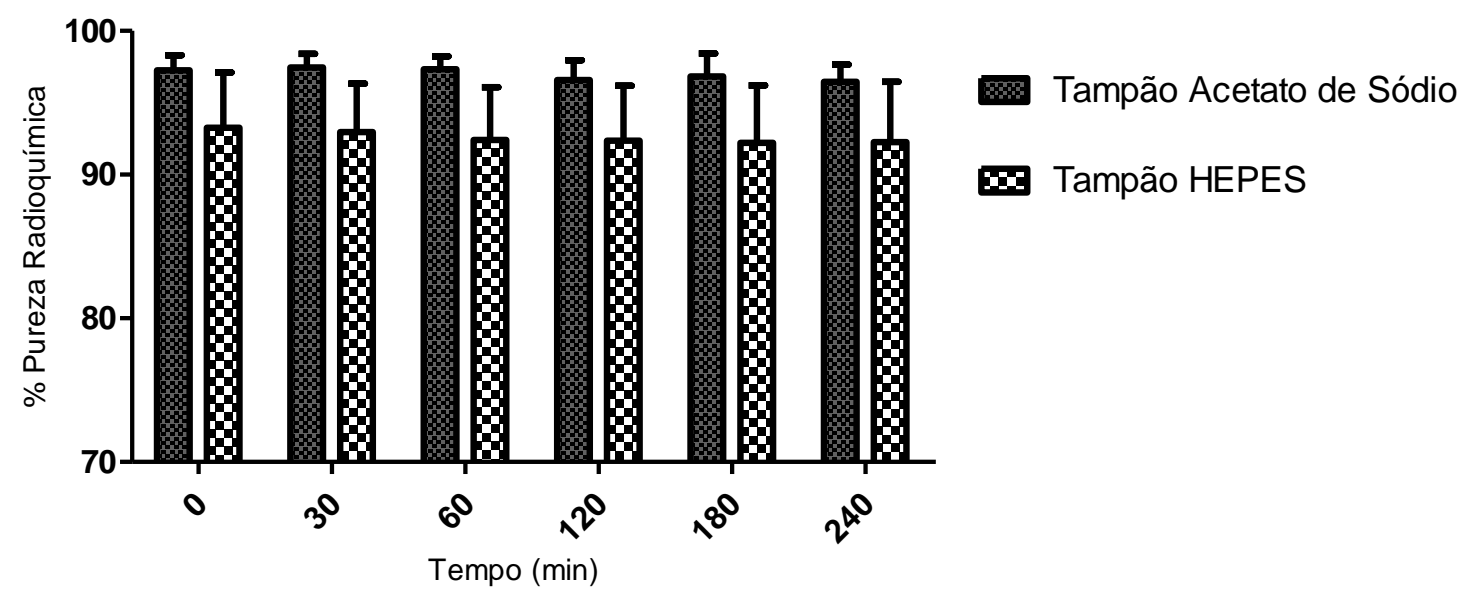

FIGURA 25: Análise da estabilidade do PSMA-HBED-CC- ${ }^{68} \mathrm{Ga}$ radiomarcado em diferentes tampões. Condições de radiomarcação: Tp. Acetato de sódio - utilizou-se a condição de marcação padrão; Tp. HEPES - $5 \mu \mathrm{g}$ do peptídeo em $100 \mu \mathrm{L}$ de tampão HEPES 0,1M pH 7,5 e $10 \mu \mathrm{L}$ de tampão HEPES 2,1M pH 7,5, $740 \mathrm{MBq}(20 \mathrm{mCi})$ de ${ }^{68} \mathrm{GaCl}_{3}$ diluído em $10 \mu \mathrm{L}$ de

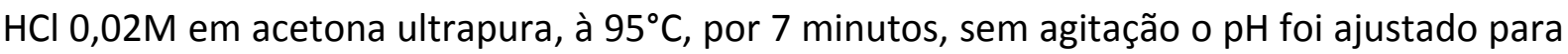
4,2 com NaOH. Sistema cromatográfico: metanol:acetato de amônio $1 \mathrm{M}(1: 1 \mathrm{v} / \mathrm{v})$ em TLC-SG $(n \geq 3)$.

Embora não tenha havido diferença significativa entre os tampões $(p>0,05), o$ tampão acetato de sódio foi escolhido para os demais procedimentos por apresentar maior pureza radioquímica no intervalo de 7 minutos de marcação, menor desvio padrão e apresentar menos impurezas para administração intravenosa em pacientes, quando comparado ao tampão HEPES (Eder et al, 2014; Farmacopeia Europeia, 2010; Velikyan et al, 2014).

\subsubsection{Estudo da variação da atividade específica}

A atividade específica dos radiofármacos corresponde à radioatividade do nuclídeo por unidade de massa ou mol (GBq/ $\mu \mathrm{mol}$ ) (Farmacopeia Brasileira, 2010). Do ponto de vista da aplicação clínica, esse parâmetro é importante no desenvolvimento de novos fármacos, uma vez que há necessidade de encontrar a atividade específica ideal, pois 
quando muito alta, pode causar radiólise e assim a desnaturação do peptídeo e quando baixa, as moléculas não marcadas competem com as marcadas pelos mesmos receptores in vivo, podendo ocasionar diminuição da captação nos sítios alvo e ainda quadros de toxicidade em pacientes (Saha, 2003).

Eder e colaboradores (2012) demonstraram que o PSMA-HBED-CC se mantém estável mesmo com altíssimas atividades específicas (1000 GBq/ $\mu \mathrm{mol})$. No entanto, estudos recentes tem utilizado atividade específica mais baixa para ensaios clínicos $(80,5 \mathrm{GBq} / \mu \mathrm{mol})$ (Afshar et al, 2015), desta forma foram analisadas atividades em torno dos valores utilizados nos estudos clínicos.

Ao analisar os resultados na TAB. 13 e FIG. 26, observa-se uma relação entre o aumento da atividade específica e a diminuição da pureza radioquímica.

TABELA 13: Análise da influência da atividade específica sobre a pureza radioquímica do PSMA-HBED-CC $-{ }^{68} \mathrm{Ga}$. Condições de radiomarcação: utilizando a condição padrão de marcação, adicionou-se diferentes atividades de ${ }^{68} \mathrm{GaCl}_{3}$ ao frasco de reação $(0,37-1,11 \mathrm{GBq}$ - 10-30 mCi). Sistema cromatográfico: metanol:acetato de amônio 1M (1:1 v/v) e TLC-SG.

\begin{tabular}{|c|c|c|c|c|c|}
\hline $\begin{array}{c}\text { Massa do } \\
\text { PSMA-HBED-CC- } \\
{ }^{68} \mathrm{Ga} \\
(\mu \mathrm{g})\end{array}$ & $\begin{array}{l}\text { Atividade de } \\
{ }^{68} \mathrm{GaCl}_{3} \\
\mathrm{GBq}(\mathrm{mCi})\end{array}$ & $\begin{array}{c}\text { Atividade } \\
\text { Específica do } \\
\text { PSMA-HBED-CC- } \\
{ }^{68} \mathrm{Ga} \\
\text { (GBq/ } \mu \mathrm{mol})\end{array}$ & $\begin{array}{l}\text { Pureza } \\
\text { Radioquímica do } \\
\text { PSMA-HBED-CC- } \\
{ }^{68} \mathrm{Ga} \\
\text { (\%) (CCD) }\end{array}$ & $\begin{array}{c}\text { Pureza } \\
\text { Radioquímica do } \\
\text { PSMA-HBED-CC- } \\
{ }^{68} \mathrm{Ga} \\
\text { (\%) (CLAE) }\end{array}$ & (n) \\
\hline $5 \mu g$ & $0,37(10)$ & 70,2 & $98,66 \pm 0,01$ & 100 & 4 \\
\hline $5 \mu g$ & $0,55(15)$ & 104,0 & $96,29 \pm 0,00$ & 98,21 & 3 \\
\hline $5 \mu g$ & $0,74(20)$ & 140,0 & $97,07 \pm 0,01$ & 98,27 & 4 \\
\hline $5 \mu \mathrm{g}$ & $1,11(30)$ & 210,0 & $84,29 \pm 0,06$ & 85,65 & 3 \\
\hline
\end{tabular}




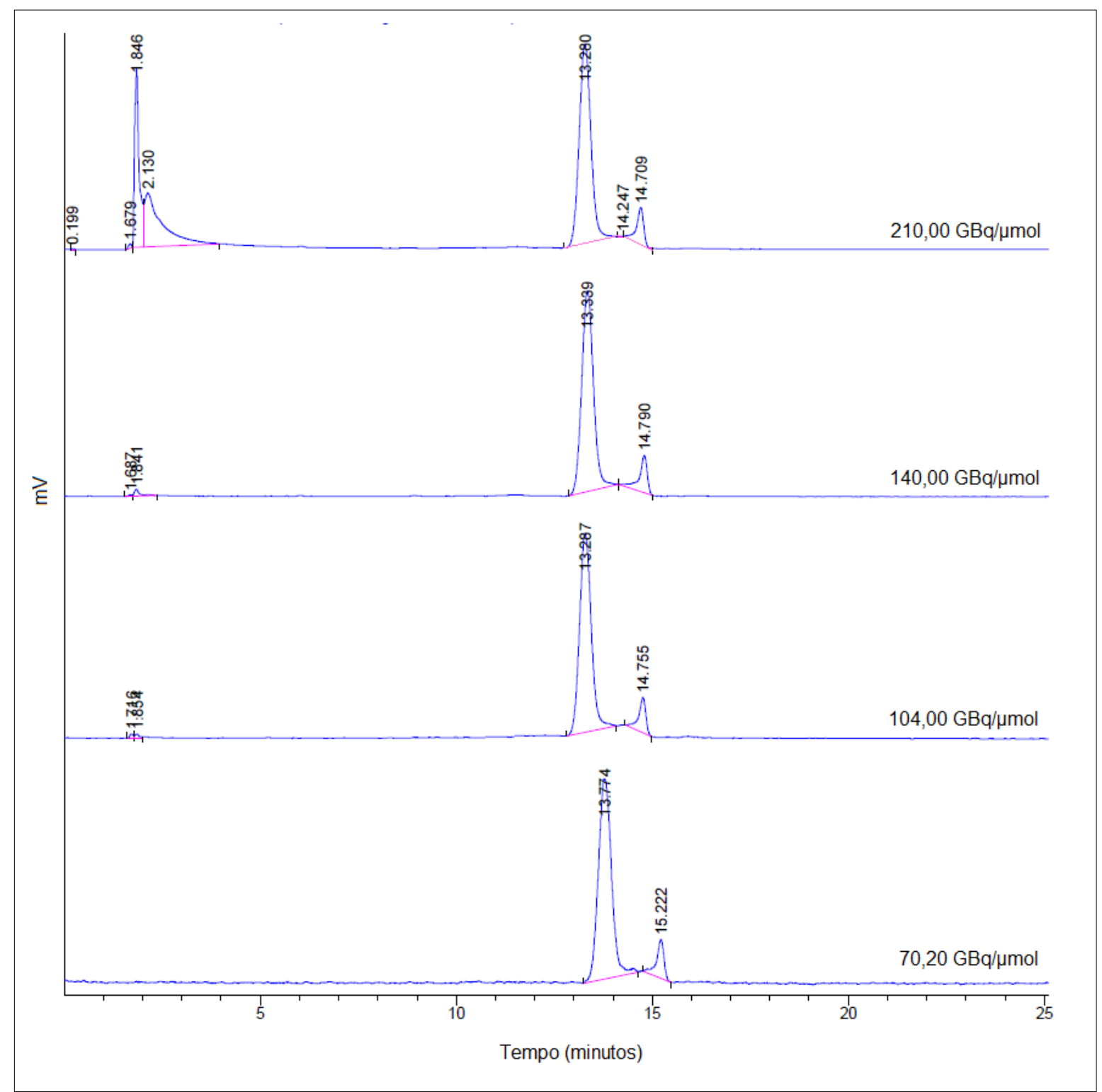

FIGURA 26: Perfis cromatográficos em CLAE do PSMA-HBED-CC $-{ }^{68} \mathrm{Ga}$ em diferentes atividades específicas. Condições de radiomarcação: utilizando a condição padrão de marcação, adicionou-se diferentes atividades de ${ }^{68} \mathrm{GaCl}_{3}$ ao frasco de reação $(0,37-1,11 \mathrm{GBq}$ $-10-30 \mathrm{mCi})$.

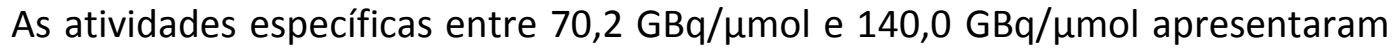
alta pureza radioquímica (> 95\%) sem necessidade de purificação, não apresentando diferenças significativas $(p>0,05)$ e se mantendo estáveis por todo o período analisado (240 minutos) (FIG. 27). 


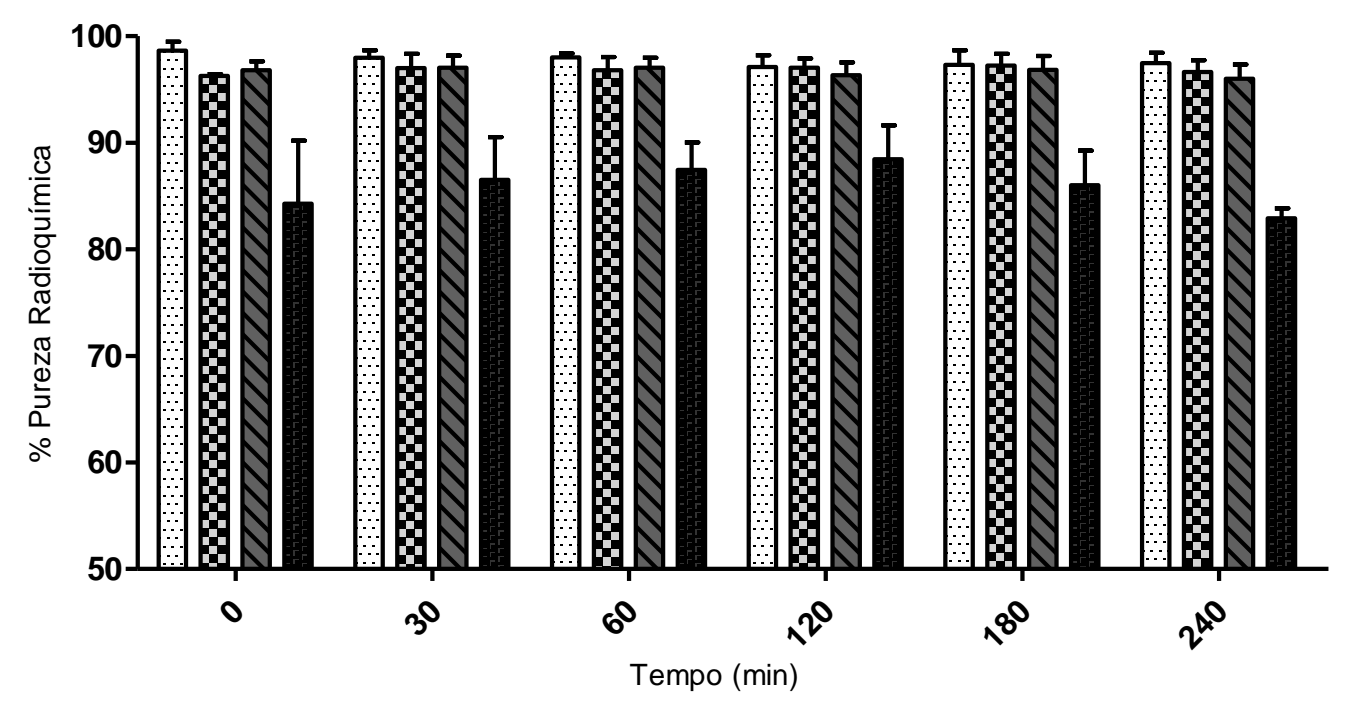

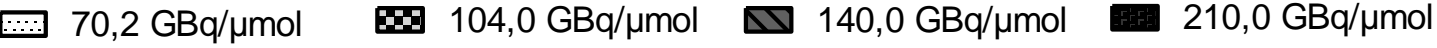

FIGURA 27: Análise da influência da atividade específica na pureza radioquímica e estabilidade do PSMA-HBED-CC- ${ }^{68}$ Ga. Condições de marcação: Condições de radiomarcação: utilizando a condição padrão de marcação, adicionou-se diferentes atividades de ${ }^{68} \mathrm{GaCl}_{3}$ ao frasco de reação $(0,37-1,11 \mathrm{GBq}-10-30 \mathrm{mCi})$. Sistema cromatográfico: metanol:acetato de amônio $1 \mathrm{M}(1: 1 \mathrm{v} / \mathrm{v})$ e TLC-SG.

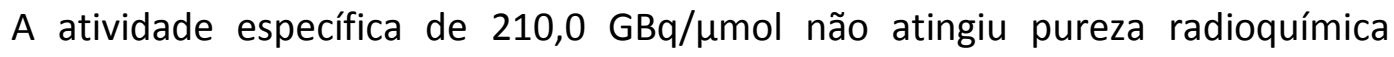
necessária ( $\geq 95 \%)$. A partir do intervalo de uma hora, nota-se nos perfis cromatográficos da FIG. 28 o sugimento de diversos picos com $R_{f}$ menores, provavelmente devido à quebra do PSMA-HBED-CC- ${ }^{68}$ Ga por radiólise. 


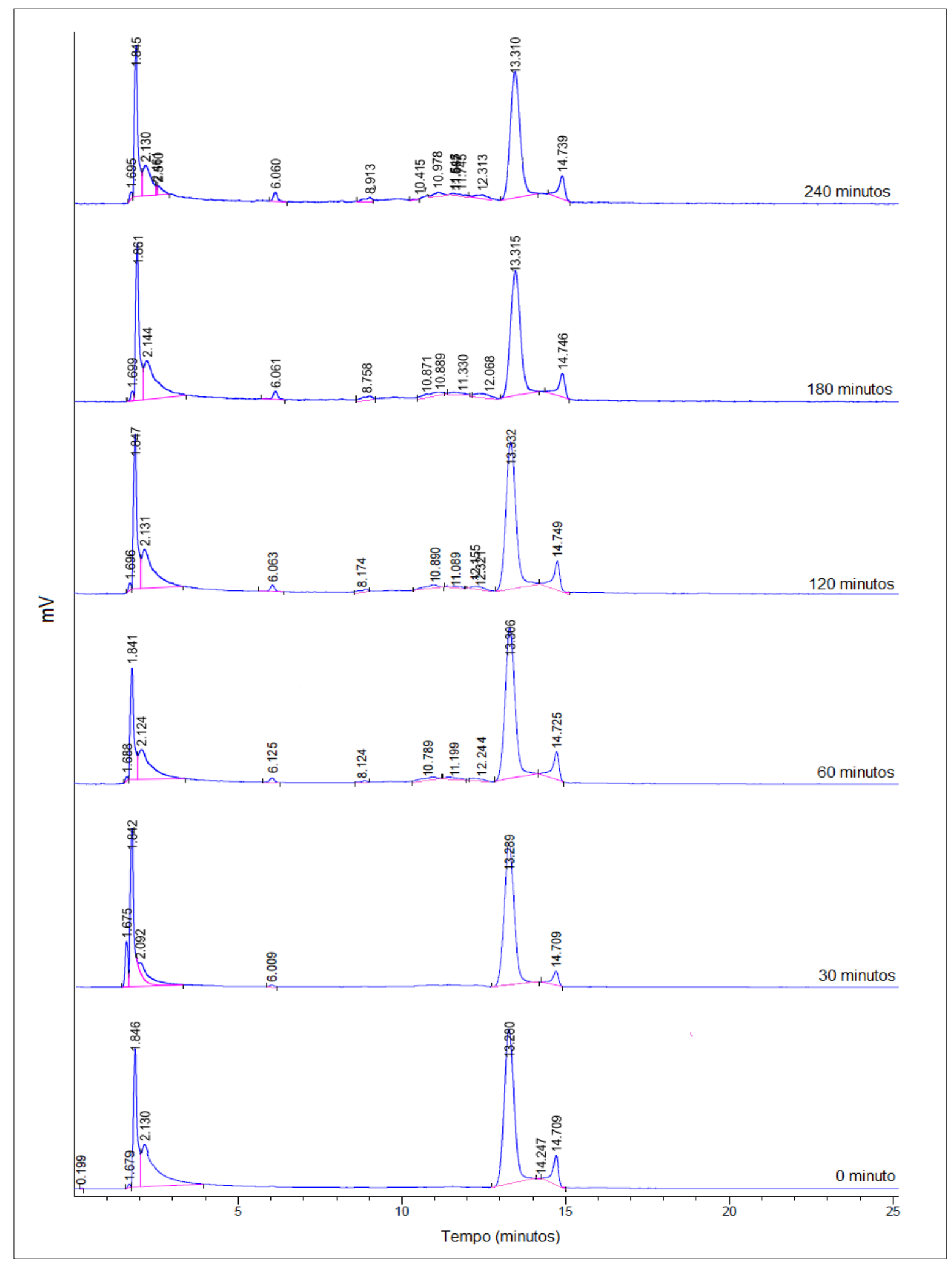

FIGURA 28: Perfil cromatográfico em CLAE mostrando a formação dos produtos de degradação do PSMA-HBED-CC ${ }^{68} \mathrm{Ga}$ com atividade específica de 210,0 GBq/ $\mathrm{mmol}$, após decorrido 60 minutos da radiomarcação. Condições de marcação: Condições de radiomarcação: utilizando a condição padrão de marcação, adicionou-se 1,11 GBq (30 mCi) de ${ }^{68} \mathrm{GaCl}_{3}$. 
O peptídeo marcado com atividade específica superior $(140,0 \mathrm{GBq} / \mu \mathrm{mol})$ à utilizada em ensaios clínicos já publicados apresentou estabilidade por até 4 horas, viabilizando sua utilização.

\subsubsection{Influência do pH na radiomarcação}

Os resultados obtidos no estudo da variação do pH de marcação estão representados na TAB. 14 e FIG. 29.

TABELA 14: Análise da influência do pH na pureza radioquímica do PSMA-HBED-CC- ${ }^{68} \mathrm{Ga}$. Condições de radiomarcação: utilizando a condição padrão de marcação com variação nos $\mathrm{pH}\left(3,5,4,4,5\right.$ e 5) e com $550 \mathrm{MBq}(15 \mathrm{mCi})$ de ${ }^{68} \mathrm{GaCl}_{3}$. Sistema cromatográfico: metanol:acetato de amônio 1M (1:1 v/v) e TLC-SG.

\begin{tabular}{|c|c|c|c|}
\hline pH da reação & $\begin{array}{c}\text { Pureza } \\
\text { Radioquímica do } \\
\text { PSMA-HBED-CC- }{ }^{68} \mathrm{Ga} \\
\text { (\%) (CCD) }\end{array}$ & $\begin{array}{c}\text { Pureza } \\
\text { Radioquímica do } \\
\text { PSMA-HBED-CC- }{ }^{68} \mathrm{Ga} \\
\text { (\%) (CLAE) }\end{array}$ & (n) \\
\hline 3,5 & $93,84 \pm 0,06$ & 97,55 & 3 \\
\hline 4 & $96,29 \pm 0,00$ & 98,21 & 3 \\
\hline 4,5 & $97,24 \pm 0,03$ & 98,24 & 3 \\
\hline 5 & $93,57 \pm 0,01$ & 97,4 & 3 \\
\hline
\end{tabular}

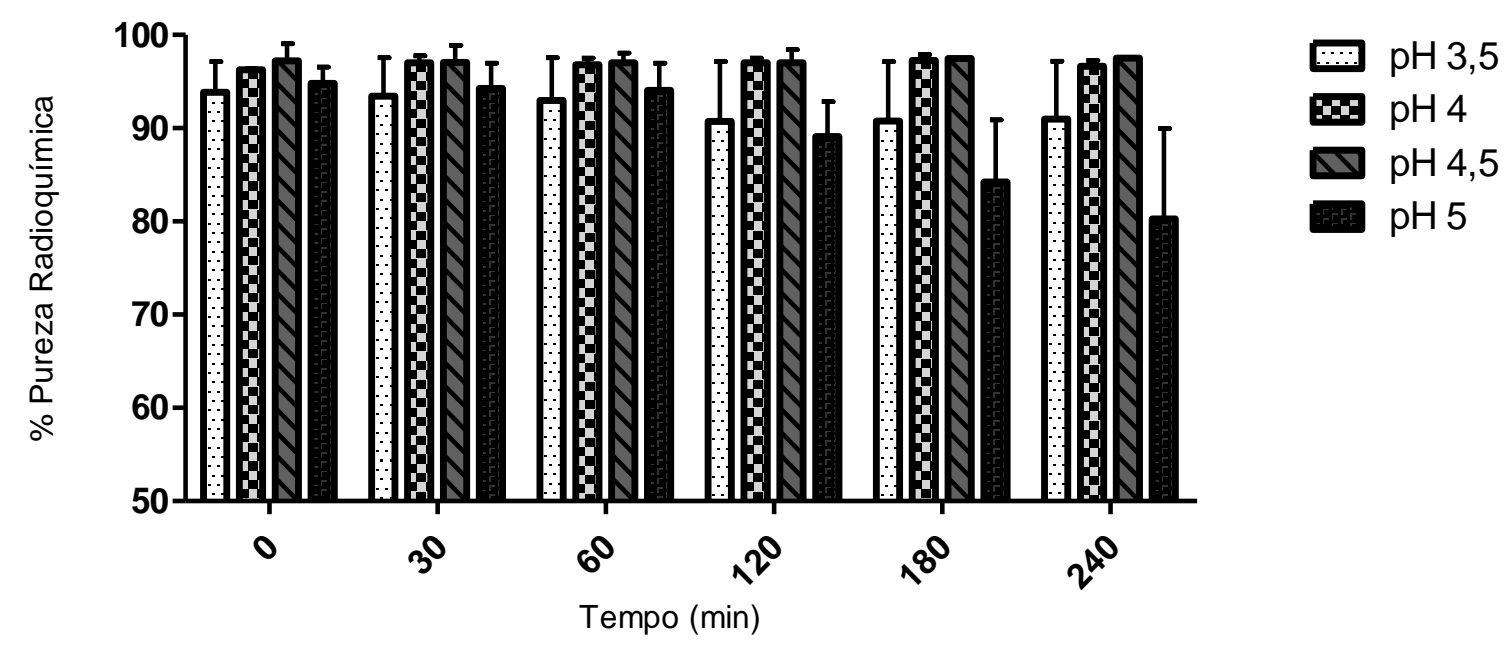

FIGURA 29: Avaliação da variação de pH na pureza radioquímica e estabilidade da marcação. Condições de radiomarcação: utilizando a condição padrão de marcação com variação nos $\mathrm{pH}\left(3,5,4,4,5\right.$ e 5) e com $550 \mathrm{MBq}(15 \mathrm{mCi})$ de ${ }^{68} \mathrm{GaCl}_{3}$. Sistema cromatográfico: metanol:acetato de amônio $1 \mathrm{M}(1: 1 \mathrm{v} / \mathrm{v})$ e TLC-SG. 
Conforme descrito anteriormente, o volume de $2 \mathrm{~mL}$ de tampão acetato de sódio $0,2 \mathrm{M}$ mostrou-se eficiente em cada caso de $\mathrm{pH}$ estudado, para manter $\mathrm{o} \mathrm{pH}$ da solução estável durante todo o período analisado. $\mathrm{O}$ pH da reação é visto como um fator crítico na formação dos diasteroisômeros e para se obter bons rendimentos de marcação (Eder et al, 2014; Schuhmacher et al, 1995).

A variação do $\mathrm{pH}$ não demonstrou influência significativa no $T_{0}(p>0,05)$, porém a pureza radioquímica ficou abaixo dos $95 \%$ para as marcações com pH 3,5 e 5. Desta forma, foram analisados os perfis cromatográficos em CLAE quanto à $P R$ e à formação dos diasteroisômeros (FIG. 30 e 31). 


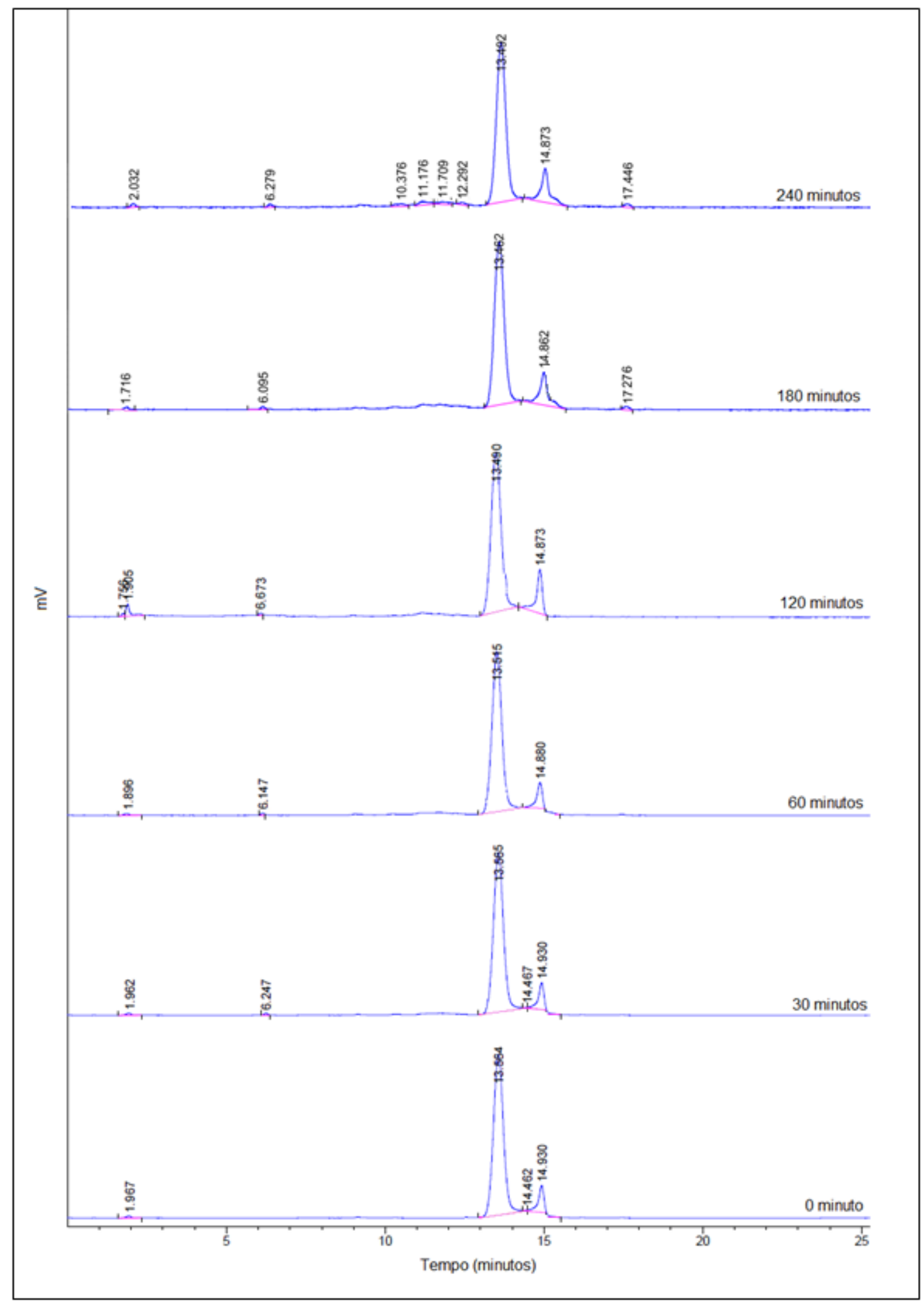

FIGURA 30: Perfil comatográfico de CLAE da formação dos diasteroisômeros do PSMA-HBED-CC- ${ }^{68}$ Ga para a marcação com pH 3,5. Condições de radiomarcação: utilizando a condição padrão de marcação com pH 3,5 e com $550 \mathrm{MBq}(15 \mathrm{mCi})$ de ${ }^{68} \mathrm{GaCl}_{3}$. 


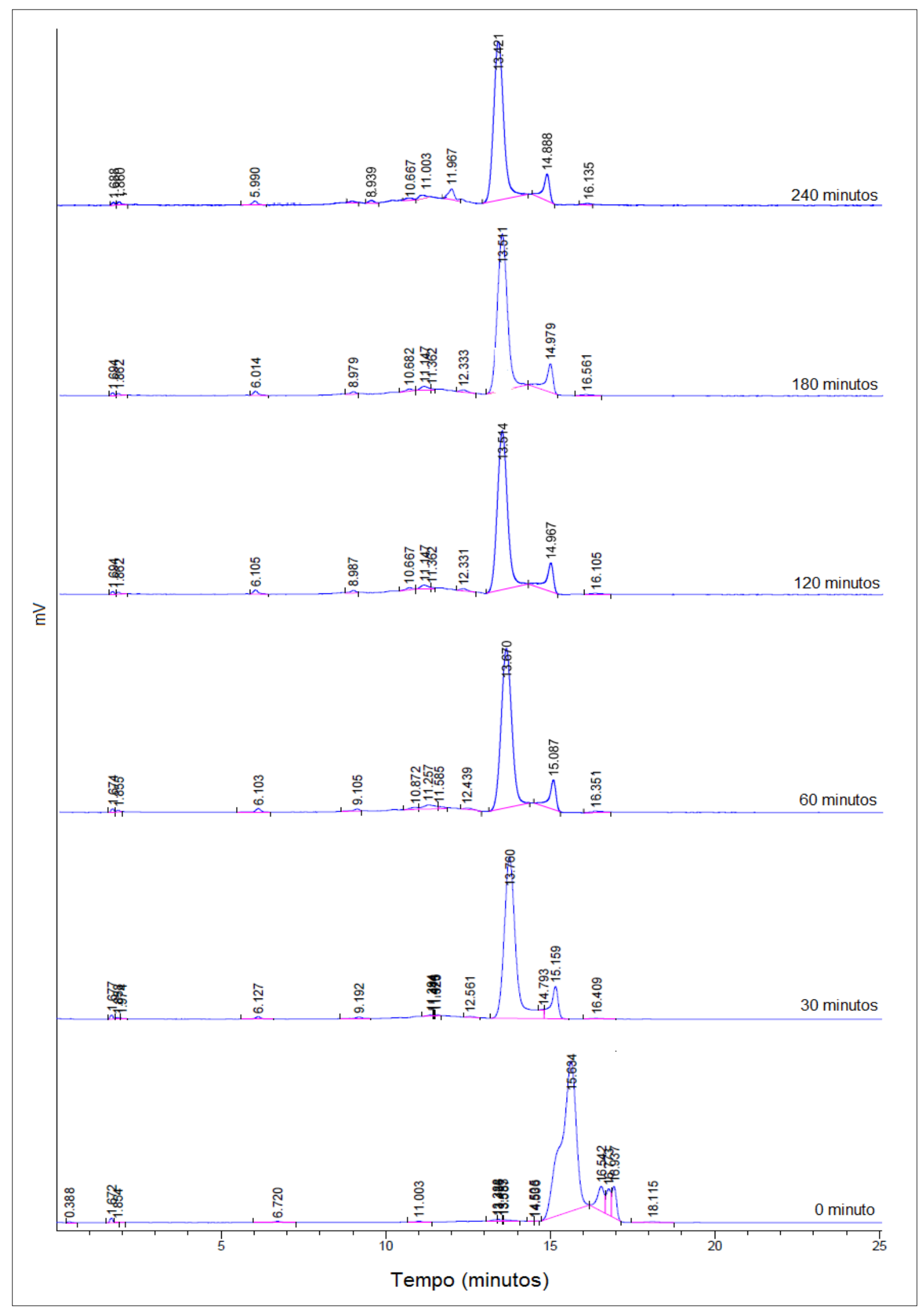

FIGURA 31: Perfil comatográfico de CLAE da formação dos diasteroisômeros do PSMA-HBED-CC ${ }^{68} \mathrm{Ga}$ para a marcação $\mathrm{com}$ pH 5. Condições de radiomarcação: utilizando a condição padrão de marcação com pH 5 e com $550 \mathrm{MBq}(15 \mathrm{mCi})$ de ${ }^{68} \mathrm{GaCl}_{3}$. 
A marcação com pH 3,5 não apresentou diferenças significativas na formação dos diasteroisômeros. Na marcação com pH 5 observa-se que no tempo zero (imediatamente após a marcação), o diasteroisômero termodinamicamente mais estável (RR) foi formado em pouquissíma quantidade, sendo o pico principal representado pelo diasteroisômero menos estavel, que nos tempos seguintes é convertido para a forma mais estável, além do cromatograma apresentar diversos picos co-eluindo.

Atualmente, ainda há poucos dados em literatura sobre a formação dos diasteroisômeros, no entanto sabe-se que na conjugação do PSMA-HBED-CC com ${ }^{68}$ Ga são formadas 3 espécies, das quais apenas duas foram previamente apresentada em perfis de CLAE (Eder et al, 2014). Acredita-se que o terceiro pico ( $R_{f}$ de aproximadamente 16) encontrado no cromatograma em CLAE para marcação com pH 5 em $\mathrm{T}=0$ represente a terceira espécie de diasteroisômero, até então não demonstrada na literatura. Posssivelmente, a identificação deste terceiro pico ocorreu devido às diferenças inerentes ao método cromatográfico empregado, como excercer menor pressão sobre a coluna e utilizar maior período de corrida, permitindo uma melhor separação dos constituintes da amostra.

As marcações com pH 4 e 4,5, conforme demonstrado nos perfis apresentados na sessão 7.2.4 (FIG. 23) e na sessão 7.3.1 (FIG. 33A), respectivamente, também não mostraram variações consideráveis na formação dos diasteroisômeros.

\subsection{ESTUDOS DE ESTABILIDADE}

\subsubsection{Análise da integridade do peptídeo após a marcação e estabilidade frente a condições de transporte}

A estabilidade de compostos radiomarcados deve ser mantida in vitro e in vivo, para que não ocorra degradação e assim distribuição irregular da radioatividade pelo organismo (Saha, 2003).

Radiofármacos podem sofrer radiólise durante o processo de marcação e armazenamento, devido as emissões radioativas que podem atingir a molécula radiomarcada e degradá-la. Desta forma, radiofármacos para PET, assim como os outros, necessitam que sua estabilidade seja garantida durante o período de armazenamento que 
inclui o transporte do radiofármaco do centro de produção para as clínicas de medicina nuclear (Saha, 2003).

Para avaliar a possível ação da radiólise e possíveis alterações decorrentes das condições de transporte, o PSMA-HBED-CC $-{ }^{68} \mathrm{Ga}$ teve sua estabilidade analisada frente ao armazenamento sob refrigeração $\left(2-8^{\circ} \mathrm{C}\right)$, em temperatura ambiente $\left(15-35^{\circ} \mathrm{C}\right)$ e na temperatura de $40^{\circ} \mathrm{C}$ (Brasil, 2012), conforme observado na FIG. 32.

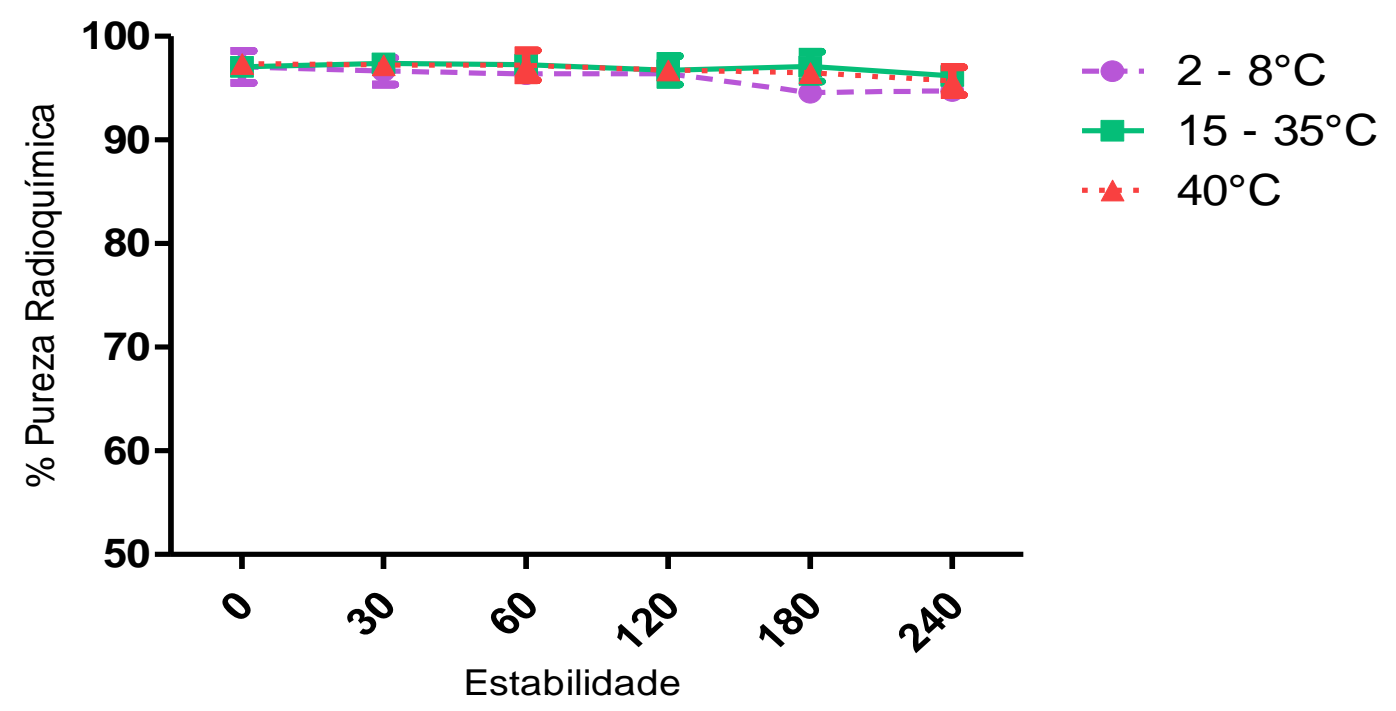

FIGURA 32: Estabilidade do produto radiomarcado armazenado sob refrigeração $\left(2-8^{\circ} \mathrm{C}\right)$, em temperatura ambiente $\left(15-35^{\circ} \mathrm{C}\right)$ e na temperatura de $40^{\circ} \mathrm{C}$. Condições de radiomarcação: a condição padrão de radiomarcação teve $\mathrm{o} \mathrm{pH}$ do tampão acetato de sódio $0,2 \mathrm{M}$ alterado para $\mathrm{pH} 4$,5. Sistema cromatográfico: metanol:acetato de amônio $1 \mathrm{M}(1: 1 \mathrm{v} / \mathrm{v})$ e TLC-SG.

A estabilidade do peptídeo radiomarcado não apresentou diferenças significativas $(p>0,05)$ quando o produto foi armazenado em diferentes condições. Considerando o decaimento da pureza radioquímica, a melhor estabilidade foi obtida no armazenamento em temperatura ambiente $\left(15-35^{\circ} \mathrm{C}\right)$ havendo um decréscimo de apenas $1,05 \%$ da PR ao final do período de 4 horas, enquanto este decréscimo no armazenamento sob refrigeração e à $40^{\circ} \mathrm{C}$ foram de $2,32 \%$ e $1,69 \%$, respectivamente. Os resultados obtidos sugerem não haver necessidade de utilização de agentes estabilizantes para preservação da estabilidade do peptídeo radiomarcado. Também sugere que o transporte do radiofármaco para os centros de medicina nuclear possa ser realizado à temperatura ambiente, sem necessidade de refrigeração. 
Na FIG. 33 nota-se que a variação na temperatura de armazenamento não demonstrou influência sobre a formação dos diasteroisômeros, apenas prejudicou a estabilidade do radiofármaco, porém sem comprometimento de sua utilização, uma vez que a pureza radioquímica se manteve acima dos $95 \%$. 


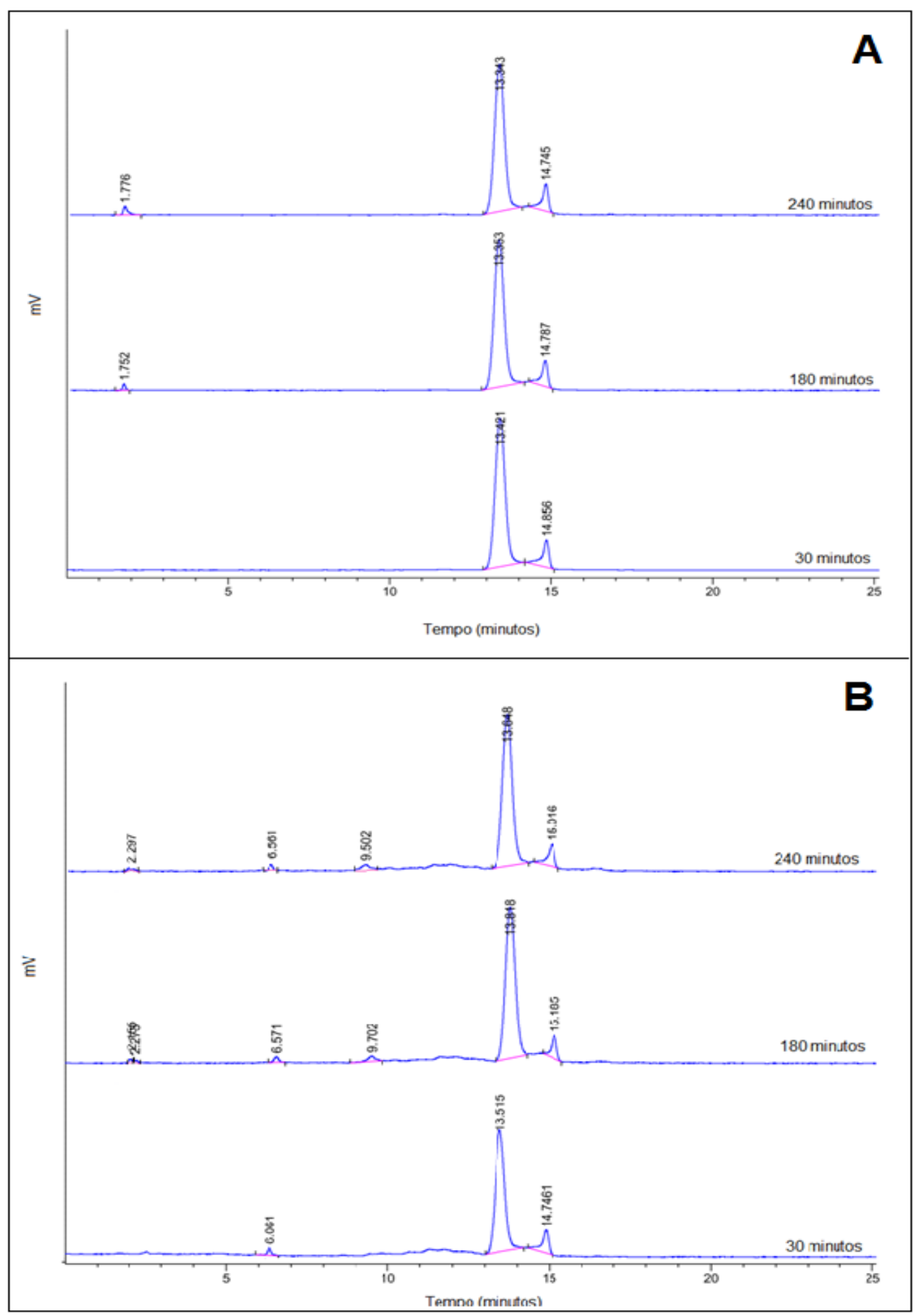

FIGURA 33: Perfis cromatográficos da influência da temperatura ambiente (A) e a $40^{\circ} \mathrm{C}(\mathrm{B})$ na estabilidade. Condições de radiomarcação: condição padrão de radiomarcação teve o $\mathrm{pH}$ do tampão acetato de sódio 0,2M alterado para pH 4,5. 


\subsubsection{Análise da estabilidade em soro humano e ligação às proteínas plasmáticas "IN VITRO"}

Uma maior estabilidade do peptídeo marcado em soro humano corresponde a maior probabilidade de ligação à superfície das células tumorais, possibilitando melhor qualidade de imagem (Pujatti, 2012). Os resultados demonstram alta estabilidade do radiofármaco PSMA-HBED-CC ${ }^{68} \mathrm{Ga}$ em soro humano, apresentando um decréscimo de pureza radioquímica de apenas $1,99 \%$ no período de 90 minutos (FIG. 34). Esta estabilidade em soro humano in vitro pode representar maior estabilidade in vivo, possibilitando boa relação tecido alvo/não alvo.

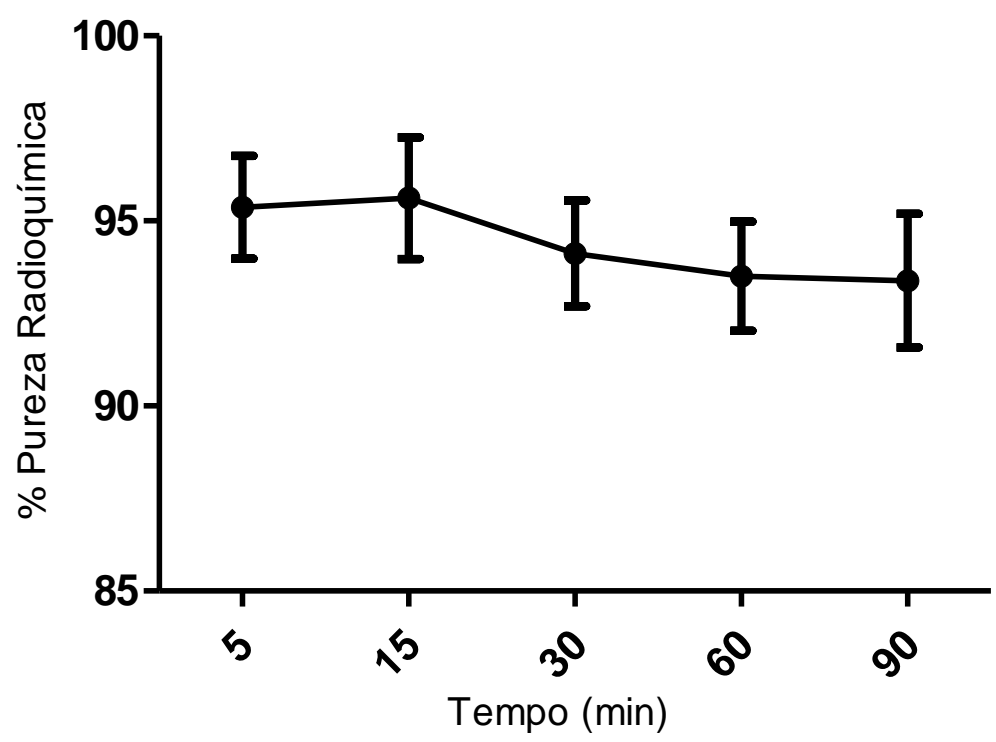

FIGURA 34: Estabilidade do PSMA-HBED- ${ }^{68} \mathrm{Ga}$ em soro humano "in vitro" a $37^{\circ} \mathrm{C}$, analisado por CCD. Condições de radiomarcação: condição padrão de marcação teve o pH do tampão acetato de sódio $0,2 \mathrm{M}$ alterado para $\mathrm{pH} 4,5$. Sistema cromatográfico: metanol:acetato de amônio 1M (1:1 v/v) e TLC-SG.

A integridade do peptídeo radiomarcado submetido a estabilidade em soro humano in vitro também foi analisada por CLAE, porém o processo de preciptação das proteínas e filtração para possibilitar injeção da amostra no equipamento envolve a utilização de etanol, o qual interfere no tempo de retenção do peptídeo no cromatógrafo assim como a linha de base. Os perfis podem ser analisados na FIG. 35. 


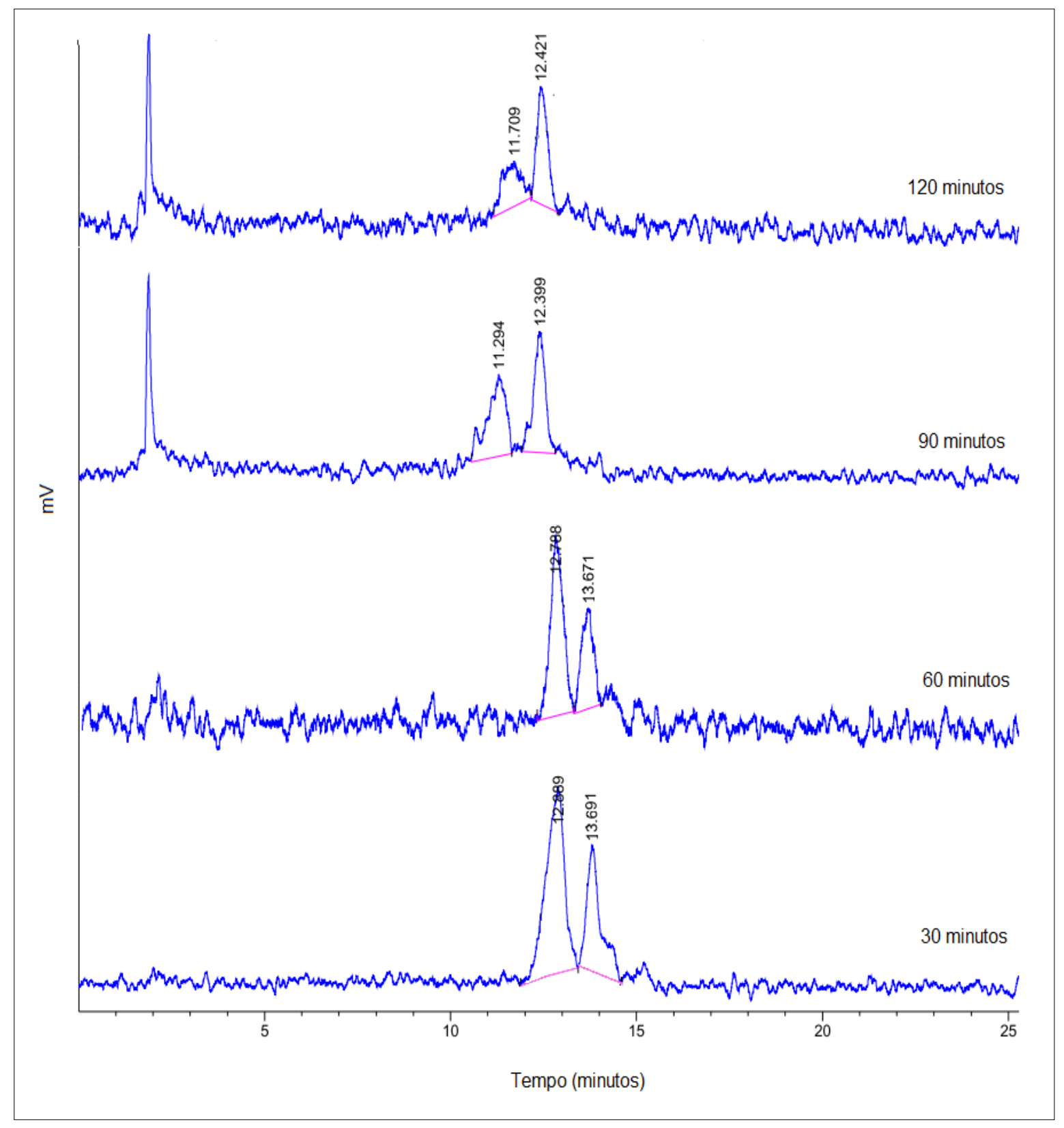

FIGURA 35: Análise em CLAE da estabilidade do radiofármaco PSMA-HBED-CC- ${ }^{68} \mathrm{Ga}$ em soro humano. Condições de radiomarcação: condição padrão de marcação teve o pH do tampão acetato de sódio 0,2M alterado para $\mathrm{pH} 4,5$.

Acredita-se que a interferência na linha de base causada pelo etanol impediu o equipamento de reconhecer alguns picos menores, uma vez que a PR em CCD para o intervalo de 30 minutos foi $95,37 \pm 2,40$.

Os cromatogramas expostos na FIG. 35 ilustram a provavel conversão do diasteroisômero menos estável para o mais estavel em soro humano, especíes observadas ao se comparar os tempos de 30 minutos e 60 minutos. Contudo, o radiofármaco 
demonstrou-se estável, sofrendo baixa liberação do radionuclídeo com PR de $93,38 \%$ ao final de 120 minutos, confirmada por análise em CCD.

A partir de 90 minutos observou-se a formação de um terceiro pico, com $R_{f}$ de cerca de 11 minutos, que pode ser atribuido a um produto de metabolização ou degradação do peptídeo radiomarcado.

A FIG. 36 apresenta o resultado do estudo de ligação do PSMA-HBED-CC- ${ }^{68}$ Ga às proteínas plasmáticas "in vitro". A baixa ligação às proteínas plasmáticas sugere rápida eliminação do radiofármaco do sangue, evitando sua metabolização pelas enzimas do soro.

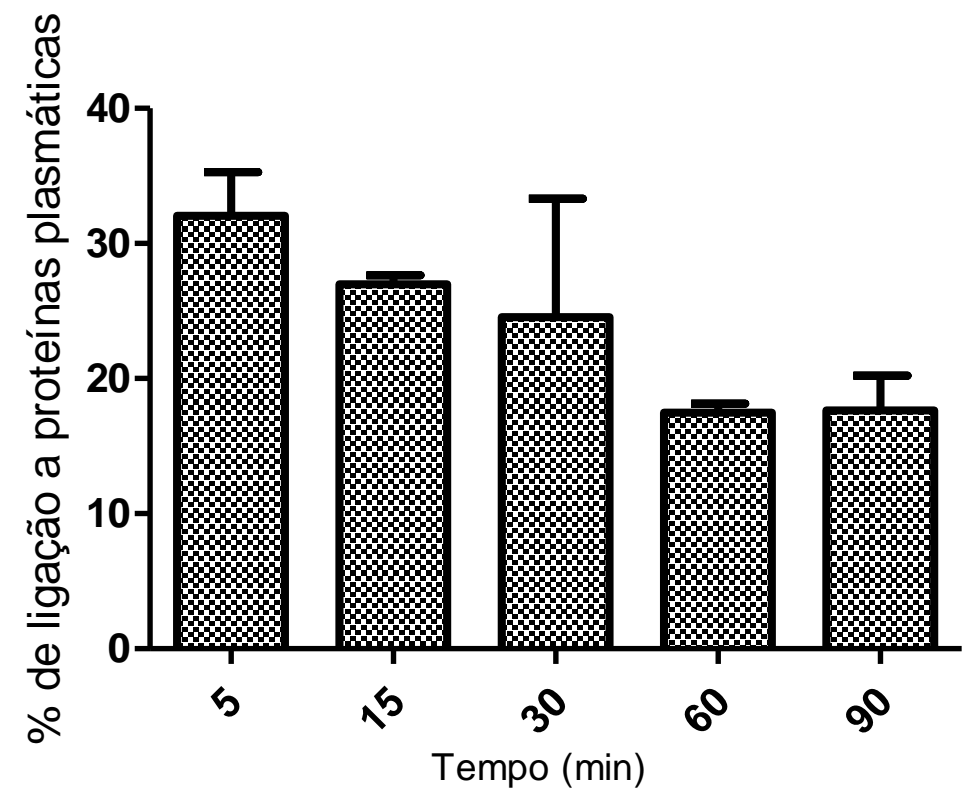

FIGURA 36: Estudo de ligação do PSMA-HBED-CC- ${ }^{68} \mathrm{Ga}$ às proteínas plasmáticas "in vitro". Condições de radiomarcação: condição padrão de marcação teve o pH do tampão acetato de sódio $0,2 \mathrm{M}$ alterado para $\mathrm{pH} 4,5$.

Inicialmente, a ligação do radiofármaco às proteínas plasmáticas foi de aproximadamente $27 \%$ no período de 30 minutos, reduzindo para $20 \%$ a partir de 60 minutos, correspondendo a uma ligação às proteínas relativamente baixa, o que sugere rápido clareamento sanguíneo.

Por fim, a otimização da marcação em sistema não automatizado permitiu a obtenção do radiofármaco com alta pureza radioquímica (> 95\%) e satisfatória estabilidade in vitro e em temperatura ambiente $\left(15-35^{\circ} \mathrm{C}\right)$. 
A metodologia proposta para radiomarcação do PSMA-HBED-CC com ${ }^{68} \mathrm{Ga}$ permite a produção do radiofármaco na ausência de equipamento de síntese automatizado, possibilitando uma ecomomia da ordem de 70.000,00 euros, uma vez que o custo destes equipamentos e seus acessorios é da ordem de: software para execução do programa $12.000,00$ reais; cassete para radiomarcação $-1000,00$ reais.

\subsection{OTIMIZAÇÃO dA RADIOMARCAÇÃO DO PSMA-HBED-CC COM ${ }^{68}$ Ga EM Módulo de SínTese Automatizado}

O Gálio-68 é um radioisótopo emissor de pósitrons com meia vida curta de aproximadamente 68 minutos. Portanto, todo o processo de síntese deve ser otimizado ao máximo para minimizar perda de atividade por decaimento radioativo e garantia do cumprimento das normas de BPF.

A otimização das marcações em bancada (modo não automatizado) e em módulo de síntese automatizado foram estudadas visando maior proximidade possível ao método de marcação utilizado pelo DOTATATO, com intuito de facilitar a produção rotineira do

PSMA-HBED-CC- ${ }^{68} \mathrm{Ga}$, utilizando módulo automatizado e programa já existentes, permitindo economia na aquisição do programa específico para marcação do PSMA-HBED-CC disponibilizado pelo fabricante do módulo.

As marcações foram feitas com massas superiores às utilizadas em bancada devido à recomendação do fabricante do equipamento, mas mantendo a atividade específica entre 70,2 - 140,41 GBq/ $\mu \mathrm{mol}$.

O aumento na massa da marcação no módulo possibilita marcar o peptídeo com maior ou menor atividade proveniente da eluição do gerador de ${ }^{68} \mathrm{Ge} /{ }^{68} \mathrm{Ga}$, não ultrapassando a atividade específica de $140 \mathrm{GBq} / \mu \mathrm{mol}$ e garantindo a estabilidade do peptídeo radiomarcado.

\subsubsection{Estudo da purificação do PSMA-HBED-CC-68Ga}

As radiomarcações preliminares em módulo utilizando o método descrito para a radiomarcação do peptídeo DOTATATO, porém com a massa reduzida para $10 \mu \mathrm{g}$ (método 1 , 
TAB. 18) possibilitaram alta pureza radioquímica (>98\%), porém com baixo rendimento da síntese $(<50 \%)$, tendo em vista que parte do peptídeo radiomarcado foi eluida do Sep Pack C18 diretamente para o rejeito.

Para marcações em módulo de síntese automatizado é esperado um rendimento de marcação inferior ao obtido em bancada, no entanto, com base na literatura para o PSMA (Eder et al, 2014), esperava-se a obtenção de aproximadamente $80 \%$ de rendimento.

Levando em consideração o $\log \mathrm{P}$ estabelecido neste trabalho que determina a acentuada lipofilicidade do PSMA-HBED-CC, e o volume final da marcação, foi estudada a influência do $\mathrm{pH}$ das radiomarcações realizadas em bancada conforme a condição padrão de radiomarcação descrita na sessão 6.2.2, sobre a capacidade de adsorção Sep Pack C18, além da eficiência do processo de purificação do radiofármaco (TAB. 15).

TABELA 15: Análise da porcentagem de pureza radioquímica (\% PR) das marcações do PSMA-HEBD-CC com ${ }^{68} \mathrm{Ga}$, realizadas em diferentes $\mathrm{pH}$, antes e após purificação com coluna do tipo Sep Pack C18 e a presença do peptídeo radiomarcado no rejeito proveniente da eluição do Sep Pack C18.

\begin{tabular}{ccccc}
\hline $\begin{array}{c}\text { Condições de } \\
\text { marcação }\end{array}$ & $\begin{array}{c}\text { Não Purificado } \\
\text { (CCD) }\end{array}$ & $\begin{array}{c}\text { \% PR } \\
\text { Purificado } \\
\text { (CCD) }\end{array}$ & $\begin{array}{c}\text { \% da espécie } \\
\text { PSMA-HBED-CC- }{ }^{68} \text { Ga } \\
\text { presente no rejeito da } \\
\text { eluição do Sep Pack } \\
\text { (CCD) }\end{array}$ & (n) \\
\hline $\mathrm{pH} \mathrm{3,5}$ & $88,19 \%$ & $96,93 \%$ & $83,27 \%$ & 2 \\
$\left(95^{\circ} \mathrm{C} / 15 \mathrm{mCi}\right)$ & $66,55 \%$ & $87,23 \%$ & $71,39 \%$ & 2 \\
\hline $\mathrm{pH} 4$ & $98,30 \%$ & $99,24 \%$ & $97,92 \%$ & 1 \\
$\left(95^{\circ} \mathrm{C} / 10 \mathrm{mCi}\right)$ & $98,02 \%$ & $99,02 \%$ & $96,05 \%$ & 2 \\
\hline $\mathrm{pH} 4,5$ & $97,28 \%$ & $99,85 \%$ & $90,20 \%$ & 2 \\
$\left(95^{\circ} \mathrm{C} / 15 \mathrm{mCi}\right)$ & & &
\end{tabular}

Foi possível observar o aumento da pureza radioquímica após a purificação do PSMA-HBED-CC $-{ }^{68} \mathrm{Ga}$, quando as marcações ocorreram com pH entre 4 e 4,5 a \% PR ficou acima dos 99\%. Entretanto, ao analisar o rejeito proveniente da eluição do Sep Pack C18 no processo de purificação, observou-se que praticamente a totalidade da atividade do rejeito era atribuída ao peptídeo radiomarcado, e não ao gálio-68 livre. Tal fato indicou que a perda de rendimento do processo deveu-se à falta de retenção do peptídeo radiomarcado no 
Sep Pack durante o processo de fixação do mesmo, e não propriamente à eficiência de marcação baixa (FIG. 37).

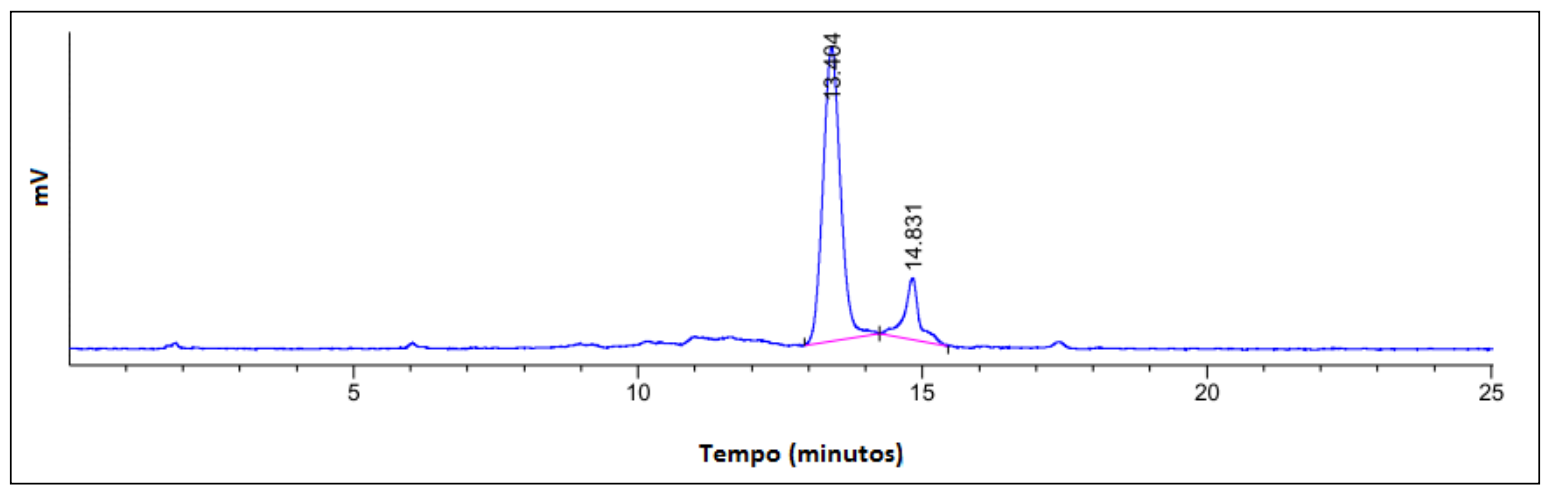

FIGURA 37: Perfil cromatográfico em CLAE do resíduo resultante da eluição do Sep Pack C18 com a solução contendo o produto radiomarcado. Condições de marcação: $5 \mu \mathrm{g}$ do peptídeo diluído em $2 \mathrm{~mL}$ de tampão acetato de sódio $0,2 \mathrm{M} \mathrm{pH} \mathrm{4,5,} \mathrm{com} 740 \mathrm{MBq}(20 \mathrm{mCi})$, à $95^{\circ} \mathrm{C}$ por 7 minutos, sem agitação.

Desta forma, foram analisados os rendimentos de síntese obtidos após purificação em Sep Pack C18 das marcações realizadas com diferentes pH, no intuito de utilizar os parâmetros com melhores resultados para análise em outro sistema de purificação (TAB. 16).

TABELA 16: Análise do rendimento de síntese do PSMA-HEBD-CC radiomarcado com ${ }^{68} \mathrm{Ga}$ em diferentes pH após purificação em Sep Pack C18.

Condições de marcação

$\mathrm{pH} \mathrm{3,5}$

$\left(95^{\circ} \mathrm{C} / 15 \mathrm{mCi}\right)$

$\mathrm{pH} 4$

$\left(95^{\circ} \mathrm{C} / 10 \mathrm{mCi}\right)$

$\mathrm{pH} \mathrm{4,5}$

$\left(95^{\circ} \mathrm{C} / 15 \mathrm{mCi}\right)$
Rendimento da síntese

(\%)

(n)

$9,04 \%$

$17,63 \%$

$26,78 \%$

$32,32 \%$

$29,58 \%$
1

2 
A variação do $\mathrm{pH}$ não demonstrou eficiência satisfatória sobre a retenção do peptídeo radiomarcado no cartucho de purificação, pois observou-se parte do peptídeo radiomarcado no rejeito de eluição do Sep Pack C18 em todos os pH (TAB 15), além de apresentarem baixos rendimentos de síntese (TAB. 16). A porcentagem de rendimento de síntese obtido após purificação em Sep Pack C18 para a metodologia com pH 3,5 foi significativamente menor quando comparado à metodologia que empregou $\mathrm{pH} 4,5$. Ainda que a perda do peptídeo radiomarcado entre as metodologias com pH 4 e 4,5 não tenham sido significativas ( $p>0,05$ ), nota-se, em termos de valores, que as radiomarcações com pH 4,5 demonstraram menor perda do peptídeo radiomarcado em comparação aos demais métodos. Mas a diferença de rendimento de síntese em relação ao pH das marcações, ainda que relacionada à porcentagem de retenção da atividade de marcação no Sep Pack, é também dependente da porcentagem de PR das marcações realizadas em diferentes pH, conforme demonstrado na TAB. 15, uma vez que a porcentagem de gálio-68 livre é maior na marcação realizada em pH 3,5 e este fato já acarreta uma menor retenção da atividade de marcação no Sep Pack.

Considerando os resultados obtidos com o cartucho Sep Pack C18, foi analisada a troca deste cartucho pelo Sep Pack C18 Plus devido suas características altamente hidrofóbicas e por possuir maior quantidade de material adsorvedor em seu interior, suportando maior volume de eluição (TAB. 17) (Waters, 2016).

TABELA 17: Análise da presença de peptídeo radiomarcado no rejeito obtido da eluição do Sep Pack C18 Plus com o radiofármaco radiomarcado em pH 4,5.

\begin{tabular}{cccc}
\hline $\begin{array}{c}\text { Condições de } \\
\text { marcação }\end{array}$ & $\begin{array}{c}\text { \% da espécie } \\
\text { PSMA-HBED-CC }{ }^{68} \text { Ga } \\
\text { presente no rejeito da } \\
\text { eluição do Sep Pack } \\
\text { (CCD) }\end{array}$ & $\begin{array}{c}\text { Rendimento de } \\
\text { síntese } \\
(\%)\end{array}$ & (n) \\
\hline $\mathrm{pH} \mathrm{4,5}$ & $47,31 \%$ & $43,56 \%$ & 2 \\
$\left(95^{\circ} \mathrm{C} / 20 \mathrm{mCi}\right)$ & $17,01 \%$ & $51,27 \%$ & 2 \\
\hline
\end{tabular}

Conforme esperado, o cartucho Sep Pack C18 Plus demonstrou maior adsorção do peptídeo radiomarcado, porém ainda houve perda do radiofármaco no processo de purificação. Entretanto, para tornar viável a utilização do módulo automatizado para 
radiomarcação é necessário garantir que o rendimento de síntese seja elevado, uma vez que a radiomarcação em bancada permite rendimentos de aproximadamente $100 \%$.

Os resultados do estudo preliminar realizado com os diferentes cartuchos Sep Pack, sugeriram a necessidade de redução do volume de marcação, como alternativa para aumentar a fixação do peptídeo radiomarcado na coluna de purificação Sep Pack. Esta estratégia foi avaliada nos estudos de marcação do módulo, conforme descritas a seguir.

\subsubsection{Estudo dos parâmetros de marcação em módulo de síntese automatizado}

Após analisados estes parâmetros com marcações em bancada, foram realizadas marcações no módulo de síntese automatizado variando-se as condições conforme discutido na TAB.6, na tentativa de aumentar o rendimento de síntese. Os resultados podem ser observados na TAB. 18.

Primeiramente, foi analisada a perda de atividade já na primeira etapa de purificação do módulo para separação do gálio-68 do germânio-68 em coluna de resina catiônica. Nesta análise observou-se perda não significante de atividade $(<92 \mathrm{MBq} / 2,5 \mathrm{mCi})$ em todas os métodos avaliados (TAB. 18).

Todos os métodos que utilizaram solução $0,02 \mathrm{M}$ de $\mathrm{HCl}$ em acetona ultrapura como eluente do ${ }^{68} \mathrm{GaCl}_{3}$ na coluna de troca catiônica obtiveram pureza radioquímica acima dos $97 \%$, demonstrando boa capacidade de radiomarcação do petídeo PSMA-HBED-CC no módulo de síntese automatizado.

A média de rendimento de síntese para o método 1 (maior semelhança com o método utilizado pelo DOTATATO) foi de $47 \% \pm 0,07$ e para o método 2 foi ainda menor com $38 \% \pm 0,14$. A diferença entre os dois métodos está na variação do $\mathrm{pH}$, tendo sido utilizados pH 4 e 4,5, respectivamente.

A troca do sistema de purificação em Sep Pack C18 por Sep Pack C18 Plus (método 3) com volume de marcação de $2 \mathrm{~mL}$ permitiu a obtenção de melhor rendimento de síntese, de $80 \% \pm 0,06$. O rendimento obtido para o método 3 está de acordo com os dados encontrados em literatura (Eder et al, 2014).

Esta condição demonstrou ser possível obter rendimento de síntese satisfatório, partindo-se de $2 \mathrm{~mL}$ de volume de reação, como preconizado para a marcação do 
DOTATATO, e utilizando ${ }^{68} \mathrm{GaCl}_{3}$ eluido pela mistura de $\mathrm{HCl} 0,02 \mathrm{M}$ em acetona ultrapura. Porém, para atingir este rendimento, que é compatível com o descrito para o PSMA-HBED-CC $-{ }^{68} \mathrm{Ga}$ obtido em módulo automatizado utilizando software próprio para o PSMA, foi necessário trocar o Sep Pack C18 original pelo Sep Pack C18 Plus, que garantiu maior retenção do peptídeo para posterior eluição, disponibilizando o produto final purificado.

Levando em consideração que a atividade do rejeito proveniente da eluição do Sep Pack C18, é composta, em média, por $90 \%$ do peptídeo radiomarcado, comprovando não haver ineficiência no processo de radioamarcação em módulo automatizado, analisou-se, no método 4 , a redução do volume de marcação para $0,4 \mathrm{~mL}$, visando não exceder à capacidade máxima de solvente necessária para saturação da coluna Sep Pack e assim permitir maior interação do peptídeo radiomarcado com a matriz da coluna no momento de sua fixação. Dentre as metodologias analisadas, o método 4 apresentou os melhores resultados de rendimento de síntese $(90 \% \pm 0,01)$, obtendo resultados superiores aos descritos em literatura.

Nos métodos que utilizaram solução de $\mathrm{NaCl} / \mathrm{HCl} 5 \mathrm{M}$ como eluente do ${ }^{68} \mathrm{GaCl}_{3}$ (método 5, 6 e 7) da coluna de troca catiônica não foi possível extrair o radiofármaco do processo de purificação final devido a completa retenção do produto no Sep Pack C18.

Os métodos utilizando solução de $\mathrm{NaCl} / \mathrm{HCl} 5 \mathrm{M}$ foram avaliados uma vez que esta solução é indicada no método descrito pelo fabricante do módulo para o software específico para marcação do peptídeo PSMA. É uma alternativa para utilização de solução isenta de acetona, solvente orgânico cujo conteúdo residual deverá ser acompanhado em ensaio de controle de qualidade do produto acabado.

A causa relacionada à retenção do peptídeo radiomarcado nas marcações que utilizaram solução de $\mathrm{NaCl} / \mathrm{HCl} 5 \mathrm{M}$ na eluição do gerador não foi determinada e o processo de marcação deverá ser melhor avaliado futuramente, de modo a solucionar este problema observado.

A TAB. 18 a seguir resume os resultados obtidos em módulo de síntese automatizado para os diferentes métodos empregados. 
TABELA 18: Variação do rendimento de síntese e pureza radioquímica obtida após purificação do PSMA-HBED-CC- ${ }^{68}$ Ga produzido em módulo de síntese automatizado em diferentes condições.

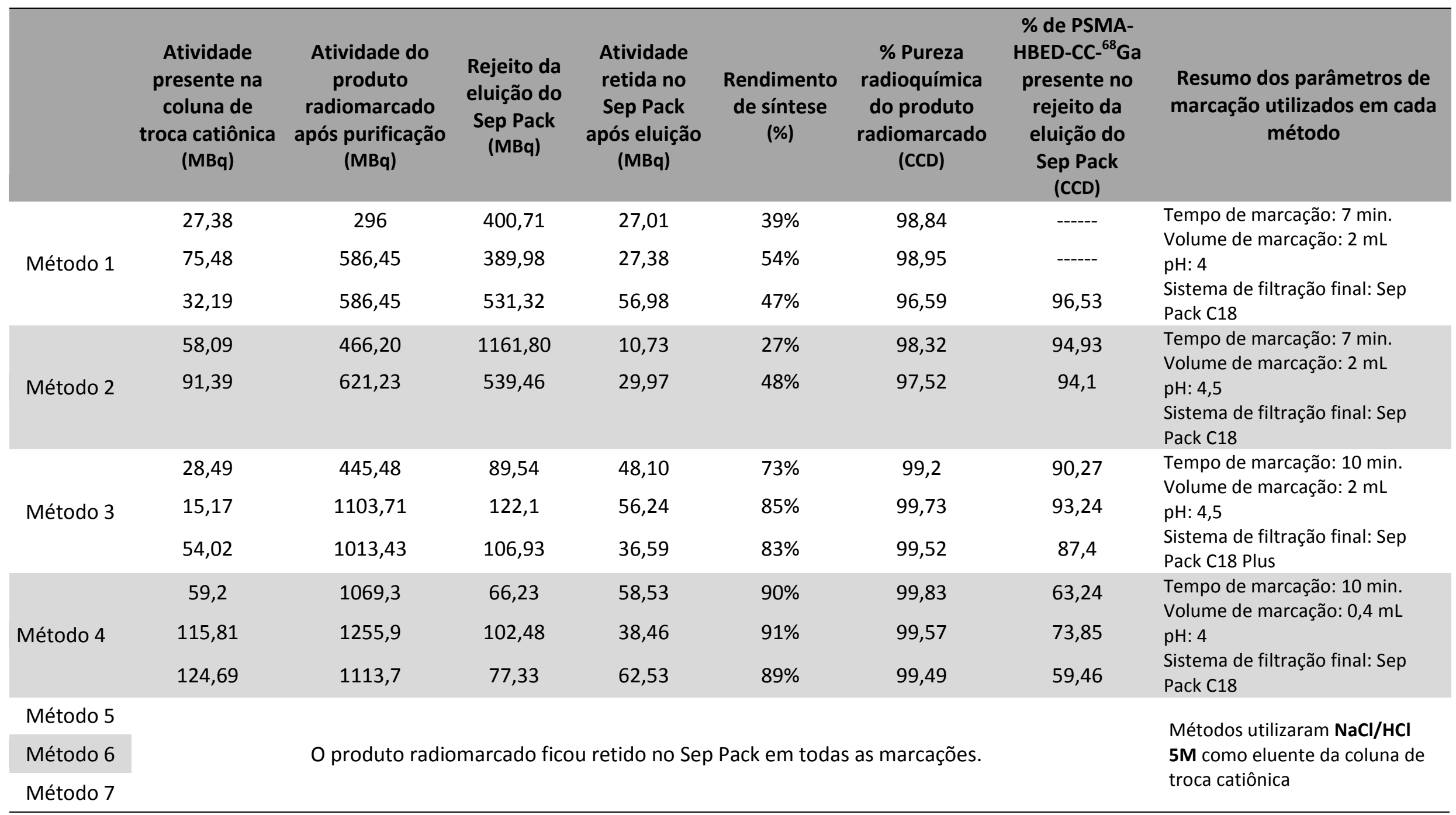


Na FIG. 38, apresenta-se o resultado do estudo de estabilidade para marcações realizadas pelo método 3 e método 4 . Nota-se que as radiomarcações possibilitaram alta pureza radioquímica ( $>99 \%$ ) e estabilidade do produto radiomarcado após 240 minutos da radiomarcação em volume final de aproximadamente $7 \mathrm{~mL}$ e $\mathrm{pH} 5$.

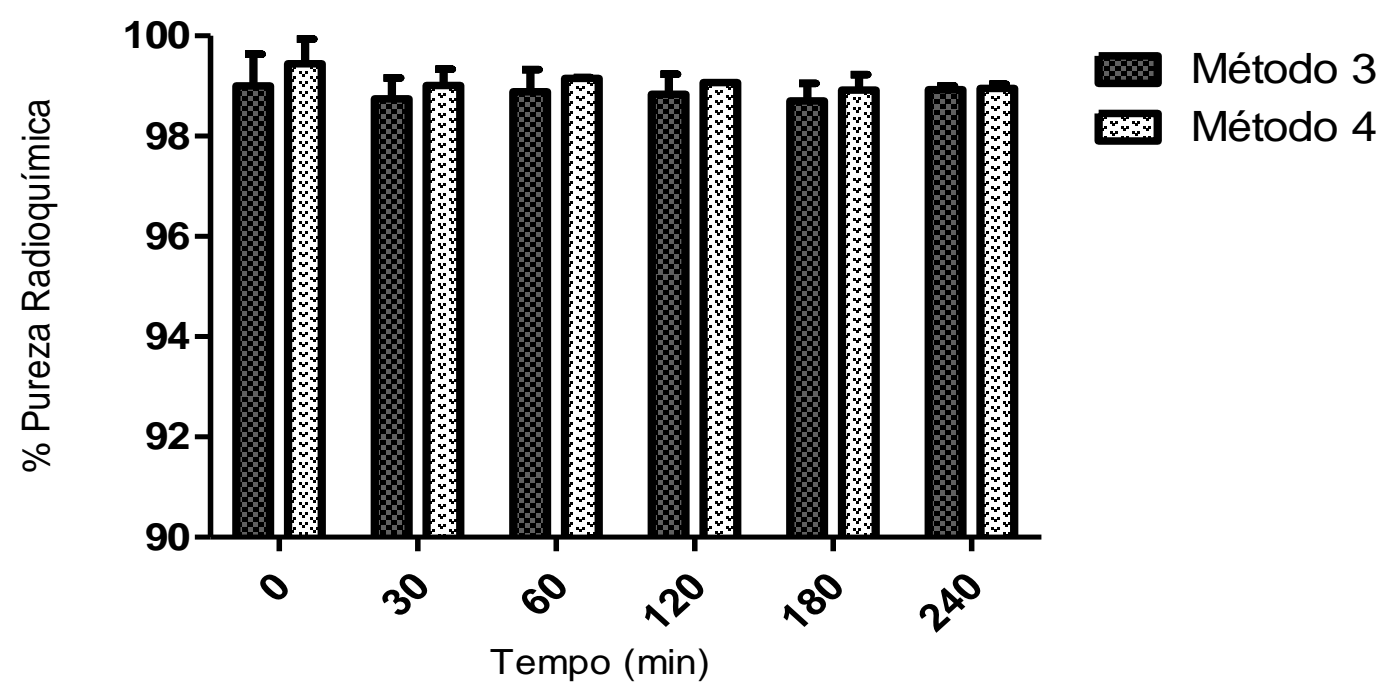

FIGURA 38: Análise da estabilidade do PSMA-HBED-CC- ${ }^{68}$ Ga (\% PR em função do tempo) produzido em módulo de síntese automatizado (método 3 e 4). Condições de marcação:

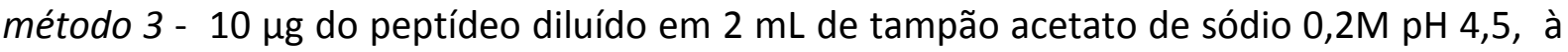
$95^{\circ} \mathrm{C}$ por 10 minutos, sem agitação, utilizando $\mathrm{HCl}$ 0,02M em acetona ultrapura como eluente para $0^{68} \mathrm{GaCl}_{3}$ e purificação do peptídeo radiomarcado em Sep Pack C18 Plus;

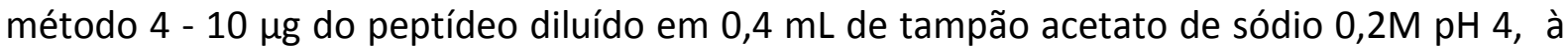
$95^{\circ} \mathrm{C}$ por 7 minutos, sem agitação, utilizando $\mathrm{HCl}$ 0,02M em acetona ultrapura como eluente para ${ }^{68} \mathrm{GaCl}_{3}$ e purificação do peptídeo radiomarcado em Sep Pack C18.

Na FIG. 39, 40 e 41 encontram-se os perfis obtidos em CLAE (método 2, método 3 e método 4, respectivamente) para análise de possível variação nos diasteroisômeros devido a alteração no pH e volume de marcação. Os produtos obtidos nos métodos avaliados mantiveram-se estáveis por todo o período analisado. 


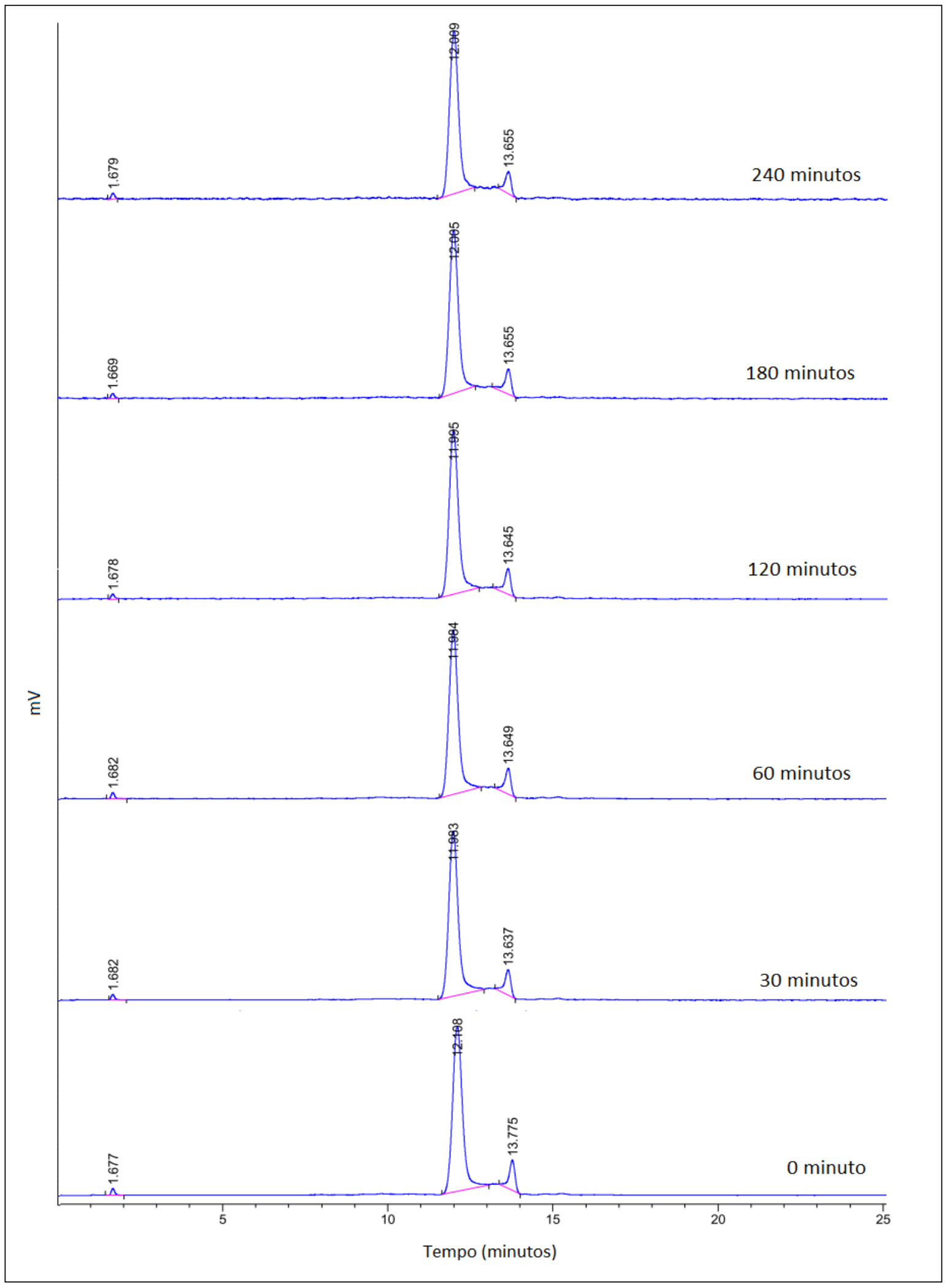

FIGURA 39: Perfis cromatográficos obtidos em CLAE para a radiomarcação de acordo com o método 2. Condições de marcação: $10 \mu \mathrm{g}$ do peptídeo diluído em $2 \mathrm{~mL}$ de tampão acetato de sódio $0,2 \mathrm{M} \mathrm{pH} \mathrm{4}$, à $95^{\circ} \mathrm{C}$ por 7 minutos, sem agitação, utilizando $\mathrm{HCl} 0,02 \mathrm{M}$ em acetona ultrapura como eluente para $0{ }^{68} \mathrm{GaCl}_{3}$ e purificação do peptídeo radiomarcado em Sep Pack C18. 


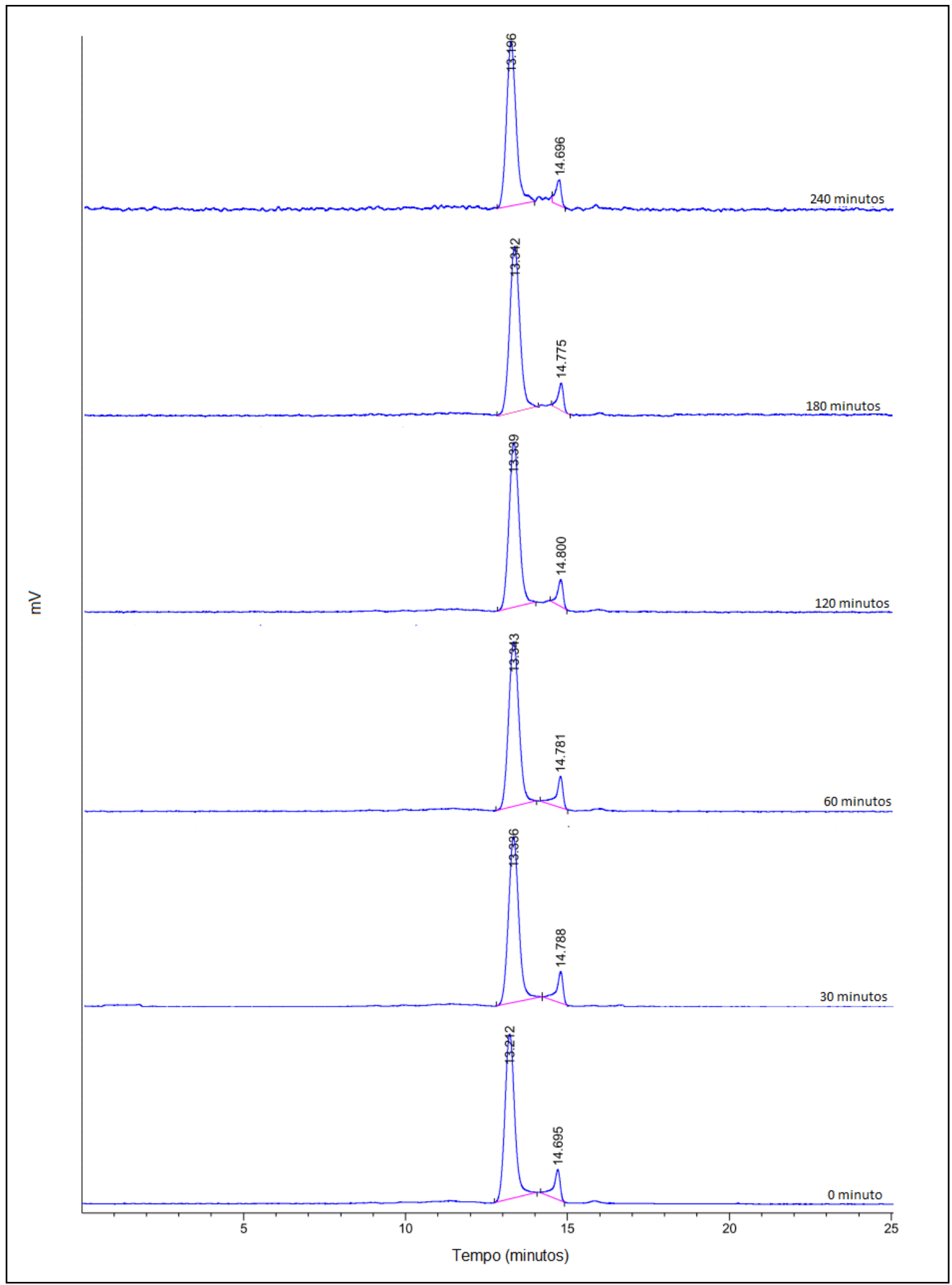

FIGURA 40: Perfis cromatográficos obtidos em CLAE para a radiomarcação de acordo com o método 3. Condições de marcação: $10 \mu \mathrm{g}$ do peptídeo diluído em $2 \mathrm{~mL}$ de tampão acetato de sódio $0,2 \mathrm{M} \mathrm{pH} \mathrm{4,5}$, à $95^{\circ} \mathrm{C}$ por 10 minutos, sem agitação, utilizando $\mathrm{HCl} 0,02 \mathrm{M}$ em acetona ultrapura como eluente para $0^{68} \mathrm{GaCl}_{3}$ e purificação do peptídeo radiomarcado em Sep Pack C18 Plus. 


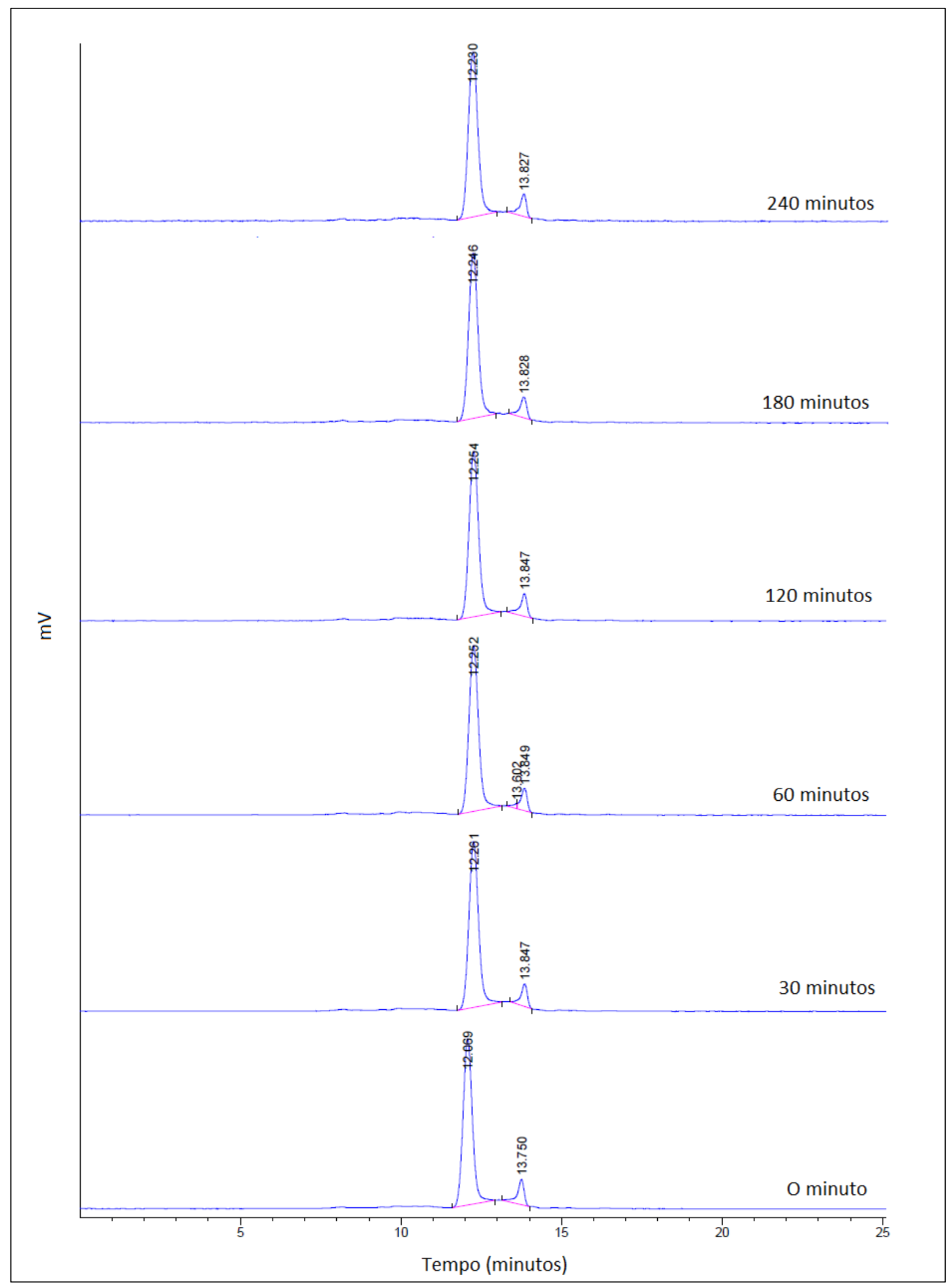

FIGURA 41: Perfis cromatográficos obtidos em CLAE para a radiomarcação de acordo com o método 4. Condições de marcação: $10 \mu \mathrm{g}$ do peptídeo diluído em $0,4 \mathrm{~mL}$ de tampão acetato

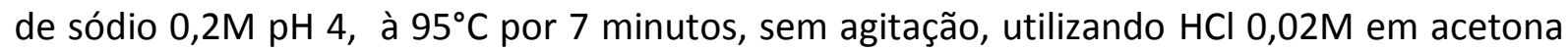
ultrapura como eluente para $0^{68} \mathrm{GaCl}_{3}$ e purificação do peptídeo radiomarcado em Sep Pack C18. 
O método 4 permitiu a radiomarcação do PSMA-HBED-CC com ${ }^{68} \mathrm{Ga}$, com alto rendimento, em módulo de síntese automatizado, utilizando o software já existente no Centro de Radiofarmácia. Apesar do rendimento da síntese realizada em módulo automatizado ser inferior ao rendimento da marcação realizada de forma não automatizada, a marcação no módulo possibilita aplicar os conceitos de BPF necessários para validação do processo produtivo. Desta forma, a diferença no rendimento (cerca de $10 \%$ ) é compensada com o ganho em controle do processo produtivo e diminuição dos riscos de contaminação do produto, uma vez que as intervenções humanas são reduzidas com a síntese automatizada (sistema fechado).

O processo utilizado para as radiomarcações no módulo de síntese automatizado utiliza tempo superior ao utilizado em bancada (15 minutos), totalizando 33 minutos. $\mathrm{Na}$ marcação em bancada, entretanto, não se considerou no cálculo do tempo de processo, a necessidade de purificação do peptídeo radiomarcado em coluna SepPack C18, uma vez que a \% PR das marcações em bancada, após a otimização das condições de marcação, atingiram valores superiores ao critério de aprovação ( $\geq 95 \%)$. Entretanto, sendo um radiofármaco de meia-vida ultracurta, a liberação do produto e o despacho para a clínica de Medicina Nuclear, realiza-se concomitantemente à realização do ensaio de pureza radioquímica. Caso o ensaio de PR apresente resultado inferior ao critério de aceitação, o produto será reprovado e não poderá ser utilizado para aplicação em pacientes e deverá ser descartado na clínica de Medicina Nuclear.

Também não foi considerado o tempo necessário para a realização do teste de integridade de membrana filtrante, requisito obrigatório para a liberação do produto para utilização em pacientes.

A vantagem da produção automatizada, entretanto, relaciona-se particularmente, a requisitos de Boas Práticas de Fabricação, incluindo, menor manipulação da amostra pelo operador, purificação automatizada do peptídeo radiomarcado em resina do tipo C18 para remoção do gálio-68 livre residual, e filtração em membrana esterilizante ao final do processo. O equipamento também realiza automaticamente o teste de integridade da membrana filtrante. Todo o processo é controlado e possibilita rastreabilidade por meio dos registros gerados pelo software do equipamento.

A marcação do peptídeo PSMA-HBED-CC com ${ }^{68} \mathrm{Ga}$ em módulo de síntese automatizado (Eckert and Ziegler), utilizando-se o software empregado para marcação do 
peptídeo DOTATATO foi possível, desde que algumas condições fossem adaptadas. Mantendo-se o volume de $2 \mathrm{~mL}$, houve a necessidade de utilizar Sep Pack C18 Plus no processo de purificação final, de modo à minizar a perda no rendimento de síntese.

Alternativamente, foi possível reduzir o volume de marcação para $0,4 \mathrm{~mL}$, pois não interfere nas condições pré-fixadas de marcação pelo software, obtendo-se rendimento de síntese ainda maior e utilizando-se Sep Pack C18 original.

A otimização das condições de marcação, foi de suma importância para garantir rendimentos satisfatórios e custo-efetividade na produção automatizada. Além disto, possibilitou a utilização de módulo e software já existente no Centro de Radifoarmácia, indicando que um mesmo sistema pode ser empregado para a marcação de diferentes peptídetos com gálio-68, gerando uma economia na aquisição de softwares específicos para cada peptídeo da ordem de 40.000,00 reais.

\subsection{ESTUDOS IN VIVo}

\subsubsection{Estudos de farmacocinética em camundongos Balb/c sadios}

A farmacocinética engloba os processos de absorção, distribuição, metabolismo e excreção dos fármacos (Storpirtis et al, 2011), expressando a relação entre as concentrações de um fármaco em diferentes regiões do organismo e o tempo necessário para que ocorra sua distribuição (Rang et al, 2007).

Estudos famacocinéticos são essenciais no desenvolvimento de novos fármacos e radiofármacos, pois auxiliam no estabelecimento de esquemas terapêuticos, concentrações plasmáticas e nos tecidos do fármaco, influência de doenças sobre a distribuição, assim como possibilitam a individualiação dos esquemas posológicos em pacientes, quando necessário (Shargel et al, 2004).

$\mathrm{Na}$ farmacocinética são propostos dois modelos matemáticos no intuito de predizer a distribuição do fármaco após administração: modelo monocompartimental (um compartimento) e modelo multicompartimental (dois ou mais compartimentos) (Rang, et al, 2007; Storpirtis et al, 2011). As abordagens permitem o cálculo de parâmetros farmacocinéticos os quais interpretam relações de probabilidade, necessários para 
estabelecer o perfil do fármaco no organismo. Para isto, é necessária a construção de uma curva que correlacione a concentração plasmática pelo tempo, e assim aplicar modelos matemáticos (não compartimental e compartimental) de acordo com o perfil da curva (Storpirtis et al, 2011).

A curva de clareamento sanguíneo obtida para o PSMA-HBED-CC $-{ }^{68} \mathrm{Ga}$ pode ser observada na FIG. 42.

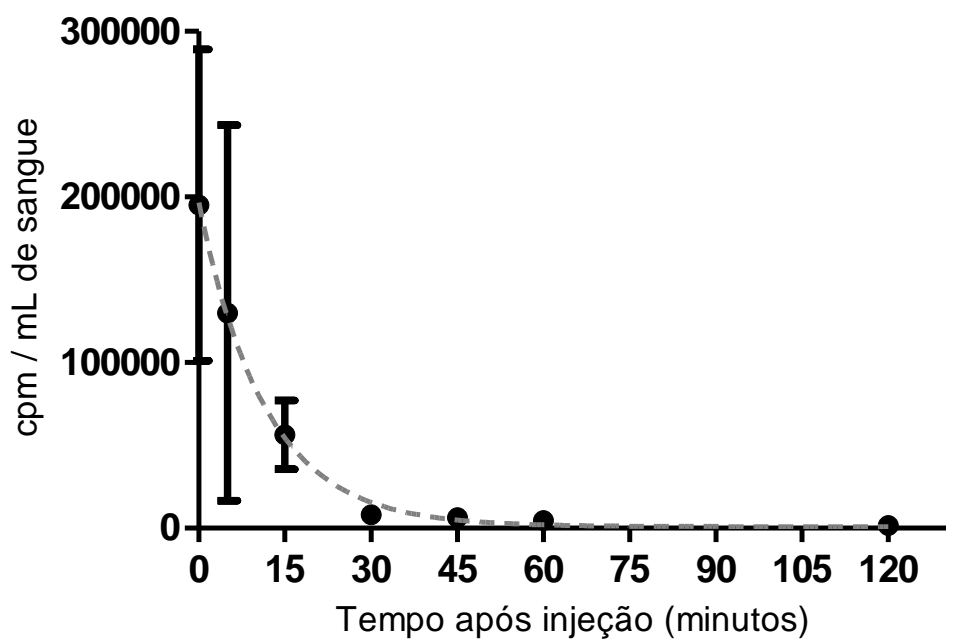

FIGURA 42: Curva de clareamento sanguíneo do PSMA-HBED-CC- ${ }^{68} \mathrm{Ga}$ em camundongos Balb/c machos sadios $(n=4)$.

Observa-se que o radiofármaco apresentou rápido clareamento sanguíneo, sendo eliminado da corrente sanguínea em aproximadamente 60 minutos. Os resultados obtidos para o clareamento sanguíneo estão de acordo aos encontrados na literatura (Eder et al, 2012; Schafer et al, 2012).

A curva de claremento sanguíneo (FIG. 42) foi utilizada para cálculo dos parâmetros farmacocinéticos expressos na TAB. 19. Os parâmetros foram calculados após ajuste dos dados para um modelo de decaimento monoexponencial. 
TABELA 19: Parâmetros farmacocinéticos para o PSMA-HBED-CC- ${ }^{68} \mathrm{Ga}$ em camundongos Balb/c machos sadios $(n=4)$.

\begin{tabular}{|ccc|}
\hline $\begin{array}{c}\text { Parâmetros } \\
\text { Farmacocinéticos }\end{array}$ & Símbolo & Valor \\
\hline $\begin{array}{c}\text { Tempo de meia-vida } \\
\text { biológica }\end{array}$ & $\mathrm{t}_{1 / 2} \alpha$ & $8,03 \mathrm{~min}$ \\
\hline $\begin{array}{c}\text { Tempo de meia-vida } \\
\text { efetivo }\end{array}$ & $\mathrm{t}_{1 / 2} \mathrm{E}$ & $59,4 \mathrm{~min}$ \\
\hline Constante de eliminação & $\mathrm{K}_{\mathrm{el}}$ & $0,087 \mathrm{~m}^{-1}$ \\
\hline Depuração & $\mathrm{CL}$ & $0,020 \mathrm{~mL} \cdot \mathrm{min}^{-1}$ \\
\hline Volume de distribuição & $\mathrm{Vd}$ & $0,23 \mathrm{~mL}$ \\
\hline $\begin{array}{c}\text { Volume de distribuição } \\
\text { corrigido pelo peso }\end{array}$ & $\mathrm{Vd}$ & $0,0071{\mathrm{~L} . \mathrm{Kg}^{-1}}^{-1}$ \\
\hline
\end{tabular}

Neste trabalho, foi utilizado o modelo monocompartimental, que tem como finalidade fármacos de absorção instantânea (intravenosa) e eliminação de primeira ordem, com distribuição instantânea e homogênea (Saha, 2003). Na prática, a distribuição do fármaco deve ocorrer tão rapidamente que a quantificação e o cálculo da constante de distribuição se tornam inviáveis. No entanto, este padrão de homogeneidade na distribuição não corresponde às mesmas concentrações encontradas nos tecidos, e sim a uma condição de equilíbrio (Storpirtis et al, 2011).

O volume de distribuição $(\mathrm{Vd})$ e a depuração $(\mathrm{CL})$ são considerados os principais parâmetros farmacocinéticos por traduzirem funções fisiológicas fundamentais do organismo, e permitirem o cálculo da meia-vida de eliminação ( $\left.t_{1 / 2}\right)$ (Shargel et al, 2004).

Outro conceito importante, a meia-vida de eliminação, também conhecida como meia-vida biológica representa o tempo necessário para que o organismo elimine $50 \%$ do fármaco administrado, e assim estabelecer o tempo requerido para eliminar completamento o fármaco do organismo (Shargel et al, 2004; Storpirtis et al, 2011).

Foi encontrado tempo de meia-vida biológica curto (8,03 minutos) o que está de acordo com o volume de distribuição encontrado $\left(0,0071{\mathrm{~L} . \mathrm{Kg}^{-1}}^{-1}\right)$, um vez que quanto menor o volume de distribuição, maior a quantidade do radiofármaco disponível no plasma para eliminação, desencadeando a diminuição do tempo de meia-vida. Mesmo considerando que o PSMA-HBED-CC- ${ }^{68}$ Ga possui alta afinidade pelos rins, e quando não utilizado bloqueadores, pode ligar-se irreversivelmete dependendo da forma enantiomérica, o que dificulta sua 
eliminação, os resultados do estudo farmacocinético sugerem tempo de meia vida biológica e efetiva curtos.

Contudo, conforme descrito na revisão bibliográfica, Eder e col. (2012) que considera a existência de diferentes enantiômeros com diferente afinidade pelos rins, supõe-se que uma vez que o caminho percorrido pelo radiofármaco em decorrência da sua afinidade pelos receptores PSMA presentes nos rins é o mesmo percorrido para sua eliminação, podemos considerar que parte do radiofármaco não irá desacoplar do receptor em questão e a porção que se desligar não voltará a ser liberado na corrente saguínea sendo eliminada pelos rins.

A depuração representa a eficiência com que o organismo elimina o fármaco, relacionando a velocidade de eliminação à sua concentração plasmática (Shargel et al, 2004; Storpirtis et al, 2011). Os valores de depuração e eliminação encontrados corroboram com o rápido clareamento sanguíneo apresentado na FIG. 42.

A eliminação do radiofármaco do organismo não é dependente somente do tempo de meia vida biológica, mas sim da relação entre a meia vida biológica (descrita em função do perfil farmacocinético e farmacodinâmico da molécula), como pela meia vida física do radionuclídeo (decaimento se mantém constante independente do processo) (Saha, 2003). Esta relação é conhecida como tempo de meia vida efetivo e para este trabalho, o valor encontrado foi de 59,4 minutos, tempo adequado para realização de imagens PET/CT e também curto o suficiente para minimizar a exposição do paciente a doses desnecessárias.

Os parâmetros encontrados permitem concluir que o radiofármaco é distribuído rapidamente para os tecidos que possui afinidade e que quando não ligado à esses tecidos, é excretado, também rapidamente.

\subsubsection{Estudos de biodistribuição em camundongos Balb/c sadios}

Os resultados do estudo de biodistribuição podem ser visualizados na FIG. 43 pelos dados expressos em porcentagem de atividade administrada em relação à atividade captada por grama de tecido (\% Al/g), e na FIG. 44 expressos em porcentagem de atividade administrada em relação à atividade total captada por órgão (\% $\mathrm{Al})$. 


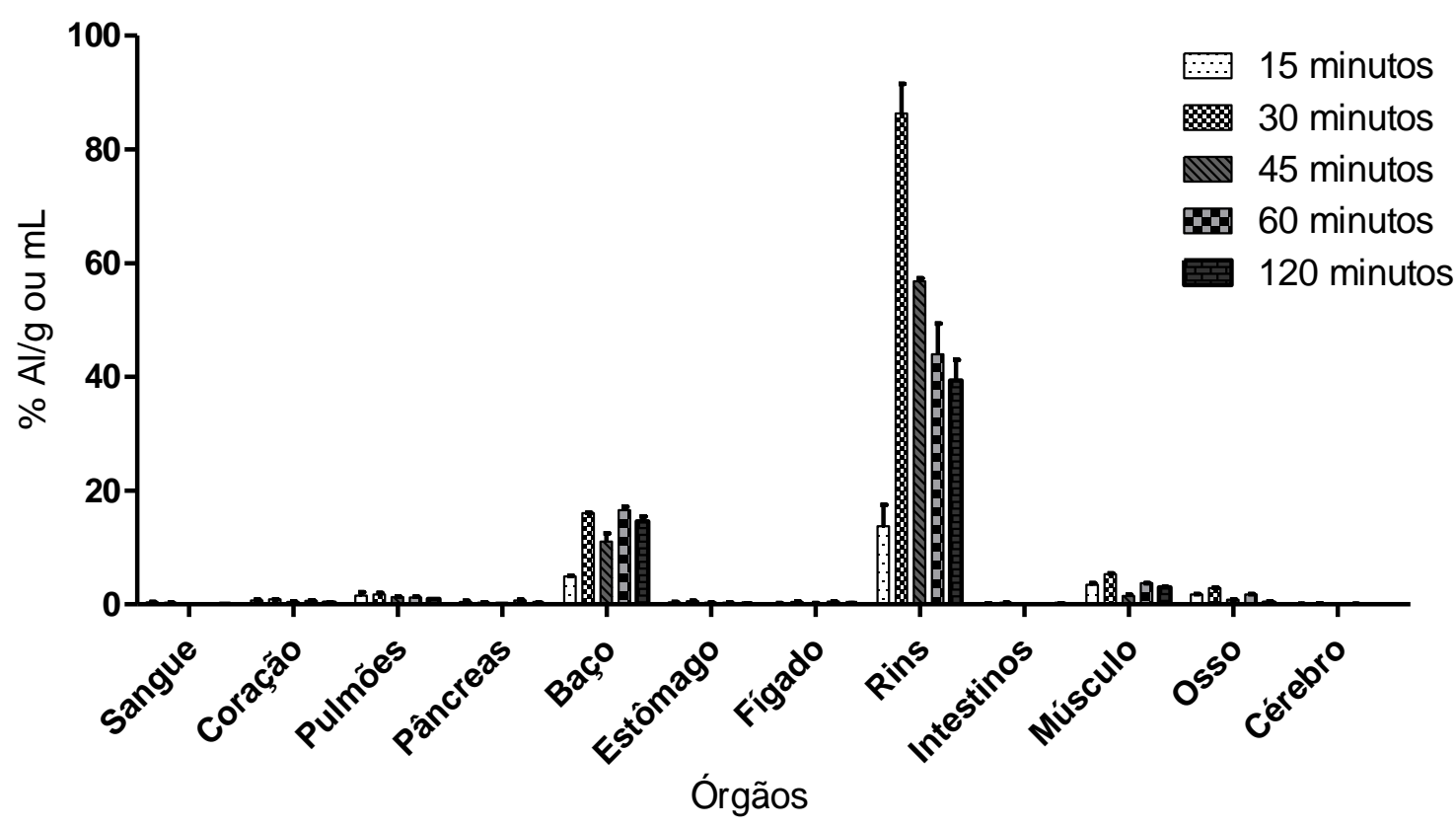

FIGURA 43: Biodistribuição do PSMA-HBED-CC $-{ }^{68} \mathrm{Ga}$ nos órgãos e tecidos (\% $\mathrm{Al} / \mathrm{g}$ ) de camundongos Balb/c machos sadios $(n=4)$

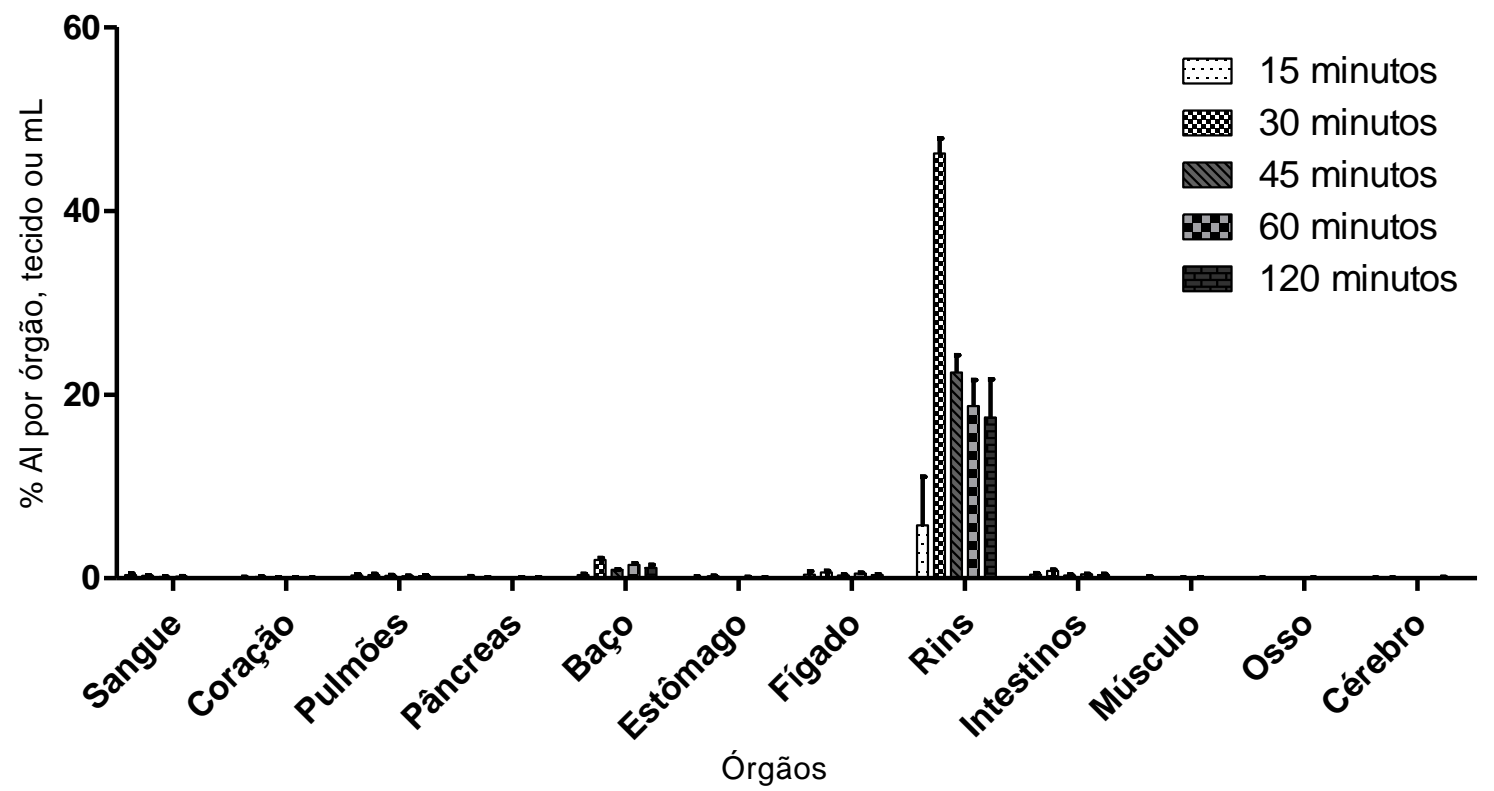

FIGURA 44: Biodistribuição do PSMA-HBED-CC- ${ }^{68}$ Ga nos órgãos e tecidos (\% Al/órgão) de camundongos Balb/c machos sadios $(n=4)$

O conceito de biodistribuição ou distribuição trata da distribuição do fármaco pelo organismo, de maneira reversível, independente de o fármaco estar na forma livre ou ligada às proteínas. Esta distribuição é dependente da permeabilidade do fármaco através 
das barreiras teciduais, ligação dentro dos compartimentos, coeficiente de partição no pH e coeficiente de partição óleo:água (Rang, et al, 2007).

Desta forma, a biodistribuição do fármaco está diretamente ligada à farmacocinética, uma vez que esta determina a distribuição do fármaco em função do tempo (Rang, et al, 2007).

Descrito em literatura é possível encontratar apenas dois estudos de biodistribuição em animais (Eder et al, 2012; Schafer et al, 2012), os quais foram desenvolvidos em colaboração apresentando os mesmos resultados. Os estudos de biodistribuição foram realizados apenas para o tempo de 60 minutos em camundongos Nude com tumor. O estudo demonstrou que o PSMA-HBED-CC radiomarcado com ${ }^{68} \mathrm{Ga}$ é rapidamente eliminado do sangue e de tecidos que não expressam o PSMA, porém apresentou alta captação no fígado, rins e baço. Esta elevada captação em órgãos não alvo que apresentam a expressão de receptores PSMA foi quase totalmente bloqueada após a administração do bloqueador PMPA (2-(fosfonometil)-ácido pentanodióico).

Recentemente, um estudo pioneiro de biodistribuição em humanos realizado através da tecnologia PET permitiu observar em órgãos saudáveis, quais as regiões de maior captação do radiofármaco, sendo observada apenas nas glândulas salivares e rins captação elevada e no fígado, baço e intestino apresentou captação moderada (Afshar et al, 2013).

A captação do fármaco no baço manteve diferença significativa $(p<0,001)$ ao longo do período de 60 minutos e nos rins a diferença na captação se manteve significativa $(p<0,001)$ ao longo de todo o período estudado. A captação do radiofármaco nestes órgãos está de acordo com os dados encontrados em literatura (Eder et al, 2012; Schafer et al, 2012). Porém, ainda que a captação tenha sido alta nos rins, os valores obtidos (\% $\mathrm{Al} / \mathrm{g}$ ) foram cerca de $95 \%$ menores que os obtidos por Eder e col. (2012) e Schafer e col. (2012) $(43,98 \pm 7,63$ contra 139,4 $\pm 21,4$ encontrado em ambos os trabalhos) expressos em \% Al/g. No entanto, os resultados encontrados na literatura foram obtidos apenas no tempo de 60 minutos após administração do radiofármaco a partir de camundongos Nude com tumor, o que poderia explicar os diferentes resultados.

No presente trabalho, de todos os tempos estudados, a captação renal foi maior para o tempo de 30 minutos, decaindo notavelmente em 45 minutos e decaindo mais discretamente nos tempos seguintes de 60 e 120 minutos. Tal comportamento pode ser explicado pela teoria de captação dos diferentes enantiômeros, considerando-se que a forma 
que se ligar irreversivelmente aos receptores renais acumula-se juntamente com a forma que se liga reversivelmente e depois se desliga, promovendo menor captação renal nos tempos mais tardios. A forma enantiomérica que se liga irreversivelmente aos receptore renais seria a responsável pela persistente captação renal, mesmo quando a \% $\mathrm{Al}$ no sangue está bastante reduzida, nos tempos de 60 e 120 minutos.

Os valores obtidos de \% Al/g para todos os ógãos analisados podem ser observados na TAB. 20.

TABELA 20: Biodistribuição do PSMA-HBED- ${ }^{68} \mathrm{Ga}$ nos órgãos e tecidos de camundongos Balb/c machos sadios $(n=4)$

\begin{tabular}{cccccc}
\hline & \multicolumn{5}{c}{$\%$ Al/g de órgão, tecido ou mL de sangue } \\
$\begin{array}{c}\text { Tempo após a injeção } \\
\text { (min) }\end{array}$ & $\mathbf{1 5}$ & $\mathbf{3 0}$ & $\mathbf{4 5}$ & $\mathbf{6 0}$ & $\mathbf{1 2 0}$ \\
\hline Sangue & $0,13 \pm 0,05$ & $0,11 \pm 0,02$ & $0,05 \pm 0,01$ & $0,07 \pm 0,02$ & $0,04 \pm 0,00$ \\
Coração & $0,68 \pm 0,28$ & $0,86 \pm 0,09$ & $0,45 \pm 0,05$ & $0,61 \pm 0,12$ & $0,32 \pm 0,05$ \\
Pulmões & $1,51 \pm 1,12$ & $1,74 \pm 0,40$ & $1,30 \pm 0,10$ & $1,18 \pm 0,23$ & $0,97 \pm 0,01$ \\
Pâncreas & $0,45 \pm 0,24$ & $0,30 \pm 0,08$ & $0,30 \pm 0,02$ & $0,68 \pm 0,19$ & $0,23 \pm 0,05$ \\
Baço & $4,88 \pm 0,17$ & $16,04 \pm 0,06$ & $11,03 \pm 2,95$ & $16,55 \pm 1,01$ & $14,58 \pm 1,24$ \\
Estômago & $0,33 \pm 0,11$ & $0,54 \pm 0,16$ & $0,27 \pm 0,09$ & $0,29 \pm 0,07$ & $0,15 \pm 0,04$ \\
Fígado & $0,16 \pm 0,16$ & $0,41 \pm 0,10$ & $0,18 \pm 0,05$ & $0,46 \pm 0,10$ & $0,20 \pm 0,04$ \\
Rins & $13,73 \pm 5,32$ & $86,35 \pm 7,29$ & $56,80 \pm 0,75$ & $43,98 \pm 7,63$ & $39,38 \pm 6,26$ \\
Intestino & $0,14 \pm 0,07$ & $0,28 \pm 0,05$ & $0,10 \pm 0,03$ & $0,15 \pm 0,03$ & $0,12 \pm 0,03$ \\
Músculo & $3,40 \pm 0,47$ & $5,29 \pm 0,27$ & $1,48 \pm 0,26$ & $3,69 \pm 0,05$ & $2,99 \pm 0,10$ \\
Osso & $1,74 \pm 0,11$ & $2,86 \pm 0,22$ & $0,83 \pm 0,05$ & $1,72 \pm 0,10$ & $0,28 \pm 0,33$ \\
Cérebro & $0,08 \pm 0,06$ & $0,10 \pm 0,05$ & $0,03 \pm 0,01$ & $0,07 \pm 0,02$ & $0,03 \pm 0,02$ \\
\hline
\end{tabular}

Tendo em consideração as diferenças de afinidade dos enatiômeros $D$ e $L$ pelos receptores de PSMA renais (Eder et al, 2012) e a influência dos parâmetros de marcação, temperatura e pH, sobre a formação dos diasteroisômeros, é possível supor a possibilidade de que a menor captação renal observada quando comparada aos resultados da literatura deva-se à menor formação dos enantiômeros com maior afinidade pelo receptor PSMA. 
Contudo, estudos têm demonstrado que a alta especificidade do PSMA-HBED-CC- ${ }^{68} \mathrm{Ga}$ pelos receptores PSMA presentes em regiões saudavéis (próstata, túbulos renais, mucosa duodenal, glândula salivar e, em menor proporção, em células neuronais, fígado e baço) pode ser contornada com a administração de bloqueadores como o PMPA (2 mg/Kg de PMPA) (Eder et al, 2012; Kratochwill et al, 2015; Schafer et al, 2012).

Quando livre no organismo, $0{ }^{68} \mathrm{Ga}$ demonstra afinidade pelos pulmões, fígado, baço, rins e osso, além de permanecer por maior tempo na circulação devido afinidade por proteínas séricas (transferrina, ferritina, lactoferrina entre outras) (Autio et al, 2015; Velikyan et al, 2013; Velikyan, 2014). Todavia, estudos pré-clínicos de biodistribuição do PSMA-HBED-CC- ${ }^{68}$ Ga demonstraram que a administração de bloqueadores (PMPA) também é eficaz na redução da ligação, quase que por completa, nos pulmões e baço (Eder et al, 2012; Schafer et al, 2012).

No presente estudo, a captação no tecido ósseo foi bastante reduzida, evidenciando a estabilidade in vivo do radiofármaco, uma vez que $0{ }^{68} \mathrm{Ga}$ na forma livre tende a acumular no tecido ósseo. Tendo em vista a baixa captação óssea e o rápido clareamento sanguíneo, presume-se que a captação no fígado e baço observadas, ainda que reduzidas, devam estar relacionadas à ligação receptor-específica.

Apesar da alta lipofilicidade do PSMA-HBED-CC- ${ }^{68}$ Ga observou-se baixa captação hepática e nos intestinos, que pode estar relacionado a seu rápido clareamento sanguíneo.

\subsubsection{Estudos de imagem}

Há apenas dois trabalhos na literatura sobre imagens PET utilizando animais para o PSMA-HBED-CC $-{ }^{68}$ Ga. Eder e col. (2012) e Schafer e col. (2012) realizaram estudo de imagem PET em camundongos Nude com tumor de células LNCaP. As imagens PET demonstraram menor captação do radiofármaco no tumor quando comparada a captação obtida em tumores dissecados. Os autores justificam este dado com possível expressão do receptor PSMA reduzida pela população de animais utilizados ou também devido à dose admisnistrada elevada causando contraste nas imagens. Contudo, os estudos concluem que o radiofármaco PSMA-HBED-CC ${ }^{68}$ Ga possui excelente especificidade in vivo, possibilitando imagens com boa qualidade de resolução. 
As curvas de tempo-atividade obtidas a partir de medidas dinâmicas em PET também permitiram Eder e colaboradores (2012) afirmarem que a forma $L$ dos enantiômeros formados no processo de marcação do PSMA-HBED-CC- ${ }^{68}$ Ga se ligam irreversivelmente aos rins, enquanto a forma $D$ possui rápido clareamento sanguíneo. Esta afirmação se baseia na alta afinadade da forma $L$ pelo receptor PSMA.

Os estudos de imagem em micro-PET/CT realizados para este trabalho podem ser observados na FIG. 45.

Foi possível observar resultados que confirmam os resultados obtidos nos estudos de farmacocinética e biodistribuição, com rápido clareamento sanguíneo seguido de exclusiva excreção renal, conforme esperado, uma vez que a via urinária é a principal via de eliminação para moléculas de baixo peso molecular e a fecal para moléculas maiores, devido a filtração glomerular impedir a passagem de moléculas com alto peso molecular (Saha, 2003).

Ao observar a FIG. 45, conforme esperado (Eder et al, 2012; Schafer et al, 2012), nota-se que o radiofármaco PSMA-HBED-CC- ${ }^{68} \mathrm{Ga}$ apresenta alta captação nos rins logo após a administração do radiofármaco, órgão com maior afinidade na ausência de tumores. 


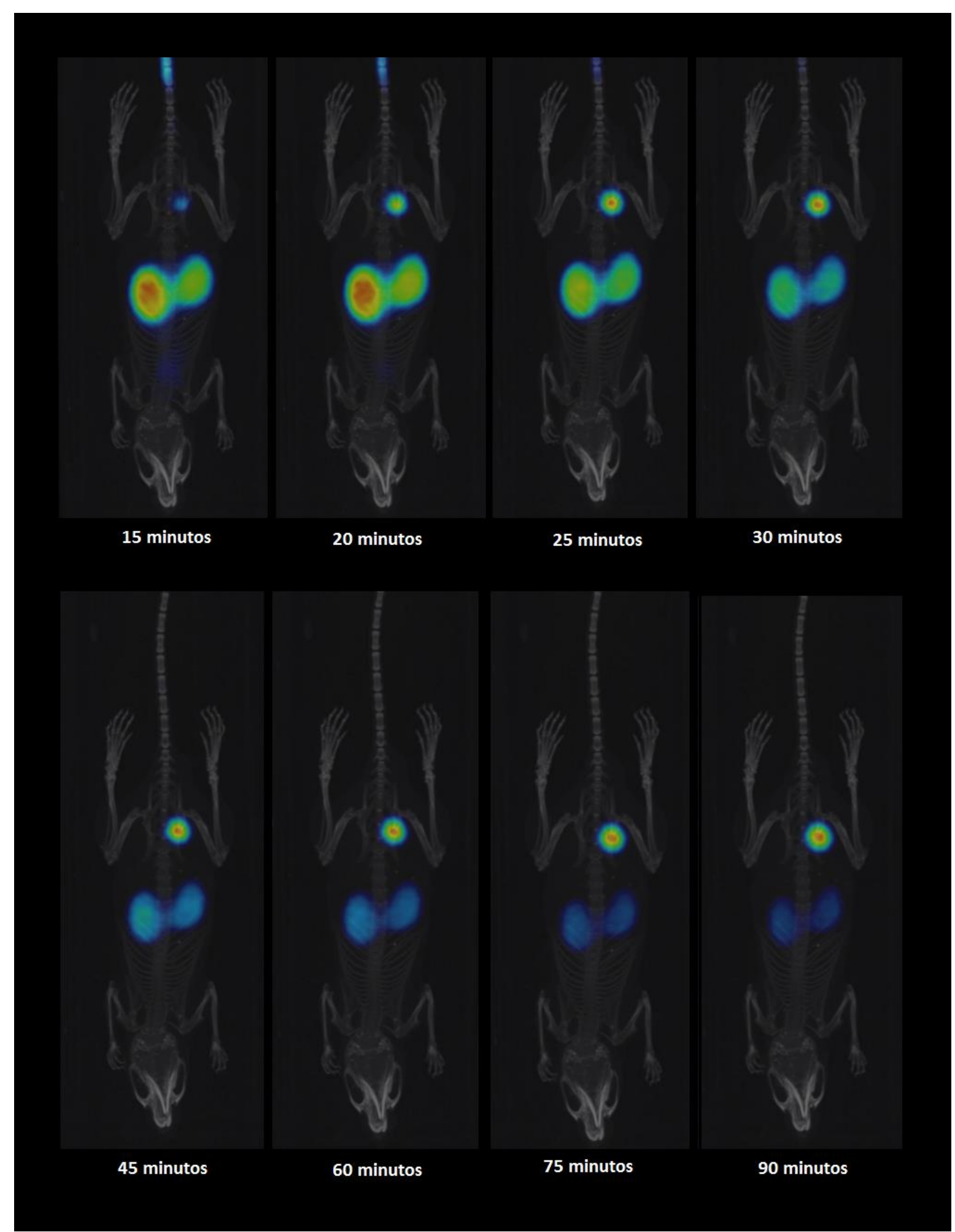

FIGURA 45: Imagens em micro PET/CT de camundongos Balb/c machos sadios, injetados com o radiofármaco PSMA-HBED-CC- ${ }^{68} \mathrm{Ga}$. 
Apesar de outros órgãos, como baço, fígado, glândulas salivares e cérebro, expressarem o receptor PSMA, o radiofármaco não demonstrou captação significativa nestas regiões, que não foram visualizadas nas imagens. 


\section{8 \\ CONCLUSÕES}

\subsection{CoNSIDERAÇões FinAIS}

Os estudos desenvolvidos neste trabalho possibilitaram a obtenção do radiofármaco PSMA-HBED-CC- ${ }^{68} \mathrm{Ga}$ com alta pureza radioquímica, em marcações não automatizadas e em módulo de síntese automatizado, mantendo-se acima dos 95\% de PR estabelecidos como critério de aceitação neste trabalho. A produção do radiofármaco em módulo de síntese automatizado obteve redimento de síntese superior ao encontrado em literatura (cerca de 90 \%) (Eder et al, 2014) e utilizando o módulo de síntese com software já existente no Ipen e utilizado para produzir DOTATATO- ${ }^{68} \mathrm{Ga}$, representando uma alternativa à aquisição de novo software.

A radiomarcação em sistema não automatizado foi estabelecida com temperatura de $95^{\circ} \mathrm{C}$, por 7 minutos, sem agitação, pois apresentou pureza radioquímica superior aos valores obtidos nos demais métodos estudos e maior estabilidade molecular do radiofármaco.

Os estudos de estabilidade do produto radiomarcado armazenado sob-refrigeração $\left(2-8^{\circ} \mathrm{C}\right)$, em temperatura ambiente $\left(15-35^{\circ} \mathrm{C}\right)$ e a $40^{\circ} \mathrm{C}$, demonstraram como melhor opção, a conservação do radiofármaco em temperatura ambiente sem a necessidade de agentes conservantes. Tal fato viabiliza o transporte do radiofármaco aos centros de medicina nuclear, sem a necessidade de congelamento do mesmo. Desta forma, o usuário final possui maior agilidade para a utilização do produto de meia vida curta, não sendo necessário descongela-ló antes do uso. 
A variação de $\mathrm{pH}$ apresentou influência sobre a formação dos diasteroisômeros e a pureza radioquímica, tornando ideal a manutenção do $\mathrm{pH}$ em 4,5.

Os estudos de estabilidade em soro humano in vitro mostraram alta estabilidade do marcador molecular, que foi confirmada nos estudos de biodistribuição.

Estudos futuros deverão ser realizados para avaliação do potencial de ligação deste radiofármaco a receptores tumorais in vitro e in vivo, a partir do desenvolvimento de modelos tumorais adequados.

Os estudos in vivo demonstraram que o radiofármaco PSMA-HBED-CC- ${ }^{68}$ Ga apresenta rápido clareamento sanguíneo e excreção renal.

Por fim, este trabalho possibilitou o desenvolvimento de metodologias de radiomarcação do PSMA-HBED-CC com ${ }^{68} \mathrm{Ga}$ utilizando o software já existente no Centro de Radiofarmácia, introduzindo o caminho para a produção rotineira deste importante radiofármaco no Ipen. 


\section{REFERÊNCIAS BIBLIOGRÁFICAS}

ABX. HBED-CC. Disponível em: <http://abx.de/>. Acesso em: 14 dez 2015.

AFSHAR-OROMIEH, A.; AVTZI, E.; GIESEL, F. L.; HOLLAND-LETZ, T.; LINHART, H. G.; EDER, M.; EISENHUT, M.; BOXLER, S.; HADASCHIK, B. A.; KRATOCHWIL, C.; WEICHERT, W.; KOPKA, K.; DEBUS, J.; HABERKORN, U. The diagnostic value of PET/CT imaging with the 68Ga-labelled PSMA ligand HBED-CC in the diagnosis of recurrent prostate Cancer. Eur J Nucl Med Mol Imaging., v. 42, p. 197-209, 2015.

AFSHAR-OROMIEH, A.; HABERKORN, U.; SCHLEMMER, H. P.; FENCHEL, M.; EDER, M.; EISENHUT, M.; HADASCHIK, B. A.; KOPP-SCHNEIDER, A.; RÖTHKE, M. Comparison of $\mathrm{PET} / \mathrm{CT}$ and PET/MRI hybrid systems using a 68Ga-labelled PSMA ligand for the diagnosis of recurrent prostate cancer: initial experience. Eur J Nucl Med Mol Imaging., v. 41, p. 887897, 2014.

AFSHAR-OROMIEH, A.; MALCHER, A.; EDER, M.; EISENHUT, M.; LINHART, H. G.; HADASCHIK, B. A.; HOLLAND-LETZ, T.; GIESEL, F. L.; KRATOCHWIL, C.; HAUFE, S.; HABERKORN, U.; ZECHMANN, C. M. PET imaging with a [68Ga]gallium-labelled PSMA ligand for the diagnosis of prostate cancer: biodistribution in humans and first evaluation of tumour lesions. Eur $J$ Nucl Med Mol Imaging., v. 40, p. 486-495, 2013.

AGÊNCIA NACIONAL DE VIGILÂNCIA SANITÁRIA. Controle de qualidade. Disponível em: <http://www.anvisa.gov.br/medicamentos/conceito.htm\#3.2> Acesso em: 09 jan 2015.

AUTIO, A.; VIRTANEN, H.; TOLVANEN, T.; LILENBÄCK, H.; OIKONEN, V.; SAANIJOKI, T.; SIITONEN, R.; KÄKELÄ, M.; SCHÜSSELE, A.; TERÄS, M.; ROIVAINEN, A. Absorption, distribution and excretion of intravenously injected $68 \mathrm{Ge} / 68 \mathrm{Ga}$ generator eluate in healthy rats, and estimation of human radiation dosimetry. EJNMMI Res., v. 5, n. 1, p. 117, 2015.

BANERJEE, S. R.; FOSS, C.A.; CASTANARES, M.; MEASE, R. C.; BYUN, Y.; FOX, J. J.; HILTON, J.; LUPOLD, S. E.; KOZIKOWSKI, A. P.; POMPER, M. G. Synthesis and evaluation of technetium$99 \mathrm{~m}$ - and rhenium-labeled inhibitors of the prostate-specific membrane antigen (PSMA). J Med Chem, v. 51, p. 4504-4517, 2008.

BANERJEE, S. R.; PULLAMBHATLA, M.; BYUN, Y.; NIMMAGADDA, S.; GREEN, G.; FOX, J. J.; HORTI, A.; MEASE, R. C.; POMPER, M. G. ${ }^{68}$ Ga-labeled inhibitors of prostate-specific membrane antigen (PSMA) for imaging prostate cancer. J Med Chem,, v. 53, n. 14, p. 53335341, 2010. 
BANERJEE S, R.; POMPER, M. G. Clinical applications of Gallium-68. Appl Radiat Isot., v. 76, p. 2-13, 2013.

BARINKA, C.; BYUN, Y.; DUSICH, C. L.; BANERJEE, S. R.; CHEN, Y.; CASTANARES, M.; KOZIKOWSKI, A. P.; MEASE, R. C.; POMPER, M. G.; LUBKOWSKI, J. Interactions between human glutamate carboxypeptidase II and urea-based inhibitors: structural characterization. J. Med. Chem., v. 51, p. 7737-7743, 2008.

BRASIL. Resolução RDC 45, de 9 de agosto de 2012. Dispõe sobre a realização de estudos de estabilidade de insumos farmacêuticos ativos. Disponível em: <http://portal.anvisa.gov.br/wps/wcm/connect/ab90a50046f1cbb3ab95bb41cdd33a01/RDC +45-2012+Estudos+de+Estabilidade+-+IFA.pdf?MOD=AJPERES> Acesso em: 18 fev. 2016.

BRASIL. Resolução RDC 63, de 25 de novembro de 2011. Dispõe sobre os Requisitos de Boas Práticas de Funcionamento para os Serviços de Saúde, Agência Nacional de Vigilância Sanitária. Disponível em: <http://portal.anvisa.gov.br/wps/wcm/connect/3fcb208049af5f1e96aeb66dcbd9c63c/RDC+ 36+de+25_11_2011+Vers\%C3\%A3o+Publicada.pdf?MOD=AJPERES> Acesso em: 12 jan. 2016.

BRASIL. Resolução RDC 64, de 18 de dezembro de 2009. Dispõe sobre os Requisitos Mínimos para o Registro de Radiofármacos no País Visando Garantir a Qualidade, Segurança e Eficácia destes Medicamentos, Agência Nacional de Vigilância Sanitária. Disponível em: < http://portal.anvisa.gov.br/wps/wcm/connect/ccf4de0046b43087bed1fe2e64280806/ResolRDC-64-09.pdf?MOD=AJPERES> Acesso em: 18 janeiro 2016.

BRASIL. Resolução RDC 210, de 04 de agosto de 2003. Regulamento Técnico das Boas Práticas para a Fabricação de Medicamentos, Anexo I, Agência Nacional de Vigilância Sanitária. Disponível em: <http://www.cff.org.br/userfiles/file/resolucao_sanitaria/210.pdf> Acesso em: 12 jan. 2016.

BUDÄUS, L.; LEYH-BANNURAH, S. R.; SALOMON, G.; MICHL, U.; HEINZER, H.; HULAND, H.; GRAEFEN, M.; STEUBER, T.; ROSENBAUM C. Initial Experience of 68Ga-PSMA PET/CT Imaging in High-risk Prostate Cancer Patients Prior to Radical Prostatectomy. Eur Urol., v. 69, p. 393396, 2015.

CHAKRAVARTY, R.; SHUKLA, R.; RAM, R.; VENKATESH, M.; DASH, A.; TYAGI, A.K. NanoceriaPAN composite-based advanced sorbent material: a major step forward in the field of clinical-grade 68Ge/68Ga generator. ACS Appl Mater Interfaces., v. 2, p. 2069-2075, 2010. 
CHAKRAVARTY, R.; SHUKLA, R.; RAM, R.; TYAGI, A.; DASH, A.; VENKATESH, M. K. Development of a nano zirconica based ${ }^{68} \mathrm{Ge} /{ }^{68} \mathrm{Ga}$ generator for biomedical applications. J. Nucl. Med. Biol., v. 38, p. 575-583, 2011.

CHAKRAVARTY, R.; CHAKRABORTY, S.; DASH, A.; PILLAI, M. R. A. Detailed evaluation on the effect of metal ion impurities on complexation of generator eluted 68Ga with different bifunctional chelators. Nucl Med Biol., v. 40, p. 197-205, 2012.

CHANG, S. S.; O'KEEFE, D. S.; BACICH, D. J.; REUTER, V. E.; HESTON, W. D. W.; GAUDIN, P. B. Prostate-specific membrane antigen is produced in tumor-associated neovasculature. Clin Cancer Res., v. 5, p. 2674-2681, 1999.

CNEN. Radiofármacos. Disponível em: < http://www.cnen.gov.br/radiofarmacos>. Acesso em: 26 jan 2016.

COLLINS, C.; BRAGA, G.; BONATO, P. Fundamentos de Cromatografia. Campinas, SP: Editora Unicamp, 2007. Cap. 1, p. 17-22, Cap. 2, p. 52-57, Cap. 3, p. 67-68 e p. 80-85.

COLOMBIÉ, M.; CAMPION, L.; BAILLY, C.; RUSU, D.; ROUSSEAU, T.; MATHIEU, C.; FERRER, L.; ROUSSEAU, N.; KRAEBER-BODÉRÉ, F. Prognostic value of metabolic parameters and clinical impact of ${ }^{18} \mathrm{~F}$-fluorocholine $\mathrm{PET} / \mathrm{CT}$ in biochemical recurrent prostate cancer. EJNMMI Research., v. 42, p. 1784-1793, 2015.

CRESPO, A. Comparison of Gallium-68 and Fluorine-18 imaging characteristics in positron emission tomography. Appl Radiat Isot., v. 76, p. 55-62, 2013.

Cyclotron Co. Generator 68Ge/68Ga. Disponível em: <http://www.isotop.ru/en/production/medical/427/446/>. Acesso em 04 fev. 16.

DECRISTOFORO, C.; KNOPP, R.; VON GUGGENBERG, E.; RUPPRICH, M.; DREGER, T.; HESS A.; VIRGOLINI, I.; HAUBNER, R. A fully automated synthesis for the preparation of 68Ga-labelled peptides. Nucl Med Commun., v. 28, n. 11, p. 870-875, 2007.

DECRISTOFORO, C. Gallium-68 -- a new opportunity for PET available from a long shelf-life generator - automation and applications. Curr Radiopharm., v. 5, p. 212-20, 2012.

DEGANI, A.; CASS, Q.; VIEIRA, P. Química Nova na Escola, 2011. p. 46, 47,48.

DIETLEIN, M.; KOBE, C.; KUHNERT, G.; STOCKTER, S.; FISCHER, T.; SCHOMÄCKER, K.; SCHMIDT, M.; DIETLEIN, F.; ZLATOPOLSKIY, B. D.; KRAPF, P.; RICHARZ, R.; NEUBAUER, S.; DRZEZGA, A.; NEUMAIER, B. Comparison of [(18)F]DCFPyL and [ (68)Ga]Ga-PSMA-HBED-CC 
for PSMA-PET Imaging in Patients with Relapsed Prostate Cancer. Mol Imaging Biol., v. 17, p. 575-84, 2015.

Eckert and Ziegler. Generator 68Ge/68Ga. Disponível em: $<$ http://www.capintec.com/capintec-inc-and-eckert-ziegler-sign-distribution-agreement-formodular-lab-and-analytical-product-lines/>. Acesso em 04 fev. 16.

EDER, M.; WANGLER, B.; KNACKMUSS, S.; LEGALL, F.; LITTLE, M.; HABERKORN, U.; MIER, W.; EISENHUT, M. Tetrafluorophenolate of HBED-CC: a versatile conjugation agent for (68)Galabeled small recombinant antibodies. Eur J Nucl Med Mol Imaging v. 35, p. 1878-1886, 2008.

EDER, M., KNACKMUSS, S., LE GALL, F., REUSCH, U., RYBIN, V., LITTLE, M., HABERKORN, U., MIER, W., AND EISENHUT, M. (68) Galabelled recombinant antibody variants for immunoPET imaging of solid tumours. Eur J Nucl Med Mol Imaging, v. 37, p. 1397-1407, 2010.

EDER, M.; SCHÄFER, M.; BAUDER-WÜST, U.; HULL, W.; WÄNGLER, C.; MIER, W.; HABERKORN, U.; EISENHUT, M. ${ }^{68} \mathrm{Ga}$-complex lipophilicity and the targeting property of a urea-based PSMA inhibitor for PET imaging. Bioconjugate Chem., v. 23, p. 688-697, 2012.

EDER, M.; NEELS, O.; MÜLLER, M.; WÜST, U. B.; REMDE, Y.; SCHÄFER, M.; HENNRICH, U.; EISENHUT, M.; AFSHAR-OROMIEH, M.; HABERKORN, U.; KOPKA, K. Novel preclinical and Radiopharmaceutical Aspects of [68Ga]Ga-PSMA-HBED-CC: A New PET Tracer for Imaging of Prostate Cancer. Pharmaceuticals., v.7, p. 779-796, 2014.

EIBER, M.; MAURER, T.; SOUVATZOGLOU, M.; BEER, A. J.; RUfFANI, A.; HALLER, B.; GRANER, F. P.; KÜBLER, H.; HABERHORN, U.; EISENHUT, M.; WESTER, H. J.; GSCHWEND, J. E.; SCHWAIGER, M. Evaluation of Hybrid ${ }^{68} \mathrm{Ga}$-PSMA Ligand PET/CT in 248 Patients with Biochemical Recurrence After Radical Prostatectomy. J Nucl Med., v. 56, p. 668-74, 2015.

EBENHAN, T.; VORSTER, M.; MARJANOVIC-PAINTER, B.; WAGENER, J.; SUTHIRAM, J.; MODISELLE, M.; MOKALENG, B.; ZEEVAART, J. R.; SATHEKGE, M. Development of a Single Vial Kit Solution for Radiolabeling of ${ }^{68} \mathrm{Ga}$-DKFZ-PSMA-11 and Its Performance in Prostate Cancer Patients. Molecules, v. 20, p. 14860-14878, 2015.

EVANGELISTA, L.; CIMITAN, M.; HODOLIČ, M.; BASERIC, T.; FETTICH, J.; BORSATTI, E. The ability of $18 \mathrm{~F}$-choline $\mathrm{PET} / \mathrm{CT}$ to identify local recurrence of prostate cancer. Abdominal Imaging., v. 40, p. 3230-3237, 2015

FAN, W.; ZHANG, Z.; ZHU, Z.; YANG, D.; CHEN, X.; WANG, J.; CHEN, F.; SONG, X. Synthesis and positron emission tomography evaluation of 18F-Glu-Urea-Lys, a prostate-specific 
membrane antigen-based imaging agent for prostate cancer. Oncol Lett., v. 10, p. 22992302, 2015.

Farmacopeia Brasileira, 5a edição. Agência Nacional de Vigilância Sanitária. Brasília: Anvisa, 2010

FERREIRA, C.L.; LAMSA, E.; WOODS, M.; DUAN, Y.; FERNANDO, P.; BENSIMON, C.; KORDOS, M.; GUENTHER, K.; JUREK, P.; KIEFER, G.E. Evaluation of bifunctional chelates for the development of gallium-based radiopharmaceuticals. Bioconjugate Chem., v. 21, p. 531-536, 2010.

FERREIRA, C.L.; YAPP, D.T.T.; MANDEL, D.; GILL, R.K.; BOROS, E.; WONG, M.Q.; JUREK, P.; KIEFER, G.E. ${ }^{68} \mathrm{Ga}$ small peptide imaging: comparison of NOTA and PCTA. Bioconjugate Chem., v. 23, p. 2239-2246, 2012.

GHOSH, A.; HESTON, W.D.W. Tumor target prostate specific membrane antigen (PSMA) and its regulation in prostate cancer. J Cel Biochem., v. 91, p. 528-539, 2004.

HARA, T.; KOSAKA, N.; KISHI, H. PET imaging of prostate cancer using carbon-11-choline. J Nucl Med., v. 39, p. 990-995, 1998.

HERLEMANN, A.; WENTER, V.; KRETSCHMER, A.; THIERFELDER, K. M.; BARTENSTEIN, P.; FABER, C.; GILDEHAUS, F. J.; STIEF, C. G.; GRATZKE, C.; FENDLER, W. P. (68)Ga-PSMA Positron Emission Tomography/Computed Tomography Provides Accurate Staging of Lymph Node Regions Prior to Lymph Node Dissection in Patients with Prostate Cancer. Eur Urol., v. 16, p. S0302-2838, 2016.

HILLIER, S. M.; MARESCA, K. P.; FEMIA, F. J.; MARQUIS, J. C.; FOSS, C. A.; NGUYEN, N.; ZIMMERMAN, C. N.; BARRETT, J. A.; ECKELMAN, W. C.; POMPER, M. G.; JOYAL, J. L.; BABICH, J. W. Preclinical evaluation of novel glutamate-urea-lysine analogues that target prostatespecific membrane antigen as molecular imaging pharmaceuticals for prostate cancer. Cancer Res., v. 69, n. 17, p. 6932-6940, 2009.

INCAa - Instituto Nacional do Câncer. Incidência de câncer no Brasil - estimativa 2012. Disponível em: <http://www1.inca.gov.br/estimativa/2012/index.asp?ID=5>. Acesso em: 06 dez. 15.

INCAb - Instituto Nacional do Câncer. Tipos de câncer: câncer de próstata. Disponível em: $<$ http://www2.inca.gov.br/wps/wcm/connect/tiposdecancer/site/home/prostata $>$. Acesso em: 06 dez. 15. 
INCAC - Instituto Nacional do Câncer. Tipos de câncer: câncer de próstata. Disponível em: <http://www.inca.gov.br/releases/press_release_view_arq.asp?ID=34>. Acesso em: 18 mar. 16.

ITG. Generator 68Ge/68Ga. Disponível em: <http://radiomedix.com/gallium-generators/>. Acesso em 04 fev. 16.

IThemba - Generator 68Ge/68Ga. Disponível em: <http://tlabs.ac.za/?page_id=294>. Acesso em 04 fev. 16.

JUARISTI, E.; STEFANI, H. Introdução à Esterioquímica à análise Comformacional. Porto Alegre, RS: Bookman, 2012.

KATZ, A.; CHAMMAS, R.; FILHO, V. O.; NOVIS, Y. S.; Tratado de Oncologia. São Paulo, SP: Atheneu, 2013.

KOWALSKY, R.; FALEN, S. W.; Radiopharmaceuticals in Nuclear Pharmacy and Nuclear Medicine. 2 ed. Washington, N. Y.: American Pharmacists Association, 2004.

KRATOCHWIL, C.; GIESEL, F.; LEOTTA, K.; EDER, M.; HOPPE-TICHY, T.; YOUSSOUFIAN, H.; KOPKA, K.; BABICH, J. W.; HABERKORN, U. PMPA for nephroprotection in PSMA-targeted radionuclide therapy of prostate cancer. J Nucl Med., v. 56, p. 293-298, 2015.

LIU, S. Bifunctional coupling agents for radiolabeling of biomolecules and target-specific delivery of metallic radionuclides. Adv Drug Deliv Rev., v. 60, n. 12, p. 1347-1370, 2008.

LOYD, V.; ALLEN, J. Introdução à farmácia de Remington. Porto Alegre, RS: Artmed Ltda, 2016, cap. 5.

LÜTJE, S.; HESKAMP, S.; CORNELISSEN, A. S.; POEPPEL, T. D.; VAN DEN BROEK, S. A. M. W.; ROSENBAUM-KRUMME, S.; BOCKISCH, A.; GOTTHARDT, M.; RIJPKEMA, M.; BOERMAN, O. C. PSMA Ligands for Radionuclide Imaging and Therapy of Prostate Cancer: Clinical Status. Theranostics. v. 5, p. 1388-1401, 2015.

MALIK, N.; BAUR, B.; WINTER, G.; RESKE, S. N.; BEER, A. J.; SOLBACH, C. Radiofluorination of PSMA-HBED via Al(18)F(2+) Chelation and Biological Evaluations In Vitro. Mol Imaging Biol., v. 7, p. 777-785, 2015.

MAECKE, H. R.; GOOD, S. Radiometals (non-Tc, non-Re) and bifuncional labeling chemistry. In: VÉRTES, A.; NAGY, S.; ZOLTÁN, K. Handbook of Nuclear Chemistry. Netherlands: Kluwer Academic Publishers., v. 4. p. 279-314, 2003. 
MAECKE, H. R.; HOFMANN, M.; HABERKORN, U. ${ }^{68}$ Ga-labeled peptides in tumor imaging. J Nucl Med., v. 46, p. 172S-178S, 2005.

MARESCA, K. P.; HILLIER, S. M.; FEMIA, F. J.; KEITH, D.; BARONE, C.; JOYAL, J. L.; ZIMMERMAN, C. N.; KOZIKOWSKI, A. P.; BARRETT, J. A.; ECKELMAN, W. C.; BABICH, J. W. A series of halogenated heterodimeric inhibitors of prostate-specific membrane antigen (PSMA) as radiolabeled probes for targeting prostate cancer. J Med Chem., v. 52, p. 347-357, 2009.

MEASE, R. C.; DUSICH, C. L.; FOSS, C. A.; RAVERT, H.T.; DANNALS, R. F.; SIEDEL, J.; PRIDEAUX, A.; FOX, J. J.; SGOUROS, G.; KOZIKOWSKI, A. P.; POMPER, M. G. N-[N-[(S)-1,3Dicarboxypropyl] Carbamoyl]-4-[18F]Fluorobenzyl-LCysteine, [18F]DCFBC: A new imaging probe for prostate cancer. Clin Cancer Res., v. 14, n. 10, p. 3060-3043, 2008.

MILOWSCKY, M. I.; NANUS, D. M.; KOSTAKOGLU, L.; SHEEHAN, C. E.; VALLABHAJOSULA, S.; GOLDSMITH, S. J.; ROSS, J. S.; BANDER, N. H. Vascular targeted therapy with anti-prostatespecific membrane antigen monoclonal antibody J591 in advanced solid tumors. J Clin Oncol., v. 25, n. 5, p. 540-547, 2007.

MINAMIMOTO, R.; UEMURA, H.; SANO, F.; TERAO, H.; NAGASHIMA, Y.; YAMANAKA, S.; SHIZUKUISHI, K.; TATEISHI, U.; KUBOTA, Y.; INOUE, T. The potential of FDG-PET/CT for detecting prostate cancer in patients with an elevated serum PSA level. Ann Nucl Med., v. 25, p. 21-27, 2011.

Modular-Lab PharmTracer. User manual for synthesis of 68Ga-conjugated peptides with pharmTracer fractionation and pre-purification by cation exchange. USA: Eckert and Ziegler, 2014.

MORIGI, J. J.; STRICKER, P. D.; VAN-LEEUWEN, P. J.; TANG, R.; HO, B.; NGUYEN, Q.; HRUBY, G.; FOGARTY, G.; JAGAVKAR, R.; KNEEBONE, A.; HICKEY, A.; FANTI, S.; TARLINTON, L.; EMMETT, L. Prospective Comparison of 18F-Fluoromethylcholine Versus 68Ga-PSMA PET/CT in Prostate Cancer Patients Who Have Rising PSA After Curative Treatment and Are Being Considered for Targeted Therapy. J Nucl Med., v. 6, p. 1185-1190, 2015.

MORRIS, M. J.; AKHURST, T.; OSMAN, I.; NUNEZ, R.; MACAPINLAC, H.; SIEDLECKI, K.; VERBEL, D.; SCHWARTZ, L.; LARSON, S. M.; SCHER, H. I. Fluorinated deoxyglucose positron emission tomography imaging in progressive metastatic prostate cancer. Urology., v. 59, p. 913-918, 2002 
MUKHERJEE, A.; PANDEY, U.; CHAKRAVARTY, R.; SARMA, H. D.; DASH, A. Development of Single Vial Kits for Preparation of 68Ga-Labelled Peptides for PET Imaging of Neuroendocrine Tumours. Mol Imaging Biol., v. 16, p. 550-557, 2014.

National Cancer Institute (NCl). Prostate Cancer. Disponível em: <http://www.cancer.gov/cancertopics/types/prostate>. Acesso em: 12 jun 15.

NUÑEZ, R.; HOMER, A.; MACAPINLAC; HENRY, W.D.; YEUNG; AKHURST, T.; CAI, S.; OSMAN, I.; GONEN, M.; RIEDEL, E.; SCHER, H. I.; LARSON, S. M. Combined 18F-FDG and 11CMethionine PET Scans in Patients with Newly Progressive Metastatic Prostate Cancer. J Nucl Med., v. 43, p. 46-55, 2002.

ORGANIZAÇÃO MUNDIAL DA SAÚDE (OMS). Disponível em <http://www.who.int/>. Acesso em: 09 dez 2015.

OLIVEIRA, R; SANTOS, D.; FERREIRA, D.; COELHO, P.; VEIGA, F. Preparações radiofarmacêuticas e suas aplicações. Revista Brasileira de Ciências Farmacêuticas, v. 42, p. 151-165, 2006.

PETRIK, M.; OCAK, M.; RUPPRICH, M.; DECRISTOFORO, C. Impurity in (68)Ga-peptide preparation using processed generator eluate. J Nucl Med., v. 51, p. 495, 2010.

PICCHIO, M.; CASTELLUCCI, P. Clinical Indications of ${ }^{11} \mathrm{C}$-Choline PET/CT in Prostate Cancer Patients with Biochemical Relapse. Theranostics, v. 2, p. 313-317, 2012.

POWSNER, R. A.; POWSNER, E. R. Essential Nuclear Medicine Physics. 2 ed. Oxford, UK: Blackwell Publishing, 2006.

PRÓSTATA. Disponível em: <http://novanatural.biz/pr\%C3\%B3stata.php>. Acesso em 17 dez. 15.

PUJATTI, P. B. Marcadores moleculares derivados da bombesina para diagnóstico de tumores por SPECT e PET. Dissertação (Doutorado) - Instituto de Pesquisas Energéticas e Nucleares, São Paulo, 2012.

RANG, H. P.; DALE, M. M.; RITTER, J. M.; FLOWER, R. J. Farmacologia. Rio de Janeiro, RJ: Elsevier, 2007.

ROBBINS e COTRAN. Bases Patlogicas das Doenças 8 ed. Rio de Janeiro, RJ: Elsevier, 2010. 
ROSCH, F. Past, present and future of 68Ge/68Ga generators. Appl. Radiat. Isot., v. 76, p. 2430, 2013.

SAHA, G.B. Fundamentals of nuclear pharmacy. 5 ed. New York, NY: Springer, 2003.

SANZ, G.; ROBLES, J. E.; GIMENEZ, M.; AROCENA, J.; SANCHEZ, D.; RODRIGUEZ-RUBIO, F.; ROSELL, D.; RICHTER, J. A.; BERIAN, J. M. Positron emission tomography with 18fluorinelabelled deoxyglucose: utility in localized and advanced prostate cancer. BJU Int., v. 84, p.1028-1031, 1999.

SBMN. Sociedade Brasileira de Medicina Nuclear. Disponível em: < http://www.sbmn.org.br/site/medicina_nuclear>. Acesso em: 26 jan 2016.

SCHÄFER, M.; BAUDER-WÜST, U.; LEOTTA, K.; ZOLLER, F.; MIER, W.; HABERKORN, U.; EISENHUT, M.; EDER, M. A dimerized urea-based inhibitor of the prostate-specific membrane antigen for 68Ga-PET imaging of prostate cancer. EJNMMI Research, v. 2, p. 2334, 2012

SCHOTTELIUS, M.; WIRTZ, M.; EIBER, M.; MAURER, T.; WESTER, H. $\quad\left[{ }^{111} \mathrm{In}\right]$ PSMA-I\&T: expanding the spectrum of PSMA-I\&T applications. EJNMMI Res., v. 5, p. 68, 2015.

SCHUHMACHER, J.; KLIVENYI, G.; MATYS, R.; STADLER, M.; REGIERT, T.; HAUSER, H.; DOLL, J.; MAIER-BORST, W.; ZOLLER, M. Multistep tumor targeting in nude mice using bispecific antibodies and a gallium chelate suitable for immunoscintigraphy with positron emission tomography. Cancer Res. v. 55, p. 115-123, 1995.

SHAGEL, L.; WU-PONG, S.; YU, A. B. C. Applied Biopharmaceutics pharmacokinetics. 5 ed. USA: Copyright, 2004.

SHARP, P. F.; GEMMEL, H. G.; MURRAY, A. D. Practical nuclear medicine. 3ed. Londres, UK: Springer, 2005.

SHAKESPEARE, T. P. Effect of prostate-specific membrane antigen positron emission tomography on the decision-making of radiation oncologists. Radiation Oncology, v.10, p. 233, 2015.

SAHLMANN, C. O.; MELLER, B.; BOUTER, C.; RITTER, C. O.; STRÖBEL, P.; LOTZ J; TROJAN, L.; MELLER, J.; HIJAZI, S. Biphasic 68Ga-PSMA-HBED-CC-PET/CT in patients with recurrent and high-risk prostate carcinoma. Eur J Nucl Med Mol Imaging. p. 1-8, 2015. 
SHUKLA, J.; MITTAL, B. R. Ga-68: A versatile PET imaging radionuclide. J Postgrad Med Edu Res., v. 47, p. 74-76, 2013.

SILVER, D. A.; PELLICER, I.; FAIR, W. R.; HESTON, W. D. W.; CORDON-CARDO, C. Prostatespecific membrane antigen expression in normal and malignant human tissues. Clin Cancer Res., v. 3, p. 81-85, 1997.

SOUZA F. C. Generation and characterization of isogenic cell lines harboring p53 mutants: A model for the evaluation of p53 and p16 INK4A replacement in the presence of p53R175H and p53R248Q. Dissertação (Mestrado) - Instituto de Ciências Biomédicas da Universidade de São Paulo. 2011.

STEVENS, A.; LOWE, I. Patologia. São Paulo, SP: Manole Ltda. 2002.

STERZING, F.; KRATOCHWIL, C.; FIEDLER, H.; KATAYAMA, S.; HABL, G.; KOPKA, K.; AFSHAROROMIEH, A.; DEBUS, J.; HABERKORN, U.; GIESEL, F. L. 68Ga-PSMA-11 PET/CT: a new technique with high potential for the radiotherapeutic management of prostate cancer patients. Eur J Nucl Med Mol Imaging., v. 43, p. 34-41, 2016.

STORPIRTIS, S.; GAI, M. N.; CAMPOS, D. R.; GONÇALVES, J. E. Farmacocinética Básica e Aplicada. Rio de Janeiro, RJ: Guanabara Koogan, 2011.

SZABO, Z.; MENA, E.; ROWE, S. P.; PLYKU, D.; NIDAL, R.; EISENBERGER, M. A.; ANTONARAKIS, E. S.; FAN, H.; DANNALS, R. F.; CHEN, Y.; MEASE, R. C.; VRANESIC, M.; BHATNAGAR, A.; SGOUROS, G.; CHO, S. Y.; POMPER, M. G. Initial Evaluation of [(18)F]DCFPyL for ProstateSpecific Membrane Antigen (PSMA)-Targeted PET Imaging of Prostate Cancer. Mol Imaging Biol., v. 4, p. 565-74, 2015.

TANG, H.; BROWN, M.; YE, Y.; HUANG, G.; ZHANG, Y.; WANG, Y.; ZHAI, H.; CHEN, X.; SHEN, T.Y.; TENNISWOOD, M. Prostate targeting ligands based on $\mathrm{N}$-acetylated $\alpha$-linked acidic dipeptidase. Biochem \& Biophy Res Commun., v. 307, p. 8-14, 2003.

The EUROPEAN PHARMACOPEIA 7.6. European Directorate for the Quality of Medicines \& Healthcare (EDQM). Gallium (68Ga) edotreotide injection. Strasbourg: Council of Europe, 2010.

THRALL, J. H.; ZIESSMAN, H. A. Nuclear Medicine: the requisites in radiology. 3 ed. Philadelphia, PA: Elsevier Mosby, 2006

TROYER, J. K.; BECKETT, M. L.; WRIGHT GL, J. R. Location of prostate-specific membrane antigen in the LNCaP prostate carcinoma cell line. The Prostate, v. 30, p. 232-242, 1997. 


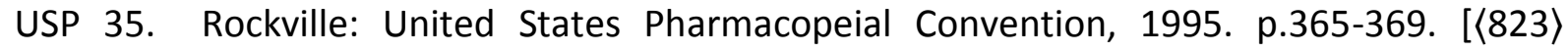
Positron Emission Tomography Drugs].

VALI, R.; LOIDL, W.; PIRICH, C.; LANGESTEGER, W.; BEHESHTI, M. Imaging of prostate cancer 18

with PET/CT using F-Fluorocholine. Am J Nucl Med Mol Imaging., v. 5, p. 96-108, 2015.

VELIKYAN, I.; ANTONI, G.; SORENSEN, J.; ESTRADA, S. Organ biodistribution of Germanium68 in rat in the presence and absence of $\left[{ }^{68} \mathrm{Ga}\right] \mathrm{Ga}-\mathrm{DOTA}-\mathrm{TOC}$ for the extrapolation to the human organ and whole-body radiation dosimetry. J.Nucl Med., v. 3, p. 154-165, 2013.

VELIKYAN, I. Prospective of ${ }^{68} \mathrm{Ga}$-Radiopharmaceutical Development. Theranostics. v. 4, p. 47-80, 2014.

VERBURG, F. A.; PFISTER, D.; HEIDENREICH, A.; VOGG, A.; DRUDE, N. I.; VÖÖ, S.; MOTTAGHY, F. M.; BEHRENDT, F. F. Extent of disease in recurrent prostate cancer determined by [68Ga]PSMA-HBED-CC PET/CT in relation to PSA levels, PSA doubling time and Gleason score. Eur J Nucl Med Mol Imaging. v. 43, p. 397-403, 2016.

WORLD HEALTH ORGANIZATION. Radiopharmaceutical products. In: Quality assurance of pharmaceuticals. A compendium of guidelines and related materials. Good Manufacturing practices and inspection. Geneva, 2004. v.2, p. 130-153.

ZALUTSKY, M.R. Handbook of Nuclear Chemistry. Netherlands: Kluwer Academic Publishers, v. 4. p. $315-348,2003$

ZAMBOGLOU, C.; WIESER, G.; HENNIES, S.; REMPEL, I.; KIRSTE, S.; SOSCHYNSKI, M.; RISCHKE, H. C.; FECHTER, T.; JILG, C. A.; LANGER, M.; MEYER, P. T.; BOCK, M.; GROSU, A. L. MRI versus 68Ga-PSMA PET/CT for gross tumour volume delineation in radiation treatment planning of primary prostate cancer. Eur J Nucl Med Mol Imaging., p. 1-9, 2015.

ZHERNOSEKOV, K. P.; FILOSOFOV, D. V.; BAUM, R. P.; ASCHOFF, P.; BIHL, H.; RAZBASH, A. A.; JAHN, M.; JENNEWEIN, M.; RÖSCH, F. Processing of generator-produced 68Ga for medical application. J Nucl Med., v. 10, p. 1741-8, 2007. 